\title{
for IMISCOE Research Series
}

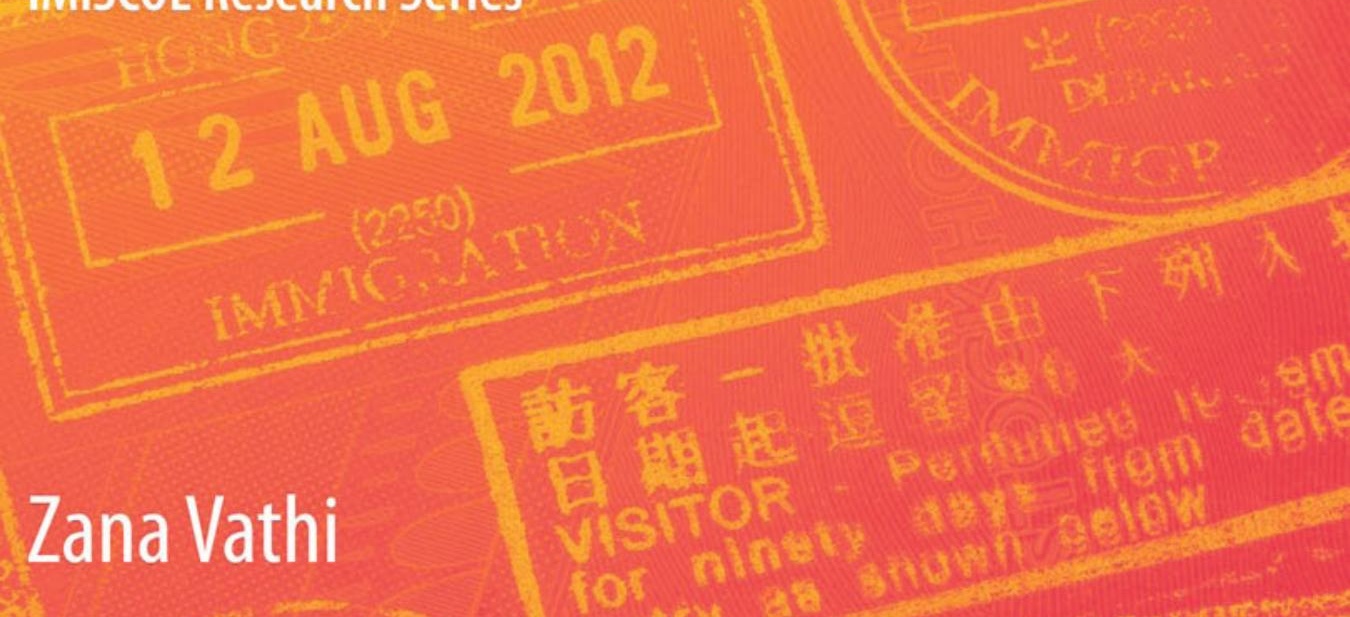

Zana Vathi

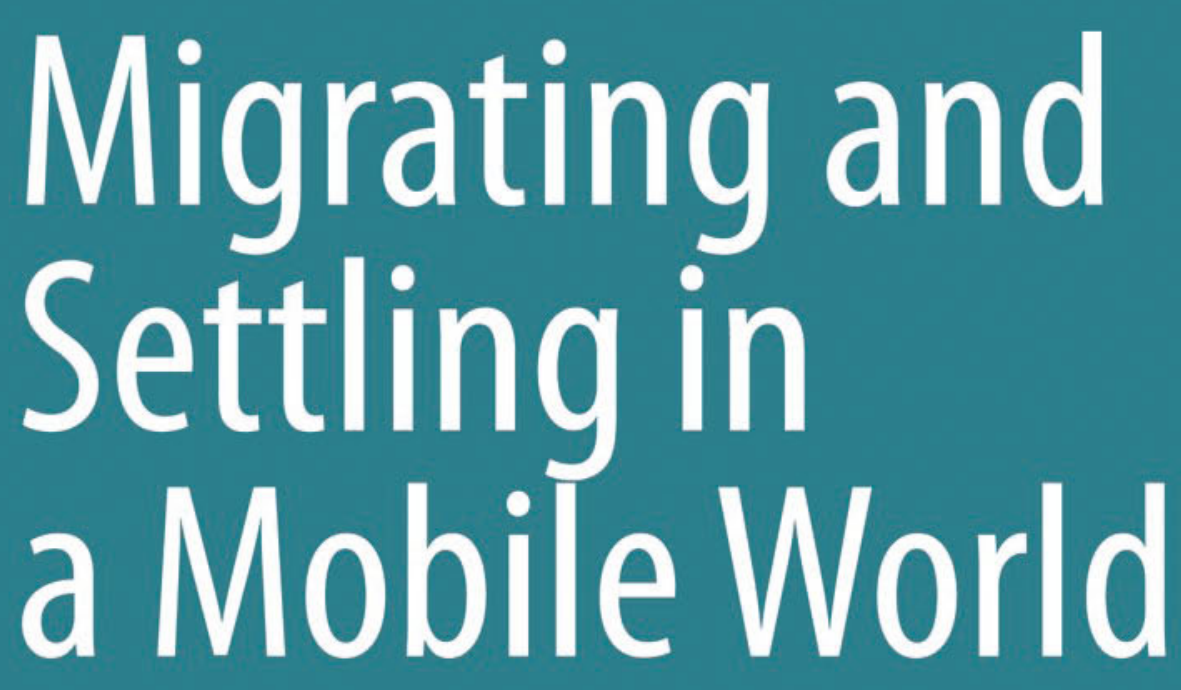

Albanian Migrants and Their Children in Europe

IMISCOE

Springer Open 


\section{IMISCOE Research Series}


This series is the official book series of IMISCOE, the largest network of excellence on migration and diversity in the world. It comprises publications which present empirical and theoretical research on different aspects of international migration. The authors are all specialists, and the publications a rich source of information for researchers and others involved in international migration studies.

The series is published under the editorial supervision of the IMISCOE Editorial Committee which includes leading scholars from all over Europe. The series, which contains more than eighty titles already, is internationally peer reviewed which ensures that the book published in this series continue to present excellent academic standards and scholarly quality. Most of the books are available open access.

For information on how to submit a book proposal, please visit: http://www. imiscoe.org/publications/how-to-submit-a-book-proposal.

More information about this series at http://www.springer.com/series/13502 
Zana Vathi

Migrating and Settling
in a Mobile World

Albanian Migrants and Their Children in Europe

帡 Springer Open 


\author{
Zana Vathi \\ Edge Hill University \\ Ormskirk \\ Lancashire \\ United Kingdom
}

IMISCOE Research Series

ISBN 978-3-319-13023-1

ISBN 978-3-319-13024-8 (eBook)

DOI 10.1007/978-3-319-13024-8

Library of Congress Control Number: 2015932144

Springer Cham Heidelberg New York Dordrecht London

(C) The Editor(s) (if applicable) and the Author(s)

The book is published with open access at SpringerLink.com

Open Access This book is distributed under the terms of the Creative Commons Attribution Noncommercial License which permits any noncommercial use, distribution, and reproduction in any medium, provided the original author(s) and source are credited.

All commercial rights are reserved by the Publisher, whether the whole or part of the material is concerned, specifically the rights of translation, reprinting, re-use of illustrations, recitation, broadcasting, reproduction on microfilms or in any other way, and storage in data banks. Duplication of this publication or parts thereof is permitted only under the provisions of the Copyright Law of the Publisher's location, in its current version, and permission for commercial use must always be obtained from Springer. Permissions for commercial use may be obtained through RightsLink at the Copyright Clearance Center. Violations are liable to prosecution under the respective Copyright Law.

The use of general descriptive names, registered names, trademarks, service marks, etc. in this publication does not imply, even in the absence of a specific statement, that such names are exempt from the relevant protective laws and regulations and therefore free for general use.

While the advice and information in this book are believed to be true and accurate at the date of publication, neither the authors nor the editors nor the publisher can accept any legal responsibility for any errors or omissions that may be made. The publisher makes no warranty, express or implied, with respect to the material contained herein.

Printed on acid-free paper

Springer is a brand of Springer International Publishing Springer International Publishing is part of Springer Science+Business Media (www.springer.com) 
To my family 


\section{Preface}

Comparative research on migration is a growing trend in academia. Yet very few studies that compare migrants and their descendants across different sites exist. Study of the integration of the children of migrants - the so-called 'second-generation'-is itself a recent trend in social science research and migration literature. Their integration is thought to be an important indicator of the degree of integration of immigrants into a specific society. This book offers an in-depth, qualitative analysis of the integration of Albanian migrants and their descendants in Europe. It is also the first full-length comparative study of the Albanian 'second-generation'. Using a variety of field methods, it compares the ethnic identities, transnational ties and integration pathways of Albanian migrants and Albanian-origin teenagers in three European cities - London, Thessaloniki and Florence - by focusing on intergenerational transmission between the first and the second generation. Greece, Italy and the UK are, in that order, the three main European countries where Albanian migrants have settled during their short but intense migration experience of the past two decades. This book shifts the focus partly to the situation and developments in Southern Europe, where awareness of and interest in issues of integration of the second-generation are still at an early phase. By studying a settling immigrant group and their descendants, this book takes a proactive approach towards the integration of ethnic minorities.

The research involved field work in each of the above-named cities, where quota samples of three categories of informants were drawn for interview: parents, their second-generation teenage children, and teachers and other key informants within the 'host' society. Findings show significant differences in integration patterns between the generations, affected by sharp differences between the three contexts and the history of immigration in each context. They also point to important withingroup and inter-group differences, based on various socio-economic indicators. Intergenerational transmission appears to be a dynamic process affected not only by context and parents' socio-economic background, but also by parents' stage of integration. The two generations prioritize and harness different forms of capital. Nevertheless, capital utilized by parents impacts on the second-generation's integration because it enables the latter to further harness social and cultural capital; the opposite—lack of such capital—obstructs teenagers' integration strategies. Mobility and 
cosmopolitanism are forms but also 'outcomes' of capital, existing and harnessed, which, in the case of the descendants of migrants, displays significant interrelations with power and agency. These interrelations and dynamics are contingent on time and space.

All research touches the lives of many people. Since this research was an international multi-sited project, the number of people and institutions involved was quite large. The author wishes to express her deep gratitude to all the participants. She would also like to thank Prof. Russell King and Dr. Anastasia Christou at the University of Sussex, and Prof. Janine Dahinden and the late Prof. Michael Bommes as part of the IMISCOE network, for their advice and support. This research would have been impossible without the sponsorship and assistance of many institutions. I extend my thanks to the sponsors of this research: Marie Curie Actions of the European Commission and the Sussex Centre for Migration Research. Other organizations, in no particular order, have been of great help: in London the Albanian organizations, especially 'Ardhmëria' and Globalb; in Thessaloniki, the Albanian organizations, especially 'Mother Tereza' and the 'Organization of Albanians of Thessaloniki', the South-East European Research Centre (SEERC) and the Antiracist Initiative of Thessaloniki; in Florence, the Department of Educational Sciences at the University of Florence, Prof. Giovanna Campani and, moreover, the various teachers in Italian schools who were crucial to the realization of the field work.

Finally, but most importantly, the author acknowledges the great inspiration and support received from her family. This book is entirely and wholeheartedly dedicated to them. 


\section{Contents}

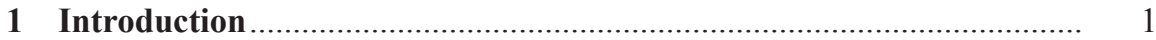

1.1 Contextualizing and Theorizing Cross-Generational

Migration Research ..................................................................... 4

1.1.1 Identity, Integration and Transnational Ties ......................... 4

1.1.2 Theories on the Integration of the Second Generation ........... 7

1.1.3 The European Second Generation ........................................... 11

1.1.4 The Albanian Second Generation ......................................... 13

1.1.5 Moving Back and Forth Between Theory and Data ............... 16

1.2 Introducing the Field Sites: Immigration Politics and

Ethnic Relations .............................................................................. 18

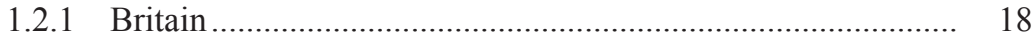

1.2.2 Greece................................................................... 21

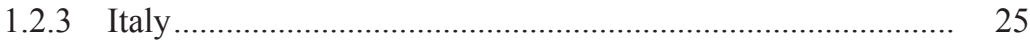

1.3 Research Design and Methods ....................................................... 28

1.4 Book Outline ........................................................................... 33

2 Identities of the First and Second Generation: The Role of

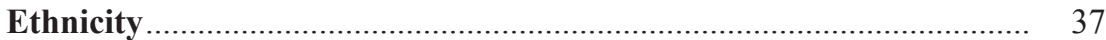

$2.1 \quad$ Identity and Ethnicity ............................................................... 37

2.2 Introduction to Albanian Identity .................................................... 42

2.3 The First Generation....................................................................... 46

2.3.1 Migrant Identity .............................................................. 46

2.3.2 The Parental Identity ........................................................ 49

2.3.3 Gender ............................................................................. 50

2.3.4 Religious Identity ........................................................... 51

2.3.5 The Role of Ethnicity .......................................................... 54

$2.4 \quad$ The Second Generation .................................................................. 56

2.4.1 Teenagers and Young People ............................................... 56

2.4.2 Gender ....................................................................... 58

2.4.3 Religious Identity .............................................................. 59

2.4.4 The Role of Ethnicity ................................................... 62

2.5 Conclusions .......................................................................... $\quad 70$ 
3 Integration: National, City and Local Perspectives............................ 73

3.1 Reviewing Integration: Philosophical, Theoretical and

Methodological Aspects ............................................................... 74

3.2 The First Generation........................................................................ $\quad 78$

3.2.1 Structural Integration....................................................... 78

3.2.2 Social Integration............................................................ 85

3.2.3 Immigrant and Ethnic Organizations.................................. 88

3.2.4 Gender ................................................................. 90

3.2.5 Discrimination ......................................................... 92

3.3 The Second Generation ............................................................. 96

3.3.1 Structural Integration...................................................... 96

3.3.2 Socialization and Integration.......................................... 105

3.3.3 Discrimination ............................................................... 111

3.4 Conclusions ........................................................................ 114

4 Transnational Ties and Attitudes Towards Return........................... 117

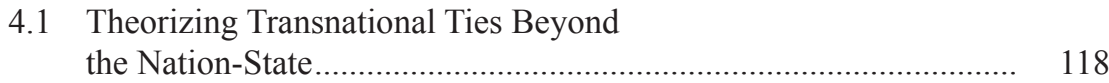

4.2 The First Generation................................................................. 123

4.2.1 Return Visits ............................................................... 123

4.2.2 Transnational Ties Through Technology ........................... 127

4.2.3 Remittances ............................................................... 129

4.2.4 Attitudes Towards Return ................................................ 132

4.3 The Second Generation ................................................................ 135

4.3.1 Return Visits .................................................................. 135

4.3.2 Transnational Ties Through Technologies.......................... 140

4.3.3 Attitudes Towards Return ............................................ 142

4.4 Conclusions ............................................................................ 145

5 Intergenerational Transmission of Ethnic Identity, Integration and Transnational Ties ................................................... 149

5.1 Intergenerational Transmission in the Context of

Migration: The State of the Art ................................................... 149

5.2 Intergenerational Transmission of Identity ................................... 151

5.2.1 Transmitting 'Albanianness'.............................................. 151

5.2.2 Language ................................................................ 155

5.2.3 Ethnicity at a Micro-Level: The Family ........................... 158

5.2.4 Lifestyle Values and Cross-Generation Tensions ................ 159

5.2.5 Migrant Identity and the Communist Past.......................... 161

5.3 Intergenerational Transmission of Integration ............................. 163

5.3.1 Parents' Settlement and its Impact on

Children's Integration ......................................................... 163

5.3.2 Transmission of the Migration Project .............................. 165 
5.4 Intergenerational Transmission of Transnational Ties .................... 168

5.4.1 General Patterns.............................................................. 168

5.4.2 Intergenerational Transmission of Attitudes

Towards Visits ..................................................................... 170

5.4.3 Intergenerational Transmission of Attitudes

Towards Return............................................................ 172

5.5 Conclusions ............................................................................ 173

6 A Cross-generational Assessment of Identification, Integration and Transnational Ties ................................................... 177

6.1 Links Between Identity, Integration and Transnational Ties.......................................................... 178

6.2 Ethnic Identity ........................................................................ 180

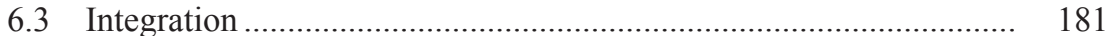

6.4 Transnational Ties .............................................................. 184

6.5 Intergenerational Transmission ................................................. 186

6.6 Re-interpreting Integration: Agency,
Capital and Power ................................................................. 187

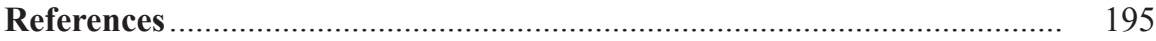

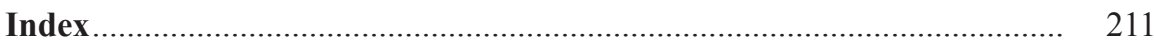




\section{Chapter 1 \\ Introduction}

This book focuses on the migration and settlement of Albanians and their children in different European cities. It analyses these processes by taking into account intergenerational transmission and views mobility as an inherent characteristic of contemporary lives, even where low-skilled and de-skilled migrants and their descendants are concerned. Building on central concepts in the social sciences and migration studies, such as identity, integration, transnationalism and intergenerational transmission, the book links these notions with the newer, developing theoretical and conceptual frameworks of mobility, translocality and cosmopolitanism. Identification, integration, transnational ties and intergenerational transmission are analysed in relation to institutional aspects of social systems as major factors affecting social relations (Giddens 1991). They are also seen in relation to time and space, in an effort to address a certain spatial and temporal essentialism that has typically characterized migration studies.

Using a variety of field methods, the book compares the ethnic identities, integration pathways and transnational ties of Albanian migrants and Albanian-origin teenagers in three European cities: London, Thessaloniki and Florence. ${ }^{1}$ Greece, Italy and the UK are the three main European countries where Albanian migrants have settled during their short but intense migration experience of the past two decades, since Albania opened itself to the outside world after more than four decades of isolation under a communist regime. The research on which this book is based involved a 3-4-month period of field work in each of the above-named cities,

\footnotetext{
${ }^{1}$ Research for this book builds on the above-mentioned observations and was furthermore tailored as part of an international comparative research initiative, The Integration of the European Second Generation (TIES), which shapes its overall approach (www.tiesproject.eu). The TIES programme tackled the broad issues of integration and focused specifically on the second generation, taking a European comparative approach. It specified a comparative dimension for all the projects under its framework, to be implemented either by including two or more countries and comparing one ethnic group across countries, or by investigating the differences between two or more migrant groups in one country. The TIES project was financed by the Marie Curie Programme of the European Commission. It was composed of a European survey - the TIES survey - that investigated the processes of integration of Moroccan, Turkish and (ex-)Yugoslavian second-generation adults in 15 cities in eight countries, and a research training network (TIES-RTN). 
where participant observation took place and interviews were conducted with quota samples of three categories of informants: parents, their second-generation teenage children, and teachers and other key informants within the 'host' society. ${ }^{2}$ Using a strong qualitative and 'grounded' approach, the research aimed to construct a broad account of the Albanian first- and second-generation experience, ${ }^{3}$ taking a transnational optic and based on inter-country comparisons. Its perspective includes the transmission of identity across generations and the multiple interactions of immigrants and their descendants within different societies across Europe and in the 'home' country.

One aspect that distinguishes this research from other studies on the second generation in Europe is that, whereas other research has focused on the second generation at an adult age, this book involves a 'new' second generation, or a second generation 'in-the-making'. This is inevitable in view of the history and chronology of the Albanian migration in Europe, which dates only from the 1990s. ${ }^{4}$ There are two main implications of this for the project's approach. Firstly, it gives us a 'privileged' position for investigating processes of integration among a newly settled immigrant group and their descendants and for comparing and contrasting different national, city and local contexts where these processes were taking place. Secondly, this study draws attention to a group potentially 'at risk' of downward assimilation, based on the positioning of the first generation of Albanian migrants, especially their concentration in disadvantaged employment and housing and their strong stigmatization and discrimination (Bonifazi and Sabatino 2003; Hatziprokopiou 2006b; Markova and Black 2007). In light of US-derived theories that emphasize role of the mode of incorporation of the first generation on the integration of the second generation (Portes and Rumbaut 2001; Portes and Zhou 1993), a disadvantaged starting point might result in entrenched downward mobility for the Albanian second generation.

The second generation in the USA and Europe came to the attention of researchers and policymakers only when it 'came of age' (Crul and Vermeulen 2006). The literature from North America and Europe points to clear examples of failure to address issues of discrimination and exclusion, which led to the marginalization of large second-generation groups. Therefore, another major objective of this project is to provide evidence and inform policymaking on the integration of second-generation teenagers, thus taking a proactive approach towards the integration of ethnic minorities. In this respect, the study follows the strong emphasis of the European research on bridging gaps between research and policymaking on issues of integration. It also responds to European scholars' concerns that, despite the growing interest in the integration of the second generation, research and policymaking in Europe

\footnotetext{
${ }^{2}$ This project required knowledge of four languages. The author is a native speaker of Albanian, has fluent English, good knowledge of Italian and reasonable knowledge of Greek.

${ }^{3}$ The term 'second-generation', while not unproblematic (see Sect. 1.2 for some discussion), is used throughout the book for practical reasons.

${ }^{4}$ The book refers to migration from the country of Albania. There is a longer history of labour migration dating back to the early 1960s of ethnic Albanians from the former Yugoslav republics and regions of Kosovo, Macedonia and Montenegro when they were part of the large-scale Yugoslav migration of the 1960s and 1970s.
} 
have lagged behind in time and scope. For example, Crul and Vermeulen (2006) and Simon (2003) observe that in many European countries the lack of recognition of the second generation as a legacy of immigration led to a general apathy among scholars and policymakers.

In addition to responding to these policy concerns, this book shifts the focus to Southern Europe, where awareness of and interest in issues of second-generation integration are still at an early stage. Informed policymaking is particularly important in this context as the lack of coherent immigration and integration policies and the negative impact thereof on the second generation's integration strategies have already been documented (Gogonas 2010; King and Mai 2009). It also needs to be pointed out that the first wave of comparative research on the second generation was carried out in the main immigration countries of continental North-Western Europe (especially in France, Germany, the Netherlands, Belgium and Switzerland); Greece, Italy and the UK were not part of past cross-national comparative research on the second generation in Europe (Crul and Vermeulen 2003).

Comparative research is a growing trend in migration studies. Yet, very few studies take a cross-generational approach and simultaneously compare migrants and their descendants across different sites. A core argument for inclusion of the first and second generation in the current research is the characteristics of migration in this particular case: Albanian migrants and their descendants are settling at the same time. Inclusion of both generations seeks to elaborate on a general observation in the literature that 'the mode of incorporation of the first generation endows the second generation with differing amounts of cultural and social capital in the form of job networks and values, and exposes them to differing opportunities, thus exerting differential pulls on their allegiances' (Levitt and Waters 2002, p. 15). Additionally, this design enables research on intergenerational transmission, which is currently an understudied topic. The focus on first-generation migrants and their descendants in this book is also related to recent developments in theorizing on migration. Portes (2010, p. 1557) maintains that a medium timeframe encompassing two or three generations is the best approach to studying migration; short-term approaches miss the durable effects of migration upon migrants and their descendants, whereas a long-term historical lens misses those effects already absorbed into the culture of the respective societies.

Studying the first generation's aspirations for their children, and the impact of the first generation's migration experiences on the second generation's identity formation, therefore constitutes an important strand of this book. Few studies have integrated parents in their investigation. When this has been done, the information on parents has been considered as subsidiary to the data drawn from the second generation (see, e.g., Waters 1994). Only a handful of studies in the field of migration and integration of the second generation have recognized the role of the family as a source of social and human capital (e.g., Aparicio 2007; Dwyer et al. 2006; Marques et al. 2007). Portes and Rumbaut (2001) and Rumbaut (1994) took a quantitative approach to investigate the second generation's prospects of integration and the impact of parents' status and child-parent relationships on the second generation's adaptation. Crul (1999) investigated the role of parents' socio-economic 
characteristics, their education in relation to their knowledge of the educational system of the host country, and their rural or urban background in relation to the process of acculturation - all this through interviews conducted with the secondgeneration youth. In contrast to these previous studies, the study presented in this book incorporates the experiences of the first and second generations and includes intergenerational transmission as an integral part of the research design, given that parents and their experiences have a direct and active role in shaping the second generation's perceptions and integration expectations.

From a theoretical and conceptual perspective, the author has observed developments in various disciplines and linked these developments to the study of migration and the second generation. The inclusion of both the first and the second generation in the research design necessitated a linking of migration studies with key sociological and geographical concepts, such as space and place, mobility and cosmopolitanism, time and generation. In turn, interpretation of the findings required a shift between deduction and induction, and involvement of sociological constructs such as capital, agency and power. Such an approach elicited important conclusions on the integration of migrants and their descendants and on the meaning and role of context, which are discussed in the following sections. Further details on this research design follow later in this introductory chapter, the purpose of which is to introduce the reader to the theoretical areas referred to in this study, to introduce the 'new' Albanian second generation and the field sites, to set out the research questions and methods, and to provide a brief overview of each chapter.

\subsection{Contextualizing and Theorizing Cross-Generational Migration Research}

\subsubsection{Identity, Integration and Transnational Ties}

This book's theoretical focus on identity, integration and transnational ties aims to provide a systematic comparative analysis of these concepts and their interactions, which is otherwise missing from the existing literature. Such an approach is highly relevant to the case of Albanian migrants and their descendants in Europe. Like many recent migrations, and perhaps because of its illegal nature (King 2003), Albanian migration has not been studied in-depth in terms of identity and social and cultural integration. The focus has mainly been on the migration process itself, and on issues of regularization and integration in the labour market. This reflects a much broader trend in European scholarship on migration and ethnic relations. Drawing on public and political concerns in relation to migration, developments in this field have tended towards binary perspectives, seeing migrants' integration in terms of a prominent public concerns (e.g., the labour market) or in terms of issues high on the political agenda (e.g., security or health) (Martiniello and Rath 2010).

Indeed, the theoretical reasons for reviewing the three main concepts of ethnic identity, integration and transnational ties are manifold. Firstly, the three concepts 
are complex and used in various, sometimes essentialized ways in migration research. Furthermore, most empirical research on ethnic identity, integration and transnationalism points to their interactions; however, they have seldom been analysed jointly. Classic studies of integration concentrate on ethnicity and assimilation, whereas more recent ones, starting from the mid-1990s' emergence of the transnationalism paradigm, take for granted the role of identity, or just focus on transnational identification, assuming its automatic existence in the transnational phenomena (Wimmer and Glick Schiller 2002). Over time, studies on identity in the context of migration have expanded, looking beyond ethnicity and bringing in other social markers, such as social class and gender (Anthias and Yuval-Davis 1992). Nevertheless, studies of the second generation have typically retained a 'hard core' focus on ethnicity. In turn, there is little of a coherent theoretical framework on transnationalism, while culture and its impact on transnational phenomena have been under-researched (Levitt 2005).

Interest in the so-called 'second generation' is itself a relatively recent trend in the academic literature on migration and integration. Originating in the USA in the past two decades, a whole body of research has grown out of observations that the integration strategies of the 'new' second generation (coming mainly from Latin America and Asia) represent more complex phenomena than those of the 'old' second generation - the children of migrants of European origin (Gans 1992). In Europe, research on the second generation has followed societal and political concerns about the failure of European societies to integrate ethnic minorities, as well as comprising a purely academic interest. It is a common view among scholars of immigration that the integration of the second generation is an indicator both of the degree of integration of immigrants into a specific society and of the more general legacy of contemporary immigration (Portes 1994). Moreover, study of the second generation has given new dimensions to the integration and assimilation debate and opened up great opportunities for comparative research on integration processes, across countries and generations, and within and between ethnic groups (Thomson and Crul 2007).

By the mid-2000s, research on the integration of the second generation seemed to have reached a stage of 'maturity', explaining different integration patterns as the outcome of an interplay of structure, culture and personal agency. There are, however, several 'gaps' and inconsistencies in the literature that highlight the need for further research. These have served as tenets for the design of the current study as a cross-cultural and cross-generational qualitative investigation of identity, integration and transnational ties. Firstly, scholars both in the USA and in Europe have argued that more attention should be paid to differences in identity formation processes and integration pathways between and within ethnic groups, in contrast to the tendency observed in previous research to see immigrant communities and ethnic groups as homogeneous entities. This essentializing tendency has been a particular worry for European scholars, as such an approach fails to capture the diversity of immigrants in Europe, in terms of national and ethnic origin, educational level, social class and religious background (Crul and Vermeulen 2003). Furthermore, most studies conducted on both continents have focused on the performance of the second generation in the spheres of education and the labour market, while issues such 
as citizenship, identity and transnationalism have remained understudied (Thomson and Crul 2007). In addition, a strong emphasis on quantitative methods and large surveys is identifiable, even while there was a growing awareness that such a methodology cannot fully capture the integration processes of the second generation. In particular, it fails to grasp the dynamics of identification processes and transnational practices (Jones-Correra 2002). European scholars have also alleged a failure of the major theoretical frameworks developed in the USA to explain different patterns of second-generation integration across Europe (Crul and Vermeulen 2003, 2006; Thomson and Crul 2007). Due to significant differences in institutional arrangements and policy frameworks between European countries, the opportunities that different national contexts offer to the second generation have been found to vary greatly (Joppke 1999).

Research on the Albanian 'second generation', on the other hand, constitutes an important, original aspect of this book. This is the first full-length comparative study of the Albanian second generation. Its focus on minor descendants of migrants - here, adolescents aged 12-19 years - expands research on children in the social sciences in general, and within the migration literature in particular. Children were long excluded from the prime focus of migration research, being seen, at best, as their parents' 'luggage' (Orellana et al. 2001, p. 578). Only recently have children come to be seen as active agents and, therefore, as research subjects 'equal' to adults (Dobson 2009; Ní Laoire et al. 2010). In many cases, research has focused mainly on children in harmful and dangerous conditions, thus excluding children who have migrated with their families, or it has viewed children only within the broad-brushed concept of family migration (Goździak and Ensor 2010). This book expands the literature on children and migration by referring to both children and to the family and role of the parents, as the latter are important factors affecting children. It does so with both a migration studies lens and a childhood and youth studies lens (Bushin 2009).

Taking these theoretical considerations into account research for this book is articulated around five main sets of questions, presented below, reflecting the range and complexity of the project and of the issues under study:

- What are the patterns of identification of the Albanian first and second generation? What is the role of ethnicity in identity construction?

- Do Albanian migrants and their children establish transnational ties with the 'homeland' and the Albanian culture? If so, what is the nature of these ties?

- What factors condition identity formation, transnational ties and pathways of integration, for example, the role of the family, the institutional framework and regularization processes?

- What are the patterns of the intergenerational transmission of ethnic identity, integration and transnational ties?

- How do ethnic identity, integration and transnational ties interact? What factors affect these interactions, and how do they ultimately impact on integration?

A grounded theory approach to data analysis uncovered complex interactions between these variables, which challenged major assumptions often employed in the 
study of migration and settlement of migrants and their descendants. The interpretations of data raised further research questions and required employment of alternative conceptual frameworks, as outlined later in this chapter, following an analysis of theory and research on the second generation.

\subsubsection{Theories on the Integration of the Second Generation}

The term 'second generation' refers to a heterogeneous group. Several authors have argued for a cautious use of the term in order to avoid methodological and conceptual problems related to it. Portes (1994) notes that the use of pan-ethnic labels fails to distinguish between native-born and foreign-born and overlooks the empirical diversity of the group. As King et al. (2006a) observe, there is a loose agreement on who is referred to as the second generation, namely native-born children of immigrants plus foreign-born children who arrived before primary school. However, further attempts to specify the group have produced terms like the ' 1.75 generation', the ' 1.5 generation' and the ' 1.25 generation' (Rumbaut 1997), referring, respectively, to foreign-born children arriving before the age of 6 , between ages 6 and 12 and after age 12. A more recent trend is shown in the work of several authors (e.g., Fibbi et al. 2007; Marques et al. 2007) who use the term rather symbolically or refer to the 'children of immigrants'. This book uses two parameters in defining generation. Apart from the classic one used by the second-generation literature, this book refers to the definition of Kertzer (1983, p. 128) who views generation as 'a relational concept bound to the realm of kinship and descent'. Furthermore, it incorporates the meaning of generation put forward by Eckstein (2002), who maintains that generations are defined by the different social conditions they experience in their pre- and post-migration times.

Original theoretical models explaining the second generation's identification and integration processes have taken a strong ethnic stance. The straight-line assimilation theory assumes that the more time spent in the host country, the more likely it is that the second generation will identify ethnically with the dominant group there (Waters 1990). Similarly, the 'second generation decline' framework developed by Gans in 1992 is based on the assumption that, facing discrimination, the second generation will turn to the ethnicity of origin and establish subcultures opposing the mainstream in reaction to low expectations of educational and job market performance. Ethnicity provides another central framework in some key concepts of the identification patterns of the descendants of migrants, such as 'optional' (Waters 1990), 'symbolic' (Gans 1994) and 'situational' (Le Espiritu 1992) ethnicity. It should be noted that these approaches take an assimilationist perspective, and the empirical evidence they refer to speaks about the third and fourth generations of immigrants in the USA or cases in which 'quantitative transformations of ethnic consciousness' have happened over decades (Le Espiritu 1992, p. 2). There is an increasing recognition in the literature of within-group differences in terms of ethnic identification and a move towards a more complex and nuanced approach (Kasinitz et al. 2004; Song 1997). 
Therefore, scholars have expanded their focus when theorizing on the determinants and outcomes of the integration process of the second generation. 'Classical assimilation' theory, a model formulated in the US context of the 'old immigration' from Europe, seemed too simplistic for the new conditions many of the post-1965 immigrants and their descendants faced (Zhou 1997a). The theoretical argumentation of straight-line assimilation has been strongly opposed by some, based both on historical grounds and on cross-national comparisons (Waldinger and Perlmann 1998). Meanwhile, the observation of Gans (1992, p. 175) that 'the line of the theory has not always been straight and bumpy-line theory might be a more apt term', was empirically supported by Portes and Zhou (1993). They also referenced ethnicity, but noted three alternative pathways for the second generation: assimilation into the poor underclass, acculturation and integration into the native middle class, and rapid upward social advancement relying on a strong ethnic community. Utilizing evidence from the experience of different ethnic groups in California, they put forward the theory of 'segmented assimilation', which attempts to explain the factors that determine into which segment of American society an immigrant group is to assimilate (Zhou 1997a). The experience of the Punjabi Sikhs in Northern California revealed that the effects of a disadvantaged starting point, coupled with strong discrimination and racism, could be buffered with the help of social and material capital from the first generation. However, this strategy of selective acculturation-strong ethnic community cohesiveness as a source of pride to counteract discrimination-seemed not to work in the case of other ethnic groups. The case of Mexicans in Central California showed what Gans (1992) called 'second generation decline': a 'lost race' between first-generation achievements and second-generation expectations, leading to an orientation towards a reactive subculture as a means of protection against discrimination, which further inhibited the upward social mobility of the second generation (Portes and Zhou 1993, p. 89).

Does the theory of 'segmented assimilation' capture the whole picture of the second generation's integration dynamics? Some of the most important 'gaps' in the theory are thought to be associated with its lack of recognition of differences within ethnic groups and of gendered patterns of integration (Waldinger and Perlmann 1998). Furthermore, European scholars point to the irrelevance of the theory in the European context, due to the marked differences between national contexts on the continent (Crul and Vermeulen 2003). However, as recognized by Zhou (1997a), 'segmented assimilation' is a middle-range theory that tries to explain why different immigrant groups face destinies of convergence and divergence and describes the patterns and factors associated with these differential outcomes. It predicts that the possible determinants of integration outcomes are manifold, including factors at an individual and contextual level.

In effect, the 'emancipation' of theorizing on the integration of the second generation has followed the same line of conceptualization. A more recent view holds that the paths to integration diverge in various ways relating to structure, culture and personal agency, and the outcome of the integration process is largely decided by their interplay in a particular context (Thomson and Crul 2007). Neither did the 'national context' theories - the citizenship and institutional approach - put forward 
by European scholars survive the diversity and dynamics of the actual integration patterns of the second generation. The citizenship view takes a macro approach and focuses on the effects of the various national models of integration and their resultant impact on immigrant integration (Joppke 1999). In contrast, the institutional approach observes that the probability of underclass formation is linked to the opportunities that national institutional arrangements for educational and labour market transition offer to the second generation, and that there is no direct relationship between the national models of integration and educational and labour market performance (Crul and Vermeulen 2003, 2006).

This theoretical emancipation is also associated with an evolution of the concept of integration and a focus on the local level to better understand integration processes. Thus, despite an ongoing heated debate on its definition, 'integration' is increasingly understood as both an organic process, shaped by factors operating at an individual and collective level, and a process which is conditioned by key events and legislative changes (Thomson and Crul 2007). As mentioned above, there is an important 'gap' in second-generation research regarding intergenerational transmission. This topic was the focus of some research in the 1980s (as reviewed by Zhou 1997b). However, the studies are very limited and there is still need for more research to identify its mechanisms and dynamics (Attias-Donfut et al. 2012; Nauck 2001; Portes 1998).

A more transgressive approach notes that, when investigating the factors affecting the integration process of the second generation, literature has primarily relied on a single frame of reference: the host society's socio-economic traits and categories (Levitt 2009; Louie 2006). Only recently have scholars started to focus on ties that the second generation establishes with the 'homeland' or its cultural heritage (e.g., Rumbaut 2002), and the potential role that these variables can play in shaping the integration process of the second generation in the host society (Levitt and Waters 2002). However, while it is widely recognized that the formative years of second-generation children are characterized by a process of reconciliation of the values held by their parents from the country of ancestry with those of the country where they live, the positioning of transnational ties in the literature on the second generation remains ambiguous (Wessendorf 2007a).

In the case of second-generation teenagers, as Reynolds (2004) observes, transnational ties lead to and become a form of 'cultural hybridity'. This can encourage the construction of multiple ethnic identities, associated with a de-essentializing process of ethnicity. Thus, rather than being fixed in their ethnicity, the process of identification among the second generation is characterized by a constant negotiation of identity, referring to multiple frames of belongingness-'homeland', 'host country' and even cosmopolitan references - moving away from a primary focus on ethnicity in plural social systems where they grow up (Colombo et al. 2009a; Wessendorf 2007a). Yet, viewing transnationalism and maintenance of ethnic identity as constantly coexisting phenomena would be rather premature. For example, De Vries (1999, p. 41) notes that the ethnicity of the Dutch Eurasians is 'a highly individualised form of ethnicity, one constructed without close contact with the coethnics and without considerable participation in an institutionalised ethnic life'. 
Consequently, an important question concerning transnationalism is whether transnational ties are a first-generation phenomenon or ties that persist in the second generation (Jones-Correra 2002; Vertovec 2001). A general view holds that assimilation is more emphasized in the second generation and the maintenance of transnational ties by the children of immigrants is not uniform and is expressed in different forms of engagement, depending on parents' socio-economic class and the context of integration (Morawska 2003). However, in contrast to research conducted in the USA which shows that only a small percentage of second-generation respondents are involved in transnational practices (Jones-Correra 2002), Zontini (2007) notes that intensive transnational experiences can be found among second-generation adults in the Italian immigrant community in the UK. Furthermore, Foner (2002) concludes that the current second generation will probably be more involved in transnational practices than previous ones. As Reynolds (2004) observes, taking her cue from the experience of Caribbean families in the UK, the availability of telecommunications and other new electronic forms of communication has given great opportunities to young people to establish regular contact with family and friends living in other parts of the world. Parker and Song (2007) similarly highlight the role of the Internet in providing new diasporic public spheres, stimulating new forms of self-expression, collective identity formation and social action among the British Chinese in the UK.

Regarding the impact of transnational ties on the integration of the second generation, Foner (2002, p. 249) writes that 'second-generation transnationalism is likely to be a mixed blessing'. Transnational ties can provide a 'safety net' to the second generation and serve as a resource activated against exclusion and lack of social capital in the host society. At the same time, transnational experiences can obstruct the strategies of the second generation to integrate and pose challenging demands on family responses. Portes (1999, p. 472) emphasizes the positive effect of transnational ties on the second generation in buffering discrimination. He points to the role of transnational activities in facilitating successful adaptation to the first generation and 'softening' the demanding and relentless process of acculturation for the second generation that often leads children to a forced assimilation, associated with the abandonment of their parental languages, unconditional adaptation to the norms and styles of the host culture and internalization of a feeling of belongingness to an inferior place in the social hierarchy. Morawska (2003) offers a useful summary of the combined patterns of transnationalism and assimilation of the second generation in the USA, building on comparisons between the mainstream middle-class/upwardly mobile and the lower-class/underclass first and second generation. She highlights differences in terms of ethnic identities, types of transnational ties/involvement and transnational activities in the 'homeland'. Furthermore, the transnational orientation of the second generation is found to change during the life course, starting to develop and peaking in adolescence, falling in adulthood with the introduction of marriage and children, and then again gaining importance in middle age and later life (Jones-Correra 2002).

To cite specific empirical examples, Louie (2006, p. 566) observes that multiple frames of reference inform the identity formation of second-generation adolescents 
and their views on education. She studied the ethnic and transnational orientations of Dominican and Chinese minorities in the USA and found that they referred to ethnic and pan-ethnic frames both in assessing their own educational attainment and mobility against their co-ethnic peers in the USA and in their homeland, and as a means to reconcile their marginalized incorporation in the USA along ethnic lines. Zinn (2005) looks at transnational links of a small sample of second-generation Albanian children as a source of better adaptation in Italy, in line with other studies that examine transnational ties as a resource employed by the second generation to counteract discrimination in the host country (Levitt and Waters 2002). Zinn (2005) notes that, while practical and institutional arrangements in the host country pose challenges for the future maintenance of these links, the second generation's experiences during visits in the 'homeland' also included instances of encountering barriers and difficulties in being accepted by Albanian society. In turn, studies of transnationalism among the second generation in adulthood have been associated with 'roots migration' or migration of the second generation to the parents' country of origin. Wessendorf (2007b) studied the Italian second generation in Switzerland and shows that intensive transnational experiences during childhood and adolescence can have a strong impact on the second generation's future life choices, extending beyond identification with the ethnic community and materializing in return migration (see also Christou 2006; Smith 2002).

Increasingly, however, the literature on the second generation's transnationalism is turning to a more integrated approach that criticizes research which conceptualizes generation as lineal, draws boundaries between the transnational and integrational experiences of different generations and overlooks various implications for the second generation of growing up in transnational social fields. In a detailed summary, Levitt and Jaworsky (2007) draw attention to the fact that, despite the existence and frequency of transnational activities and visits, being raised in transnational social fields gives the second generation certain skills and social connections which can be activated at different stages of life. More recently, Levitt (2009) notes that the transnational experiences of the second generation consist, in effect, of an integral part of growing up in a new destination. Second-generation adolescents, according to her, are not just passive receivers of the host society's culture and observers of homeland traditions; living a transnationalized adolescence, they create their own practices, which leaves a legacy to younger immigrant-origin teenagers (Orellana et al. 2001).

\subsubsection{The European Second Generation}

Whilst theorizing on the integration of the second generation has so far been dominated by US scholars, research on the second generation in Europe is rapidly developing. However, the research material on the two continents differs, due to several factors (Crul and Vermeulen 2003). For example, the danger of 'underclass' formation as an end-result of downward mobility, though common to both debates, seems particularly prominent in the USA in view of specific features of the US economy, 
society and urban structure, while the concept of an 'underclass' itself is deemed as inappropriate for research on incorporation in Europe (Martiniello and Rath 2010). As Waldinger and Perlmann (1998) observe, there is a strong focus on the economic structure in the US literature while other factors (e.g., demography) are almost ignored. This creates a tendency among American scholars to see ethnic groups as homogeneous, which fails to capture the diversity of immigrants in Europe in terms of education, social class and religion (Thomson and Crul 2007).

It should be mentioned that 'segmented assimilation'- the model based on the divergent ways in which ethnic groups integrate into a receiving society-has inspired some initial research in Europe. However, scholars observe that, rather than a 'segmented assimilation', there is a 'spotty' social mobility across generations of immigrants in Europe (Simon 2003). As a result, European scholars question whether a return to a modified form of 'classical assimilation' would better explain the integration patterns of the second generation in Europe (Thomson and Crul 2007). Furthermore, findings on the role of the ethnic community in the European second generation do not always support the 'ethnicity as social capital' assumption, which constitutes one of the pillars of the segmented assimilation hypothesis. In particular, clear differences have been found along gender lines within ethnic groups. Several studies conducted in different European countries find that the Turkish second generation is faring less well in education today compared to other ethnic groups, due to its 'closure', which is said to be a serious obstacle especially to the advancement of girls (see, e.g., Crul and Vermeulen 2003; Timmerman et al. 2003). Similarly, Worbs (2003) observes that gender-specific obstacles deter second-generation women's upward mobility. She found that participation rates in vocational training and employment of the second generation in Germany are lower for young women of immigrant origin, although those women achieved higher educational levels than men.

Thirdly, an original development in European scholarship is the focus on the role of the national and institutional context, which is largely ignored in the USA, although cross-national studies are still needed to better understand the impact of the national context on the positioning of the second generation across Europe. Crul and Vermeulen (2006) compared integration indicators of the Turkish second generation across Europe and found significant variance in the opportunities that different national contexts offer. For example, the French educational system seems to encourage the second generation to pursue studies at university level, whereas the German context with its apprenticeship system ensures a smoother transition from school to the labour market, but blocks off access to university. As a result, Crul and Schneider (2010) put forward a new theory of integration, based on the experience of the second generation in Europe. The comparative integration context theory is based on the assumption that integration is deeply affected by differences in the contexts where integration takes place-more precisely, the institutional arrangements in education, the labour market, housing, religion and legislation. The other major assumption, which is in line with other scholars' arguments (e.g., Glytsos 2005; Portes 2010), is that rather than focusing on the present state and the final outcome, integration should be studied by focusing on the underlying processes over time. 
The educational performance of the second generation in Europe varies greatly across countries and different ethnic groups (Crul and Vermeulen 2006). Several studies on school performance of European second-generation pupils show that educational performance is generally improving, however, alongside high drop-out rates. Simon (2003, p. 1105), for example, reports that $46 \%$ of the Turkish secondgeneration youth left school without any diploma, compared to an average of $25 \%$ in France. However, these data conceal those immigrant-origin students who do succeed. Westin (2003) notes high drop-out rates among the second-generation migrant-origin youth in Sweden, but also an over-representation of this secondgeneration youth among those who perform well in comparison with native Swedes. Similarly, Timmerman et al. (2003), on the second generation in Belgium, report that while a relatively high proportion of Moroccan boys drop out of school and become marginalized, the proportion of those who do very well at school is twice as large. In explaining variations in educational performance, Crul and Vermeulen (2006) list a number of indicators found in the national systems of education across Europe that have clear implications for the differences between countries in educational performance of the second generation. Major factors include school duration, face-to-face contact hours with teachers, selectivity and the amount of supplementary help and support available to children within and outside school. However, inter- and intra-group differences in educational performance are seen to be an outcome of an interplay between social and economic exclusion, discrimination in education, ethnic cohesion and values, and the supportive role of family members (Crul and Vermeulen 2003).

While there is a tendency to consider educational attainment as a 'predictor' of subsequent labour market integration and upward mobility (Dronkers and Levels 2006), recent research shows that this expectation can 'fail to materialise' in the case of the second generation (Fibbi et al. 2007, p. 1139). Data from different European countries show an improvement in the educational performance of the second generation coupled with higher unemployment rates and concentration in low-profile jobs, compared to the native population in the same age range and educational level (Aparicio 2007; Simon 2003; Timmerman et al. 2003; Westin 2003). These data speak of a problematic transition to the labour market and provide further support to the hypothesis of discrimination in the host society towards second-generation communities (Fibbi et al. 2007), returning the focus once more to structure and policies.

\subsubsection{The Albanian Second Generation}

The main features of the Albanian second generation are inevitably related to the history and chronology of Albanian migration in Europe. Contemporary Albanian migration dates only to the beginning of the 1990s, and its dynamics developed rapidly during the past two decades, which has clear implications for the age range and integration strategies of the second generation. According to statistics of the Government of Albania (2005), the largest communities of Albanian migrants in Europe are found in Greece $(600,000)$, Italy $(250,000)$ and more recently in the UK 
$(50,000)$. World Bank (2011, p. 54) estimates confirm 600,000 Albanians in Greece, but increase the figure for Italy to 400,000 . The flows to Greece and Italy date from 1990 and 1991. The flow to the UK dates mainly from the late 1990s. However, due to high rates of family reunification and settlement, Albanian children constitute the largest second-generation group in the first two countries (Gogonas 2010; King and Mai 2009). In Greece, from calculations based on census and other sources, Baldwin-Edwards and Kolio (2008) conclude that, of the 120,000 non-Greek residents of all ages born in Greece, the largest group of 110,000 were of Albanian origin. Data from Italy likewise reveal a rapid growth of the Albanian pupil population, which accounts for $17.7 \%$ of the population of students of immigrant descent and makes them the largest foreign-origin group (Caritas data, cited in King and Mai 2009). The data from Greece and Italy point to the fact that the majority of the second generation is foreign-born. This is also expected to be the case of the Albanian second generation in the UK, which became a receiving country for Albanian migrants only a little over a decade ago (King et al. 2006b). ${ }^{5}$

The Albanian second generation in Europe is a new and almost completely unstudied group. Some expectations of their integration prospects can be derived from data on the performance and integration of the first generation, which would indicate a disadvantaged starting point for the second generation. Research has shown that Albanian migrants in the three main receiving countries are concentrated in low-status jobs, live in marginalized neighbourhoods, do not organize in communities and face strong racial discrimination (Bonifazi and Sabatino 2003; Hatziprokopiou 2006a; King et al. 2003; Kosic and Triandafyllidou 2003; Mai 2005). The discrimination documented against the first generation points to the importance of studying ethnic identity in this particular second generation.

Moreover, following the major theories on second-generation integration would lead us to conclude that the Albanian-origin youth will soon repeat the story of those ethnic minorities in the USA and Europe that have faced downward assimilation into the poor 'underclass'. This implication can be derived especially from Portes and Zhou (1993) who consider the concentration of the first generation in poor inner-city neighbourhoods and the presence of racial discrimination as factors that are likely to negatively influence the integration of the second generation. The absence of an ethnic community should also bear serious implications, as Portes and Rumbaut (2001) consider the pathway of 'selective acculturation' - a strong ethnic identity and a second generation embedded in the ethnic community - as the best scenario for successful integration of the second generation.

It should be mentioned immediately that the most recent research shows striking signs of improvement in the situation of Albanian migrants in the main host countries. According to King and Mai $(2008,2009)$, Albanian migrants in Italy are the most integrated migrant group among all non-EU migrant groups. Similarly, Hatziprokopiou (2006a) points to an improvement of living and working conditions and better integration of Albanian migrants in Greece in recent years, especially after the migrant regularizations of 1998 and 2001. However, strong negative stereotypes in

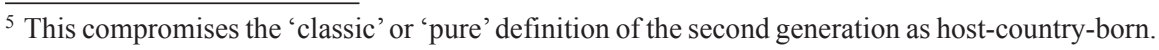


the media persist (Bonifazi and Sabatino 2003), and Albanians show little tendency to identify with the ethnic culture, to establish organizations and to use institutional structures (King and Mai 2009; Mai 2005). Research has also highlighted the negative impact of the institutional environment and policy implementation practices on Albanian migrants' socio-economic integration and perceptions of identity (Kosic and Triandafyllidou 2003). In particular, Gogonas (2010) points to the negative impact of a very tight citizenship and naturalization regime, which in Greece causes a great deal of insecurity surrounding the integration of immigrants, with further consequences for the second generation's efforts to become part of Greek society. The Greek results are supported by the findings of Zinn (2005) in Italy. These data raise concerns about the integration of the Albanian second generation-firstly, because the mode of incorporation of the first generation is recognized to have significant impact on the amounts of cultural and social capital transmitted to their descendants (Levitt and Waters 2002). Research conducted in Switzerland and Austria (Fibbi et al. 2007; Herzog-Punzenberger 2003) has also found a strong relationship between naturalization, school performance and labour-market integration.

But how are these conditions affecting the Albanian migrants and their children? There is very little data on the Albanian second generation. Some attention has been given to the issues of integration of the descendants of migrants in the two main 'host' countries (Greece and Italy). Meanwhile, the Albanian second generation in the UK is to date completely unexplored. Anecdotal and journalistic accounts from Greece suggest a high educational performance of Albanian-origin students. Thus, while gender and length of residence in Greece are significant variables related to school performance, Albanian students in Greece outperform other foreign-origin students. Studies conducted in Italy show similar results: generally, high educational achievements on the one hand, but also a marked tendency of male students to leave education and enter the labour market in early adolescence. For example, Fava (2007) studied the educational performance and the integration of children of immigrant descent in schools in different provinces of Italy. Pupils of Albanian origin record high academic attainment, with girls significantly outperforming boys; but somewhat counter-intuitively Albanians also score high on intentions to quit after middle school. Furthermore, while Zinn (2005) reports that in Italy early-years schooling of children is important to Albanian migrants, Fava (2007) shows Albanian parents to score lower than the average of the first generation in Italy in their interest towards the educational performance of their children and their desire for their children to pursue studies at university level.

Without overlooking the importance of the above-mentioned studies, this existing research in Italy and Greece takes mainly a limited-variable quantitative approach and offers a general overview of the second generation as a whole, while inter- and intra-group comparisons and qualitative research on their identification processes and integration strategies are largely missing. Some evidence on these topics comes from the studies of Zinn (2005) and Gogonas (2010) on the intergenerational transmission of native language and the role of the educational system in Italy and Greece, respectively. Educational systems and the general schooling policy on foreign-origin children differ significantly between countries in Europe and, 
likewise, between Greece, Italy and the UK (Eurydice 2004). The educational system in the UK is legally bound to actively promote racial equality, although research has documented some negative issues related to the integration and performance of ethnic minorities in education (Chadderton 2010). The system in Italy is characterized by a general climate of indifference toward multiculturalism and intercultural education (Zinn 2005), whereas in Greece schools take an ethnocentric approach and focus on monocultural and monolingual teaching, reflecting an exclusionary Greek national identity (Benincasa 2002). Gogonas (2010) emphasizes the incapacity of teachers to recognize the importance of bilingualism, widely acknowledged in the literature as a factor that promotes academic achievement and expectations among immigrant-origin teenagers (Golash-Boza 2005).

\subsubsection{Moving Back and Forth Between Theory and Data}

The design of this research observes major theoretical and conceptual frameworks on identity, integration and transnationalism, as well as the key studies on the second generation discussed above. However, several of its findings called for a review of major strands within migration research and for links with major sociological and geographical notions. Firstly, the data called for an analysis of migrants' and their descendants' understanding of contexts of integration. Accordingly, symbolic and spatial 'units' of reference in terms of identification, integration and transnational ties, often equated with the notion of nation-state, were unpacked and analysed referring to space, place and mobility. Along these lines of argumentation, both the comparative design and the city-based approach of this research take into account findings on cities and migration, and thus respond to the lack of research on the way children of migrants relate to their urban context. Cross-cultural research on migration primarily consists of studies that compare migrants across nation-states. But it is not only national settings that vary. Recently, cities have become increasingly prominent in the literature on the incorporation of immigrants (Brettell 2000). In fact, as White (1999) maintains, cities are a product of migration (both internal and international), yet they have only recently been analysed as distinct contexts of incorporation. This omission is related to an assumption that has long been the rule in migration studies - that nation-states are homogeneous entities as settings for migratory phenomena (Glick Schiller and Çağlar 2009, p. 183). As a result, data taken from research in cities have been considered as representing the situation in the whole nation-state, although paradoxically most research has been conducted in 'gateway' cities: those cities where immigrants initially settle and which attract significantly more immigrants. Nevertheless, research on cities as migration contexts is still lacking, especially regarding the second generation (Christou 2011).

The inclusion of the first and the second generation in the current research also uncovered a differentiated view on movement and mobility, which can be linked to major recent developments in social sciences research. While the study of the second generation has significantly contributed to our understanding of identity, integration and transnationalism, a new paradigm has taken the social sciences 
by storm. Mobility emerged as a key concept in the 2000s, offering new insights on the conceptualization of culture, identity and transnationalism (Salazar 2011) and greatly impacting the study of cosmopolitanism. Szerszynski and Urry (2006, pp. 114-115) define cosmopolitan predispositions and practices as extensive mobility in relation to many places and environments, further characterized by consumption, curiosity, willingness to take risks, ability to understand, semiotic skill of interpretation and openness. The role of mobility is emphasized in cosmopolitan practices. Yet, although transnational practices and ties are considered a favourable precondition, they are insufficient for the growth of cosmopolitanism (Kofman 2005; Sheller and Urry 2006). Seen as the antidote of place, being in itself a socialized movement (Cresswell 2006), the concept of mobility furthermore emphasizes the spatial and temporal characteristics of multiple forms of movements of people (Glick Schiller and Salazar 2013).

In integrating mobility into the study of the intergenerational processes of migration and settlement, this book, however, refers to the definition of mobility by D'Andrea, Ciolfi and Gray (2012, p. 150):

As both predicament and opportunity, new globally-related mobilities do not mean free movement in a 'flat world', but rather index a complex of actual, potential, uneven and disabled possibilities that are unequally actualized across multiple domains and fractures of social life.

Concepts of mobility and cosmopolitanism have been criticized as concentrating on elites. There have been claims, especially in the case of cosmopolitanism but also for mobility, that these concepts ignore the power differentials that impact the access of different groups to the practices to which they refer (see, e.g., Beck 2002). Despite their focus on elites, these concepts proved useful in the current study in analysing the processes and imaginaries that characterize migration and the everyday lives of Albanian migrants and their teenage children. The findings of this research thus contribute to our understanding of locality, mobility and cosmopolitanism in relation to the integration of low-skilled or de-skilled migrants and their descendants in European cities. Empirical findings related to these concepts are presented in Chaps. 2 through 6.

Furthermore, this research examines integration dynamics using the concepts of agency, capital and power. Bourdieu (2004) is clear on the role of capital in the structure and functioning of the social world. He defines capital as 'accumulated labour (in its materialised form or its "incorporated", embodied form) which when appropriated on a private, i.e., exclusive basis by agents or groups of agents enables them to appropriate social energy in the form of reified or living world' (ibid., p. 15). Theoretically, capital is seen to have different forms, varying from financial capital and human capital, in terms of quantifiable assets, to different forms of social capital, which refers to the processes of social interaction that provide benefits to individuals (Bankston and Zhou 2002; Portes 1998). ${ }^{6}$ This book views capital as a utilitarian resource, which is either harnessed and enhances integration or is

\footnotetext{
${ }^{6}$ Although social capital has also been found to have a restricting and negative effect, as in the 'integration' of second-generation girls in the case of ethnic enclaves (Worbs 2003).
} 
lacking among the first and second generation, leading to their marginalization and absence of social mobility. Findings show that different forms of capital impact on the integration of the first and the second generation, with the capital that is disposed of and transmitted by the first generation affecting the integration of the second generation.

More specifically, the findings of this book are in line with theoretical work maintaining that capital is interrelated with power and agency, with the possession of capital resting on the basis of power, and with power marking agency (Bourdieu 1989). A common view in the literature that recognizes power as a factor shaping the social world is that people are situated in different social locations, which are influenced by power hierarchies. Power hierarchies are also taken as the mechanisms that make individuals subjects through the imposition of categories, and the control they have on the law of truth, which individuals must recognize and others should also recognize in them (Foucault 1982, p. 781). In turn, power and agency are interrelated. As Ratner (2000, p. 430) maintains, the individual notion of agency as based on personal meanings ignores the barriers that agents encounter in their struggles for a sense of equality, democracy and fulfilment.

These 'mega' concepts have been integrated in migration research, but they have not been the basis of significant theoretical development in the field. In a recent review article, Bakewell (2010) maintains that migration theories have either overestimated the role of agency or structure, or gone for a middle ground, but none have analysed in-depth the actual impact of these aspects of social reality on migration processes. Other questions remain unanswered regarding the role of capital and power.

- To what extent does capital impact on the integration of immigrants and their descendants?

- What kinds of capital affect the identification, integration and transnational ties of the first and the second generation, respectively?

- Is capital and its effect on identification, integration and transnational ties contingent on time and space?

- How do the first and second generation perceive capital and power and their importance for integration?

These questions are little studied in migration research. This book makes a modest contribution towards answers, based on detailed empirical evidence.

\subsection{Introducing the Field Sites: Immigration Politics and Ethnic Relations}

\subsubsection{Britain}

Like many European countries, Britain has experienced sizeable levels of immigration in its modern history. However, the post-war migrants, including large nonwhite and non-Christian immigrant cohorts, arrived earlier in Britain than in most 
other countries in Europe. The 1960s and 1970s were a time of immigration restrictions for the country, at least as far as labour-migrant recruitment was concerned (Kymlicka 2000). This situation, as in the rest of North-Western Europe, changed rapidly by the beginning of the 1990s. The decade of the 1990s was one of substantial net immigration as a result of the British government's programme for voluntary migrants and waves of asylum-seekers (Hampshire 2005).

Favell (1998), however, notes a distinct dualism in British immigration and integration politics. The discourse seems to be divided between the issue of nationality and border control, on the one hand, and strong measures for ethnic minority integration, on the other hand. This emphasis on the development of multiculturalism is also associated with a persisting focus on race and an emphasis on the integration of post-colonial migrants, thereby overlooking the new migrants. This was later rephrased by Favell (2000) who cites research showing that race and ethnicity in Britain nowadays bear less importance than class and other social factors in marking minorities' integration, or rather their lack thereof.

Other literature suggesting that race and ethnicity have lost their importance could, however, be rather premature. For instance, Platt (2005) examines the social mobility of the second generation, finding that although education and class of the parents matters, particular ethnicities and religions are also important predictors. Cross (2000, p. 364) notes that the integration of those populations that are more similar to the majority has been more difficult than for those with a distinctively divergent cultural origin. He explains this within the framework of pluralism and separatism applied towards minorities in Britain. The integration of post-colonial migrants, according to Cross, has succeeded via the outcome of offering them 'the benefits of non-integration' and concessions in the form of ethnic entrepreneurship and community resources. This strengthens the rationale underlying claims that the old framework, focusing on race relations, is inadequate for analysing the conditions of new migrant groups in Britain.

Three main features characterize the new immigration to Britain: the reduction of immigration from Commonwealth countries in the Caribbean and South Asia; increased migration from Eastern Europe and East Asia; and the opposition towards asylum-seekers, as scepticism regarding their legitimacy has increased (Berkeley et al. 2006, p. 1). The issue of the new migrants is especially pertinent in relation to the laws and practices on asylum, as the 1990s recorded, as mentioned above, a substantial rise in the number of asylum applications. Hampshire (2005) argues that the recent tendency to acknowledge the positive impacts of migration is associated with an increase in emphasis on welfare parasitism, stigmatization and penalization of asylum-seekers and an increasing antagonism towards sponsored immigration. New Labour policies further eroded the rights of asylum-seekers, considering them to be a threat to the management of migration waves (Flynn 2005); and the new coalition government of Conservatives and Liberal Democrats seems even more determined to reduce immigration, including highly skilled and student entrants from outside the EU.

Although fewer migrants entered Britain in the 1990s compared to most other European countries (this changed in 2000s, especially after 2004), the new migrants 
have been made unwelcome. They are 'blamed' for the further increase of immigration into the country and for 'ruining' the balance of privileges and rights already in place for the old minorities (Favell 2001). Britain became a destination for Albanian migrants only in the late 1990s. Although their numbers are small compared to other minorities in the country, Albanians arrived when the political discourse was already characterized by stigmatization and penalization of asylum-seekers and an emphasis on the negative impact of new arrivals on school, health and welfare systems (Hampshire 2005). The size of the community is hard to estimate, and different figures are reported both from official sources and key informants. An IPPR report on new communities settling in the 1990s in Britain estimated the Albanian community to be just under 2,300 in 2001, compared to just 150 recorded in 1991 (Kyambi 2005). The Government of Albania reports the Albanian community in Britain to be the third largest in Europe, estimating it at around 50,000 (Government of Albania 2005). Key informants interviewed for this research maintain that the community has grown to 100,000 .

\subsubsection{London}

Immigration in London is not a recent phenomenon. Indeed, historians go back 250 years when looking for the origins of London as the 'city of nations' (Akroyd 2000 , p. 701). The same is true for its multicultural tensions, but also its openness and acceptance. As such, London has a particular position in Britain's immigration history. Its variety and heterogeneity have impacted the notion and redefinition of Englishness itself. Holmes (1997), furthermore, points to London as a principal destination and location for many immigrant groups, whose immigration and residence experience in Britain is bounded within the capital.

London's dynamic relationship with immigration is very much related to its character as a global city with an imperial past (Eade 2000). Like other global cities, London is characterized by an increase in informalization and casual labour markets - an aspect closely related to immigration as a source of low-wage labour for economically marginal sectors of production, including the service economy (Sassen 1991). However, compared to other global cities, such as New York and Los Angeles, up to the early 1990s the growth of low-paid employment in London was impeded by a relatively generous welfare system and a limited supply of 'fresh' migrant labour. But then, with the increase in immigration over the past 20 years, a notable 'migrant division of labour' has emerged in London, characterized by a disproportionate growth of managerial jobs and a lower, but still significant, growth in low-paid jobs, the latter being mostly taken by new migrants. The emergence of such a divide necessitates a closer look at the place and lived experiences of migrant workers in London, as such polarization brings with it major political challenges, which negatively impact the situation of new migrants, most of whom are constrained to low-grade jobs (May et al. 2007).

Most of the research on global cities, and on London in particular, has focused on the economic dimension of the local, urban impacts of globalization. Relatively few 
studies have focused on the everyday experiences of ordinary people (Dürrschmidt 1997). Eade (1997) points out the lack of research on the meaning of such structural developments for individuals and how they relate to collective categories such as 'classes' and 'minorities'. The racialized boundaries between insiders and outsiders are found to be still in evidence in the transition of London from an imperial to a global city, and while the attention of researchers and commentators has been on the inner-city areas, it is often in the outer suburbs that a more general process of racialization takes place. Eade (2000) maintains that assimilation can be questioned on several grounds: racial beliefs of the native population enhance the exclusion from the white majority of African- and Asian-origin populations; many of these minorities prefer to keep their own culture and pass it on to future generations; the second and third generations of these minorities are creating new cultural identities, which in turn challenge assumptions about a coherent and lasting national culture within which all newcomers should assimilate.

The integration of new migrants exhibits worrying features, too. Together with the polarization of the labour market and the lack of secure low-waged jobs, the reception of new migrants throughout the country, and in London in particular, is found to be affected by the local labour market, local housing pressures, local and regional demographics, and political leadership on migration. The integration of new migrants is especially hampered by the diversity and pace of new migrations, which in turn affect the information available to the local authorities. Besides, there is a widely held view among public authorities that 'race relations' refers to the established white communities and 'visible' ethnic minorities, but not to the new European immigrants, while the required emphasis on local-level integration is still misconceived (Pillai et al. 2007).

The situation with new migrants becomes even more problematic when the large number of 'illegal' immigrants is considered, and the fact that no large-scale regularization campaign has ever taken place in the UK. Recently this issue seems to have come to a high level of discussion, at least within London, with the mayor of the capital advocating the regularization of illegal immigrants through an 'earned amnesty' scheme, estimating the number to be 400,000 in London alone (cited in Vollmer 2008). The initiative seems to be supported by the general public in London, set against a background of negative media coverage and immigration policies that insist on a regime of law and order against irregularity (Vollmer 2008). London, however, is not a homogeneous entity, and this should be taken into account in any analysis of processes associated with it, such as the 'new' migration of Albanians.

\subsubsection{Greece}

Like other EU countries, debates on diversity and related issues in Greece encompass the 'old ethnic minorities' and the new immigrants of the 1990s and thereafter, although in the latter case the weight placed on the diversity 'issue' is of a larger scale. Set against a history of large-scale emigration in the 1950s and 1960s, Greece became host to a considerable number of immigrants after 1989. By 2007 
the number of immigrants is reported to have reached 1.2 million or $10 \%$ of the total population and $12 \%$ of the labour force, giving Greece one of the highest percentages of immigrants within the EU (Gropas and Triandafyllidou 2007, p. 9).

Albanians in Greece constitute the largest Albanian migrant community in Europe (600,000; Government of Albania 2005). They are also by far the largest immigrant group in Greece. With calculations based on census and other sources, Baldwin-Edwards and Kolio (2008) conclude that, of the 120,000 non-Greek residents of all ages born in Greece, the largest group of 110,000 were of Albanian origin. Immigration of Albanians in the 1990s was largely irregular; the only way to immigrate legally was through a tourist visa or family reunification procedures. However, the first regularization programme for immigrants in Greece was not until 1998 , and two-thirds $(241,561)$ of the undocumented immigrants regularized that year were Albanian (Hatziprokopiou 2006a).

On the other hand, the predominance of one ethnic group among the new immigrants makes the Greek case unique in Europe. Rovolis and Tragaki (2006, p. 99) maintain that the 'average' immigrant worker in Greece is young, male and from an ex-communist country, pointing to a clear gender division in the reasons and forms of migration. However, although most immigrants come from the neighbouring countries of Central and Eastern Europe, newer waves originate in Asia and the Middle East, and to a lesser extent in Africa (Baldwin-Edwards and Apostolatou 2008, p. 21). As a result, immigration patterns in Greece are affected and represent features of three different models: the Balkan model, the Southern European model and the global model (Fakiolas and King 1996). Specific patterns of immigration to Greece reflect proximity between countries of origin and destination, the sudden transition of Greece into a migrant-receiving country, greater weight of specific immigrant groups (notably Albanians) and immigrant ethnic Greeks, a late policy response towards immigration, and specific features of the Greek economy and labour market (Hatziprokopiou 2004).

In effect, migration policy in Greece is characterized by a lack of legal migration channels, reactive measures against largely illegal immigrant flows, and a fragmentation of existing measures that often causes previously regularized immigrants to revert back to illegal status (Gropas and Triandafyllidou 2007). The Greek authorities have been reluctant to accept that immigrants are settling and creating communities (Baldwin-Edwards 2009; Triandafyllidou and Veikou 2002). Very minimal measures have been made for immigrants' integration. Those that are in place focus on assimilation, ignoring the increasing diversity in Greek society, while migrants' legal uncertainties significantly affect their economic bargaining power, impeding their integration (Baldwin-Edwards 2009). Triandafyllidou and Veikou (2002, p. 191) attribute some of the delay in authorities' response towards immigration to the novelty of the phenomenon, while the lack of an integration policy reflects the fiercely ethno-cultural definition of Greek nationality and citizenship. This also shows up in policy implementation and institutional culture.

The definition of Greek nationality and citizenship is rooted in the way Greek identity is constructed (Kapllani and Mai 2005). The main historical influences on Greek nationalism are the Enlightenment, which impacted the building of nationstates in Europe, and Greece's classical past, which contributed to a conceptualiza- 
tion of the Greek national community as both singular and universal (Gropas and Triandafyllidou 2007).

Tzanelli (2006, p. 40) takes the discussion further, pointing to a conflation of the discourse on Greek national identity with that of race, because of the symbolic references to Greekness as based on 'blood bonds'. She maintains that the Greek identity is composed of two main discursive layers. First, the 'civic' and the 'ethnic' are interchangeable in the Greek identity. Second, the naturalized status attached to the ethnic notions of identity creates the potential for ethnic identity to take racial connotations, also inspired by the international definition of Greekness as unique and practices of homogenization at the European level (2006, p. 45). Other research relates the emergence of this conflation to the social changes that have taken place in Greece since the late 1980s and the country's ambivalence of belongingness (e.g., in Europe, in the Balkans, in the Mediterranean), which impacts the perception and definition of difference. This has caused the emergence of racism based on both biological and cultural characteristics, which greatly impacts the opportunity structure and positioning of immigrant groups (Lazaridis and Koumandraki 2001).

Nevertheless, Greek national identity has been under significant pressure in the past 20 years and has shown signs of transformation in response to changing international and internal conditions (Kapllani and Mai 2005). Immigration as a new phenomenon in the 1990s has been an important factor in this transformation, but also in revitalization of the racist discourse (Triandafyllidou 2000). However, the development of this new identity has been slow to emerge and impact on policies and their outcomes for immigrant and minority-origin residents in Greece (Baldwin-Edwards 2009). The problematic situation of the welfare system in Greece adds to the difficulties that immigrant families face (Hatziprokopiou 2004). Many immigrant-origin children drop out of high school to enter the labour market. The recent economic crisis has only compounded the problems of survival for immigrants there.

It is important to see developments in Greece within the larger context of global developments. As a result of these, changes in national identity are under way, and immigration policies are being impacted by external pressures exerted by EU integration and the large immigrant population in the country (Hatziprokopiou 2004). Nevertheless, the emergence of a kind of de facto multiculturalism has found partial recognition in public debate, so that cultural and religious diversity is slowly being recognized (Rovolis and Tragaki 2006). Yet, at the same time, the presence of immigrants has made evident the different traits of Greek identity by leading to the construction of a hierarchy of Greekness, with different immigrant groups at different levels around the ethno-national main core (Triandafyllidou and Veikou 2002, p. 189; Tzanelli 2006).

\subsubsection{Thessaloniki}

Thessaloniki is the second largest city in Greece, with over 1 million inhabitants. It is also one of the oldest cities in Europe, dating back to $315 \mathrm{BC}$, with a continuous urban history and a rich multi-ethnic and cosmopolitan past (Mazower 2004). 
Its diversity is related to its positioning between Western Europe, on the one hand, and the Balkans and Eastern Mediterranean on the other, which has given Thessaloniki both Oriental and Occidental features. While other cities in Greece expanded without planning, Thessaloniki was characterized early on by strong governmental policies (Leontidou 1990).

Early policies were broadly related to the nation-state building process and the foundation of the Neo-Hellenic state in Greece in the nineteenth century. Moreover, the city experienced two major events in the early twentieth century that brought about key changes in its urban structure - the great fire of 1917 and the arrival of 117,000 refugees after the war with Turkey in 1922 (Hastaoglou-Martinidis 1997, p. 494). Also relevant, however, were the emerging nation-state and its ideology (Mazower 2004). This ideology gave rise to a process of modernization which influenced the shaping of the city towards three purposes: to ensure a link with the West, to disguise its rural past and its related memories of foreign rule and backwardness, and to provide a conduit between the ancient past and the modern new state (Hastaoglou-Martinidis 1997).

Thessaloniki was, as a result, created as a 'new' European city, to restore 'civilisation', with its space arranged according to models adopted by other European nations. This reformed the old traditional town according to the needs of a centralized state and the new urban space was seen as a laboratory for creating new social values through a homogenized and unified structure. This in turn impacted the social, demographic and ethnic composition, especially noticeable in the case of the main ethnic and religious communities and, even more so, in placement of the refugees, who were dispersed across different areas of the city (Hastaoglou-Martinidis 1997). These spatial divisions persist today, with the eastern part being richer than the western areas and a mixed centre, although the presence of a large and dispersed middle class softens the social divisions (Hatziprokopiou 2004).

In effect, the refugees and the state's policy on their settlement reflect broader issues related to attitudes towards multiculturalism and diversity. Although the city's history is marked by significant discontinuities, the different pasts, notably the Roman, Byzantine and Ottoman periods, were largely denied through publishing programmes, research institutes' agendas and the educational curriculum. This is clearly seen in the renaming of public places, the erasure of the Ottoman period and its heritage, and the denial of the refugees' presence who were assimilated through various policies, despite their contribution to the transformation of the city into a regional metropolis (Hastaoglou-Martinidis 1997). Thus, inspired by nationalist claims and emphasizing the Hellenic past at the expense of other important influences, the city's claimed history is rather one of 'forgotten alternatives and wrong choices of identities assumed and discarded' (Mazower 2004, p. 474).

Currently Thessaloniki is host to a large number of immigrants and, like many other Mediterranean cities, it is transforming itself into a multicultural metropolis. Immigrants in the city account for $7.2 \%$ of the total number of immigrants in Greece, the main groups being Albanians (75\%), Georgians (9\%) and Bulgarians (5\%) (Hatziprokopiou 2004). Thessaloniki's migrant population is thus mainly composed of immigrants from the Balkans and the former USSR; Athens is far more 
mixed and diverse. The new immigrants are gradually contributing to the city's urban transformation, through their use of social space, their residential settlement, and the characteristics of the labour markets they have access to. Their integration and participation in the different domains of social and economic life is significantly affected by their regularization, whereas their settlement appears to follow the social geography of the city, which may well counter segregation trends fuelled by exclusion by the locals. In turn, immigrants' cultural proximity with the natives impacts their visibility and adaptability in the city (Labrianidis and Hatziprokopiou 2010). However, spatial proximity does not lead to social proximity, as inclusion and exclusion operate differently in different domains and levels. Various factors, such as national origin of the migrant population, the time spent in the receiving country, agency, place and the proximity offered by the common Balkan context appear to be interdependent elements that shape every migrant's incorporation experience (Hatziprokopiou 2006a, pp. 269-270).

Nevertheless, at a city level, the impact of the new waves of immigrants has uncovered old debates on the city's complex cultural identity. So far, the new discourse on multiculturalism lacks substance (Mazower 2004). Perhaps not surprisingly, due to its historical past, the city has been the epicentre of harsh debates over the issue of the name of Macedonia, objections against the use of the Rotonda, a Roman monument, as a cultural centre, the downplaying of its Ottoman past in favour of its Byzantine tradition when chosen as a European capital of culture, objections towards the non-inscription of religious beliefs on the Greek identification cards, and brutal abuse of the rights of immigrants, both first and second generation (Hatziprokopiou 2006b). These issues reveal the city's continuing difficulty in coming to terms with the diversity within.

\subsubsection{Italy}

Italy has a special profile in relation to the history of immigration in Europe, due to its long tradition of emigration and switch to being a country of immigration starting from early 1970s. The reversal from mass emigration to mass immigration matches that of Greece, but in the Italian case the 'migration turnaround' started two decades earlier (King et al. 1997). The Italian turnaround was a consequence of three main trends: the slow decline in emigration after its peak in the 1960s, the subsequent growth of return migration, and then the rapid increase in the number of immigrants, starting in the 1970s and escalating from the 1980s onwards (King and Andall 1999).

There are several differences between contemporary immigration in Italy, the earlier migrations in Northern Europe and the later immigration to Greece. First, the number of immigrant groups is significantly larger in Italy, while their relative size is far smaller. This has implications for integration policies. Second, there are fewer families entering Italy, but a larger number of single migrant women, and migration from Eastern Europe and South Asia is more significant than that in Northern Europe (except South Asians in Britain). Third, the colonial experience 
is insignificant in Italy; rather, immigration is taking place in a more transnational world than when previous waves of immigration to Northern Europe and the USA took place (Grillo 2002).

The employment and integration of immigrants in Italy is differentiated according to gender, nationality and regional location. Indeed, the impact that the different labour market opportunities across the regions have on the recruitment and distribution of migrant labour is one of the distinctive features of Italy as an immigration country. This impact is more concretely seen in the migrants' working practices, in their possibilities for social integration and in their internal mobility within Italy (King and Andall 1999, p. 147). Strong identities of Italian cities are thought to underpin the fragmentation and regionalism within Italy, which persists in its contemporary history. Although since 1948 the development of a more cohesive national identity is noticeable, regional 'roots' are still very visible, 'vocalized' by regional dialects that act to counter the development of strong national identity since they keep alive the local or regional culture (Moss 2000).

As with Greece, the political response to the reality of immigration has been delayed and fragmented. Immigration policy has been organized around three overlapping but broadly consecutive stages: the control agenda, the social agenda and the difference agenda (Grillo 2002, p. 16). Scholarly work initially focused on 'push' factors in the sending countries, overlooking the changing nature of Italian society (Calavita 2005; King and Andall 1999, p. 144). Migration started to be treated as a policy issue only in the mid-1980s (Bonifazi 2000; Boswell 2003), characterized by a politically opportunistic stance and a short-term approach (Foot 1995; Triandafyllidou 2000). This is partly explained by the involvement of the Catholic voluntary sector in organizing the response to immigration, which in turn had an impact on the character of immigration policies, putting the focus on assistance-oriented measures (King and Andall 1999). Even so, the first initiative and framework for immigrant integration policies was established only in 1998 under the Turco-Napolitano Law (Gabrielli et al. 2009).

According to Zincone (2006, p. 347), Italian immigration policies are characterized by three main strands. There has been some continuity in the stance taken towards immigration despite the frequent changes in governmental coalitions. Second, the authorities have mostly focused on the conceptual part of policymaking rather than the actual policies. Thirdly, despite strong public opposition towards immigration, which grew especially during the 1990s, Italy is known for its frequent mass regularizations of illegal immigrants (Boswell 2003, p. 123). It should be mentioned, however, that immigration legislation has continuously tended towards restrictive measures. These changes partly reflect internal political pressures, but also the impact of the EU legislation and the positioning of Italy in a series of international migration systems that cross East and West, South and North. Italy is one of the founding members of the EU, and the country's geographical position makes it a gateway for the entry of immigrants into the EU (Favell 2002; Triandafyllidou 2000).

Similar to other nation-states that have become immigrant-receiving countries, the arrival of immigrants in Italy has triggered important discussions on national 
identity. The particular response that each country formulates towards immigration varies according to the transnational migration experiences of each society, the philosophies of integration developed in recent decades and the national political cultures (Grillo 2002, p. 4).

Albanians arrived in Italy in the early 1990s when Italian society itself was undergoing a major transformation in order to subscribe to new discourses of European identity (King and Mai 2008, p. 19). Albanians are nowadays one of the largest immigrant groups in the country, exceeded only by Romanians. They have challenged the established notion that skin colour is the signifier of immigrant status. These 'new others' are characterized by their large relative size as an immigrant group and by their cultural, economic and moral 'difference' from Italians (King and Mai 2008, 2009). The settlement of Albanians in Italy now shows signs of rapid stabilization and integration. This is firstly seen in the increasing number of women, who in 2001 consisted of $40 \%$, compared to less than a quarter in the early 1990s. More importantly, the number of Albanian-origin pupils in Italian schools increased tenfold from the 1990s through to the 2000s, and Albanian-origin children are the largest foreign-origin group in Italian schools (King and Mai 2009, citing Caritas Migrantes 2009).

\subsubsection{Florence}

Florence is one of the most celebrated Italian cities and a major centre of international culture. Its history and overall identity are related to its medieval and Renaissance treasures, which make Florence one of Italy's prime artistic and commercial centres, but also a very popular touristic attraction. Perhaps as a result, conceptualizing Florence and its ideology as a city and as a living context over thousands of years is not easy. Yet, Florence has played an important role in the political, cultural and economic life of Italy (White 2000).

Florence was at the centre of the nation-building process. It became the capital of Italy in 1865,4 years after its unification. The city also pioneered Italy's early economic development. Moreover, Florence's ancient city centre, with an urban tradition that dates from the age of Dante, has marked the historiography of the Italian city in a wider sense (White 2000, p. 40). Florence is also associated with Italian unification and the establishment of the Italian national identity. Due to historical fragmentation within Italy, even upon unification in 1861 there was no language known as Italian, apart from a fourteenth-century Florentine language that was used by the great Tuscan writers of that century and known by a small elite at the time. It was the prestige of Florence and writers such as Dante, Petrarch and Boccaccio that influenced the choice of the Florentine dialect as the official language of Italy. It remains today the national language and continues to serve as a strong basis on which a sense of belonging to the nation is built (Moss 2000).

Florence's strong local identity, however, also exhibits signs of closure and exclusivity towards newcomers. White (2000) goes back to the writings of Dante and points to a dualism in the vision that Florentines held of their city. The myth of an 
earlier Florence was contrasted with the commercial dynamic of the urban culture, while at the heart of the dualism were the nuova gente-people migrating from the surrounding areas and further afield, attracted by the possibilities offered by its dynamic economy. A parallel can be drawn here between the past and the tense encounters since the 1990 s between newly settling immigrants from abroad and traditional city dwellers. Nowadays Florence is a touristic centre and cultural repository, which brings substantial revenue to the city's economy. The city's diversity is growing, and $10.3 \%$ of its population of over 364,000 people at the end of 2007 were foreigners. In 2008, foreign residents in Tuscany numbered 309,651; nearly a third of whom resided in the province of Florence, the largest of Tuscany's ten provinces. Four immigrant communities are numerically dominant in the Tuscan region: Romanians $(64,280,20.8 \%)$, Albanians (61, 940, 20.0\%), Chinese (26,050, $8.4 \%)$ and Moroccans $(24,150,7.8 \%)$. The Chinese are particularly numerous in Prato, a city-province adjacent to Florence. The Romanians, on the other hand, are mainly recent arrivals, so that for the second generation and school-age cohorts, it is the Albanians who are by far the most numerous foreign-origin group in Florence and Tuscany (and in fact in Italy as a whole; for details see Caritas/Migrantes 2009).

The discourse on immigration continues to refer to the image of a 'divided city' over the settlement of new ethnic communities, suspected as unable to 'fit in' ${ }^{7}$ As White (2000, p. 70) furthermore puts it:

The forms of reaction on the part of pre-existing Italian communities to the sheer cultural otherness detected in a gente nuova while in part a continuum from Dante's time to our own have significant inflexions in the present. In other words civic insularity both endures and takes new forms, which is not the least reason for its being so hard to root out.

\subsection{Research Design and Methods}

The research for this book took a qualitative and comparative approach. Other scholars working in the field of immigration and integration note that qualitative research is most suitable for capturing the transnational and identity experiences of the second generation (Jones-Correra 2002). Another point in favour of qualitative methods is the fact that, compared to other second-generation groups in Europe, the Albanian second generation is a significantly smaller community (except in Greece), whose profile and dynamics can best be captured through relatively smallscale and intensive studies.

From a philosophical point of view, a 'loose' social constructionist perspectivethe idea that we construct both our realities and the way we interpret them-shaped the approach and understanding of the narratives of respondents in this research (Burr 2003). Social constructionism is not radically relativist; it differs significantly

\footnotetext{
${ }^{7}$ Although conflict and unrest over immigration has been recorded in other Italian cities, see, e.g., Foot $(1995,2001)$ on Milan and Turin.
} 
from postmodernism in its acknowledgment that certain universal aspects of human life exist, and is based on the assumption that there is a variety of representations of the social world and human psychology, as there are some essential attributes of people and processes. Critical realism is another epistemological approach, which stands at the opposite pole from postmodernism (Harré 2002). In vogue in the 1980s, more recently migration scholars have returned to critical realist epistemologies in order to develop more sound migration theories (Bakewell 2010; Iosifides 2011). Overall, critical realism places a strong emphasis on the importance of processes, based on continuous conceptualization and reconceptualization (Pratt 1995). This approach resonates closely with research conducted for this book, based on multiple processes - migration, identity formation, integration, transnationalism, intergenerational transmission - and, therefore, intersected with social constructionism to shape the overall research process and data analysis and interpretation. Another reason for the adoption of a critical realist approach for this book is because, as Iosifides (2011) contends, realist qualitative methods have the potential to develop 'explanatory critiques'. These critiques enable specific ideological constructions to be linked on the basis of their relationship to structures of exploitation and power asymmetry. As such, they can contribute to social change by explaining how unequal relations are produced and reproduced.

Due to the complexity of the research aims and questions research for this book took a multi-sited comparative approach. The multi-sited approach responds to the long-standing question of the value and the positioning of the 'local' in single-sited ethnography (Falzon 2009). This, coupled with the post-1990s focus on transnational phenomena, required a move to multiple sites of observation and participation that bridge dichotomies such as the 'local' and the 'global', 'lifeworlds' and the 'system' (Marcus 1995, p. 95). The case for comparative multi-sited research is also supported by recent writings on the second generation and transnational childhood, which highlight the need for closer attention both to the differences between national contexts and to the role of local settings (Morawska 2003; Thomson and Crul 2007; Zeitlyn and Mand 2012).

Accordingly, the current research is based on what is known as a divergent comparative approach (Green 1997), in that it examines Albanian migrants and their descendants at three different research sites, following the migrants as they 'diverged' out from a common point of origin: Albania. Context was analysed as a composite of the national and city levels. According to Hantrais (1999), cross-national studies should contextualize the social phenomenon under examination by referring to national institutional settings. However, a newer approach in comparative studies has emphasized the need to focus on internal differences within nation-states. The city as context has been particularly highlighted in migration research, with a focus on differences between cities in terms of structure, ethnic composition, historical patterns of minorities' settlement, and the size and characteristics of the immigrant groups concerned (Favell 2001; Foner 1998). Glick Schiller and Çağlar (2009) propose an approach that moves away from a focus on so-called global cities and the typical criteria related to them, such as density of population and economic power. They suggest instead an approach that considers all cities as global and which fo- 
cuses on city scale, whereby attention is given to a city's positioning in a field of power against regions, states, multi-state entities (such as the EU) and the 'world system'.

These considerations are reflected in the design of this study. Firstly, the three city-sites differ significantly. The main differences are related to regimes of diversity, history of immigration and time of arrival, and relative size of Albanians as an immigrant group at each of the sites. The UK stands out as a country with a long history of immigration, where Albanians consist of one of the 'new' migrant groups arriving in the 1990s. Although they are potentially a sizeable group among the new immigrants, the size of the Albanian population is rather insignificant when compared to the old minority groups of Asian and African origin. This contrasts with the situation in Greece and Italy, where Albanians arrived in large numbers in the early 1990s, when the two countries were experiencing a structural shift from being countries of emigration to ones of immigration. Due to the differences in each of these two southern countries' ideologies of nationalism, however, the position of Albanians as an immigrant group differs, with implications for attitudes and policies on immigration and integration - and, above all, on the experiences of the migrants.

The three cities also differ significantly in size and in their urban cultures and politics. While London is a 'global' city, Florence and Thessaloniki are smaller urban centres. 'Super-diverse' London has pioneered British multiculturalism-although not completely successfully, given that many immigrant-origin communities remain concentrated in deprived areas and suffer from various forms of social exclusion. Meanwhile, within a country still broadly hostile to immigrants, Florence has been the first city to adopt pro-immigrant measures, and the region of Tuscany is the main centre of the development of interculturalism in Italy. In contrast, Thessaloniki has witnessed some of the harshest racist events towards immigrants and diversity in Greece. These differences have affected the course of settlement and perceptions of integration of Albanian migrants and their children, as we will see in later chapters.

There are, however, significant differences between the Albanian communities in the three countries. In Greece, most Albanian migrants are low-skilled and from working class and generally rural backgrounds (Hatziprokopiou 2006a). Albanian migrants in Italy come proportionally more from middle-class backgrounds and from the more urban and relatively prosperous parts of the country (King and Mai 2008). This has implications for the selection of first- and second-generation participants, since parents' social class and educational level are widely associated with the second-generation's educational performance and integration prospects (see, e.g., Van Niekerk 2007). Finally, the Albanian community in the UK is much smaller than those in the other two receiving countries, it arrived more recently and most of its member come from the mountainous and poor northern region of Albania (King et al. 2003).

Data collection took place over a 1-year period starting in December 2007. Fieldwork was designed to include three stages, each taking place over a 3-month period (with an intermission of 3 months between June and September 2008). Ethnographic research was accompanied by in-depth interviews and focus groups. The 
three sets of participants were children of Albanian migrants within the age range of 12-19; first-generation Albanian migrants (parents of adolescents or of children approaching adolescence); and teachers or principals in the mainstream schools attended by Albanian-origin pupils. In addition, 12 key informants were interviewed across the three sites: five in London, three in Thessaloniki and four in Florence. These were Albanian community activists and others with knowledge of the Albanian community. The total number of interviews amounts to $167 .{ }^{8}$

The average age of teenagers interviewed was 15.5 years; the average time spent in the receiving country was 10 years, so most of them could be classified as the ' 1.5 generation' (Rumbaut 2002). Parents' average age was 42 years, and they had been in the migration countries for an average of 12 years. Pseudonyms were used for all parents and children. In the case of the children, attempts were made to keep their pseudonym similar to the 'category of name' they held in reality-for example, in a case of a child in Greece being baptized and holding a Greek name or a secondgeneration teenager born in Albania but given an Italian name. ${ }^{9}$

The decision to include adolescents as participants was based on three main lines of reasoning. Firstly, because the Albanian migration took place since the 1990s, the Albanian second generation is concentrated in young age brackets. Secondly, ethnic identification processes start to develop and are found to be particularly dynamic during adolescence (Phinney 1992). Finally, articulating issues of identity and discrimination would be demanding for children of a younger age, which would consequently bear higher risks and ethical implications.

It is worth mentioning that research for this book involved ethical and positionality issues. The project involved participants from different groups, in terms of age, nationality and social status, and took place at three research sites located in three different countries. More importantly, the topics covered, such as identity perception, discrimination and parent-child relations, and the methods used, which required substantial time and contact with the participants, could make research seem 'invasive' and make access even more difficult than, for example, a study of migrants' structural integration. Furthermore, several scholars and professional bodies note that the researcher should expect special issues to arise when working with minors (American Sociological Association 1997; Barnardo's Statement of Ethical Research Practice; Lindsay 2000).

One of the main issues that emerged as crucial in terms of guarding the participants' interests and well-being was ensuring double consent in the case of minors: the consent of parents or teachers to the children's participation, and the consent of the children themselves. The literature leaves latitude for this requirement to be waived where it is clear that participation in the research involves minimal risk or risks no greater than those in everyday life, where parental permission is impossible or would not protect the child or young person, and where the emotional and social maturity and particular vulnerabilities of the young people have been evaluated and

\footnotetext{
8 The sample in London comprised 11 Kosovan-origin teenagers and 12 Kosovan mothers.

${ }^{9}$ This is in acknowledgement of the important role that names are found to have in the way identities of immigrants in general are perceived (see, e.g., Silberman et al. 2007).
} 
the risks of participation are considered to be low (ASA 1997). It is not straightforward to obtain consent for children and young people to participate in research. For example, as parents and teachers are entitled to be legal representatives of minors, they may impose their attitude, leading to possible coercion.

Following Christensen (2004, p. 165), children in this research were considered as 'fellow human beings'; therefore, they were treated equally in terms of informed consent but also in terms of their opinion during and after the interview process. Indeed, some of the most interesting spin-off findings on children's integration derived from 'final word' questions included in the interview schedule for the children. These questions invited the latter to express their opinion on the interview itself and to offer their 'expertise' on the issues that their co-ethnics face in the respective location. Some of the 'casual' final suggestions made by the teenagers that I found revealing and helpful for future work were that it would be good to ask those who had finished school whether they are working or are in the street (Albi, London), to see how an Albanian-origin teenager can be successful and famous in school despite her or his origin (Maria, Thessaloniki) and to take into account that integration can also depend on the person and not only the place (Klotilda, Prato).

Ethical issues were not limited to experiences in the field. Since there is a gap between research and the desired positive impact on policymaking, documenting migrants' experiences, presenting them formally and making these accessible to a broader public raises concerns about the use that could be made of the study. This reflects one of the major ethical dilemmas posed by Crow (2000, p. 69) and a question that every researcher should ask: the purpose of researching a particular topic. A mismatch between groups' portrayal in research findings and their own expectations of the research could lead to rejection and resentment from the communities studied, as has been experienced by other researchers (e.g. ScheperHughes 2000). Cognizance of this risk shaped my overall approach to data analysis and dissemination.

Nevertheless, the way I was perceived in the field and the attitude of the people I worked with towards me were significantly affected by my sharing the same nationality as those researched, by my being single and a professional woman, and especially by the combination of these traits. Firstly, my dual position as a coethnic 'insider', but also an 'outsider' in terms of education and socio-economic status, shaped interactions in the field. Like Kraidy (1999, p. 461), my positionality was affected by two main world views: the 'native' culture and the world view of the ethnographic, academic, systematic and, therefore, instrumental knowledge. My entry to the field, however, was more complicated, as I was entering Albanian 'communities' in other countries and I already had 'imaginative' relationships with each of these countries. In the end, through my work with the various communities in Europe, I was also perceived and could have acted as a 'diasporic agent'. This was also seen to be in the participants' interest in the other communities in Europe where research had taken place - and it will be more 'materialized' in this book, which will, in turn, contribute to the establishment of virtual links to these same communities. 


\subsection{Book Outline}

This book is organized in six chapters. After the key theoretical assumptions and concepts, context and methods are introduced in Chap. 1, the focus shifts to the presentation and discussion of the findings. Chapters 2 through 5 present findings around the major concepts involved in this research: ethnic identity, integration and transnational ties, followed by a chapter on intergenerational transmission. Chapters 2 through 4 are organized in two main sections, starting with an analysis of the relevant data on the first-generation Albanian immigrants as parents of teenagers and then continuing with data on the second-generation teenagers. Chapter 5 analyses the intergenerational transmission of identity, integration and transnational ties by focusing on the main emerging themes, respectively. The final chapter encompasses the three main concepts and the intergenerational transmission, and discusses the findings of each empirical chapter, focusing also on the interrelations between these concepts as they played out in the data. Throughout these five chapters the comparative context of the three countries and cities is highlighted where relevant. Summaries of the chapters are presented below.

Chapter 2 is the first in a sequence of four 'results' chapters. The main focus here is on the role that ethnicity plays in the identity formation processes of both the first and the second generation. As all of the following chapters in this book, it starts with a theoretical discussion of the main concepts - in this case identity and ethnicity. This theoretical discussion is followed by a section on the identities of the first generation and a subsequent section on the identities of the second-generation teenagers. The chapter integrates the findings of this project with literature on identity and ethnicity in different life stages, and on ethnic identity of immigrants and their descendants. The findings show that there are important differences between the first and second generation in how they experience identity. While the first generation experiences its identity mainly in relation to roles and status, the second generation's identity is mostly focused on age-related emotions and activities, although in-group differences are significant. In terms of ethnic identification, however, one of the main results of this research is that the ethnicity of origin, as least in primordial terms, is not a main reference point in the identification processes of the Albanian migrants and their children. Locality impacts the identification of migrants and their descendants. As mentioned above, city identity and urban culture is important for the identification of these groups, especially in the case of the teenagers. This identificational trend is particularly evident in Florence where teenagers make strong references to the local culture and its universal value.

Chapter 3, on patterns and dynamics of integration, employs various concepts commonly considered under the umbrella concept of integration. These are referred to here to capture variation in the composition and history of immigration of Albanian immigrants in each country studied. The chapter investigates structural and socio-cultural integration and thus draws from the literature related to each of these types of integration as well as on studies that encompass the two; for example, experiences of the second generation with the educational system. Although the spatial 
and demographic context plays a significant role in shaping differences in terms of integration across the three sites, the socio-economic background and capital of the first generation appears to affect the integration of both migrants and their children. More importantly, the way the two generations conceive their integration is significantly different: parents and children strive to integrate into different sectors of the receiving society. In very broad terms, social and cultural integration is much more appreciated by the second generation, while the first generation puts most of its efforts into structural integration. The second generation also has a different appreciation of the opportunity structures than the mono-dimensional appreciation by the parents, who aim with their migration project at economic prosperity and education for the children.

Chapter 4, on the patterns of transnational ties between generations, is broadly based on the finding that transnational ties can vary among different generations and across different research sites. This chapter investigates this variation, describing and analysing the establishment, maintenance and disruption of transnational ties and factors that influence such instances for each of the generations. The findings are analysed in relation to other research in the field. Transnational ties show different patterns between and within the two generations. In the case of the first generation, integration is usually prioritized over transnational ties, especially in terms of distribution of family resources and the orientation towards future life goals. The concepts of 'transnational ways of being' and 'transnational ways of belonging' (Glick Schiller 2004) find support in the data, although both were found to change over time. Transnational ways of being are common among both the first and the second generation. Transnational ways of belonging are more emphasized among the first generation, although this belonging is mostly to their past in Albania and to their families, rather than a symbolic belongingness expressed in the name of an ethnic group towards a homeland. In turn, the geographical approach, emphasizing space and place, and associated mobility tendencies and orientation, is more of a second-generation phenomenon. The teenagers are also significantly more prone towards mobility and cosmopolitan imaginaries and practices compared to the first generation.

Chapter 5's focus is on the patterns and mechanisms of transmission between generations. The intergenerational transmission of ethnic identity, integration and transnational ties is analysed by examining the relevant processes rather than endstate 'outcomes'. For example, the intergenerational transmission of transnational ties goes beyond what is already discussed in the literature - that is, whether transnational ties are only a first-generation phenomenon or persist in the second generation. Far from a 'quantifiable' process, intergenerational transmission appears here as complex and fragmented. Its features appear to be changing over time, involving redefinitions by both parents and children of concepts, values, practices and their importance. Intergenerational transmission appears as a two-way process, largely conditioned by parents' capital and experiences of discrimination of both the first and the second generation. Means and strategies of transmission are focused on counteracting stigmatization and are characterized by a lack of focus on ethnic identity and culture of origin, in favour of endowing the second generation with universal values and life-long lessons. 
Chapter 6 rounds off the analysis with a review of and answers to the research questions summarized in Chap. 1. It also considers implications and avenues for future research in the field. The final main research question of this book deals with the relationship between ethnic identity, integration and transnational ties and the factors that affect this relationship drawing on findings presented in Chaps. 2 through 5. The book ultimately explains identification, integration and the development of transnational ties by referring to agency, power and capital, seen here as contingent on time and space. While the insistence of the parents on their children's education appears in this study to be an important factor, as in many other studies of the integration of the second generation (e.g., Modood 2004; Zhou 1997b), the main finding of this study is that capital appears in various forms and levels and impacts on integration while different forms of capital are differently important for the first and the second generation. Financial and human capital emerge as important for the first generation, which is able to ascertain through experience that expertise and skills in the workplace will give them more security and increase their agency. As mentioned in Chap. 3, social capital based on individual characteristics that affect socialization, and are derived from peer group networks - an aspect completely ignored in the second-generation literature - is very important for the immigrantorigin adolescents to feel integrated. Mobility appears to be both a form and an outcome of capital and, therefore, an important factor in this cross-generational analysis, pointing towards differences in terms of integration outlooks, aspirations and perceptions of the first and the second generation.

The book ends with a call for a reassessment of the term 'second generation', drawing attention to the essentialist focus on the children of migrants as a particular and homogeneous group - a status that is forged in the academic and policymaking settings. The findings ultimately show that the particularities of identification, integration and transnational ties of the children of migrants are affected by structural factors and are not inherently idiosyncratic to this group.

Open Access This chapter is distributed under the terms of the Creative Commons Attribution Noncommercial License, which permits any noncommercial use, distribution, and reproduction in any medium, provided the original author(s) and source are credited. 


\section{Chapter 2 \\ Identities of the First and Second Generation: The Role of Ethnicity}

Having set the scene and introduced the main research questions in Chap. 1, the focus now moves on to identity, which is one of the main topics analysed in this book. Following the established literature, this chapter privileges analysis of the role of ethnicity in identity construction, but concludes that, for Albanians abroad, ethnicity in the primordial sense is not intrinsic to their identification processes. This chapter, and the three that follow, starts with a theoretical and conceptual section. In this case major developments are examined in the field of identity and ethnicity, pointing to the privileged status that ethnic identity has had in the study of migrants' and their descendants' identities. A historical introduction to Albanian identity identifies key moments that have defined the country's socio-cultural and political life. These have had repercussions for the starting point, the course and the 'outcome' of migration and identification of Albanian migrants and their children.

The empirical sections that follow are based on a thematic and comparative analysis across the three sites (London, Thessaloniki and Florence) and the three main groups: the first-generation migrants (parents), the second-generation teenagers, and teachers and key informants. The chapter examines the identities of the first generation, then analyses migrant and parental identity, and perceptions and understandings of gender and religious identity, concluding with the role of ethnicity in identity processes.

The third part of the chapter focuses on the identities of the children of migrants. The most prominent dimensions emerging from the data are teenager identity and perceptions of gender - and their role in identity processes - and religious identity. Once again, the role of primordial ethnic identity was downplayed. The chapter ends by drawing some conclusions on identity and the role of ethnicity.

\subsection{Identity and Ethnicity}

The literature on identity is characterized by various strands that are based on different epistemological and disciplinary approaches working at different levels. Indeed, one could not agree more with Gilroy (1996, pp. 224-225) who stylishly points 
to 'the passage into vogue' of identity and the 'academic mess' that surrounds the concept. One of the most confusing and analytically problematic approaches has been the 'soft' constructivist version, which posits that identity is multiple, fluid and always changing, which raises questions about its operationability and usefulness as a research construct. Brubaker and Cooper (2000) in their explicit 'attack' acknowledge the importance of the developmental approach in establishing the term and at the same time 'blame' Erikson (1968) for the start of a saga of confusing terms and models that made identity an ambiguous analytical concept. They instead propose the use of three clusters of terms: identification and categorization; self-understanding and social location; and commonality, connectedness and groupness. This reorganization of the identity literature highlights the growing emphasis on the processes and agents that do the identifying, the cognitive awareness and the multiple forms and degrees of commonality and connectedness discussed under various types of collective identities. Relating identity to a shared culture and perceived common origin has been the way ethnic identity has been differentiated from other social identities (Barth 1969; Jenkins 1997; Levine 1999; Vermeulen and Govers 1994).

Wimmer (2008) notes that academic discourse on the conceptualization of ethnicity has evolved around two dichotomous terms: 'primordialism', based on the assumption that ethnic membership is acquired through birth and thus represents a 'given' characteristic of the social world; and 'instrumentalism', which posits that individuals choose between various identities according to self-interest. Nowadays, this dichotomy has been blurred and the two terms are no longer seen as mutually exclusive. Viewing the dichotomy through a cognitive lens, Brubaker et al. (2004) argue that the real difference between the primordial and the situational stance is that the former emphasizes the tendency of participants to naturalize real or imputed human differences in the ways groups are conceived, while the situational approach can explain how ethnicity takes relevance in particular contexts and everyday interactions.

The development of ethnicity from the primordial stance to the cognitive approach has been long and fragmented. It is important to note here the definition of ethnic groups by Max Weber (Roth and Wittich 1976, p. 389):

\footnotetext{
[W]e shall call 'ethnic groups' those human beings that entertain a subjective belief in their common descent because of similarities of physical type or of customs or both, or because of memories of colonization and migration; thus belief must be important for the propagation of group formation; conversely it doesn't matter whether or not an objective blood relationship exists (italics added).
}

A crucial moment was the introduction into this debate of the concept of boundaries by Barth (1969), who considered ethnicity a product of a social process, attributing thus a more active role to individuals' and groups' engagement in redefining their ethnicity, by seeing ethnic identity as defined by the combination of the view one has for oneself and the views of others about one's ethnic identity. Others have followed a similar line. For instance, Alba (2005, p. 22) maintains that ethnicity 'is a distinction that individuals make in their everyday lives that shapes their actions and mental orientations towards others; and it is typically embedded in a variety of social and cultural differences between groups that give an ethnic boundary concrete 
significance'. Jenkins (1997, p. 165) delineates the post-Barthian anthropological model of ethnicity based on four propositions:

- ethnicity is about cultural differentiation (bearing in mind that identity is always a dialectic between similarity and difference);

- ethnicity is concerned with culture, or shared meaning, but it is also rooted in and is the outcome of social interaction;

- ethnicity is no more fixed than the culture of which it is a component or the situations in which it is produced and reproduced;

- ethnicity is both collective and individual, externalized in social interaction and internalized in personal self-identification.

Jenkins (2004) furthermore points to the contrast between individual and collective (ethnic) identities by maintaining that the individual identity emphasizes difference whereas the latter, similarity. By considering identity 'a practical accomplishment, a process', Jenkins $(2004$, p. 23 ) maintains that both individual and collective identities use a unified model of the dialectical interplay of processes of internal and external definition, with time and space being central to both these processes.

As signalled above, ethnicity is built on two major constructs: identity and culture (Nagel 1994). Ethnic identification, however, is not a 'flat' and uniform process across contexts and groups. Jenkins (1997) maintains that culture is taken for granted until the moment when identity is problematized along the interaction across the boundaries. Barth (1969, p. 14) recognized that the features that are proclaimed as distinct are not always objectively selected, but consist of those that the main actors regard as significant. The salience of ethnic categories can vary in different sociocultural systems; they may be 'inactive' or may pervade social life - in general or selectively in limited sectors of activity.

This view is furthermore elaborated by authors who relate ethnic identity and its performance to structure. While acknowledging these theoretical assumptions and the role of agency in identification processes, Nagel (1994, p. 155) maintains that 'the chosen ethnic identity is determined by the individual's perception of its meaning to different audiences, its salience in different social contexts, and its utility in different settings'. She further notes that ethnicity is both the product of actions undertaken by ethnic groups as they shape and reshape their self-definition and culture, and the 'outcome' of external social, economic and political processes and actors that shape and reshape ethnic categories and definitions. This view partly reflects the 'situational' stance on ethnic identity, which holds that ethnic identity is unstable over time and lifespan, with different settings 'activating' different aspects of one's possible group identities.

But what are the factors and actors that influence identity formation, and how do they combine in affecting the way that individuals and groups identify? Until recently, academic work on racial and ethnic identities has emphasized Barth's relational perspective and has considered these identities as the result of a process of self-definition, as well as of the construction of symbolic boundaries and assignment of collective identities by others (Lamont and Molnar 2002). However, most of the post-Barthian literature has overlooked the importance of external definition 
and social categorization and has mostly analysed ethnicity based on internal definition and group identification. Neither Barth nor the members of the Manchester School who developed the situational approach have paid sufficient attention to the external constraints that condition ethnic identification. The main working concepts extensively used in the study of ethnic identity, such as boundaries and choices, have proved to be useful to analyse the already established ethnic categories, but they do not explain how some ethnic categories are developed and engaged in social action (Levine 1999). This has been ordinarily associated with a conceptualization of social relationships as egalitarian and conflict-free, based on equitable negotiations (Jenkins 1997).

External categorization is, however, seen as framing and conditioning the internal malleable construction of identity at an individual level, and as a means used by political entrepreneurs to affect collective identification and modify collective action (Glick Schiller 2012b). Barth (1994) proposed a multiple-level approach, which entails a combination of the interpersonal interactions at the micro level, the processes that create collectivities at a meso level, and the role of state at the macro level.

Increasingly processes of identification are associated with issues of power. Barth (1994, p. 16), in his review of academic work on ethnic boundaries, maintains that the process of the construction of a boundary is a joint work shared between members of both contrasting groups, "though they are probably differently empowered in their ability to impose and transform the relevant idioms'. This empowerment is related to the salience of ethnicity in local settings as a result of differentiation, which results in ethnicity becoming an integral part of an individual's point of view of selfhood starting in early primary socialization. External categorization, however, features as an important factor in shaping ethnicity and the element through which power differentiations are expressed and materialized (Sökefeld 2001).

This view is taken up by Wimmer and Glick Schiller (2002), who furthermore emphasize that the anthropology of ethnic groups within modernizing or industrial nation-states tended to describe these as culturally different from the 'majority' population because of their varying historical origin, including their history of migration, rather than to see these differences as a consequence of the politicization of ethnicity in the context of nation-state building itself. The "politicization of ethnicity' was a central part of the nation-state project to define all those populations thought not to represent the 'national culture' as racially and culturally different, which contributed to efforts to build unity and identity (Glick Schiller 2012b). ${ }^{1}$ A newer conceptualization of ethnicity that followed maintains that ethnic boundaries are the outcome of the classificatory struggles and negotiations between actors situated in a social field and the behaviour and strategies of these actors are determined by three characteristics of a field: the institutional order, distribution of power and political networks (Wimmer 2008, p. 970).

However, Levine (1999, p. 168) maintains that too much emphasis has been put on forces of personal development and calls for more attention to be dedicated to the interaction between the mind, society and culture as main factors influencing

${ }^{1}$ As we saw in Chap. 1, this was certainly the case in Italy and Greece. 
the engagement of ethnic categories. Levine's view is part of the cognitive strand in studies of ethnicity, which criticizes the tendency towards 'groupism' in conceptualizing ethnic groups, taking them as the ubiquitous and elementary constituents of social life. Rather, this movement concentrates on 'group-making' through activities of classification, categorization and identification and considers groups as collective cultural representations (Brubaker and Cooper 2000, p. 45).

The cognitive approach, with its emphasis on cultural representations and the involvement of the mind in the elaboration of ethnic categories, gained even more credit with the introduction of an interactional model of identity formation by Todd (2005, p. 433). She gave full recognition to power relations and resource distribution as two important variables in explaining identity change. However, she notes:

\footnotetext{
If we posit a slowly changing 'cultural sub-stratum' that may underlie more radical category change, we need a different model of how identity-categories function. We need to recognize not just the complex and varying meanings of these categories and their lack of fixed or foundational status, but also their social 'embeddedness' and their personal 'anchorage', which allow change or stasis to occur out of phase with other variables, and to affect them in turn (ibid.).
}

The new model associated the process of identity formation and change with intentionality expressed in the incorporation of new elements of meaning and value while rearranging the old, or a combination of social practices in a new way, which leads to the production of different meanings. Todd (2005) maintains that the social constraints and the cognitive schemas rooted in early infancy are thought to condition this process, while calling for identity and culture to return into the models attempting to explain socio-cultural transformation.

On the other hand, wider social and cultural institutions and principles of social differentiation are thought to be strongly related to ethnic identity. Firstly, ethnicity is considered one of many sources of identification, overlapping with some important others, among which social class and gender feature strongly (Banton 2008). Anthias and Yuval-Davis (1992) call not only for a distinction to be drawn between notions of ethnic identity and ethnicity, since the latter refers to a practical term expressing mobilization on the basis of ethnic ideas, but also for consideration of ethnicity's intersections with class and gender, as other prime social divisions. Furthermore, this overlapping is seen to have implications for the process of external categorization. Broader principles of social differentiation impact on the ability of certain actors to categorize others, especially on the basis of relations of power and authority (Jenkins 1997).

This is why the concept of boundaries is back to the fore in studies of identities in various disciplines, emphasizing the need to look at the intersections of multiple identities. Interestingly, the idea of boundaries related to socio-cultural differences within ethnic groups dates back to the 1960s, with Gordon (1964, p. 234) defining an ethnic group as 'a large subsociety, criss-crossed by social class, and containing its own primary groups of families, cliques and associations - its own network of organizations and institutions'. However, as Çă̆lar (1997) maintains, in migration studies, ethnic identities (national or religious) are treated as the most basic identities that people possess, to the exclusion of other forms of identification, with ethnicity treated as the naturalized marker of an immutable cultural differ- 
ence. Recent studies on ethnic and racial boundaries are increasingly focusing on the construction of collective identities and are attempting to elaborate models that link cognitive and cultural aspects with the social processes underlying ethno-racial boundary-making (Pachucki et al. 2007).

The context-dependency of the nature of ethnic and racial boundaries is further supported by Alba (2005). He maintains that the process of defining the boundaries between immigrants and natives depends both on features of the social and institutional spheres of the host societies and on the characteristics and histories of the immigrant groups themselves. More importantly, Alba (2005) proposes the concept of 'boundary' as useful in conducting cross-country comparative research in ethnic and racial studies - which of course this study does.

The concept of boundaries, however, falls short in explaining the meaning, the content and the purposes that ethnic meanings serve. Nagel (1994, p. 162) points out that ethnic boundaries help us to understand who we are, but do not explain what we are, or, as she puts it, what fills 'Barth's vessel' (see also Anthias and Yuval-Davis 1992, p. 4). Here the concept of culture, seen itself as fluid and negotiated, proves useful in animating and authenticating boundaries by assigning historical, ideological and symbolic systems of meaning. For this reason, both the concept of boundaries and that of identity are employed in the current research, which also pays attention to class and gender differences.

\subsection{Introduction to Albanian Identity}

The national and cultural trajectories of Albania are marked by a unique and fragmented course of development, both historically and contemporarily. The factors that shaped their features appear to be bound to Albania's geographical location and, although not exclusively, to politics operating at different levels (Morgan 2002). The process of national and cultural self-definition continues today, and the two elements - the national and the ethnic - continue to be intertwined in contemporary discourse. The cliché that represents Albania as a country between the West and the East (Winnifrith 1992) has now come under attack as the country leaves behind its immediate need for economic recovery and prepares for major political projects towards the West (Kadaré 2006).

Both its timing and the 'content' of Albanian nationalism differ significantly from those of other European and Balkan countries. Albania started its attempts at national statehood several decades later than its neighbours (Lubonja 2002). Language and folk culture were at the basis of this uprising, while the process as a whole was led by intellectuals, most of whom operated from abroad (Morgan 2002). Renaissance (Rilindja) is thought to be the most significant cultural and patriotic action in the history of Albania, as it responded to the historical momentum of differentiating Albanians from the Ottoman Empire, nurturing national self-consciousness. This process was unique in that internal national unification and the task of representing claims to the outside world were merged into one (Malcolm 2002, p. 71). Borrowing from the European romanticism of the nineteenth century, it was 
based on typical myths of pride in uniqueness as a people. Thus the movement embodied a shift towards ethnic identification. 'Albanianness' was based on the link to Albania in terms of 'blood', language and culture, but not on religion, especially when the latter was associated with the Ottoman Empire (Morgan 2002).

Albanian nationalism is based on several important myths: of historical and geographical origin, of ethnic homogeneity and cultural purity, of permanent national struggle, and of indifference to religion. These myths appear both as historically informed and as important elements of identity that have been the basis of historical and political claims (Malcolm 2002, p. 73). Similarly, Albanian culture is 'an original minor culture', marked by different cultural influences due to its geographical position (Morgan 2002). Lubonja (2003, p. 3) talks about roots and layers of Albanian culture. Firstly, he points to rites and traditions based on patriarchal clan cultures enshrined in kanun, ${ }^{2}$ on top of which is positioned a long influence of Byzantine and Ottoman culture followed by the Rilindja and its influence on the diminishing importance of religion. More recently, but importantly, is the culture created and imposed by 50 years of communism, influenced also by the culture of other communist allied countries, notably Russia and China. These communist cultures also drew selectively from cultural elements of the past, by, for example, excluding religion, but retaining certain institutions, such as the family.

The broad tolerance accompanying religious openness is in effect based on a general ambivalence and fragility that characterize Albanian identity (Kadaré 2005). This fragility and ambivalence is also reflected in the choice of the main institutions of Albanian culture and nationalism. The choice of Skanderbeg as a national hero represents a strategic move from religion to ethnicity and, with Skanderbeg being a Christian, a move closer to the Western world (Lubonja 2002). ${ }^{3}$ Indeed, unlike the rest of the Balkans, religion had a minor role in the Albanian uprising against the Ottomans, while ethnicity, 'blood' and native language were more important in determining group identity (Morgan 2002). On the other hand, this loose attitude towards religion has been considered historically to be one of the main obstacles to building a strong national identity (Misha 2008). Instead, family and kin constitute the main institutions of the Albanian culture (Dingo 2007). The kin group as 'the living microcosm of Albanian society' and besa $a^{4}$ constitute two important elements of Albanian identity, especially in reaction against social and political organizations imposed from outside (Lopasic 1992, p. 104).

While, from a nationalist perspective, the three religions-Islam, Catholic and Orthodox - were seen as dividers of Albanians, communism saw them as 'opium of the people' and part of the old conservative world (Lubonja 2002; Misha 2008). It should be mentioned that matters of ethnicity and identity, and related social and political allegiances, were proscribed in Albania as in many other socialist countries in Central and Eastern Europe (Morgan 2002). Communism, in effect, constituted a

\footnotetext{
${ }^{2}$ Albanian Customary Law collected by Lekë Dukagjini in the fifteenth century. For details on the controversial and difficult interpretation of kanun in contemporary Albanian life see SchwandersSievers (1999), Tarifa (2008) and Young (2000).

${ }^{3}$ Skanderbeg signifies unity and glory as he fought against the Ottoman invasion of Albania in the fifteenth century.

${ }^{4}$ Besa means keeping the given word under any kind of conditions and being loyal.
} 
paradox in terms of its impact on Albanian identity. Being represented as a saviour from the evils of the past and a starting point for construction of a new world and new people, it retained a great deal of the nationalist mythology, since this held an important place in the collective memory of Albanians (Lubonja 2002). However, when it came to the meaning of state and nation, communism had a strongly negative effect. Communism's overall ideology paid little attention to the concepts of state and institution. Instead, it taught the Albanian people to save all their devotion and respect for the communist party (Kadaré 2005).

The new communist state, nevertheless, built much of its legitimacy on national mythology and the creation of a new homogeneous national culture as an important part of its modernizing project, with folklore its main source. There was a symbiosis of national-communist ideology with national mythology, with the 'glorious' past marked by four major moments: the Illyrian battles, the time of Skanderbeg, the Albanian renaissance and the partisan war. Its two main heroes were Skanderbeg and Enver Hoxha (Lubonja 2002, p. 95). In the meantime, communist ideology was preached as the only culture and the bearer of all truths, although its basis rested upon 'frozen moral and ideological truths', non-challengeable from the intellectual and political elite. The everyday rites and traditions of kanun and religion were radically transformed, although the clan and honour (besa) proved resistant to these changes (Lubonja 2003, p. 6). The cultural changes were also strongly associated with shifts in the communist orientation of Albania. After the break with the Soviet Union in the 1960s, the communist regime introduced a politics of isolationism. This stance supported a selective Albanian state-sponsored patriotism, with only certain elements of Albanian culture being granted legitimacy, while religion, historical consciousness and ethnic customs were controlled or completely suppressed (Morgan 2002).

More importantly, communism had an impact on identity and national belongingness. Communist ideology imposed on the people became the main instrument of repression used by the communist party, while the masses increasingly believed in a virtual reality made up of the new myths of the communist era (Lubonja 2002). On the other hand, communism's disregard for the state and its institutions gave rise to a weakening of national belongingness, as the communist state focused its devotion towards the Soviet Union as the real fatherland (Kadaré 2005). By the mid-1980s, however, ethnicity was reappearing as an important category of belongingness, while the idea of the unity of workers of the world and the idealism of achieving communism were weakening, together with the regime's legitimacy (Morgan 2002).

Nevertheless, the long period of isolation and the ensuing collapse of communism caused a major identity crisis, which was especially evident during the 1990s. With the withdrawal of the national-communist myths and symbols, Albanians lost their past and found themselves unprepared for the future in a world that was changing rapidly, whilst simultaneously discovering the distorted perception they had of themselves and their history during communism (Misha 2008). Albania's nationalist ideology was distorted more by communism than those of the other postcommunist countries in the Balkans. In the absence of a strong collective identity, 
Albanians in the 1990s returned to the fragmented social organization and action based on individual clans trying to survive (Lubonja 2002). The period of communism, like in other ex-communist countries, was seen as a historical accident (Misha 2008). Soon another myth was created: that of the West, which appeared both as a promised land, where everyone could freely choose to go and start a new life, and as a saviour, as the place where one aspires for freedom and democracy (Lubonja 2004). It also represented an element of continuity with Albania's pre-Ottoman past and an opportunity for Christianity to re-establish itself as Albanians' original faith (Lubonja 2002).

More generally, the post-communist period was characterized by a simultaneous 'chaos and crisis' in terms of moral and cultural values (Lubonja 2003). Once communism collapsed, the new Albanian state sought a balance between the continuous aspects of its history and the universal elements that inevitably were incorporated in Albania (Lako 2009). This was part of a contradiction that many ex-communist countries experienced: the demand to return to the traditional and national values abused by communism and, on the other hand, integration at a global level and reconnection with other countries and cultures. At a more micro level, the impact of communism was evident in the 'standard individual', since communism aimed to create a unique homogeneous culture. Nevertheless, the Albanian culture at the end of communism was a mixture of three main ingredients, which were incorporated in different dosages: the patriarchal and traditional, the national, and the communist (Lubonja 2003).

While the initial stage of post-communism was characterized by a 'competition' between the regimes and styles of the pre-communist era and the Western ones, together with a dose of nostalgia for communism (De Waal 2005; SchwandnerSievers 2004), there has since been a growing maturity, with discourse moving towards national identification (Frashëri 2007; Kadaré 2005, 2006). The myths of the West and of nationalism remain strong today; and there is a new awareness and confidence, not least as a result of a sense of betrayal and disillusionment that has made Albanians sceptical.

Migration is strongly related to these transformations and appears at times to be both the consequence and the cause of 'crisis' and renewed confidence. The articulated superiority of being Albanian goes hand in hand with escape from and denial of Albania for a better life elsewhere (Lubonja 2002). Misha (2008) refers to the overcrowded 'Partizani' ship ${ }^{5}$ as an important symbol of Albanians' first confrontations with the outside world, and suggests that these confrontations caused a serious crisis of self-confidence. This was part of a process of devaluation of the main social and cultural institutions, which rested on the basis of community life and in turn caused the social fragmentation which characterized Albanian society during the transition period.

\footnotetext{
${ }^{5}$ The 'Partizani' was one of the ships that Albanian migrants occupied and travelled to Italy on in 1991. It symbolically represents the migration of Albanians after the fall of communism. It is also found in secondary-school books in Italy on contemporary Europe and modern transformations of Italy.
} 
On the other hand, negative Western representations of Albania and in turn Albanian migrants' own perceptions of identity and their strategies of integration have impacted 'Albanianism at work' (Hall 1999). These representations seem to have over-emphasized the importance of kanun and simplistically explained Albanians' violence and victimhood as a 'natural' cultural predisposition. Although hiding Albanian identity was noticed also in earlier migrations (Blumi 2003), these representations are probably at the roots of Albanian migrants' mimicry and self-denial (Schwandner-Sievers 2004, p. 126).

\subsection{The First Generation}

\subsubsection{Migrant Identity}

Studies on identities of Albanian migrants are rare, and comparative studies and those on the identities of the children of migrants are almost non-existent. Studies on Albanian migration have focused mainly on the migration process, issues of regularization and integration in the labour market (see the reviews by King 2003; Vullnetari 2007).

Among various identity traits that the Albanian immigrants perceive and experience, their migrant identity is very strong and has 'blurred' distinctions based on class. ${ }^{6}$ The act of migration is now recollected with fascination but also with a more mature reflection on the historical and personal conditions at the root of the act (see also Vehbiu and Devole 2010). In general, reflections on identity were more common among migrants interviewed in Florence than in the other two sites and more common among the highly skilled or highly educated migrants. On the other hand, the search for an identity was an initial unconscious push for migrating (Mai 2002), although this is often recognized only after many years of staying abroad. The quote of Lela (female, 37, Florence) below shows how the act of migration has marked her life history, representing an undefined identity search unacknowledged at the time.

In the beginning there isn't any push... I didn't have any objectives like I am going to do this or that. I wanted to just go, that's it! I didn't come here with a plan; when I arrived in Italy I was nineteen years old with two children. I couldn't really think of any project for the future... But everyone was leaving so I thought I should try too... I wanted to go! I wasn't thinking of anything else.... I don't think people had clear ideas in those times. Albania was... I don't know how it was in those times [in the early 1990s]. A huge mess.

The first migrants encountered a sympathetic reception, both in Greece and in Italy, due to the limited knowledge of Albania apart from its history of harsh dictatorship. However, this lack of knowledge was also alienating and disempowering for the migrants, and it was then followed by a negative image of Albania and Albanians which emerged in the years to come. Some migrants' narratives indicate that their

\footnotetext{
${ }^{6}$ Migrant identity is treated for the first generation only since this was hardly relevant for the teenagers. In fact, many teenagers explicitly rejected the migrant label.
} 
migrant identity was perceived in association with the mentality and values of the socialist regime, which guided them in the settlement period and beyond. Others acknowledge the changes that they experienced, contrasting their 'new' mentality with the way of life and values they used to have under communism.

There are also differences between those arriving at the beginning of the 1990s and those arriving later, particularly after 1997, in terms of their migrant identity and the relevance of ethnicity. Due to differences in the timing of the migration to Britain compared to those to Greece and Italy, this trend also represents a general difference across the three sites. Those migrating at a later stage had different motivations, with improving their family's financial situation being a very clear goal. Those who left earlier had a different kind of migrant identity. Michelino, who left on the first ships in 1991, remembers the politicization of the act of migration and the burden of guilt and treason that the very first migrants carried. He is typical in still calling himself a refugee, a term articulated in the public discourse and which became part of the ordinary vocabulary in Albania in the early 1990s referring to all migrants.

Michelino (male, 46, Florence): What pushed me to go? What pushed the whole of Albania! If Enver [Hoxha] had been alive most probably he would have come with us! [smiles]... I thought 'I am going there, whatever happens'.

Clara (his wife, 42): Also the curiosity, for example, what is there on the other side of the sea? Because every time we were on the beach we would wonder. I was 24 , he was 28 ; we had never been out of Albania. And those years were a period of darkness for Albania.

Imaginaries and curiosity about the terrae incognitae were part of this big escape (Salazar 2011). Other migrants recollect the purpose and the outcome of migration more as cultural exchange and the desire to integrate in the 'outer' world. Taking a comparative approach towards the three subsamples, the desire to know the world and engage in an identity search is most common among Albanian immigrants in Italy, compared to those in Thessaloniki and London. This could reflect the greater knowledge of the outer world among the urban-origin migrants from western and central Albania, where most of those living in Florence come from. Migration was an adventure, a search for alternatives, fulfilment of a need for transgression for the first migrants, as opposed to the slightly more meticulous step it represented for those migrating later.

A professional identity is often strongly linked to these narratives on migrant identity, especially among those adults experiencing de-skilling and those few who managed to find a job requiring some skills related to their previous education and job experience. The majority of those experiencing de-skilling, refer to their professional identity when they evaluate their decision to migrate and discuss instances of discrimination and their children's education and job prospects.

Bardhi (male, 43, Thessaloniki): A big problem that I experienced was with the language. I couldn't... I couldn't express myself! Having been a teacher in Albania, I was used to expressing myself with a rich vocabulary, with a language that suited me, and through language you show who you are... Here you don't have a possibility to express yourself. Who you are... and then the jobs that you have to do here; you must be in very good physical, emotional and health conditions. To handle different jobs, to adapt to this society that has a job for you, that offers [only] a physical job... All these change you as a person! 
Those who found a job in the host country that to some degree matched their qualifications exhibit a strong professional identity woven in with a migrant identity and a parallel assessment of opportunity structures in both the host country and in Albania. But the 'joint' migrant and professional identity is also evident in the narratives of the low-skilled. For example, the professional identity of women in Thessaloniki is closely related to the domestic sector and the type of relationships constructed and values recognized or negotiated through this kind of work.

Furthermore, a migrant identity is associated with feelings of settlement and long-term residence in the host country. Over time, migrants change their perception of their positioning in the host society. There is a process of adaptation and acculturation that they refer to, which often involves acquiring habits and forming attitudes in accordance with those encountered in the host country. Long-term migrants also explicitly distinguish themselves from newcomers, including those from the same place of origin; and they start to make claims towards the host society and the Albanian government in terms of migrant rights and diaspora organization. This is most evident among the migrants in Greece and Italy, while in Britain this process is affected by acquisition of British citizenship and the rights and obligations associated with it. Abaz, below, is typical in attributing changes in the attitude of Greek society towards Albanian migrants to the significant progress of Albanians in terms of labour market integration.

\begin{abstract}
Abaz (male, 44, Thessaloniki): The attitude of Greek society has changed. Now it is different, it's like they got to know us; there isn't equality, but it seems like they got used to us. And it was us [that caused the change] because, to be fair, when we arrived here it was like we were freed from the chains. Not only those who escaped from the prisons, but also us that were free. I had a job in the state administration and when I came here... It was like we were freed. We experienced a huge change. Because the difference between Albania and Greece in those times was [huge].
\end{abstract}

The first generation, however, still feels economically disadvantaged after 'starting life from zero' in the respective host countries. Instead, they strive for their children to have a more secure start. On the other hand, migrant identity is also experienced and constructed in relation to labels and categorizations developed within the home country; as Hemming (2009, p. 585) puts it, migrants experience 'the status paradox of migration self-deception' during their visits home (see also Glick Schiller and Fouron 2001). Their migrant identity and apparent 'success' gives rise to the migration of others, but this 'success' is partly a self-deception because of the low-status jobs migrants perform. Meanwhile, as Lida (female, 46, Thessaloniki) points out, migrants are seen as 'lost' from the home country; a disjuncture therefore emerges:

Like it or not, one lives [belongs] where one can work, so we are twice foreigners. Firstly here in Greece we are immigrants, and also in Albania, when we go home, we are like foreigners... Things have changed in Albania, people see us as 'from Greece', as people from a foreign country because they don't know how it is [being a migrant].

Finally, the migrant identity is reinforced by the feeling of having no support from the Albanian state. Apart from a higher consciousness on the part of the migrants of receiving inefficient service from the Albanian consulates and embassies abroad, they refer to the apathy of the Albanian state and its inability to campaign for the rights of its citizens living abroad. At a deeper level, migrants express disappointment and 
a feeling of great solitude at being exposed to hardship and discrimination abroad and feeling unprotected and small because of a poor and powerless home country.

\section{Box 2.1 The identities of the first migrants: Instances of pre-modernity, masculinities and migration}

Tony is an Albanian who has a shop in the centre of Florence. He had been difficult to convince to talk to me. Today I went there and tried my luck. We soon started talking and Tony showed me pictures of two important moments of his life. The first was a picture of him doing his military service (ushtrinë). As I could recall from my own childhood, and as Tony told me, military service was an important experience for men during communism. When a man went ushtar, all of his kin would gather and celebrate like when he got married. This was an important milestone towards manhood, related to duty, hardship, separation and war. It was also the time when a man left home, in many cases for only two years of his life. It was common for men to marry and live at home with their parents. It was a period of 'crazy stuff', of independence, and a time to grow up.

The next picture portrayed Tony upon his return from his first trip to Italy. He had been on one of the boats that left Durrës in 1991 and were turned back by the Italian authorities. Tony had long hair and a bit of beard - both common features of young men who opposed the communist regime at the beginning of the 1990s. His face was grimy, as he had been travelling in bad conditions, and he was wearing a rather large cross, which Tony indicated having bought as a symbol of transgression against 'atheist' Albania during his first migration experience in 1990 in Greece, which had lasted a few weeks.

\footnotetext{
Me leaving Albania was just like when Kuqo (typical name for dogs in communist Albania) was released. He used to run away, wander around the fence... in the end he would come back to his home... We had no rights; we were denied the right to speak, to entertain ourselves, to dress as we liked, to grow our own hair! Who would have a problem because one would want to keep long hair?! I completed military service in 1986 and returned home... and those years the communist regime was close to collapsing. One of the most transgressive things I did was to go to the tailor and ask for a coat to be made; orange with blue stripes. It was fantastic; very fashionable!
}

The second picture brought back images of the early 1990s and the discontented young people who were just starting to realize how much they had been lied to. Their meeting with modernity provoked rage and, at the same time, pride at being among those who were 'gone' [emigrated].

\subsubsection{The Parental Identity}

The importance of family to the Albanians abroad is mentioned in other research (e.g., King and Mai 2008). However, among migrants of the first generation that participated in this study, references to the family and parenthood have enhanced 
meaning. Family is not only an important value but also an important structure, a 'living microcosm' to which a parent's identity is related (Lopasic 1992, p. 104). Parental identity features as the main element of identity of the first-generation parents in all three study sites. With the exception of a few highly skilled migrants for whom their professional identity was of key importance, the vast majority of the parents said that being a parent was the most important thing to them.

Mirela (female, 35, London): Being a parent is the first main thing and it never changes. The others complement each other, you can't categorize them easily; work is important, my personal advancement is important, but the security of the children and their welfare is my top priority.

Monda (female, 50, Thessaloniki): The main thing is the family, to raise the children in a good way, for them to have the most positive future. That's all. I have just left myself on the side. I have dedicated my life only to work and the children, and nothing else.

Parent and migrant identity are interwoven in the first generation and are generally experienced as the most important identity traits. Often, the family and parenthood are emphasized over ethnic labels:

\begin{abstract}
Agron (male, 42, Thessaloniki): The most important thing for me is being a worker and a parent. That's what keeps us alive, not being either Albanian or Greek. If you have a job, you work, you keep the family. These two are the most important things: work and being a parent. If you have these two you are okay.
\end{abstract}

Parental identity is also important because of the precariousness inherent in migration and living in a foreign country with no family or kin support. The lack of social integration and the difficulty of developing a career are also important reasons for the prime focus on the family and children.

Marjeta (female, 37, London): Being a mother is not bad at all [laughs]. I am very happy as a mother. I would have liked to have come here younger, so I could have progressed further, because my age doesn't allow me to go further. Now I have left this to the children.

\title{
2.3.3 Gender
}

Migration has given rise to changes in the understanding of gender among the first generation. These changes are mostly experienced by women and are reflected in their attitudes towards divisions of gender roles, based on gender inequalities and the hegemonic patriarchal understanding of family and male identity in Albania. These differences are especially stark between Albanian men and women in Florence. The impact of the host society has been significantly different for women and their partners, materializing in different trajectories of occupational mobility and at times culminating in serious tensions in their relationship, and even divorce. In turn, a rapid and silent assimilation in the host society and partnerships with Italian natives have brought other identity crises and a heightened understanding of gender relations and the need for self-empowerment. Among women in the Florence subsample, some (though only a few) chose being a woman as the main identity trait, as opposed to being a mother. In these narratives women indicated being able to articulate a sense of empowerment, independence and individuality as a result of migration. 
Lela (female, 37, Florence): Donna — a woman. And I say this because I am a free woman. If I make a good or a bad decision, it doesn't matter because if it's a good decision I have taken it myself, and if it is a bad decision it will be an experience. Saying I am a mother is still limiting. Because at the same time I am a professional, at the same time I am also proud to be Albanian... But in any case, I am a person, I am a woman and this includes everything, 360 degrees!

These women show increased agency and autonomy, expressed in a significant change of their role in the family, in their capacity to make decisions, propose and lead family projects, and in their resistance towards reproduction of 'gender roles' among their children. In Thessaloniki and London, narratives on gender are less emphasized. Immediate issues such as regularization and employment seem to take priority and blur or obstruct discussions on negotiation of gender roles. Nonetheless, as we will see in Chap. 3, different paths of integration have significantly impacted perceptions of gender in London. Nevertheless, women note changes as a result of migration in their way of dressing and expressing their 'femininity'.

Dila (female, 45, Thessaloniki): It has changed a lot [the mentality], it's different here. What can I say, the going out and these things. Because in Albania... Berat [her home town in Southern Albania] used to be very fanatical! [smiles]... [D]resses with... straps were out of the question, but even dresses without sleeves! Or short dresses, miniskirts... no.

Changes in perceptions of gender are less evident in men. Certain practices, such as involvement of men in housework and in the raising of children when the mothers are at work, are seen as normal at all three sites, at least in the case of the more educated and those originating from urban areas in Albania. In other cases, gender roles in the host country clash with persistent patriarchal ideas of male superiority in the family and excessive jealousy and control towards the wives. The case of Pali (male, 48 , Florence), below, is interesting because of his reappraisal of patriarchal values:

Here in Italy I have corrected something that has to do with the family. I had married, had finished university, had a child, but I had a mother whom I considered a saint. And I had it fixed in my mind that my mother was in the first place, and then father, then the brothers and sisters, and only then my wife. Here I came across a passage from the Bible that talked about the family. I was convinced in the meantime that I was perfectly right and I had serious conflicts with my wife. But in that case I got a good lesson from the Bible that says that when you marry, the wife has left her parents and has united with you. It is important socially that from that moment you will take a trip together and the wife is the most important person in your life.

The following section analyses in greater depth the way migration has affected the first generation's religiosity. This element within the identity of Albanian migrants is especially emphasized by the second generation, as we will see.

\subsubsection{Religious Identity}

Recent literature tends to place religion central in migration studies; the religion of immigrants in Europe is often perceived as problematic, depending on the religiosity of the native population and the historical institutionalization of religion (Foner and Alba 2008). Some scholars have shown that religion supports and is transformed by the migration experience (Levitt and Jaworsky 2007). The relation 
between migration and religiosity has its own particularities in the case of Albanian first-generation migrants. Since religion was banned in Albania, parents grew up without religion. ${ }^{7}$ At this later stage of their migration history, many comment that religiosity was instrumental in their integration and in the full integration of their children. This instrumentality is perceived differently according to the importance of religion in the host country. Monda (female, 50, Thessaloniki) described the religiosity in her family, though her husband said he was strictly an atheist:

I am baptized. I go and light [candles]... because there has remained the tradition that you need to believe in something, but not that I am a fanatic of faith. Here we became Christians; just like in every other religion it means don't steal, don't kill... I don't insist on my faith... my faith is for myself, not to give to other people... For example, my son bought a motorbike and said he wanted a panagia [a saint's icon]. 'Here it is', I gave him one. My daughter goes to the children's groups [in the church] that get together to sing, but I don't oblige her to follow that line.... I believe in God; it probably doesn't exist, but my father left this to me: that God does exist, and he told me that God is for everyone, for the Muslim, for the Roma, for the Christian.

Religiosity among first-generation migrants is understood as spirituality, as believing in certain universal values, such as respect towards humanity, doing good and helping those in need. Some parents embraced religion as part of the freedom to try ways of living and choose especially things that were prohibited in Albania, like religion. Yet others chose the 'religious route' in order to facilitate the integration of their children, who could thus participate in activities with their peers.

However, while baptism has helped social integration at a micro and meso level, and bearing a Greek-Orthodox or Catholic name has counteracted offspring's visibility as foreigners, Albanian parents had to later recognize that, as Tzanelli (2006, p. 39) points out in the case of Greece, religious conversion could not truly 'open' participation in the Greek 'nation' to outsiders. As consciousness of the (limited) opportunity structure and (closed) identity politics of the host country develops only over years, religious conversion is also referred to as an 'identity sacrifice' that generates few positive outcomes in terms of integration. In some cases reflections on religiosity are associated with feelings of resistance towards the pressure Albanian migrants experienced in the early years of immigration from the host society to get baptized and to baptize their children. At the same time, their narratives point to the role of the godparents, who are often natives related to the family as employers or neighbours, as a source of support and as important for the families in the context of their limited social integration.

\footnotetext{
Abaz (male, 44, Thessaloniki): We don't believe a lot, but now we are mixed with religion because the children are baptized. We feel ourselves Muslim, but we don't follow any rites.

Entela (female, 42, Thessaloniki): My children are baptized. I got them baptized when we came. Not that I wanted, but a Greek neighbour insisted, 'I want to baptize them! I want to baptize them...!' And the children believe in God, but it's not that they go to church and take a special interest [in religion]... like asking which [saint's] day is today or which celebration... no. But they do believe. I see them for example praying 'God, will you help me? Mum, please pray God that he helps me get a good grade.'
}

\footnotetext{
${ }^{7}$ The constitution of 1976, Article 37, prohibited religion in Albania until 1990, when the communist regime collapsed (Dingo 2007). In practice, religion had been suppressed by Enver Hoxha since the late 1960s.
} 
Fig. 2.1 'Religious corner' in an immigrant family home in Thessaloniki

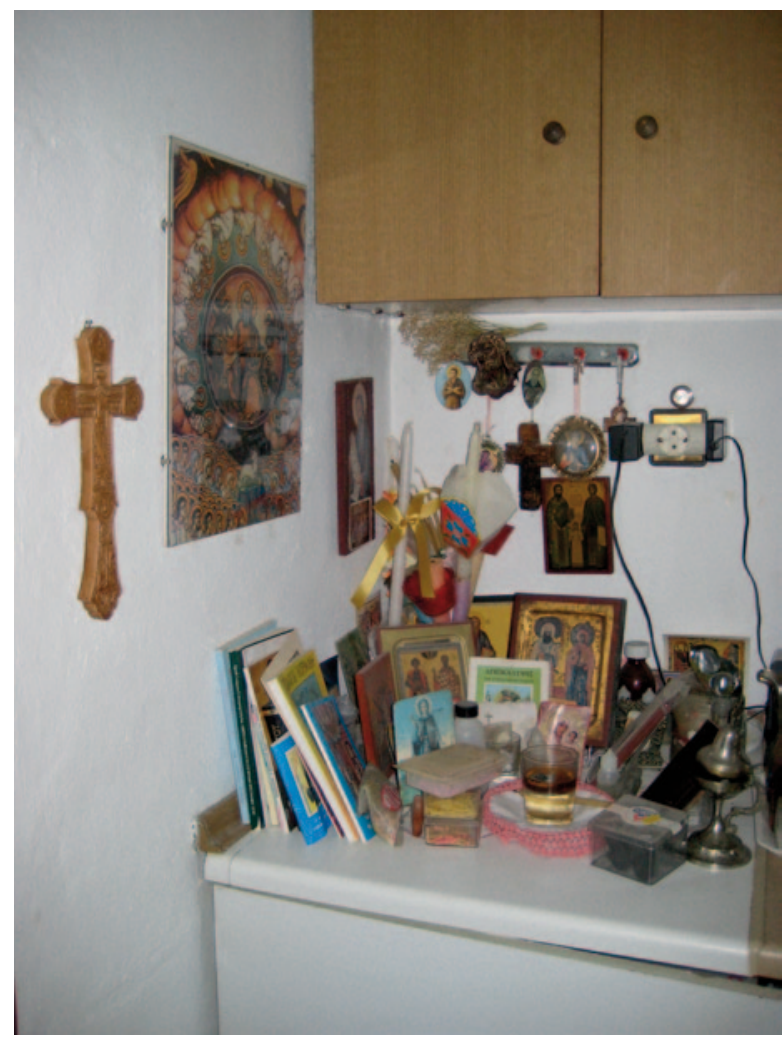

The presence of religion in migrants' lives is sometimes reflected in their household decoration, with icons, crosses and pictures of saints (Fig. 2.1). Rather different from the situation of Albanian migrants in Greece, parents in Florence are relaxed towards the religiosity of their children. Indeed, many of the adults admit to being non-religious and uninterested in religion.

There are some instances of religious conversion and baptism among the first and the second generation, but these are far less common in Florence than in the Greek context.

Dora (female, 43, Florence): My youngest son got baptized... he was praying when he was on his own secretly. He used to go to a religious school... So he used to light a candle and pray... like he was doing at school.... My son was embarrassed because none of us prayed, in our house we never talked about religion. We never mentioned it. Because as a teacher [in Albania]... I had always to mention the name of Enver Hoxha and the party in the lesson.... One day we spoke with the teacher and he said, 'Marino has decided to get baptized.' We said, 'We have no information on religion. If you think that it is the right thing to do, he can do it.' He was baptized and chose the teacher as godfather.

Religiosity in the country of residence has given many Albanian migrants of Catholic and Orthodox origin the opportunity to reconnect with their faith of origin, since the intergenerational transmission of religiosity was interrupted by communism. ${ }^{8}$

\footnotetext{
${ }^{8}$ Prior to communism, approximately $70 \%$ of Albanians were Muslim, $20 \%$ were Orthodox (mainly in the south) and 10\% were Catholic (mainly in the north).
} 
For some families from Northern Albania where the Catholic religion was prevalent, migrating to Italy has enabled them to experience a continuation in the family's religious tradition. A similar pattern was evident among Southern Albanian migrant families with Orthodox Christian backgrounds. But the link with religious continuity is not automatic. Some families of Orthodox or Catholic heritage do not pick up their religious origins once abroad.

Unlike in Florence and (especially) Thessaloniki, the first generation in London experienced no pressure to assimilate in terms of religion. The multicultural composition of the environment they live in makes religion a 'secondary' issue for their integration. Religiosity is a topic that Albanians in London relate to casually and curiously; they experience a freedom to choose their positioning.

Flutura (female, 43, London): I like being a Muslim, but here in kurbet [Albanian term for migration] you cannot follow the traditions. When we were in Albania we used to buy nice things for the children and give some money to the beggars. Here I put some money in the charity boxes during Eid or Ramadan. Or I say to my mother that she gives to the poor from the money that I send her.

There was also some mention of the traditional connection with the Muslim religion and the customs that were revived in Albania after the fall of communism. For Flutura, above, migration interrupted her 'religious' practices in Albania, which she tries to experience transnationally through her mother who lives there.

\subsubsection{The Role of Ethnicity}

Ethnic identification of the first generation appears in three main ways. First, most of the parents said they felt Albanian and identified themselves as such. Self-identification can function as a means of 'measuring' ethnic identity (Jenkins 1997; Stephan and Stephan 2000), although their self-identifying narratives may be biased. Second, some parents expressed deprecation towards Albania and the Albanian identity. Third, along with the general low importance they gave to ethnicity, some parents self-identified as being 'a good person', referring to universal human values. Symbolic ethnic identification as Albanian seems to be marked by the act of being born in Albania and having lived there most of one's life. It is uncommon for parents to question their Albanian identity; they describe their identification against a uniform host-society culture without commenting on the subgroups and diversity encountered in the environment where they live. Comments on culture and ethnicity of origin are at times marked by a 'loose' attitude towards the uniqueness and distinctiveness of the Albanian culture.

Fatmir (male, 41, London): Our culture has been mixed, five hundred years with the Turk (occupation) and then came the Greek, the Italian and the German. And it's even more mixed now because we are all over the place and we have mixed with all races.

Otherwise, the predominant attitude towards ethnicity among the long-term firstgeneration migrants appears to be part of a broader 'identity work' that has taken place alongside settlement and integration in the host country. This is most 
recognizable among highly skilled migrants, who remember this process as being associated with changes and disruptions of the identification process. Their recollections also indicate differences from parents who migrated later. The first-generation migrants who migrated to Greece and Italy in the 1990s were harshly discriminated against. In striving for acceptance, some cut their ties with Albania, changed their names, got baptized and also baptized their children. Expecting better integration for themselves and their children, some of them wholly adopted the host country's identity. Some Albanian migrants in Greece were able to register as members of the Greek minority in Albania, and encouraged their children to identify as Greek. As Valmira (female, 38, Thessaloniki) recollects below, many parents have been on a long 'identity trip':

Of course these are not the early years. I would be lying if I said that it's the same as
the early years, because many progressive steps have been made... although slow steps.
I remember when I came for the first time to Greece, I saw how small the Albanian was.
Basically how small it felt if you would say that you were Albanian. When I was hanging
around in the beginning, since I was speaking in English they were asking 'Where are
you from?' 'I am from Albania' and they would be looking at each other and I was asking
myself 'What's going on.... What is he saying with that look?' And this way I lost all the
respect that I had for myself and for Albania, for my parents, my relatives, my friends and
for everything I had experienced and had learnt in Albania. I lost it completely, I 'deleted'
it and it took a long time to understand that people are individuals who have their qualities
and those not from Albania (foreigners) are not Gods! Everyone has his own merits and
faults. It took a long time, it took a long time.

In Britain, parents faced far less pressure to hide or abandon their Albanian identity. The lines along which the Albanian community identifies were also less clear for Albanians in London due to their shorter time of residence than their counterparts in Greece and Italy. Being a small minority among many minorities and the ample space provided by the multicultural character of London make the first generation there relatively 'invisible', compared to Albanians in Greece and in Italy. As a result, those in London expressed a symbolic attachment to Albania and appreciation of both the Albanian and the host society's culture. In London, there was little evidence of the identity 'contraction' observable among parents in Greece, in particular.

In Florence, the process of acculturation and assimilation was already evident among the first generation. Although not ethnically articulated, Albanian immigrants are very receptive to Italian ways and tend to embrace practices from the context where they live. King and Mai (2009, p. 207) found that 'the key aspect of Albanian diasporic identities in Italy is the co-existence of specific conditions of vulnerability with a strong drive towards assimilation'. This is a very rational way of identifying and belonging, based on everyday life and interests and also an affinity to the Italian culture and language even before migrating to Italy (see Mai 2005). In one case, a respondent described herself and her husband as born in Albania per caso (by chance), in order to express their open-mindedness and orientation towards the West, seen through Italy, even during communism. Figure 2.2 illustrates how the Italian culture and language has 'taken over' Albanians' assimilation in Florence. Note that the invitation pictured is in Italian, as were the festivities themselves. The food served was a typical Tuscan menu. 


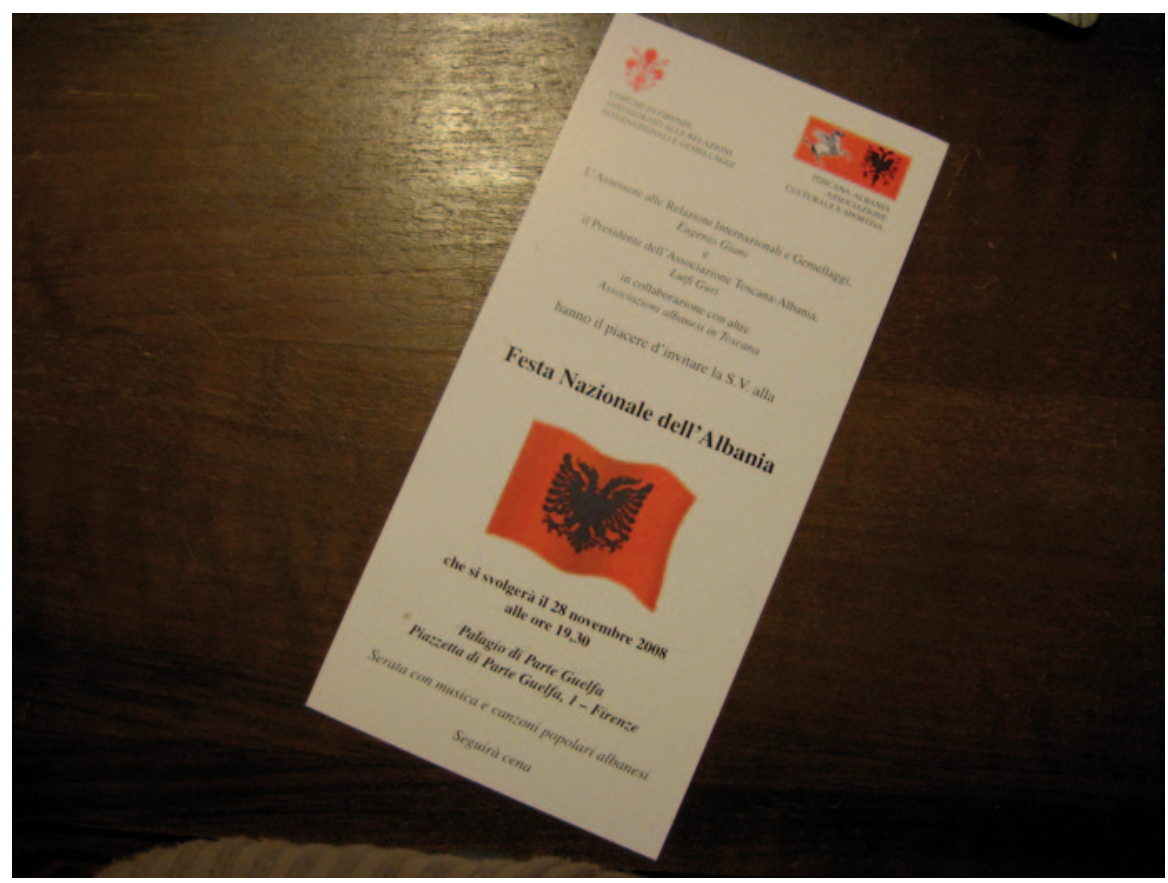

Fig. 2.2 Invitation of the Albanian community to participate in the Albanian national celebrations in Florence, November 2008. Note that the invitation is in Italian, as were the festivities themselves. The food served was a typical Tuscan menu

The first generation in Thessaloniki and Florence also shows receptiveness towards host cultures by integrating them into their family setting. This is seen in the cooking and arrangement of houses, though it is more in evidence among the highly skilled and those from urban areas in Albania. In rural-origin families, the internal arrangement of the dwelling reflects the model typical of Albanian post-communist houses, with the bufe (a cupboard with decorative cups, mugs, pictures of relatives and vases) in the central part of the room and prominent sofas against the walls (see also Dalakoglou 2010).

\subsection{The Second Generation}

\subsubsection{Teenagers and Young People}

Like first-generation migrants, teenagers, too, show multiple identities. As mentioned in Chap. 1, the literature on the identity of immigrant-origin teenagers has focused on the role of ethnicity, despite research showing that family, peer groups, schools and neighbourhood are also important referents in identity development among adolescents (Kroger 2007, p. 76). In line with these findings, multiple 
identities seemed to arise naturally among Albanian young people, although teenagers' narratives indicate that they defined themselves largely through non-ethnic identity traits. Being a teenager or young person seems to be of primary importance and what most defines them as a person.

Orjana (female, 15, Thessaloniki): At this moment, teenager. This is the one... because... Well, okay. I am a teenager, I have my own problems. Everyone thinks that I haven't grown up yet; they don't give me that much importance.

On the other hand, being a student and having hobbies, such as music and sports, and clothes and style were important to many teenagers.

Lajmir (male, 18, London): I think since my main goal is the studies,... 'student' is the most important. That's something that I do full-time; I also work, I organize events, I sing, but still that's the main thing. If I had to do only one thing, I would leave everything and would choose my studies.

Rudina (female, 18, Florence): So... [I feel like] a fashionista [smiles]. That's the closest to me and the one I care the most about. The clothes, the shoes... combine everything. I like it, I care about this.

A differentiated migration experience has also affected teenagers' identity. Differences are apparent between those who were born in Albania and those born in the host country, and between older and younger siblings. Loss of friends, harsher discrimination and more responsibility within the family make older siblings and those born abroad more mature, and the teenager identity is not as developed or casually experienced as with the younger respondents. This is also seen in the tendency of younger siblings to have more hobbies, while older siblings are more studious and pursue professions that are expected to generate a more secure financial reward. An Albanian mother in Thessaloniki describes the different emotional impact that migration has had on her two sons:

Entela (female, 42, Thessaloniki): The elder one suffered a lot. He changed environment, when he came here he didn't know the language... And still, he came here in January and started school in the third year, learnt the language and at the end of June had all his grades $10 \mathrm{~s} !^{9}$ But he closed himself off, he used to stay on his own.... Whereas the younger one came here at two years old... so he didn't really feel the transition much.

Related to the trend mentioned above, differences were observable between siblings in terms of autonomy and individuality. Those who migrated with their parents had a greater sense of responsibility. Older teenagers often assumed the role of carer and mentor to younger teenagers and at times mediated between the parents and the younger siblings, who claimed an adolescence like those of their native peers. The Albanian-origin teenagers, especially those who had migrated with their parents and even more so, those who had experienced the emigration of one of their parents and then joined the rest of the family abroad, felt they had grown up faster and earlier and were more mature than their native peers.

Children of Albanian migrants commonly experienced restrictions in the expenditures that their parents were willing or able to make on age-related activities and goods, for example, having their own mobile phone, having a bike, or going on

${ }^{9}$ Ten is the highest grade in Greek primary schools. 
school trips abroad. In many families, children shared a room. Some of them shared the responsibility for raising younger siblings as well. Furthermore, different from parents' plans for economic security and expectations for a lifestyle similar to what they were used to in Albania, teenagers aspired to have an independent life when they came of age. This is also part of their assimilation process and an expression of an individual lifestyle, as opposed to the more collective and patriarchal style in Albania.

As a result, because of the way they were growing up, their increased agency lead the Albanian-origin teenagers to draw a distinction between themselves and the natives. Lack of material goods, restricted entertainment opportunities, and parental discipline and restrictions tended to block their socialization with the native youngsters, along with conflicts in the family. An excerpt from a focus group with teenagers of Albanian origin in Tuscany explored some of these issues.

Klejdi (male, 17): I cannot really make friends with Italians. Can't quite connect with their conversations and all that.

$\ldots$

Dana (female, 15): Albanians are more mature; things are more familiar, whereas the Italians of our age are a bit...

Xhilda (female, 18): When I was little yes, I made friends with Italians; I had a l'amica del cuore (best friend). But then when you grow up you see you grow up in another way and you feel the distance.

...

Klejdi: It depends on what you like. It's not that I don't stay at all with Italians. There are boys it's a pleasure to hang out with, they know how to have a decent conversation and everything. They are not children! There are indeed Italian guys who have these qualities. But the majority I don't like as characters. It's their mentality in terms of friendship, they are not real friends, they only mind their own business.

$\ldots$

Xhilda: And then the way of entertaining. If you go out to clubs with Italians you just stare all the time, you don't know what to do. Whereas with the Albanian friends it's different, I have fun.

Klejdi: In my opinion, it's not whether they are Italians or Albanians. It depends on how people grow up, with what kind of difficulties.... Superficial boys are those who had everything when they were little, whereas boys who had difficulties have had to progress by themselves. They are more mature, more serious, they don't talk rubbish!

\subsubsection{Gender}

Gender is one of the themes that is powerfully articulated in teenagers' narrations of negotiating between home and life in the 'host' country. The gender roles that are so prevalent in post-communist Albanian society seem to have been 'transported' by the parents to the host country, although there are mothers who make an effort to counter gender divisions. Below are the perspectives of a mother and a teenager in London.

Marjeta (female, 38, London): It happens sometimes... that we respect more... well, it has remained from the old people that respect for the boys, for the brothers, is higher. But this creates conflicts with the daughter. She says, 'Why mum? Girls and boys should be equal. 
Why do you consider more the boys and you neglect the girl?' Because we are still with the old way. The boys are to be respected [laughs]. She always says, 'Why mum? He should respect me and I respect him in turn. The respect is reciprocal.' And I say, 'Firstly, because he is a brother, then he is older than you... other people wish for a brother; you have them and you don't know their value.'

ZV: Being a girl, does it affect you or will it affect you?

Era (female, 14, London): Yeah, a bit. I think it will, like you would mostly be at home doing like the ladylike work like jobs, housework, stuff like that... and if it's a boy it would be different because you would be considered as a man of the house, but yeah, because like...yeah. I just... I think it will affect me, but in small ways. If I was in another country like Albania, it would affect me more than it would here, but it still happens.... Like um... if my brother... didn't like clean his room, it wouldn't be that like much of a big deal, but if I didn't it would, because I am a girl.

As seen in the quotes above, 'traditional' gender roles are generally vigorously opposed by the girls, while in the case of the boys the attitude is mixed. Some boys expressed gendered perceptions of marriage and parenthood.

Erjol (male, 17, Florence): For example, yesterday I was with the guys of my group and there came two women that go around Tuscany and listen to young people and give advice to them. And when we were talking I was looking at her and told her ' 28 years old, with who do you live?' 'Alone' she said. 'So 28 years old you haven't married, you don't have children? You live on your own, you like your life? Sorry, but you go around like this?'

From the data it appears that the education of the parents and their origins in Albania (rural versus urban) have a major role in determining the attitudes of secondgeneration teenagers. Many parents and teenagers mentioned young friends and acquaintances who were engaged at a very early age, especially in London and Greece.

Daniela (female, 17, Thessaloniki): I have left my family now and live with the family of my fiancé. I help with cooking so that they find food ready when they come back from work tired. I do the laundry, sweep and tidy up. All these. That's why I haven't started working yet. They work and I stay at home.... This is the everyday life of a woman, the housework and all.... I have chosen this: to stay home and be a housewife, have children and do the household chores.

In the case of Daniela above, engagement at an early age, which is always to someone from the same ethnic group, living either in Albania or in the 'host' country, results in the end of age-related activities, such as taking part in sports clubs. Sometimes, it is a reason for second-generation girls to quit education. Gender divisions within the Albanian family are thus reproduced in the host country, despite many girls' acknowledging migration to Greece as an opportunity for a life that is different from those of girls in Albania.

\subsubsection{Religious Identity}

Recent studies from the USA show that religion both supports and is transformed by the migration experience (Jones-Correa 2002), while the children of immigrants are increasingly turning to 'inherited religion' as their primary source of identity 
(Chong 1998; Levitt and Jaworsky 2007). Attitudes towards religion among Albanian-origin teenagers, however, tells a different religious story. Across the three sites a number of my teenage interviewees answered positively to the question of whether they were religious, although they seldom identified religion as their primary identity marker.

At the two Southern European sites, references to religion included religiosity as a means to be accepted by their native peers, but in some cases, religion seemed to be genuinely associated with faith. As noted in the previous section of this chapter regarding the first generation, the decision to get baptized was often associated with pressure from Greek and Italian acquaintances and the host society in a broader sense. Teenagers' narratives mention the role of godparents - often natives related to the family as employers or neighbours - as a source of support and their family's limited social integration. As a result, children in Greece and Italy had largely adopted the Orthodox and Catholic religions, respectively. They were exposed to religion at school or were active in Sunday school. They attended church occasionally (though were seldom 'fanatic' about religion), while their name-days were marked by celebrations within the family. They also showed religious awareness and knowledge, which was often lacking in the parents.
$\mathrm{ZV}$ : Are you religious?
Genti (male, 18, Thessaloniki): Me... a little bit. There is no need to go to church, to pray and do other things to feel religious. The issue is do you believe or not, is faith in your heart or not. God didn't ask us to build churches and to go and pray, he never asked such a thing. God asked us to reflect and understand our mistakes and to be good people; this is my logic.
Aulona (female, 24, Florence): To tell you the truth I am not such a passionate believer. I believe in God, I pray to God and I believe in the main personages of religion... God is Jesus, the Virgin Mary... But that's all. I am not really a person that goes to church every Sunday. When I was little and we were living in Puglia, because in the small village where we were there was this tradition... so with my friends I would go to church every Sunday because there was this thing that if you didn't go... eh... whereas now that we moved here, if I go it's because I feel like going... sometimes, not always; I am not that close... I believe in God, I thank him every morning. And I have this concept that it's not absolutely neces- sary to go to church to pray to him, to thank him... Whereas my mum and dad are Muslims.

Especially in the Italian context, religious institutions and settings have been important sites for 'social time' for children and as sources of support for the parents, so they have played a significant role in integration - at least for some families. The sites and activities most often mentioned include religious education in schools, Sunday School, the church choir, Italian lessons and courses in the church, church dinners, gifts of clothes and help with accommodation. These have affected parents' and children's awareness and perception of religiosity, and somewhat increased their religious orientation. As Selim (male, 66, Florence) explains below, religiosity has also been inspired by parents' desire for their children to experience religion, which was banned in Albania.

To tell you the truth, when our daughter was little we thought we didn't want her to grow up like us. Because we lived in an era when religion was banned. So we thought our daughter should grow up with a religion, so for this reason... we decided that she became Catholic. 
In Greece, religion is often highlighted by Albanian-origin teenagers as the crucial element of cultural distinction perceived by the host society, representing a barrier to inclusion and a basis for expression of racism towards them. Baldwin-Edwards and Apostolatou (2008, p. 9) maintain that, for the greater part of the twentieth century, both the Greek state and society have exhibited a very high degree of ethnic politicization. Although the relationship between religion and ethnicity is 'intimate' (Hammond 1988, p. 3), in Greece the national ideology in Greek political culture and public discourse is based on a hegemonic form of Helleno-Christian nationalism. Religion, therefore, holds great importance in drawing political, social and cultural frontiers between 'us' and 'them' and in constituting individual and collective identities. Moreover, although religion is mostly experienced as ceremonial, Helleno-Christianism becomes very important for the natives to define themselves against the immigrants. The quote below shows this from the perspective of one of my youngest interviewees:

$\mathrm{ZV}$ : Is your family religious?

Maria (female, 12, Thessaloniki): It is, it's Christian. My parents believe in Christ, they are Christians... They believe in Easter. We baptized my sister... all of us are baptized. And I think my parents got baptized so that they could get married, because if you aren't baptized, you can't get married. They got married here.

In general, the religiosity of the teenagers represents a 'cultural discontinuity' between them and the secularity of their parents. This is especially significant in Greece, less so in Italy, and least significant in Britain. But often this generational religious discontinuity was a source of confusion for the younger generation. Here Geri describes his ambiguous feelings towards religiosity:

ZV: Are you religious?

Geri (male, 13, Thessaloniki): You mean Christian?

$\mathrm{ZV}$ : Whichever religion, I don't know...

Geri: I don't know, but my parents are Muslims. Well, me too. If my parents are, I will be, too. [smiles]... I would like to be Christian [smiles]. Also Muslim, but I would like it better to be Christian, I like it better.

ZV: Do you feel Christian?

Geri: Yes, I do, I would like to be baptized but.... We will find a godfather and then we will see whether I will get baptized, if they want [my family]... I like it better to be Christian; I don't know why, but I would like to.

Most of the teenagers in Greece and a good number in Italy had been baptized, as Christian Orthodox or Catholic respectively. By contrast, teenagers in London were freer to recognize their families' Muslim background, although, like in Albania, few families actively practised religion.

Eliana (female, 15, London): We do what they call Bajram... yeah, little Eid and big Eid, we do that sometimes because my grandparents are Muslim. And my parents are Muslim or claim to be Muslim, even though we don't go to mosque. I was about to say church! [laughs]

$\mathrm{ZV}$ : So is your family religious?

Eliana: Not really. They are not really religious. I can't really say that I am Muslim, because I eat pork, and I don't really know much about Muslim, I know more about Christianity. But right now I don't think I have a religion that I am really focused on. It is hard to keep up a Muslim religion, my grandparents were strict Muslims, had headscarves, but my parents are not that strict. 
Eliana's comments hint at the more nuanced views of religion which are possible in Britain with its pluralistic religious populations, especially in a big and diverse city like London where there are many minority-origin children of Muslim faith—something which is largely absent in Florence and Thessaloniki (or in Rome or Athens).

On the other hand, the negative connotations given to Muslims in the public discourse lead some parents and children to distance themselves from the Muslim religion and identity. ${ }^{10} \mathrm{~A}$ distancing from the Muslim religion was also evident in the articulation of religiosity among teenagers in Florence, while references to religiosity in terms of Islam are almost non-existent among the teenagers in Thessaloniki. This is similar to other research showing that the religious identity of the second generation is related to the social and historical context in which it emerges and is by no means static (Peek 2005). This leads to the final trend distilled from the interviews with the teenagers, namely that their interest in religiosity generally diminishes in late adolescence, matching the declining interest in religion of "native' youngsters as they grow older.

\subsubsection{The Role of Ethnicity}

It is by now clear that the process of identification of Albanian-origin teenagers across the three sites of this study displays a variety of trends. The strongest is teenagers distancing themselves from the Albanian identity, and this dominant trend will be analysed in due course. First, some other patterns are worthy of note. Some of the teenagers show a measure of symbolic attachment to the Albanian identity, accompanied by an interest and some knowledge about Albania and its culture. This symbolic ethnic identity (Gans 1994) is also expressed as a reaction against negative identification imposed by other teenagers in the host country, including instances of discrimination. In this case, there may be symbolic identification with Albania and Albanian identity, but the teenagers have fundamentally adopted the customs and habits of the 'host country'. This pattern is most evident among the children of migrants originating from urban areas in Albania, and among those with educated and skilled parents. They feel attached to Albanian cultural traditions, such as traditional dance, and are willing to engage in a discussion of Albanianness as 'being in their blood'.

\section{Manjola (female, 18, London): I follow Albanian tradition; my family taught me so. I am very close to my father who teaches me the Albanian tradition.... We in Britain, it seems to me, keep more the Albanian tradition than the families in Albania.}

There is also a hybrid identity being constructed (Bhabha 1994), at times not recognized or consciously acknowledged, across the three sites. Genti (male, 18, Thessaloniki) articulated this in a rather neat way: 'I feel like I have a mum from Albania and a dad from Greece; something like that.' But there are broader influences too.

\footnotetext{
${ }^{10}$ These negative connotations increased after the 7/7 events, when British citizens of immigrant descent and of Muslim religion bombed the public transport in London causing many victims. See Cole and Maisura (2007) for more on the implications of such events.
} 
Teenagers' hybrid identity draws from everyday cultural practices and a combination of the host country and home country culture, youth culture and other global cultural developments. The 'ethnic narratives' of these teenagers refer to age-related experiences, like their way of dressing, their favourite music and friendship circles, as characteristics that mark their daily 'ethnic' experience. This also resonates with Barth (1994, p. 14), who defined the cultural content of ethnicity as analytically organized in two orders: the overt signals or signs (the external features through which identity is often shown, such as dress, language, housing, and general style of life) and the basic value orientations (such as those on morality and excellence by which performance is evaluated). For both orders of Barth's typology, a distinction should be drawn between explicit self-identification and the underlying identity processes, where both overt signs and subtle signals are constructed and redefined. The primordial ethnicity - both Albanian and, especially, Greek - is referred to when a stance is taken and external categorizations are discussed or resisted. Pan-ethnic identities, European in this case, are also engaged as part of the self-identification process and 'nationalistic' avoidance, showing a relation to wider contextual issues.

Identity shifting is also very common, usually evident among teenagers who are comfortable talking about ethnic identity and those who do not experience an identificational impasse because of the stigmatization of Albanian ethnicity. Some interviewees revealed both an openness towards assimilation as a strategy to integrate (usually in Greece) and an interest in keeping their culture and not forgetting their roots (Fig. 2.3).

Anna (female, 16, Thessaloniki): I believe that we should keep this unity we have, because
living in Greece we inevitably take Greek as their culture. But we shouldn't forget our
identity, that is, we shouldn't forget our roots and who we are in reality, because this is not
good. I mean, you take others' culture and you forget your own. That's why it is good that
there are these [ethnic] organizations because they remind you of who you are and where
you are from.

Another general tendency of the teenagers is to downplay the importance of ethnic categorization. Indeed, some teenagers distanced themselves completely from this topic. Hall (1996, p. 169) maintains that 'we are all... ethnically located and our ethnic identities are crucial to our subjective sense of who we are'. Challenging this assumption, most of my teenage participants responded that they did not identify themselves in ethnic terms. ${ }^{11}$ In some instances, they did refer to human values as frames shaping their identities, such as being 'a person of all groups', being 'a good person', and so on.

ZV: Do you speak at home about Albanian culture, Greek culture? Do your parents make a distinction? Do you?

Kleo (male, 18, Thessaloniki): We don't distinguish between cultures. I am not a person that pays attention to culture. I won't distinguish between Greek, Albanian or English culture. I don't deal with this kind of thing, culture. The culture of one person is same everywhere, that of being a [good] person. That is the main culture: to be a [good] person.

\footnotetext{
${ }^{11}$ This is not to deny that Hall may be right, in the sense of ethnicity being 'assumed' and 'subconscious' and thus 'unspoken' in the interview setting.
} 


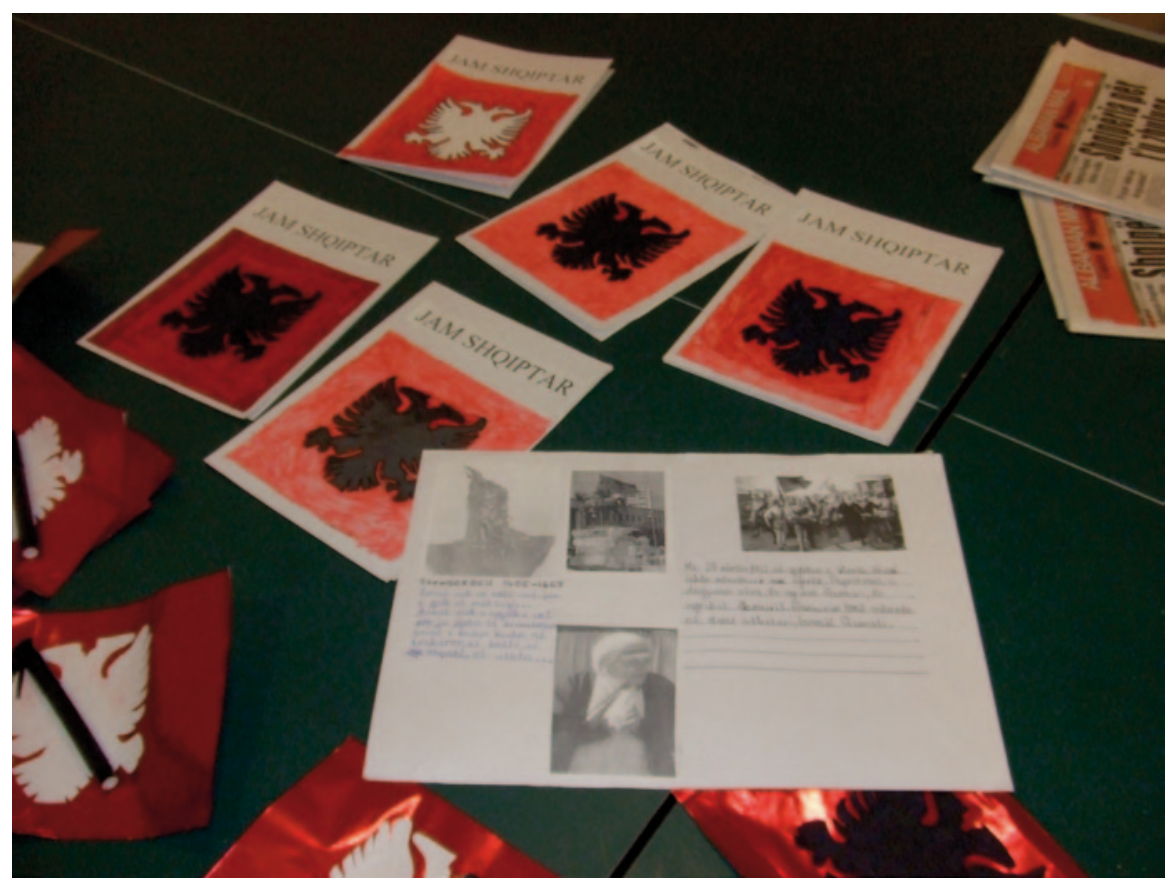

Fig. 2.3 Albanian flags and Albanian symbols painted and prepared by second-generation children in London in the Shpresa Organisation national celebrations, November 2007

Following Werbner (2010), bodily expressions and ordinary customs are seen as indicators of ethnicity; although they also express deeper, underlying understandings and experiences of individuality and autonomy versus the discipline and hierarchy advocated by parents. Nonetheless, a social orientation and tendency towards sharing as opposed to individual behaviour among teenagers is an expression of Albanianness.

ZV: You said you identify with Albanians and Albania. Why is that? Where do you see your commonalities?

Altin (male, 16, London): I mean, because this is England, so there is English people, so if there was one or two Albanians then of course you will try and be close with Albanians; you can stick together, you can fight off enemies together, you know what I mean? You can help each other, so... being Albanian, if I am Albanian and you are Albanian then we have more in common, we have hobbies in common, we have favourite food, favourite whatever.... Culture, you know... for example um... Albanians, if I buy food, if I buy chicken and chips for example, I will always, if I am with another Albanian, or even with an English person, I would always say, 'Do you want some? Take some', you know. English people, they are not really like that. If they have something, they will eat it themselves, do you know what I mean? Just small things that make a big difference, stuff like that.

Ethnic identification can be situational. The same teenager might assume any of the three main stances (Albanian, host country, hybrid) on different occasions and when discussing different topics during the interview. Darina (female, 13, London) illustrates in the following excerpt: 
I can be English, I can be Albanian, I can change like that; it's no problem for me.... I behave English when I am at school or when I have an interview with my headteacher... Yes, of course, I speak English to them. Or when I go to the job centre with my mum, for something similar... or for the British (passport) that we went and did those things... [I was] English, I spoke English without a problem. And Albanian when I am here [the premises of an Albanian association], or when I am in Albania.

Across the three sites, family, weddings and community or 'collectivity' were considered as the main markers of Albanian culture. As a result, solidarity within the family and among kin is a feature that the teenagers commonly referred to when claiming identification as Albanian. This was the case for both boys and girls. Ethnic identification can also be conditioned by the setting, such as visits to Albania and the connection that teenagers have with family and kin there. Indeed, a high appreciation of family in Albania strengthens children's propensity to feel and identify as Albanian, in contrast with the individualized life and solitude experienced in the country where they live. For some respondents, ethnic identification as an Albanian was also related to their being born in Albania and having their roots there. This was acknowledged alongside a rational belongingness to the host country because of the opportunities there and a civic responsibility towards the country of residence.

Erjola (female, 14, London): I feel Albanian mostly because my parents are from there, I know a lot of Albanian people, I have been there, I have aunties and uncles and so on.... I think I feel Albanian mostly when I go there, because here you get so used to other people from different backgrounds and so on, and you kind of forget about yours and you hear other people and it is mostly English. And when I am here I mostly feel English. When I do feel Albanian it is mostly when I am with my family, at home, my Albanian friends' house. And obviously I am Albanian.

Aldo (male, 16, Thessaloniki): I would be better described by the name Albanian because I like the name Albanian better, because it is where I was born and it will always follow me like a second name, the place I was born. I don't think I am Greek because I came to Greece. I believe that this is a place that gives me work, gives me life and that I shouldn't create problems or obstacles in this place, but I should work and make money. But the first thing for me is to have my fatherland first.

A positive appreciation of the ethnicity of the country of origin is often associated with a preference for a boyfriend, girlfriend or future partner of the same ethnic origin. Some teenagers expressing a double-identity and belongingness also indicated such a preference. Symbolic identification as an Albanian in general coexists with a rational appreciation of belongingness to the 'host' country, based on the opportunities and better living standards there. This symbolic identification was most evident among children in London. This may be related to the fact that most of the children I interviewed were recruited through Albanian organizations; the funding of Albanian organizations in London is often focused on the promotion of ethnic identity, while pressure to assimilate and discrimination are less than in Greece and Italy.

The way that teenagers in each of the three city contexts perceived the 'host' country's identity and culture is also important. There was a marked difference in the way teenagers referred to the host country's ethnic and national identity. This was articulated in strong primordial terms in Thessaloniki, with teenagers recognizing the high appreciation given in Greek public discourse to antiquity and the 'sharp edges' of Greekness. In Florence, as we will see more specifically in the 
next chapter on integration, strong references were made to the local culture and its universal values. In London, there was a perception of a fluid English culture, with a strong influence of other cultures and not holding to old or embedded traditions and conventions. Darina, Fabiola and Xhilda shed light on these differences in the extracts below.
ZV: What do you know about English culture?
Darina (female, 13, London): Um... English culture? They love football; eggs, beans, sau- sages in the morning, sit on the couch and watch TV.... [laughs] What do you want me to say? They love the pub.... That's it, because I am not interested much in the culture.
Fabiola (female, 13, Thessaloniki): I believe they had since ancient times a well-known civilisation, with Plato, but now they have degraded into whatever... Because they had this civilization, it doesn't mean that it is the same now. They 'give themselves airs' because they think it is the same now, but it is not. They speak continuously about their history, ancient times, and all that rubbish they say about the history.
Xhilda (female, 18, Florence): When I go to other cities and I tell them I live in Florence... 'Ah, Fiorentina...' I speak with a Florentine accent and they like it. 'But I have Albanian origins...', 'Ah, they say, you are Alba-Toscano... si....'. They don't call me Alba-Italian, but Alba-Toscano.

In London, Albanians' geographical dispersion and the fact that Albanian pupils constitute only very small percentages in schools means that their 'fluid' and 'light' identities as Albanians reflect a fragile identificational capacity, especially when faced by strong ethnic and religious identities performed by other minority groups in London, supported and even affirmed by the schools. Albanians have no racial distinctiveness or typical ethnic business niche, which, coupled with a 'loose' organizational and community life, leaves the children with no stable 'ethnic reference'. The very drawn-out regularization process creates uncertainty, while the stigma associated with refugee status creates a more concrete identification impasse.

Discrimination and bullying experienced at school also appear to be important reasons for hiding and rejecting Albanian identity. Yet, this outcome may also be interpreted as an attempt by these teenagers to find their own niche. Being dispersed and consisting of a small minority in a very mixed multicultural environment prompts Albanian teenagers to keep a low profile in terms of ethnic identification.

Lola (female, 39, London): In the beginning there were many young people who didn't want to admit that they were refugees, they didn't want to admit their Albanian identity. They were trying to pretend they were British, or there were cases when they were under the influence of other communities; for example, in Wood Green there are many Jamaicans and the young people... didn't have that attitude to say 'I am Albanian' and to stand up.

Contraction of identification strategies and rejection of the Albanian identity are important features of the identificational processes of the Albanian-origin teenagers in Thessaloniki. This is not to say that the symbolic ethnic identification is lacking, as can be noted from the mother-and-father quote below, but it is much less common in Thessaloniki compared to London.

Jorgo (father, 53, Thessaloniki): You can ask our daughter 'Which is the most beautiful language in the world?' She will say 'Albanian!' And which is the most beautiful country in the world? 'Albania'. 
Monda (mother, 50, Thessaloniki): Our daughter was six years old when we took her for the second time to Albania. We were on the bus, when she asked 'Are we getting close [to Albania]?' 'Yes', I told her. 'Where is our border?' And I showed her. 'Here?' she asked and she sat down and kissed the ground. All the people on the bus started laughing.

Lamont and Molnar (2002) and Wimmer (2008) see avoidance of ethnic categorization as a boundary-blurring strategy of ethnic minorities to counter racist stigmatization, while 'universalizing' human values and references to local urban lifestyle are deployed to counter perceptions of sharp ethnic divisions. However, a distinction should be drawn between the primordial and the more situational forms of ethnicity (see Kibria 2002). Both avoidance and self-identification in ethnic terms are referred to externally and primordially articulated ethnic identities, which in general are not questioned or challenged. This is not to say that a consciousness of the politics of such distinctions is missing, as Joana tells us below. However, selfidentification and the related strategies here are rational, expected to change over time and conditioned by the attitude of the host society, the economic conditions of the country of origin and the opportunities available in the future.

\footnotetext{
$\mathrm{ZV}$ : From all these qualities that we mentioned, which one characterizes you?

Joana (female, 16, Thessaloniki): That of a teenager!

$\mathrm{ZV}$ : Would you say that in another time you would choose another category as the most relevant?

Joana: Yes, I would. I would choose Albanian in future... because the more time passes, the more Albanians are liked better here in Greece, because now we still have a little bit of racism.
}

The situation is different again in Florence. The process of identification of the second-generation teenagers there is characterized by a rather 'linear' assimilation, following the same process as that evident among the parents described above, with less contraction of ethnic identification processes and an impact of locality on these processes. There are also expressions of a 'cosmopolitan ethnicity' (see Warikoo 2004, p. 383 on the ethnicity of Indo-Caribbean teenagers in New York), although the social conditions faced by second-generation Albanians in Italy are very different from the super-diverse environment of New York. Professional identity is also strong among some of the second generation who are successfully integrating into the labour market.

\footnotetext{
Aulona (female, 24, Florence): First of all, I am a designer. And then Albanian; I don’t deny it, in the end I am proud. Okay, I do feel Italian, because I have grown up here. I combine both cultures, almost fifty-fifty... and I am glad that it's like this. And when I went to France, although I stayed there very little, but seeing their culture... The more cultures I can combine, the better it is, I like it. Like the Italians say, I feel a citizen of the world, more or less.
}

The second generation also experiences a 'hierarchy' among the various despised categories of immigrants and minorities and this affects their general perception of their origin. While the negative articulation of the Albanian identity creates an identity contraction or a lack of interest in cultivating Albanian culture, the term 'extra-communitarian' (extracomunitario), as a stigmatizing umbrella term for all residents in Italy who originate from underdeveloped countries, creates another 
'identification phobia' among teenagers. These hierarchies are also observable in the attitudes of Albanian-origin teenagers towards current and future partners. Teenagers who feel integrated in Florence and identify with the national or local culture oppose a choice of partner from their own ethnic group or from other discriminated ethnic groups in Italy, such as Moroccans and Romanians. In this last aspect, they display a high degree of assimilation into mainstream (racist) Italian norms.

At all of the three sites, schools are important institutions impacting the 'content' of ethnicity for Albanian-origin children. The process of 'discovering' ethnicity is coupled with becoming conscious about the negative articulation of Albanianness in the host country's public discourse, experienced in the micro-level and meso-level institutional settings. These instances are experienced as confrontations in early years of schooling and as exclusion on the basis of ethnicity, these being harsher for children who arrive at or after school age. Stigmatization has wider connotations that include 'Albanian' as 'other', 'different', 'immigrant' and 'Muslim', contributing to a broader politicization of Albanian ethnicity. The national media and its role are prominent in 'launching' and further elaborating these connotations (see King and Mai 2002, 2008 on Italy). Although the lay jargon of 'racism' is part of the teenagers' narratives, in substance their narratives support Anthias's (1992) argument that racism is not necessarily built on explicit racial categorizations, but by using the ethnic category as a building-block it is materialized in exclusionary practices towards groups defined on the basis of racial and ethnic categories.

Blerim (male, 13, Thessaloniki): Because I was from Albania, they used to insult me. 'You are Albanian!' They used to beat me up. Everyone was against me. But after that, from the third year onwards, because I changed schools after that, some people left, some came, people changed and now they stopped. Now I am the same as the others.

In many instances an 'anti-Albanian' articulation has been internalized and further developed among the second-generation teenagers themselves. Images taken from the media and stereotypes suffered at school have created negative perceptions among teenagers towards Albanian migrants in the host country and towards Albania in general. This is evident teenagers' attitudes towards co-ethnic classmates, especially when they are newly arrived from Albania and have not yet acquired language proficiency. Intra-group exclusion is also practised towards relatives or other first-generation migrants. As most Albanian migrants have very humble jobs, children associate Albanian identity with a poor and not-so-interesting lifestyle, and with uneducated and uncivilized behaviour.

As a result, a main feature of ethnic identification strategies of Albanian-origin teenagers at the three sites consists of a distancing from their own ethnicity, striving to cross the ethnic boundary to the host society, but facing insurmountable difficulties, living thus at the edge of the boundary. Helplessness and an 'identification limbo' characterize the identification narratives of Albanian-origin teenagers, especially in the Greek context. These teenagers speak the host country's language as their main or only language, they have adopted the religion and are heading towards assimilation, but are denied a Greek identity. Changing the positioning of the boundaries is hampered by weak ethnic agency - the ability of people to change the conditions around them, especially the way they deal with their positioning within 
a society or with discrimination, by relying on the idea of belonging to a certain group of people, by the belief in a shared common past and common destiny and the assertiveness that comes with this belief. Changing the boundaries' meaning is made impossible by the resistance within Greek society and its ethnocentric Greek identity. As the account of Maria shows, this forbidden identity is experienced as alienating and disempowering.

ZV: Do you see yourself being part of an ethnic group?

Maria (female, 12, born in Greece): I don't think so. Basically I wouldn't like to be part of an ethnic group. But often this can't even happen. I can't say 'my country'... that Greece is my country, that this is the history of my country, and that this is the religion of my country... I can't say this. This would have been good, but this is not possible.... Let's say, the teacher says, 'Now we will do history'. I can't say, 'Oh, the history of my country'. Because the other children will hear and they will say, 'She went mad! This is not the history of her country. This is the history of $m y$ country'... Yes. Greece is not my country. But neither is Albania... It is not possible for Albania to be my country, because I know neither the language, nor the traditions, nor the history, nor anything from religion. I really know nothing from the history and traditions... So I constantly feel like I am somewhere at the border. I can go neither that way, nor this way!

The absence of ethnic agency disables strategies to counter stigmatization; the same absence seems to negate the creation of a reactive or adverse identity in its classic definition. This is observable among boys who employ the role of the 'reckless', asserting themselves by breaking rules, but again not referring to any collective ethnic frames. The recognition of discrimination in the case of girls shows the converse trend at times: a clear distancing from discriminative attitudes towards Greeks or any other people on the basis of ethnicity.

Lela (female, 36, Florence): In many things, my sons feel Italian. But it's enough that just a small thing... for example, when they hear something on TV or when the police stop them. Or in a nightclub when they show their identification document and, 'Ah, you are Albanian'.... Then they have this nervous reaction and they take their motorbike helmet they write ' 100 per cent Albanian' or 'skiptar'. ${ }^{12}$ This is all at a time when they feel Italian, but friends, institutions, whatever happens, tell them, 'You are Albanian; you are not like me!' And it's there where this nervous reaction comes from, when thinking, 'So I am Albanian!' but with the frustration that they are Albanian but they do not know the culture, the history and the Albanian language.

Arjana (female, 17, Thessaloniki): [I am] Albanian and a person who doesn't want to have hate for the Greeks or any other people, because that's not how I think it should be. Even if a Greek hassles me, it's not for me to react, I don't like these things; it's part of my character that I don't like to fight. I want to show that even though they are racist towards Albanians, I am cultured and this is my attitude; if you want, don't speak to me anymore.

Reading the literature on ethnicity from a 'generations perspective', one line of argumentation that emerges is that ethnic identity changes 'quantitatively and qualitatively' (Le Espiritu 1992) in different directions, over time and generations. In my sample there is a difference between the first and the second generation, and even between teenagers and their younger siblings (see also Song 1997). Most of the teenagers interviewed had younger brothers or sisters. In a few cases I was able to interview siblings, either separately or together. The older children, generally born

${ }^{12}$ Misspelling of shqiptar, which means Albanian. 
in the early 1990s, who came with or joined their parents in the first years of migration, tended to have very developed agency, as sometimes they had to take on some parenting duties. Certain features of 'migrant identity' (Waters 1994) - being selfsufficient, studying harder than the others, being more goal-oriented and achieving the main goal of their parents' migration plan ('a better future for them') - seem weaker in the younger siblings.

ZV: Do you see any differences between you and your younger sister?

Vilma (female, 16, Thessaloniki): Yes, there are differences between me and my sister because she has become just like the Greeks. She always has to ask my mum about her lessons, like 'Mum, can you have a look at this?' Greeks don't do their homework themselves; they have to ask their parents. I tell her, 'Try to do your lessons yourself; you will make a mistake, but you will learn for the next time.' She is the type that needs to ask mum. She is still very young, but it seems she is a bit insecure about what she does.

Another account is from a parent in Florence.

Lela (female, 36, Florence): When they (two sons) fight, the older one beats his chest and says 'I am Albanian!' He has this patriotism, I don't know where it comes from because he came here at five years old. And jokingly I tell him, 'But what do you know of Albania? What kind of Albanian are you?'... Or he has this protective attitude towards me because he is the man of the house... there are some things which make me think there must be something in the DNA. [smiles]

\subsection{Conclusions}

This chapter analysed the multiple identities of first-generation Albanian migrants and their children, taking a comparative and thematic approach. The findings show that there are important differences in the experience of identity between the first and the second generation. While the first generation experiences its identity mainly around roles and status, the second generation's identity is mostly focused on agerelated emotions and activities. Nevertheless, there are important in-group differences. The usual distinctions apply here in terms of different socio-economic status, education and work position among parents, which in turn affect the way children perceive and experience their identities; these aspects are comparable with those found in other research on the identification of the second generation (see Levitt and Waters 2002).

In terms of ethnic identification, however, one of the main results of this research is that the ethnicity of origin, as least in primordial terms, is not a main reference in the identification processes of the Albanian migrants and their children. Other identity traits are much more important to the teenagers; references to the primordial ethnicity are determined by contextual characteristics and factors, rather than by parents' or the ethnic community's 'legacy'. The primordial ethnicity itself is perceived as a symbolic and external entity to which Albanian-origin teenagers have to relate in their everyday lives. These findings contrast with previous studies of other second-generation groups and countries, which have established ethnicity as a core of factors influencing the identity and integration strategies of the second generation. 
There are important differences between the research sites, mainly related to the importance that ethnicity has in the public realm of each of the countries where the three cities are located. Despite these differences, among both parents and children consistent patterns of ethnic identification were found, varying from a symbolic attachment to ethnic identity to a contraction of identification and denial or avoidance of Albanian identity. As the latter constitutes a major trend among the second generation, there is little cognizance of a 'blending of cultures', which is an expectation that one would have when working with second-generation teenagers. Especially in Greece, there is a contraction of the ability to relate to any of the 'cultural sources': the Albanian one is unwanted, as it is highly stigmatized in the everyday environment, and the 'host' one is unwelcoming, with full membership and belongingness denied. This is explained by the role of actors situated in a social field in the process of boundary making (Barth 1969; Wimmer 2008). Specifically, Wimmer (2008) distinguishes between strategies that attempt to change the location of existing boundaries and those that do not aim to shift the location of a boundary, but try to modify its meaning and implication by challenging the hierarchical ordering of ethnic categories, de-emphasizing ethnicity and emphasizing other social divisions, or shifting one's own position in relation to the boundary.

Albanian second-generation teenagers generally show weak ethnic agency, though such agency is needed to implement strategies that target the location of existing boundaries or their meaning by challenging the hierarchy of ethnic categories. The boundaries are externally erected, and strategies requiring group ethnic action are not in evidence. There is some tendency towards boundary crossing and repositioning, performed at an individual level and accompanied by indifference towards co-ethnics and referring to the negatively articulated 'Albanianness' as the reference for distancing. When positioning themselves along the boundaries, external categorization and identification by others are the main frames referred to by Albanian-origin teenagers. According to Jenkins (1997, p. 61):

A claim to ethnic identity must be validated by an audience of outsiders or others- - because without such an audience the issue would not arise - but it seems to make little sense to talk about an ethnicity which does not at some point and no matter how weakly or tenuously recognize itself as such.

Discrimination appears to be an important factor shaping identification processes, a detailed analysis of which follows in the next chapter. Highlighting the difference between the primordial understanding of ethnicity and the experience of ethnicity in everyday life is important. As Kibria (2002) maintains, most of the research on the second generation has focused on primordial ethnic identity, which is indeed what is referred to by both parents and children when reactive identity or avoidance and rejection of Albanian identity are articulated and experienced. Nevertheless, ethnic identity and its transmission are understood and experienced as major factors related to Albanian migrants' and children's everyday lives, especially in relation to 'host' institutions and the public realm. The impact that this understanding has on migrants' and their descendants' perception of their identity depends on their socio-economic status and also represents gendered patterns (Anthias and YuvalDavis 1992). 
An important finding from this research is that locality impacts on identification of migrants and their descendants. As mentioned above, city identity and culture is important for the identification of these groups, especially among teenagers. This identificational trend is especially evident in Florence, where teenagers make strong references to the local culture and its universal values.

The factors affecting external identification - the 'host' institutions and the public realm and discrimination - and the role of the city are further discussed in the next chapter, which focuses on processes of integration.

Open Access This chapter is distributed under the terms of the Creative Commons Attribution Noncommercial License, which permits any noncommercial use, distribution, and reproduction in any medium, provided the original author(s) and source are credited. 


\section{Chapter 3 \\ Integration: National, City and Local Perspectives}

Many studies have been conducted on the integration of migrants. Integration has also been at the heart of public discourse on immigration and is a reference term for numerous policy documents. This policy focus has contributed to an often negative political connotation of integration in academia nowadays. Nonetheless, integration remains a central concept in explaining the processes that make migrants part of a receiving society (or, as is often the case, that marginalize them from the mainstream), despite alternative concepts that have been developed over time. These processes are the focus of this chapter, which, following the model of the previous one, is made up of four main sections: a conceptual and theoretical section on integration, a section on the integration patterns of the first generation, then one on the second generation, followed by conclusions.

Each section draws material from the three sites of this study and is written comparatively and thematically. Since integration is conceptualized as a process, rather than an 'outcome', the current chapter describes and analyses patterns, dynamics and strategies of integration of the two main groups of participants in each of the three cities. Findings reveal integration to be a process that changes over time and is significantly affected by legal status and regularization procedures, experiences of discrimination, and socio-economic status and capital. The process of integration, moreover, differs significantly between the three sites and the two generations analysed. Variation between the sites is associated with differences in immigration politics and institutional arrangements. Differences between the generations are affected, in turn, by their different 'spatial cognitions' and an overall difference in aspirations for integration driving the two generations' strategies. 


\subsection{Reviewing Integration: Philosophical, Theoretical and Methodological Aspects}

As this research encompasses different sites, groups and two generations, a variety of concepts used to describe the process of immigration and settlement in the receiving country and beyond are relevant. It is important to recognize the existence of other concepts in relation to integration, not least because their definition and use have been built on the basis of progressive research grounded on early work in the field (see Gordon 1964, pp. 60-68). Terms describing migrants' insertion and settlement in the host society can be divided into groups referring to different stages and modes of integration, such as adaptation and acculturation. Other terms, such as incorporation and assimilation, can be classified on the basis of the different philosophies they draw upon. Another division refers to terms that describe the insertion into different systems, networks and structures, the most well-known being the distinction between structural and social integration (Engbersen 2003). In this section, the backbone of the discussion is provided by the concept of integration, seen as an umbrella term that encompasses manifold other terms referring to similar or connected processes.

Since the early stages of academic work in the field, integration has been conceptualized as a process through which a group becomes and functions as a part of a society. According to Gordon (1964, p. 246), 'in social structural terms, integration presupposes the elimination of hard and fast barriers in the primary group relations and communal life of the various ethnic groups of the nation'. However, the evolution of the terminology that describes migrants' patterns of settlement and interactions with the host society has been characterized by a 'politicization' and an increased emphasis on government involvement. Nowadays integration rhetorics are associated with those on state policies, although the roles of migrants' agency and of the migrant communities are acknowledged as important factors (Thompson and Crul 2007).

The notion of integration has returned to the political and academic agenda as an alternative to another major concept, assimilation. Developed in the nineteenth century after the first wave of migrants, in the 1970s and 1980s assimilation was criticized by social scientists for its emphasis on the demand imposed on minority groups to abandon their cultural and ethnic identities and conform to the receiving society's ethnocentric cultural practices and norms (Joppke and Morawska 2003). The new notion of integration is conceptualized as a two-way or multi-actor process, based on mutual change - of both the receiving society and the minorities (Favell 2001). Another dimension of 'new' integration is recognition of cultural plurality, as opposed to the essence of the original notion of assimilation, which emphasized cultural absorption into the mainstream (Joppke and Morawska 2003).

Modern definitions of assimilation have observed these ideological changes and moved away from the idea of integration as a process that forcefully overrules a minority ethnic group's distinctions. Alba and Nee (1997), in redefining the term, take a more 'agnostic' perspective regarding the object of assimilation and maintain 
that the process does refer to the involvement of the majority group. In order to avoid the pitfalls of earlier definitions, they define assimilation as 'the decline, and at its endpoint, the disappearance of an ethnic/racial distinction and the cultural and social differences that express it', maintaining that the direction of change will depend upon the minority group, the historical moment and the aspect of group difference under consideration (ibid., pp. 863-864). Different from its previous definition within the straight-line model of assimilation, the concept refers nowadays to a more complex process. Assimilation is increasingly associated with a segmented and multi-path model (Portes and Zhou 1993), which sees the incorporation of migrants as leading variously to upward assimilation into the middle class; downward assimilation into the lower class; and 'enclave' assimilation, which itself can display upward and downward intra-group trajectories (Morawska 2003, p. 134).

The concept of incorporation, on the other hand, is seen as less politically inflected than other major concepts, such as integration, inclusion and assimilation. Thus, it is preferred in some recent migration research (Glick Schiller and Çağlar 2009), although it is not clear how this concept resolves the issues associated with the concept of integration.

Nevertheless, interest in assimilation has grown. Joppke and Morawska (2003) maintain that assimilation remains the key concept in explaining normatively the integration of migrants. This is especially so because of a growing emphasis within the assimilation debate put on the socio-economic equalization of life chances between immigrants and the natives, or the structural dimension of assimilation. This stance is supported by Brubaker (2001, p. 542) who argues in favour of the 'return of assimilation'. Brubaker considers assimilation to be a process, rather than the end result of minority groups' integration. The process is seen as taking place in a multigenerational immigrant population, without requiring individual-level changes, and its outcomes are rather heterogeneous; that is, they occur as changes in the features of a group in order to become similar to that of a reference population. These changes are especially expected in the socio-economic realm, as the new assimilation concept is seen as not opposed to difference, but to segregation, ghettoization and marginalization.

A distinction between the dimensions of assimilation is important to understand the underlying dynamics of integration. The first typology was developed by Milton Gordon (1964, pp. 70-71), who distinguished several 'sub-processes' occurring in seven stages. Cultural assimilation or acculturation is the first in Gordon's model; this sub-process may take place even if other types of assimilation do not occur and is seen to be continuous. However, Gordon (1964) considers structural assimilation to be a crucial sub-process, as its occurrence, either simultaneously with or subsequent to the cultural one, leads to the other types of assimilation, while the opposite trend - cultural assimilation giving rise to structural assimilation-is not possible. Gordon's model has since been reviewed and modified, with new models putting more emphasis on structural and economic dimensions of assimilation. According to Alba and Nee (1997), Gordon's multidimensional account overlooks important forms of assimilation. Alba and Nee (1997) further argue that such omission is vital 
as socio-economic mobility significantly impacts the social conditions necessary for the occurrence of other forms of assimilation.

The role of structure in producing social inequality thus features prominently in these conceptualizations of assimilation, as it is structure that conditions migrants' access to social resources and, consequently, their realization of certain life options. Esser (2004) elaborates on this in an attempt to set out a new theory on intergenerational integration. According to Esser, assimilation can refer both to social integration and to specific patterns of the social structure of a society. In terms of social integration, a process of individual assimilation can occur, which takes the form of inclusion of individual migrants into subsystems of a host country associated with increased similarity with the native population regarding cultural traits, positioning in the labour market, intermarriage and emotional identification with the host society. Secondly, structural integration depends on certain aspects of a societal system: above all, social inequality and social differentiation. With regard to social inequality, assimilation refers to the complete disappearance of variances in education, occupation and income between ethnic groups. Social differentiation, on the other hand, refers to a weakening of ethnic institutionalization or coding expressed in the decline of ethnic boundaries. The converse outcomes of structural assimilation are ethnic inequality and ethnic differentiation, which refer to the persistence of ethnic differences, respectively, on the horizontal plane (e.g., in lifestyle and professions) and on the vertical plane (e.g., in education, professions).

Two more concepts worth analysing in conjunction with assimilation are acculturation and adaptation. Acculturation presents difficulties similar to those of integration and assimilation, as they revolve around the reference population compared to which acculturation takes place and the direction of change and its dimensions are determined (Alba and Nee 1997; Berry 2003). In the model of Gordon (1964), acculturation features as one of the sub-processes of assimilation - that of cultural and behavioural assimilation. Gans (1997, p. 877), however, observes that acculturation is a faster process than assimilation and maintains that the difference between them is based on a more general distinction between culture and society. Accordingly, while acculturation refers to the newcomers' change of cultural patterns with reference to those of the host society, assimilation refers to the newcomers' shift of membership from formal and informal ethnic associations and other social institutions into those of non-ethnic origin and agenda in the same society. Adaptation, on the other hand, consists of relatively stable changes that take place in individuals or groups. This concept is multifaceted, having psychological, socio-cultural and socio-economic dimensions. Each dimension is different in regard to the times and places they occur and the predictors to which they are related; however, they are both conceptually distinct and empirically related to some extent (Berry 2003, p. 30).

More than any other concept reviewed thus far, multiculturalism represents the converse agenda to assimilation. Multiculturalism is a fairly recent term that was first developed in the USA in the 1960s as cultural pluralism, and then appeared in various forms in Canada, Australia, the UK and elsewhere (Glick Schiller 2004; Wieviorka 1998). Nowadays multiculturalism stands for a situation in a society 
in terms of demography, as a philosophy, and also as a policy agenda and practice (Parekh 2000). Furthermore, Joppke and Morawska (2003) distinguish between de facto and official multiculturalism. The former is common in liberal nation-states and consists of a recognition of minority rights and design of policies that protect minorities within broad human rights and liberal political philosophies. Official multiculturalism, on the other hand, is much less widespread. It goes beyond de facto multiculturalism by engaging states in deliberately and explicitly recognizing and protecting immigrants as distinct ethnic groups. Nevertheless, within liberal states' integration policies two major changes are recognizable: a move away from official multiculturalism and the revaluing of citizenship. The latter is associated with a de-ethnicization of citizenship and a move towards jus soli as the basis of naturalization regimes.

Apart from differences in the policy agenda, debates on these concepts have given rise to methodological changes in the way that integration is studied. These are particularly relevant to this study due to its cross-cultural design. Although early definitions of concepts such as assimilation and acculturation as well-interpreted by Gordon (1964) refer to a two-sided process in which two cultures meet and affect each other, migrants' integration processes have been expected to happen mainly as a minority group assimilating into the majority. This is based on a unified, reified concept of a state and society as unproblematic, and which is then under threat by immigration and subsequent disintegration, although research has repeatedly shown that no such society exists (Favell 2001; Joppke and Morawska 2003). A current trend in the migration and ethnic minority literature is research that leaves the majority population out of the picture or includes it as a source of discrimination. But this neglects factors that affect everyone alike, such as age, gender and socio-economic status and not necessarily differentially in relation to ethnic origin (Banton 2001, p. 159). Recent research talks about 'fading majority cultures' because of increased communication and growing proportions of the first and second generation in large urban areas, accompanied by the infiltration of the global culture in otherwise perceived homogeneous 'receiving' cultures (Van Oudenhoven and Ward 2013).

As a result, comparative frameworks and a focus on the city as a specific site of integration have been among recent developments in the conceptualization and study of the term. Favell (2001) reminds us that comparative studies using national context as the frame of reference have tended to reproduce national stereotypes. Similarly, Glick Schiller and Çağlar (2009) take a city approach, although they discuss this choice as a call to focus on locality at different scales. Alongside these developments that reject the nation-state as a container of society and as a unit of analysis for integration, other concepts such as cosmopolitanism, (super-)diversity and mobility have emerged. The concept of cosmopolitanism was introduced in the previous chapter. It is thought to have the potential to 'correct' the disadvantages of methodological nationalism and to reflect changes resulting from globalization (Beck and Sznaider 2006; Vertovec and Cohen 2002). Vertovec (2007, p. 1049) notes that super-diversity is the outcome of different factors that mutually condition each other. Among these, legal status is considered to be key and also an element 
of difference within the same ethnic group, leading to different social capital and to socio-economic and ethnic ties to different members.

Illegality has been subject of research that tackles both the involvement of the state and impacts on migrants and their integration 'outcomes'. This links to two further theoretical considerations, each derived from a different interpretation of the migration-development nexus (Faist et al. 2011). The first proposition, already acknowledged in the Marxist-inspired migration literature (De Genova 2002; Potts 1990), is that the category of the 'illegal alien' serves to create a class of legally and socially vulnerable cheap labour for employers to exploit whether as overworked and poorly paid agricultural workers (like Albanians in Greece) or as sweated labour in the low-status niches of the metropolitan economy (Albanians in London). The second proposition is that, although illegality is the product of immigration control, its extent varies according to the agency of migrants, for instance, in achieving security of residence, employment improvement and social integration (Ruhs and Anderson 2010). Meanwhile, the increase in transnational mobility (which is a subject of Chap. 4) has further created a proliferation of types of undocumented migrants and reconfigurations of migrant 'illegality'.

\subsection{The First Generation}

\subsubsection{Structural Integration}

\subsubsection{Regularization and Interaction with Institutions}

Since one of the main goals of migration is economic improvement, Albanian migrants have experienced a significant structural integration, especially in terms of the labour market. This process has been highly conditioned by legalization, which is widely considered to be the first step towards integration. For many Albanians, however, 'getting papers' has been a long process, dependent on institutional and economic factors and followed by complications in terms of actual implementation (Glytsos 2005). At all three sites, the lengthy process of regularization and uncertain residence rights have affected migrants' strategies of integration and feelings of belongingness, while creating stressful spatial immobility and affecting migrants' psychological well-being.

Nevertheless, there are important differences in regard to the history of immigration and the regularization process in each of the three countries. While most migration to the three sites has been irregular (King 2003), the different legislative and policy frameworks in place in each of the countries has affected migrants' regularization and, subsequently, their integration. In Greece and Italy, Albanians migrated illegally and over a longer span of time than in Britain. They got regularized after a few years while creating networks with other co-nationals and sometimes migrating and re-migrating back and forth to Albania. The most successful regularization 
'story' is that of Albanian migrants in Florence, reflecting three waves of Italian regularization in 1995, 1998 and 2002. Migrants here recognize the role of the right to apply for long-term residence, for family reunification and for Italian citizenship on their perception of integration. As King and Mai (2004) found among Albanians in Lecce and Modena, Albanians in Florence are moving rapidly towards structural integration. They show a high degree of incorporation, especially structurally and occupationally, appearing as a 'mature' immigrant group that experiences settlement and is starting to conceive itself as a minority.

\section{Box 3.1 Integration Italian Style}

Today I visited an intercultural centre in Pontassieve, a commune in the Florence area. I went to meet one of the ladies working there who had offered help in contacting teachers and Albanian families. I found many Chinese immigrants waiting in the corridor because the centre offered help with their papers. Generations of migrants pass through here, and new groups take the place of older ones. The intercultural centres, as an Albanian mediator commented, are mainly concerned with newly arrived immigrants. Migrants who have been in the country for a long time and have children do not frequent the centres, as they focus on language learning and sometimes help in terms of acquiring papers.

In the waiting room I saw many posters advertising projects of an intercultural nature. They offered greetings in different languages and pictures of people of different ethnicities. I also saw various kinds of books that would be of use to those teaching Italian to immigrants, such as The Guide for Learning Italian for Foreigners. Symbols of integration-regularization, contact between different ethnic groups, language - were neatly displayed here as an inheritance from the older European regimes of integration. However, the approach towards integration in Italy, at least the official stance to it, is interesting as it is based on an understanding of interculturalism as a more advanced form than assimilation, or even multiculturalism. The progressive idea of interaction between the native mainstream and immigrants and of mutual adjustment and change is at the heart of interculturalism. Ordinarily, though, intercultural education is strongly focused on teaching Italian to immigrants, and the policy framework has little to do with changes in the native majority. This speaks of a one-way process of assimilation expected of minority groups. In any case, interculturalism is primarily a regional or even local approach, in use mainly by municipalities in Tuscany. A specialist on immigration and integration at a local level opines:

When the local government does not offer services to foreign citizens this results in the creation of ghettos, or social enclaves, because the solution to the problems does not come from the institutions but from within the community. In order to prevent this phenomenon we decided to create services that are available and specifically for the foreign citizens.... We also sponsor cultural activities, so we do support the ele- 
ment that relates to the traditions of the country of origin. But if I were completely honest we have chosen the way of the services. Basically, you are a foreigner, you arrive in a city that receives you...; you are not alone, you have the municipality beside you. Because immigration is the mirror of the hospitality that we manage to give to the others.

In Greece, acquirement of papers is one of the major factors affecting integration. This is also related to the contradiction that migrants feel: they are long-term residents in the localities where they live, yet they have an insecure legal status. Moreover, Albanian migrants experience a different treatment than migrants of, for example, Russian origin, both informally and in formal terms, in their interactions with institutions and state structures (Psimmenos and Kassimati 2003). Indeed, the unsettled situation regarding residence papers is associated with feelings of humiliation, exploitation, dehumanization and imprisonment (see also Vullnetari 2012). This is on top of migrants' heavy workload and other worries, such as high expenses and their children's future. Unlike Albanian immigrants in Italy, this uncertainty blocks claims of participation in the host society. 'Papers' also impact on belongingness, civic responsibility and engagement, obstructing feelings of being 'at home' and the experiencing of sustainable emotional attachments (Yuval-Davis 2006).

\begin{abstract}
Agron (male, 42, Thessaloniki): Let me tell you what our real problem is. If we could feel some kind of security in the Greek state, in terms of papers I mean, we would be very happy here. Because we have escaped the suffering we had in Albania, the children are growing up here, and we want to adapt to this state. Just like it is in Germany or Italy, where you can get the citizenship, it doesn't matter if you are Albanian or whatever. You can vote in the local election for the road where you walk every day, because you are where your job is. Albania for us is like a remote, foreign country! Because you are where you eat, where you pay your contributions, it's there where you can raise your voice!... But we have been here for twenty years and we don't have papers.
\end{abstract}

In Britain, the Albanian community is composed mainly of those who migrated together with their children at the end of the 1990s. Albanians arrived in Britain when the political discourse was already characterized by a stigmatization of asylum-seekers and their alleged impact on the health and welfare system (Hampshire 2005). The routes that the Albanian migrants followed to enter Britain were limited to claiming asylum as Albanians after the Pyramid Crisis in 1997, claiming asylum as Kosovans after the refugee crisis in 1999, entering illegally through smuggling (usually in the back of lorries), and more recently, though family reunification.

Nevertheless, the Albanian community in Britain is now a 'settled' community. The family amnesty of $2003^{1}$ and the subsequent naturalization of Albanian migrants in the mid-2000s marked important events in this process. The majority of those who now reside in the UK claimed asylum, but the consequences of this choice were more challenging than first predicted. The serious repercussions for their integration in the UK developed throughout the period of settlement, which

\footnotetext{
${ }^{1}$ Family Indefinite Leave to Remain (ILR) Amnesty, introduced by the Home Office on 24 October 2003.
} 
lasted on average 6 years. The immigrants describe their first years of arrival as years of great uncertainty, fear and stagnation. A feeling of fatality, a 'suspended' life and psychological persecution were expressed in numerous interviews as part of the process of applying for refugee status. This was reflected in participants' refusal to be voice-recorded yet again.

Flutura (female, 43, London): Wait a minute! Will you write my name and other details?... because we have had a terrible time with interviews and papers... Oh, we have filled sacks with papers and interviews and we don't know... We are terribly scared of interviews!

As the migrants themselves recognize, Albanians in Britain had a different starting point also because of the material support they received from the state. Arriving in Britain as asylum-seekers, they became part of various social assistance programmes, which significantly improved their family's access to welfare.

Qerim (male, 46, London) narrates: I am satisfied with the way this country handled our situation; they have treated me very well, even when I was with a 'negative'. ${ }^{2} \ldots$ Because we came here for economic reasons and they gave us the opportunities to achieve something. I came here in 1998 from Italy.... Even though I remained here though I was sent the 'negative' they still gave me a house, nobody stopped me in the street, they gave us help for our children... I am grateful. I know the ones who were returned [to Albania] would speak differently. But they forget that they came here with nothing and returned with their pockets full. We came here with all the others like little children and they let us grow and stand on our feet. For me England is a second mother.

Albanian migrants paid a high cost for their naturalization. They remained cut off from their families for years - a traumatic experience, especially for those who had never migrated before. Many faced a life dilemma - whether to stay and continue the nightmare of waiting for refugee status or 'crack under pressure' and return. The grief of the regularization period was especially pronounced when migrants' close family members were ill or had passed away, and migrants had to decide whether to go to see them one last time or attend their funeral, thereby fulfilling important family obligations according to the Albanian culture, or to stay and further their goal of settling in Britain.

Mimoza (female, 39, London): We had too much pressure, too much time waiting, waiting endlessly... It was so, so bad!... Yes, I lost my sister six years ago and I couldn't go [to her funeral]. At that moment I wanted to withdraw my application [for asylum] to go back. I don't know what kept us here! I couldn't go.

The process had serious impacts on some migrants' health. Migrants and community activists recollect threats of dispersal, detention and false alarms of them being returned during the years of waiting for the 'brown envelope' - the outcome of their application for refugee status. Migrants suffered stress and depression stemming from the application and the questioning of the Home Office.

Yet, despite the negative consequences, the choice to come to Britain as asylum-seekers enhanced these migrants' integration in other respects. In contrast to Albanians in Greece and Italy, Albanian migrants in the UK were much in contact with state structures throughout the process of settlement and were beneficiaries

2 'Negative' is the term Albanians in Britain use for their asylum request being refused. 
of many systems of support. These included access to information and opportunities for education and language training. Moreover, there was no pre-established ethnic community, and little chain migration, so this first wave of migrants came into direct and immediate contact with different parts of the host-society structure. In retrospect, this process of 'socialization' with institutions was empowering and helped them to learn some of the country's social and political rhetoric.

Facing difficult problems in regularization led Albanian migrants to move towards naturalization (see also Da Lomba 2010), although there is a tendency to emphasize the instrumental character of citizenship; feelings of belongingness are usually downplayed when the decision to naturalize is discussed. Migrants' narratives refer to the benefits of having host country citizenship in terms of avoiding the hassle and expenses of paperwork and stress of residence documents and securing freedom of movement. ${ }^{3}$ Nevertheless, citizenship is also seen as a means to secure ties with the host country in elderly life and to make return to Albania an option both for them and for their children.

\subsubsection{Integration in the Labour Market}

Because of their lack of legal status, many Albanian migrants initially worked 'in the black economy' and were badly exploited. Yet this was rarely voiced as discrimination by the first generation, because the possibility to work was perceived as a valued opportunity. For many, employment was their main goal, so that they could improve their financial situation; therefore they took every opportunity to work during the time they could stay in the host country. Working conditions improved significantly after they gained legal or refugee status and, in some cases, full citizenship. For those who were still in an irregular position, however, the reality of labour-market exploitation persists. This problem is especially felt in Greece.

There are some differences in attitudes towards work between the initial migrants and those arriving later. Bardhi (male, 43, Thessaloniki) recalls that naïve materialistic urge and curiosity about a less materially restricted life prompted his initial migration to Greece:

Many friends of mine came to Greece, and were telling us how Greece was. Many positive things. They were talking about high wages; for example, after two or three weeks of work you could buy a TV whereas in Albania you would have to work forty years for that! A CD player or tape recorder, or a pair of jeans meant something big for us in those days.

Over time, financial prosperity and economic security generated feelings of belongingness, contrast both with their current symbolic belongingness to Albania and with their past life there. As the migration process 'matures', migrants are empowered to express their opinion on the pros and cons of their decision to migrate. For instance, the difficulties of the integration process and the immediate need to work have affected the family planning of the immigrants. In many families who

\footnotetext{
${ }^{3}$ The attitude towards freedom of movement may have changed after the visa liberalization for Albania of 8 November 2010.
} 
migrated in the early 1990s there is a considerable age gap between the siblings. Some immigrants have decided not to have children because of their inability to properly provide for them.

In general, there is some upward mobility in the labour market, especially among those who were educated in Albania or come from urban areas, although most jobs are related to sectors involved in migrant issues, such as healthcare, welfare, law and education. However, many parents experienced a de-skilling process, which they remember painfully.

\begin{abstract}
Monda (female, 50, Thessaloniki): Although I wear plastic boots and gloves, I am still known as a high-class lady! One should not lower her personality or morality wherever she is. Sometimes you may feel down though... I fell into pessimism after I had an operation... and was asking myself, why did I leave my job in Albania? I was a teacher, why did I have to leave the job? I had only one child, I could have taught him better values probably. I don't know... I regret that I came here... firstly because I cannot work in my profession, secondly in this country we have remained without a pension! And we are not settled yet, we don't have papers.
\end{abstract}

Integration in the labour market differs significantly across the three sites. Variations are mainly related to differences in accessibility to the educational system, the characteristics of the labour market and the nature of the opportunity structure. Some of the migrants experienced de-skilling and expressed contempt at not being able to enter education to back up qualifications earned in Albania with further qualifications in order to get an office-based job. The education and training system in Greece is particularly inaccessible, while many highly educated migrants in Florence have managed to 'convert' their degrees, a process facilitated by their familiarity with the Italian language. In Britain the educational system is even more flexible.

Integration in the labour market also depends on the structure of employment in the respective cities. Although a dream for a better career was one of the factors that inspired migration, the highly skilled who migrated to Thessaloniki find it very hard to realize this goal, as Monda related above. Consider too, for example, migrants trained in the arts. In Thessaloniki, this sector is underdeveloped. In Florence, the situation is different, as the arts sector is very developed, but there other segments of the highly skilled labour market are less prominent. In London, there is a distinct polarization between the highly skilled and the low skilled (Kostovicova 2003). However, after regularization was completed, a category in the middle was created of people who own their businesses. The British labour market is also more flexible and more experience-based than in the other two countries, providing opportunities for vocational training and voluntary work that are absent in Greece. The main obstacle to the structural integration of Albanian migrants in London is the lengthy regularization procedure, which is reflected in delayed social integration. Instances of exploitation in the labour market are common, usually expressed in very low wages.

Eliana (Albanian female, 15, London): My parents... it was very hard for them. Cause they had to work at very low, low, low wages, beneath the low wages [that is, minimum wage], cause they didn't know anything. And they had to work extra hard; some were paid $£ 100$ a day and they were paid $£ 25$, cause they didn’t know any better. They still don't know the 
laws, what's right and what's wrong; they know the basics like not stealing and all that, not that they would break the law, but I am saying... They didn't know at the time; they didn't know about human rights. So they were unfairly treated. So they had to work extra hard. And they had the Home Office passports to get.

Among the three sites, Florence appears to be a city with rather particular elements affecting migrants' integration in the labour market and beyond. Firstly, Florence is appreciated by both parents and children as a special place for their integration, due to its left-wing orientation and its reputation as accepting towards immigrants. Florence offers a dynamic and flexible labour market and, therefore, many opportunities for low-skilled migrants in the tourism sector and in the area's industrial enterprises. It is also noted as having more work opportunities for women, such as restaurant jobs in the city centre. The prominence of tourism, however, limits job options in other sectors and restricts opportunities for professional advancement. In general, however, the opportunity structure of Florence is appreciated - both for the economic prosperity it has allowed the first generation and the potential mobility of the second generation. Because of these assets, Florence has been a target for migration within Italy of Albanians who initially settled in the south. Moreover, due to its cultural heritage and international reputation, Florence is an inspiring destination for artists, especially painters. The highly skilled parents interviewed saw Florence as a good location to raise their children, due to its rich cultural capital.

However, Florence is one of the most expensive places in Italy to live, and this creates housing difficulties. Housing problems in Florence were documented long before Italy and Florence became immigrant-receiving areas (King 1987, p. 127). The situation is even more problematic for the Albanian immigrants, since they experience discrimination in the housing market - as immigrants and as Albanians. Long-term immigrants are increasingly buying flats in order to escape the extremely high rents, but also to avoid discrimination.

On the other hand, successful participation in the labour market has changed public opinion towards Albanians in the two Southern European cities under study. This is recognized by the migrants and is attributed to their high participation in the labour market and contribution to the economy. Cases of collaboration and joint ventures between Albanian immigrants and locals are a sign of such participation, which in turn enhances feelings of integration. The arrival of other immigrants and the consequent increase in the multicultural composition of the host countries has reduced the 'visibility' of Albanians as an immigrant group, as was explained by Clara in Florence and by a discussion group of fathers in Thessaloniki.

Clara (female, 41, Florence): In the beginning my brother, who knew very good Italian, would call for a job: 'Hello, I am looking for a job.' 'Where are you from?' This was the first question! 'Look madam, please don't hang up. I am a good person and have a good work experience... 'But where are you from?' 'I am Albanian.' She would hang up immediately! Whereas now things have changed. You go and present yourself and say, 'I am from Albania', and the employer says 'It doesn't matter [where you are from]'. It's sufficient that you have the required qualities [for the job].

Ismail: They [native Greeks] have started to see the Albanian with a different eye, not like they used to see him in the beginning. And this is due to the Albanians themselves.

Neritan: They have changed it [their attitude] because we [Albanians] work a lot! Albanians are the most correct and hard-working people here in Greece. Although they tried very hard 
and with all means 'të na bëjnë rezil' [idiom: to give us a bad a reputation], we showed who we are!

\title{
3.2.2 Social Integration
}

\subsubsection{History of Immigration and Impact on Social Integration}

In general, Albanian migrants have prioritized their economic goals over social integration. As a result, their narratives on social integration are much more limited than those on regularization, family and children's education. Participation in cultural events and organizations and clubs is minimal, apart from a few activities of the immigrant organizations, mainly of a cultural nature. Social integration seems to be negatively affected by a lack of networks and of efforts to create them.

\begin{abstract}
Anila (female, 35, Florence): Can I tell you something? In the fourteen years that I have been living here, I have started this year to go to the cinema because I go with my daughter. Because my husband works every day; on Sunday we are home, what to do first? We have to stay with the children, we have to do the family shopping and this and that... So basically our economic conditions haven't allowed us any kind of entertainment. We do beach holidays in Albania. We are limited in our expenditures for clothing, not to mention brands... We don't have any kind of entertainment.
\end{abstract}

There is a lack of investment in creating relationships with the locals, which is acknowledged as a missed opportunity for networking and integration. Some longterm first-generation migrants acknowledged the negative effect of their initial minimal contacts with locals on their later reluctance to invest time in establishing relationships with them, despite acknowledging the overall change of attitude of the host society towards immigrants, and Albanians in particular.

As a result, belongingness is mostly felt towards the family. Only rarely do migrants refer to wider friendship circles. Contact and interaction with locals is mainly through work. Across the three cities, but especially in London, migrants differentiate between native and Albanian friends. Albanian friends are intimate friends, while native friends are seen more as casual acquaintances with whom they socialize mainly in the public realm. Friendships, especially among mothers, mainly take the form of family visits to homes. Oftentimes the patriarchal attitude of Albanian men towards their wives is an obstacle to the creation of networks and social integration. Albanian men oppose socialization with other families, apart from their kin or very close friends, and they are suspicious of socialization with natives. This attitude spills over to the socialization of children, especially girls.

Flutura (female, 43, London): I try to send her [teenager daughter] everywhere so that she does not remain ignorant of life. But my husband doesn't always agree. You know how Albanian men are! When I used to go to the college to take English classes, he used to get nervous. Now he has started with my daughter; he asks why I have to send her there.

Social integration differs a lot across the three cities. It is more developed in Florence, and least developed in London. One of the main reasons for this 'delay' in 
London is the Albanian population's relatively recent arrival there coupled with the lengthy regularization process that migrants went through. A direct effect of this process has been a disinclination towards learning the language, though isolation and feelings of stagnation have blocked social interactions of Albanian immigrants with both locals and co-nationals. Hence, in the British case, we can speak of a social integration impasse, which persists despite the emerging success regarding integration in the labour market.

Mimoza (female, 39, London): Now we are adjusted to this society, but for five or six years we suffered a lot. We didn't have papers, we weren't allowed to work! It was very bad because I wasn't used to being like that, just staying at home doing nothing. I was used to going to work and having a free life. That's why I think it was not good [migrating to Britain]. But now I am working, my husband is working, the children feel English. That's why we are staying, but we are still not happy with this.

Social integration in London was also affected by the dispersal policy the migrants were subjected to upon arrival, which inevitably affected the establishment of relationships with the locals, although dispersal was in many cases followed by internal migration towards London. Interviewees reported having few friends or acquaintances apart from a limited group of other Albanian families. Because of the absence of chain migration, the number of relatives or kin they have in Britain is also small. There is a general feeling of solitude and isolation because of the lack of the supporting kin structure that the first generation was used to in Albania.

Although most of the interviewees, both parents and children, have now received British citizenship (the 'British', as they call it), some migrants reside on a 'leave to remain' status of a duration of 1-3 years and have to reapply again at the end of this term. A minority were still waiting for the outcome of their refugee application. These 'uncertain diasporans', as Kostovicova (2003, p. 64) calls them, are the most vulnerable group, as they feel isolated and left behind from the rest of the community, those who got the British. In Greece and Italy, Albanian migrants have more relatives because of the chain migration in both countries. Partly for this reason, social networks and, in general, social integration are based on and organized around relatives and co-villagers who migrated to the same country or city at various points in time.

Social integration is also affected by differences in patterns of settlement and spatial segregation. In all three cities, Albanian immigrants are generally rather dispersed. In Florence and Thessaloniki many live in the centre of the city, but some have moved to the suburbs to avoid the high rents in the centre. In Florence, this sometimes follows an initial period of living in the city centre as a newly arrived migrant employed in tourism. Immigrant neighbourhoods are not so typical of the two southern cities, but there are nevertheless spatial divisions on the basis of social class and concentrations of well-off city inhabitants in particular areas. These are areas where Albanians do not live. Interestingly, the narratives from Florence and Thessaloniki portray these cities' working-class suburbs as the 'normal' native neighbourhoods where an immigrant can integrate discreetly. In these areas there is thus a more direct contact with the 'mainstream', which affects the overall course of integration.

In London the situation is somewhat different. Here, too, the Albanian population is dispersed, but over a much wider distance given the vast scale of this city. 
There are some relative concentrations, for instance, in outer East London (e.g., Ilford and Dagenham), but - another difference-Albanians in London also live in a variety of different ethnic contexts, some in predominantly 'white' working-class estates, others in highly mixed, multicultural neighbourhoods.

\subsubsection{Cultural Similarity and Difference}

Perceptions of cultural difference, and of similarity with the culture of the host society, play a role in way Albanian migrants experience social integration. In general, the two Southern European cities offer a contrast with London in the perceptions Albanian migrants have of culture and socialization. But differences are also noticeable between Thessaloniki and Florence, the latter standing more in the middle of a continuum between the 'Southern' culture of a community, centred on family, kin and traditional norms regarding gender, and the 'Northern' European culture based on individuality and equality. An important phenomenon in terms of social integration, especially evident among parents in London, is the 'lagging behind' of the parents. Migration has created a 'social integration delay' since parents became, through their migration, 'disintegrated' from their societies of origin and were unable to socially integrate in the host societies. There is also a difference between the reaction of migrants from rural regions and those from urban areas in regard to relationship with locals. Those from urban areas show a higher predisposition to establish relationships with the locals - both natives and other minorities.

The process of adjustment of the first generation of Albanian migrants in London was marked by culture shock. Once the goal of settlement was achieved, Albanian migrants found themselves in a multicultural environment characterized by a mix of people of different races and ethnicities and, also, by individuality and social phenomena like single-parent families, drugs, gambling, teenage gangs and murders-all of which were unusual in Albania. This prompted parents to concentrate on the family and on the education of their children rather than attempt to establish relationships with people in the areas where they lived. But this is not the whole story. Migrants also appreciated the multicultural environment of London and the presence of people from all over the world, which makes the city less hostile towards foreigners. Feelings of anonymity and comfort thus characterize many migrants' perceptions of these neighbourhoods, and these feelings are enhanced by the lack of marked social stratification in such areas.

Migrants in Thessaloniki, in turn, feel some continuity of their culture and traditions. This is expressed through references to pan-ethnic identities, such as references to the Balkan culture, pointing to the similarities between the Albanian and the Greek way of life. Albanian immigrants in Florence likewise feel an affinity towards the Italian culture - something they felt even before migrating to Italy. As a result, appreciation and adoption of local social and cultural values, followed by a certain strategic mimicry or assertive adaptation (see also Romania 2004) is rather natural for Albanians there. 
Tony (male, 41, Florence): I can't say I learnt so much from the Italians, because as far as I can see we are similar as people, it's not the difference between the Middle East and Italy for example, I think it's the same way of living, of thinking, that's how I see it. I haven't had difficulties getting into the Italian way of living. And I have followed the way of imitating them, not because they know more or are better, but because I live here. So I have learnt to lie a little like they do, to be less faithful like they are, so that I can live with them. I have stopped thinking like a pigheaded [man] and started asking what was said, why it wasn't done that way!... So some harsh traditions we inherited from communism I left behind, and I got what I liked in the Italians, the tolerance... I don't know whether it is because they are Italian or because they haven't lived under dictatorship... but on tolerance they have taught me something.

Other parents, however, point to what, in academic terms, we might refer to as the liminality of Florence as a tourist destination, which makes micro-level interaction and socialization with the locals more difficult. The character of Florence as a tourist destination is not new. In fact, Adamson (1993) describes the same patterns in his study on Florence at the beginning of the twentieth century, with the transformation of Florence into a Mecca for foreigners, to the resentment of the ordinary inhabitants of the city. The same insight is found in the Albanian immigrants' narratives, wherein Florence is seen as 'cold' and 'commercial', in contrast to the values that Albanian migrants appreciated back home, in particular the collectivity of life and lack of social stratification. The appreciation of liminality is a sign of integration itself, related to a feeling of permanence and settlement that migrants increasingly experience, as opposed to the short-term nature of newly arriving migrants and tourists.

\subsubsection{Immigrant and Ethnic Organizations}

The role of ethnic or immigrant organizations across the three sites is diverse, although it differs between countries, while the intensity of their involvement and the variety and type of their activities has also changed over time and differs across various organizations within the same country. Their main function is to bring together the Albanian community based on its distinct features and needs in the respective country. Organizing community gatherings on occasions of national celebration and cultural events with Albanian artists are typical activities. Language classes, in the host-country language for the first generation and in Albanian for the second generation, are a common purpose of such organizations.

While a transnational orientation brings about their formation, these organizations contribute to immigrants' structural and social integration (see also Fauser 2007; Schrover and Vermeulen 2005). This is both through concrete projects tailored and funded for these purposes, but also through provison of a meeting point for the immigrants of both generations where networking and socializing takes place (Fig. 3.1).

In London, for example, mothers prepare Albanian coffee and chat about their everyday problems while children attend a class in Albanian or practise traditional Albanian dance. In Thessaloniki, women decided to meet on 8 March every year 


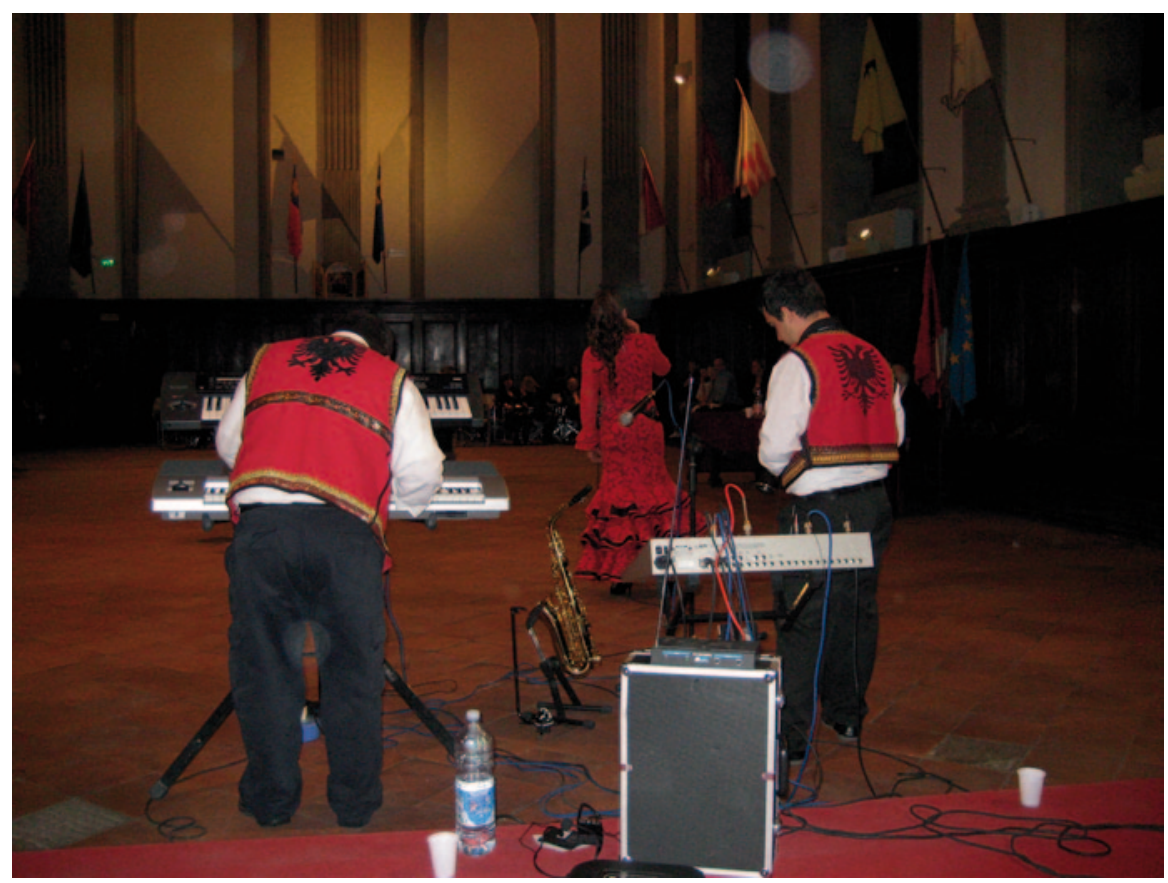

Fig. 3.1 Celebration of the Flag Day by the Albanians in Florence, November 2008

to celebrate Women's Day together, as they used to do in Albania. ${ }^{4}$ In Florence community life is more haphazard although there are many more cultural events with Albania as a theme, stemming from Florence's emphasis on art and history in general. These organizations also establish connections between parents and hostcountry institutions. They can take on the role of mediator between a family and school or social services. This role is especially important in London, where some parents spoke little English and the families had no relatives and social support.

However, the impact of such organizations should be evaluated in relation to the low level of organization of Albanian immigrants across the three sites. Many parents expressed mistrust towards Albanian immigrant organizations and their leaders, some said because of irregularities in these organizations. Competition and lack of cooperation between different Albanian organizations also reduces their impact.

Agron (male, 42, Thessaloniki): Organizations are of no value here, nobody considers them; nobody recognizes them because of the structure they have. They take funding from the EU through various programmes and don't do much.... They are like the political parties in Albania, divided just like the parties there.

Few instances were found of co-ethnics organizing in Thessaloniki and Florence, and there may have been some bias in the findings for London, since recruitment of many interview participants took place through Albanian organizations. Nev-

\footnotetext{
${ }^{4}$ Women's Day is a popular holiday in Albania since the communist regime's times, when it was known as Mother's Day.
} 
ertheless, as Schrover and Vermeulen (2005) observe, the activity and prosperity of immigrant organizations depend on the political opportunity structure and the character of the immigrant community. In line with this argument, the character of organizations in London is more 'ethnic' and those in Thessaloniki are more of an 'immigrant organizations' type. The existence in London of a previously settled Kosovar community, which is more prone towards organization, seems to have played a role in this regard.

Meanwhile, the discourse on multiculturalism has been adopted by Albanian community leaders and activists in London in their efforts to establish a solid community life. This lobbying is perhaps still naïve when compared to the discourse of the old minorities and their lobbying for public resources on the basis of a reified community culture as described by Baumann (1996). Nevertheless, the Albanian diaspora in London imitates the minorities' action and, in the words of Brubaker (2005), sounds rather as a 'stance' or 'claim' of the new Albanian lobby-in-themaking to be counted as one of the many constituent communities of London's multicultural population. A similar attitude is noticed in parents' and children's acknowledgement of the achievements of other minorities, which inspires their integration strategies.

Unlike the 'generous' space, support and funding that Albanian organizations obtain in London, alongside opportunities to affect local authorities' activities, immigrant organizations in Thessaloniki depend on EU funding. In Florence there are hardly any 'functioning' organizations. The Albanian community gets organized mainly on an ad hoc basis and for major national celebrations or spectacles with Albanian artists. Albanian migrants acknowledge the lack of and need for such organizations, as places where they can put in requests and their children can socialize and learn Albanian.

Clara (female, 41, Florence): Albanians in Italy feel like orphans. There is no place where we can go... or you register an injustice done to you or someone else... or even the TV when they say racist things towards Albanians... there is none that can raise its voice for these things!

\subsubsection{Gender}

The integration process has played out differently for men and women, especially in London and Florence. An important differentiating factor has been the histories of immigration and regularization in each host country. In Greece and Italy, men generally migrated first; women followed later. The consequent regularization of women has had an empowering effect on them, which in turn has affected the attitude women assume towards gender relations within the family. The discriminatory gender effect of regularization is especially evident in Thessaloniki where women do not always have independent residence papers due to their work in the domestic sector. They are thus dependent on men. Hence, changes in perceptions of gender and divorce are far less marked, although it should be noted that my sample of 
first-generation migrants in Thessaloniki contains more rural-origin and low-skilled migrants compared to Florence.

The traditional division of gender roles 'inherited' in Albania, and reproduced in Albanian immigrant families, is itself a factor affecting the integration of men and women through the impact of this division on structural integration. The typical roles within the family — man as the breadwinner, woman as the child-bearer - have exposed men and women to different segments of the host society's structure and impacted differently their socialization and social integration. Another factor that has played a role is the 'gendered' qualities of the labour market for migrants. For example, in Greece and to some extent, too, in Italy, the jobs accessible to Albanian migrants are construction for men and domestic work for women. Men working in construction with co-nationals or immigrants from other countries learn little about the culture of the place they live, and they sometimes also lag behind in language learning. Domestic work - cleaning, childcare and care of elderly-gives women more direct contact with Greek and Italian society.

In London, where men and women often migrated together, the gendered encounter with the labour market was patterned in a different way. Men took up employment soon after arrival. In general, migrant men had more than one job, which left them little time to explore opportunities for education or socializing. This worked differently for women, as they stayed home with children or worked part-time, while attending courses in further education colleges and taking classes in English. The consequences of these differences started to appear more clearly once the vital issue of status was resolved. In contrast to the findings of King et al. (2006b), this study found that the migration experience had influenced some women's perceptions of gender roles, lead to tension in families and subsequent divorces.

Mirash (male, 39, London): England has helped Albanians, but it has also damaged them. The Albanian family has been damaged. I know 30-40 cases of people with children divorcing and divorce is becoming a normal phenomenon. The wife says to the husband: 'Fuck off; you've got no chance to touch (beat) me!' Or the husband, father of five, goes to the nightclub!

First-generation Albanian migrants in Florence felt the migration experience had a great impact on their identities and vision of life in general, with men and women referring to different experiences. Mothers in particular point to the possibility to adopt plural roles beyond that of wife and mother. Being able to start a family and bring up children away from kin and shape home life according to their nuclear family's needs, standing up to their husbands and in-laws, interacting with institutions, developing independent work relationships and learning a new working and spending culture are experiences that mothers mentioned as significant. These experiences were built around their own decisions or participation in decision-making in the family. Men, meanwhile, acknowledged changes in their perception of the world, their conceptualization of relationships and interactions in general. They learned more about tolerance and communication, humility and a new way of life, although this division between genders is not always clear-cut.

Nevertheless, the way and degree that integration is experienced in Florence differs significantly between mothers and fathers. Women tend more towards assimi- 
lation. They find the migration experience empowering, by 'finding themselves'. They become more active and accumulate human and social capital independently through their work experience and interaction with locals. Although the educational system in Italy is inflexible and makes it difficult for highly skilled parents to convert their diplomas and get into education, mothers took advantages of opportunities to gain qualifications by taking courses, for example, in inter-cultural mediating and social work. Men have lagged behind women in these major transformations experienced. They have tried to hold on to patriarchal concepts of family and marriage. The conservatism of the fathers, coupled with jealousy and the assumed right to restrict and control the wife and family, have hindered the possibility of other members of the family to interact and integrate with locals and co-ethnics.

\subsubsection{Discrimination}

Discrimination is a sophisticated and developing concept dating back to the 1950s. It is thought to be an element of the organization of social life, with family, ethnic group and state being just a few of the most important social 'units' on which discrimination is based. The concept becomes clearer if we see discrimination as a form of selection, whilst unlawful discrimination relates to specific grounds for unfavourable selection, such as gender, race, ethnicity and religion. Discrimination and inequalities are related in a circular fashion; discrimination causes inequalities, and these, in turn, give rise to discrimination (Banton 1994).

The experience of prejudice and discrimination is one of the most defining features of the Albanian migrants' integration story. Discrimination occurs in various domains and settings. The Albanian language appears to be the main factor of 'visibility' for Albanians, since there are no specific 'racial' or significant cultural differences (see also Colombo et al. 2009a). Media has been a major factor in the emergence and worsening of discrimination, more evident in Greece and Italy than in London. There are many instances in the narratives when parents refer to the negative behaviour of Albanian immigrants in the early 1990s and the role that illegal status and the long waiting time period for regularization had on this behaviour.

However, discrimination is not a uniform phenomenon. Apart from changes over time, the generations also experience discrimination differently. The first-generation migrants are quicker to perceive discrimination against them both as migrants and as Albanians; they narrate in more detail these instances and relate to them directly. As the quote of Lida shows below, some adults accept a certain subordination and stick to their migrant identity while justifying these 'costs' of their migration decision with the prospect of a better life for their family. In other cases, an individualist approach towards identification and the lack of ethnic agency described in Chap. 2, reduces Albanian migrants' sensitivity and reactiveness towards discrimination.

Lida (female, 46, Thessaloniki): There may have happened an injustice, but I have just stepped back, I haven't been aggressive. I haven't shown my real feelings to that person, because we are in a foreign country. This is not our country, we have come here for a better life, a different and more beautiful life, but we can't make the laws here, basically we cannot behave like this is our country. It will never become our country! 
Marios (teacher and community activist, 50, Thessaloniki): For example, there was a football game between Albania and Greece in Tirana and Albania won and so Albanian migrants here were celebrating, and some fascists, nazis and nationalists, with the tolerance of the police, attacked them. Thessaloniki's mayor made some declarations like, 'Well, they have to respect the country that gives them food to eat, they have to keep a low profile and they have to learn that you can only be born Greek; you cannot become a Greek!' But here there are many, many Albanians that respect the way he makes politics! They have told me this is the way that he must do it. They tell me, 'I understand him. If I was him in my country, I would do the same thing.'

There is, however, a difference between the low-skilled and the highly skilled in the way they experience and interpret discrimination. The highly skilled tend to be more analytical, relating their explanations to wider economic and social processes in the host country and to historical factors, national identities, the performance of Albanians as an immigrant group and their personal characteristics and aspirations.

Dora (female, 43, Florence): Whenever I entered a family [as a domestic worker] I would be thinking how I should behave. I didn't know the language and would wonder whether I would be able to present my true self, because I used to suffer this 'Albanians... Albanians...' especially because I couldn't express myself, I didn't know anyone, so I knew it would take time. Because I had noticed that to be an Albanian or a Moroccan meant that you had a [bad] name on your shoulders, you had an extra responsibility.

These long-term migrants recollect and interpret migration experiences and instances of discrimination within an context of multiculturality and inter-ethnic relations, and also a 'new wisdom' gained through migration itself. This is associated with an analysis of the change over time of the positionality of the main actors that led to a different social categorization of them as migrants and Albanians as a group.

Demir (male, 52, Thessaloniki): We Albanians, probably incidentally, have made two revolutions in Greece. The first revolution was the economic revolution.... The second process was the help we gave to soften the racism that was cultivated for hundreds of years by the Church and politics. So basically we Europeanized them! If you would compare the xenophobia of 2008 with that of 1992, the difference is huge. In those years you couldn't speak Albanian because people would pick up the phone and call the police!

In other cases, migrants' empowerment and social mobility are evident in their recognition and deployment of social hierarchies or categories in the host society. In several narratives, Albanian immigrants distinguish themselves from other more recently arrived migrants (and also from internal Italian migrants arriving from Southern Italy). On the other hand, migrants recognize the 'new' discrimination now occurring as more subtle and indirect, experienced as an individual's 'acceptance' by the natives 'as an exception to the rule' rather than referring to the positive performance of the Albanian migrants challenging existing negative stereotypes. Pali's story, below, resonates with the findings of King and Mai (2008, p. 189) from other urban settings in Italy.

Pali (male, 48, Florence): There is a phenomenon that happens... and you are made to feel like you lack something, when someone looks at you in some sort of way and while you are thinking he is being gentle, he says 'what a pity you are Albanian'. You see, when they want to make you a compliment they say to you: 'You don't look like an Albanian!'... This is what people say to you here as a good word, but this is the worst insult, the worst slap [in the face]! 
As hinted at above, reasons for the occurrence of discrimination differ across the three countries. In Greece and Italy, discrimination because of nationality is strong. Since discrimination is based on a racialization of difference, as mentioned in Chap. 1, the Albanian ethnicity is the basis for the occurrence and experience of discrimination. In Greece, a salient ethnicity and a very fragile multiculturalism created in the first generation a feeling of being excluded but also 'disallowed' to belong. As Triandafyllidou (2000) observes, discrimination in Italy is likewise perceived as being caused by a strong national identity based on a magnificent cultural heritage, here related also to the particulars of the city.

As a result, labour market discrimination on the basis of origin is blatant in Greece and Italy. Most of the Albanian migrants interviewed were in low-profile jobs in specific sectors of the economy. As mentioned above, there was a clear typology of men in construction and women in domestic work, though this was most strongly in evidence in Greece. Segregation was automatic based on origin; skills and previous education were not recognized. Occupational mobility is blocked by discrimination; or at least, access to the opportunity structure is significantly reduced as a result of it. Interactions with work colleagues are one setting where discrimination repeatedly manifests itself. Demir (male, 52, Thessaloniki) was asked whether he socializes with his workmates after work:

\begin{abstract}
Yes, I do. But these Greeks have a strong taste for joking. Once we were gathered to have dinner together, when one of the friends of my work boss started to call: 'Hey, donkey!' I didn't answer, but he continued, 'Hey, you donkey?' When he got fed up he said, 'Demir?' 'Yes', I answered. 'What's up?' 'Well, it's a while I am calling you, but you don't answer.' 'I didn't hear you calling me. I heard you calling a donkey and was wondering how come this man knows how to communicate with donkeys. You must have something to do with their kind', I answered, and the whole table exploded in laughter.
\end{abstract}

In Britain the status of refugee and the associated claims on public funds are seen as a major cause of discrimination of Albanians. Discrimination in London seems to be subtle, less verbalized and directed towards Albanian immigrants mainly on the grounds of them being foreigners and asylum-seekers or people on benefits. Professionals, on the other hand, mentioned another source of discrimination: co-ethnics' resentment of their successful integration and increased competition in the labour market.

Mimoza (female, 39, London): In fact, living in London, it's not bad; they are used to a lot of people [from different countries]. But some people... they are jealous, because we go to school, we learn, we are able to find jobs. You know in a way, they don't like us... you can see it in their face; they don't like it. Not that they talk in a bad way, but I can see that they are a bit jealous... first is being a foreigner. And the other: if they see that you have a qualification and are able to find a job, some people may be jealous, 'Why do you come here and get the job?'

Similarly, the discrimination experienced in Florence is described as more subtle. Participants used the term razzismo sottile ${ }^{5}$ as an indirect expression of their subordination as migrants and as Albanians. This is encountered in the public spaces,

\footnotetext{
${ }^{5}$ Italian for 'thin' or subtle racism.
} 
in parks while they try to socialize their children and in celebrations in schools where parents also participate. There are also cases when parents, especially mothers, say that it is also the Albanians themselves who do not make an effort or are sceptical and insecure about their reception by Italians, which in turn blocks their socialization(Fig. 3.2).

Nevertheless, across the three cities, discrimination seems to have changed over time, along with the integration of Albanians in each country. Recently, a more positive representation of migrants is noticeable in the public discourse in the host countries, which has a positive impact on migrants' perception of their integration. In Italy, positive documentaries have been aired on Albania and general political support was offered by the Italian government to Albania in the process of EU integration. In Greece this is less evident, though examples can be found.

Mirjeta (female, 36, Thessaloniki): I must say that recently we haven't heard the TV speaking badly about Albanians. Quite the opposite, there have been two movies on Albanians, and the characters were positive, the actors themselves were Albanians. They were focusing on immigration and the Albanian migrant was portrayed as hard-working, loyal, although a bit high-tempered, like the Albanian is, but in general good.

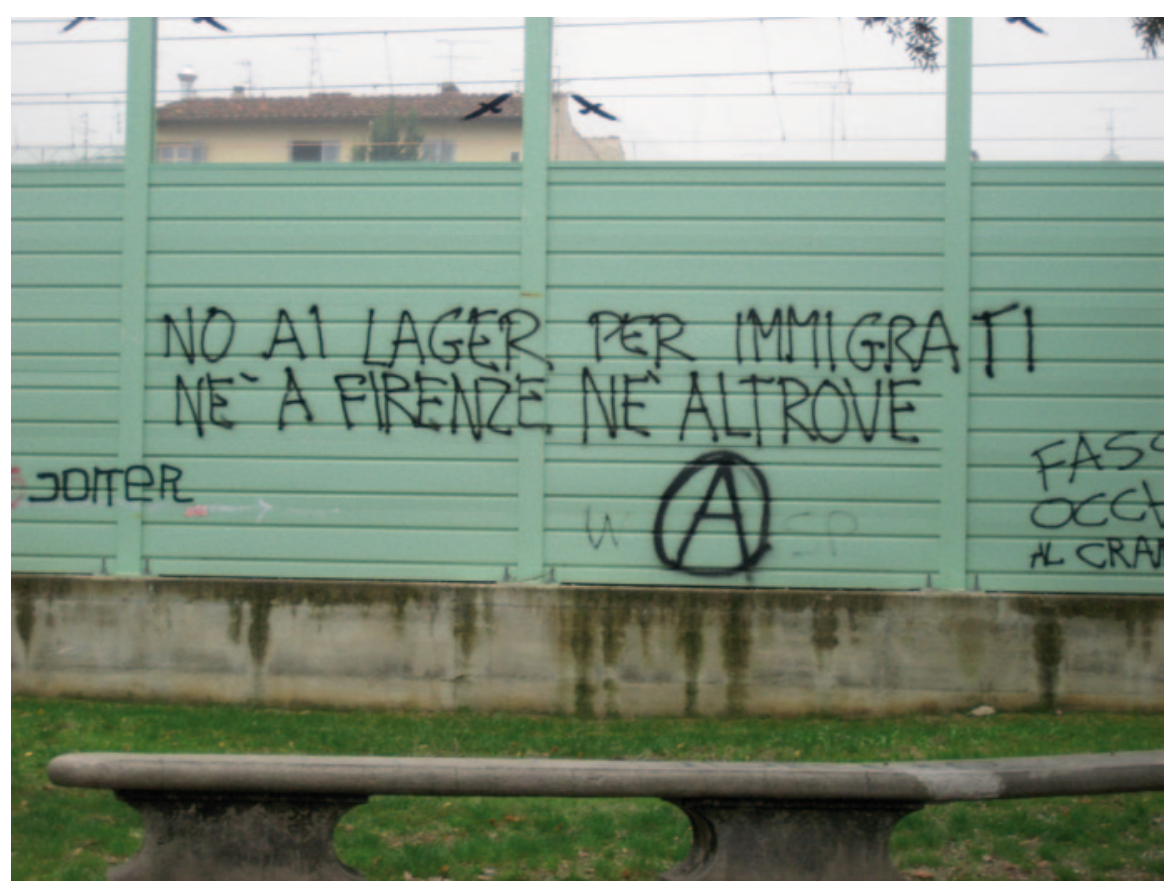

Fig. 3.2 'No to immigrant camps/ghettos, not in Florence nor elsewhere': anarchists' graffiti on wall surrounding secondary school in Campo di Marte, Florence, November 2008 


\subsection{The Second Generation}

\subsubsection{Structural Integration}

\subsubsection{Educational Experience and Performance}

Studies on the second generation have found that educational performance affects the second generation's structural and social integration in schools and their future integration in the labour market (Crul and Vermeulen 2003, 2006). Although it depends on numerous individual factors - such as age at arrival, prior schooling, parents' education and stage of integration, language skills and number of siblings - the migration experience as a whole has impacted their school integration. Integration in schools was especially difficult for children who arrived at school age and had to start a 'new' education without the required language skills.

In general, Albanian-origin teenagers have little support from their parents in terms of help with lessons and education choices. This is due to parents' long working hours, their lack of experience with the educational system in the host country and their lack of proficiency in the language. This is a particular problem among teenagers in London, who on average were older when they migrated. Older siblings or cousins living in the host country are main sources of support with and advice on school studies, given that parents are unable to help. Parents' lack of language proficiency makes it difficult for them to assist children in most subjects, although some are able to help with maths. Regardless of their language skills, parents find it difficult to help children beyond elementary school, because of differences in the educational system and a general lack of specialist knowledge of the host country.

ZV: How do the children do at school?

Donika (female, 45, London): Unfortunately, I couldn't be of much help to the older ones. Sometimes the second son is a little jealous and says, 'How good, mum, that you can help Jessica. When I was doing the same grade you couldn't help me. You couldn't instruct me or buy me books....' I try to explain to him that at that time I didn't know the language and when you don't know the language it is embarrassing to go to the schools and not be able to speak.

In general, Albanian-origin teenagers have performed rather well across the three sites. Most of those participating in this study reported average to high grades, with girls outperforming boys and showing a greater appreciation of education. There were a few cases of teenagers who were top-performing students and serving in school councils and youth campaigns in London. Some were sports and dance champions and winners of international fashion competitions in Florence. One teenager who participated in this study 'carried the flag' in Thessaloniki as the best student in the school. ${ }^{6}$

\footnotetext{
${ }^{6}$ For insights into the significance of these 'flag-carrying' ceremonies see Kapllani and Mai (2005) and Tzanelli (2006).
} 
Teachers are crucial to teenagers' progress in schools. Naturally, experiences are varied. In general, however, relationships with teachers are more positive than those with peers, and fewer instances of discrimination were reported from teachers than from students. For their part, the teachers interviewed reported good experiences with Albanian-origin pupils. The vital role of teachers is illustrated in the following conversation:

Altin (male, 16, London): Teachers are very important. If you have a good teacher, you learn. Um... extra lessons maybe, but we already do that, because now we gonna have a week off for half-term and my teacher says he will be at school during that week, so if anyone wants to come into the school and do extra work, coursework or whatever, he will be there to help. So really, I think that's very good.

$\mathrm{ZV}$ : Are your parents able to help you with the lessons? Have they been helping you before? Altin: To be honest... I mean, they are disadvantaged, they can't speak, read or write English as well as me. So really I don't need their help. They can't really teach me anything I don't know, you know... um... so only teachers really can help me.

However, there are important differences between the three cities in terms of educational system and the provisions that each system makes for the immigrant- and minority-origin students, including the way that diversity is acknowledged in the educational curriculum and by the teachers. Thessaloniki has intercultural schools where children of minority origin go to study, although these schools are open to natives as well. There are also projects that support bilingual teaching assistants to work in schools and help minority-origin students in learning. Florence had three intercultural centres in different areas of the city where trained teachers and bilingual assistants helped students of minority origin to study Italian. ${ }^{7}$ In Britain many schools had an 'ethnic minority achievement unit' with trained teachers. They sometimes hired bilingual teaching assistants, who have been crucial helping children in their initial integration in schools.

Parents and teenagers expressed different views on the quality and reputability of education in the host country. While parents in all host countries had reservations about general attitudes towards education, especially the level of discipline that children were subject to in schools (too lax in all cases!), parents in Greece expressed serious concern about the quality of education. Both the parents and children in Thessaloniki make strong references to frontistiria-private courses on school subjects that run in parallel to the mainstream educational system-as an obstacle to the teenagers' performance at school. The private courses are impacting the quality of education in Greece, as it is almost indispensable for students to sign up for them, while also affecting the attitude of students and teachers towards mainstream education. Immigrant families lack the resources to sponsor parallel learning. In 2006 a family was quoted a price of $€ 2700$ per year for a child to study five subjects in a frontistirios after school. This family decided not to enrol the child there. Since the private courses are especially important to prepare for university entry exams, they have to be factored in as an expense for immigrant families who wish their children to pursue higher education. Parallel private courses are therefore

\footnotetext{
${ }^{7}$ The centres were called Giufà, Ulysse and Gandhi.
} 
a cause of educational inequality between immigrant-origin students and natives. ${ }^{8}$ Moreover, they can be expected to translate into inequalities in the chance of entering higher education and then highly qualified jobs on the labour market.

Anna (female, 16, Thessaloniki): Now that we have frontistiria, we have this idea in our head that 'good that there are frontistiria'... So we go to school, because we have to go to school, not to go there to learn. Basically we have frontistiria so we go to school to spend some time with our friends. We have frontistiria and we have this idea that we will do well, we don't quite need the school.... So basically we go to school uselessly, we don't learn. The teachers also behave like, 'Let's finish with the book because we have to finish it', and that's it. They don't want to go too deeply with the lessons and teach us. They do the lesson because they have to do it.

Another factor that creates disadvantages for the non-native pupils is the design of the educational curriculum. Many teenagers find subjects such as the Ancient Greek language and history and religion in Greece very difficult to grasp, and impossible for their parents to provide help with. More importantly, these subjects are crucial parts of the scientific track of the educational system leading to university studies. This hierarchical Greek system invites an interpretation through the work of Bourdieu (1989, 2004), who considers family support and scholarly culture and curriculum as two main sites of the aesthetic habitus (Fowler 1997, p. 47), where cultural capital is accumulated.

Teachers, too, were perceived as displaying a different attitude towards minorityand immigrant-origin students, again, especially in Greece.

Entela (female, 42, Thessaloniki): The behaviour of the teachers towards our children depends on the culture of the teacher, on his kindness. Some teachers are fair, some discriminate against our children, they exclude them, they don't see them with the same eye. I remember one occasion when my son was attending the gymnasium. The teacher had asked a question and he had raised his hand. 'Although I was raising my hand the teacher would not ask me. In the end I asked him, "Sir, I have been raising my hand all the time, why don't you ask me? I know the answer." "Okay, tell us what you know." And then he turned to the students and said to them, "Aren't you ashamed that an Albanian knows better our history?" I told him, "Sir, it is true that I am Albanian, but I am studying in the Greek school, I am studying the same books!"”

In Florence and London unfair treatment by teachers was experienced as more indirect, mainly as teachers imposing a 'double demand' on immigrant-origin teenagers, picking on them excessively or, conversely, ignoring them and favouring interaction with the 'native' students. However, I also noted a tendency for teachers to be too positive in their comments on the educational and overall performance of Albanian-origin teenagers, displaying a kind of political correctness since the group is stigmatized in the countries under study.

This section on the second generation's educational performance closes with observations by some of the teachers who were interviewed. First, as Jorgos (teacher, 42, Thessaloniki) explains, and very much in line with my own observations during the field work, even when teachers are keen to acknowledge and promote diversity,

\footnotetext{
${ }^{8}$ This inequality can be accentuated by the existence of private or semi-private schools, which are not accessible to immigrant-origin children due to their high cost.
} 
teenagers lack the agency and, at times, the interest in engaging in such initiatives, preferring a low profile in order to secure invisibility.

The immigrants' children themselves avoid opening such discussions [about diversity]. They don't want discussions like these to take place... On my part, many times I tell them in class, because I believe it... that it is a richness that there are kids from different countries, who speak different languages, who have different cultures; it's a resource, because it's like having an orchestra where they play violin, guitar, drums, saxophone, instead of having an orchestra that only plays...violin or only the guitar. But there are no structures within the school that will bring this difference out as an advantage.

The role of teachers in the classroom and their ideological perception of diversity often reflected the general ideas on diversity in the country: ethnocentricity in Thessaloniki, a more local identity in Florence, and multiculturalism constructed around large groups of old-established minorities in London. There were also differences related to the number of Albanian-origin students in schools: schools in Thessaloniki and Florence had large numbers of Albanian-origin students, but they kept a low profile and did not counteract discrimination; the very small groups of students in London schools were almost invisible among the highly diverse minority-origin student body there. Some of the teachers' narratives point out implications of the centrality of ethnicity in the host country and the group positioning with respect to the native mainstream and other minorities for the integration of the minority-origin students in schools. Paolo gives a rather extreme view of the 'superiority' of Italian and Florentine culture, whilst John, in London, articulates the ease of overlooking the situation of Albanian pupils in his school.

\footnotetext{
ZV: Are there discussions in the class about diversity?

Paolo (teacher, 57, Florence): Yes, there are. For example, I am personally Euro-centric, so I think that the Western culture is superior... So basically I don't think that all cultures are the same... like American anthropology claims. I insist on the classic culture, on the terms of civilization, of political freedom, of equality between individuals... I think that the Renaissance is the basis of global civilization. The students are in Florence, so I try to teach them the Renaissance [smiles]. I am sorry, but this is how I see it.

John (teacher, 44, London): We used to have two Albanian community workers and they were fantastic people. But now we find that we have less need of somebody with that particular community connection, and we cannot afford as a school to hire a community worker for every small group of students, which is a shame. Do we have Albanian celebrations? No. We've had international evenings in the past where we've encouraged families to come in and do things, but we haven't had that much of a focus on the Albanians.

ZV: Why would that be?

John: Partly I think because there aren't as many Albanians as, say, the Turkish and the Indians. They don't seem to also... there aren't... there don't seem to be any really wellknown festivals that are associated with the Albanians and that's because... before... you couldn't get into Albania. It was very much a closed country under what's his name? [ZV: Enver Hoxha] Yeah, it was very, very strange. Okay, there aren't a lot of people that know very much about Albania. Even now, when things have opened up a lot more, it's still not a country that a lot of people know about. If I say to friends outside teaching, for example, 'Where is Albania?' They would say 'Well...?'
}

While there is a striking contrast between the views expressed by the teachers above, it is worth mentioning that the differences between the three countries in their immigration and multicultural policies - and the 'political correctness' that 
characterizes the British educational system and prevents the expression of racist views - were sometimes mentioned by the teenagers themselves.

\subsubsection{Future Employment Plans and Transition to the Labour Market}

Both girls and boys across the three cities placed emphasis on securing good jobs that would bring them financial security. Living up to their parents' expectations and making their parents proud drives teenagers in their pursuit of educational success.

An interesting phenomenon is teenagers' choice or preference for what might be regarded country-specific professions, such as Formula One driver or fashion designer in Florence, positions in the corporate banking and legal services in Britain, and doctor or teacher in Greece. Of course, such jobs were not mentioned by all respondents, but they were sufficiently typical to create a place-distinctiveness. There were also many cases of boys and girls preferring gender-typical jobs, such as mechanic and plumber for the boys and hairdresser and secretary for the girls. Often, high ambitions for specialized and lucrative jobs have to be sacrificed for more pragmatic choices.

Many Albanian-origin teenagers attended technical and professional institutes or vocational training, which were seen as routes to earlier and 'safer' employment, and some boys studied construction in these institutes so they could work in their father's construction firm. This reflects the growth of private enterprises of Albanian immigrants, especially in Florence and Thessaloniki. A few of the teenagers interviewed expressed contempt at the 'normal' jobs associated with immigrant status (e.g., labourer, domestic cleaner).

There were, however, differences in teenagers' expectations in terms of their future chances in the labour market. Youngsters in London expected fair treatment in employment and a career in accordance to their educational performance. This is in line with the general expectation that a good education translates into good chances of employment and earnings. In the other two cities the situation was different, due to the economic problems faced by Greece (especially) and Italy. In general, there was an emphasis on 'high-return' professions, such as lawyer, working in a bank and having one's own business. Linguistic assimilation is considered an important factor for advancement in the labour market in all three countries. The two interview segments below are typical responses to questions about careers in the London setting.

$\mathrm{ZV}$ : In the future you said that you want to become a dentist, so you definitely want to go to university.

Darina (female, 13, London): Yes, definitely, without a doubt... because I like to know that I am secure... I like to do things for myself, so that I can be someone in life, not just like any person; I wanna be somebody, yes. So to work for myself, and make my parents proud of me.

$\mathrm{ZV}$ : Do you want to go to university?

Era (female, 14, London): Yeah, definitely, because I want to have a good career. I don't want to end up having a normal average plain job, cause England is just becoming more and 
more expensive and you will need a good job to have a good life. You can't be anything like a cleaner to live properly [laughs]. You gonna need a good education.

In contrast to London, teenagers in Thessaloniki and Florence anticipate discrimination in the labour market, in addition to the difficulties they expect to experience when trying to access higher education. Transition to the labour market for the second generation in Italy is expected to be facilitated by the acquisition of citizenship, but most of my respondents had not yet reached that stage. Setting the issue of citizenship aside, we have already noted how, especially in Greece, but also to some extent in Italy, the structure of the secondary education system creates inequalities in terms of access to higher education, which are then perpetuated in career pathways. Furthermore, at both Southern sites, parents mentioned nepotism and corruption in the host society as a phenomenon which would make the advancement of immigrant-origin people even more difficult, due to their lack of networks. This is one of the reasons why many second-generation Albanians at the two Southern sites were contemplating future migration towards North-Western Europe. By contrast, in Britain, parents and children were optimistic about the possibilities offered by the educational system and the flexible labour market.

Nevertheless, wider international research on the second generation and their transition to the labour market has increasingly reported unequal treatment and job status incompatible with educational performance, the former being lower than expected (Fibbi et al. 2007). Heath and Cheung (2007) propose three explanations for differences in the progress of minority-origin people in the labour market. The first is the dominant conception of nationhood, which usually varies between ethnic and civic. The second is patterns of social reproduction, such as rigid class structures versus meritocracy. The third explanation is economic structures and conditions, such as the presence of a deregulated market economy. Since these factors are different across the three sites, it remains to be seen what the future of the Albanian second generation will be in terms of labour market integration, when they come of age.

\subsubsection{Attitudes Towards Citizenship}

Attitudes towards acquisition of host country citizenship by Albanian-origin teenagers can be grouped into several categories. Firstly, citizenship is widely cited as a source of better opportunities. These include freedom of movement and integration in the labour market in the host country and elsewhere in Europe. In Florence and Thessaloniki, many teenagers saw citizenship in instrumental terms, as a means to facilitate future migration. Yet many teenagers saw citizenship more broadly, as acknowledging their legal and civic obligations towards the host country, where they would stay. A second category is represented by teenagers who felt citizenship would give them full right to identify as British, Greek or Italian and to ultimately justify their feelings of belongingness to the host country. For them, citizenship represented a deeper connection, instrumental to erase any recognizable difference, especially in relation to institutions. 
Ilda (female, 14, London): If I didn't have my passport, people would call you an immigrant. They would make fun of you at school. They would find out somehow, and I would feel really... left out. I really wanted my passport; so... I couldn't wait until I got it.

ZV: Do you want to get Greek citizenship?

Anna (female, 16, Thessaloniki): I do, because it would be easier for me. So basically, I will have the qualifications for a job. If they see Albanian passport... citizenship, they will take a bit more reserved attitude, they will be more distanced. We say there isn't racism, however there is; we all are a bit racist, in all things. But if you are Greek, they see you differently... To me it would mean simply a paper. It is just a paper, it is not anything else; it doesn't change anything else; because I have the Greek culture, the Greek manners, I have taken them essentially because it is here that I grew up.

$\mathrm{ZV}$ : What does it mean to you being a British citizen?

Altin (male, 16, London): To me, all it means is that I won't get kicked out of Britain, I can go travel all around the world, because a British passport is very... has got a high status, you know.

There is also a claim on the part of teenagers to have the 'new' citizenship as the institutional recognition of their assimilation, as shown by research conducted in Italy (Colombo et al. 2009b; Riccio and Russo 2011). The Albanian second generation is quite vocal in its claim for Italian citizenship, although this is less evident in the public realm, especially compared to other second-generation groups in Italy. ${ }^{9}$

\begin{abstract}
ZV: What would it mean to you having Italian citizenship?
Aulona (female, 24, second generation, Florence): It's just about papers, because I have already integrated both cultures... both the Albanian and the Italian. I wouldn't feel any difference really; I feel Italian and also Albanian. But citizenship would help me in terms of bureaucracies, more than in terms of personal affairs.
\end{abstract}

Similarly, teenagers in Greece saw Greek citizenship as a source of rights (free movement, less need to pay money for red tape), but to them it also has a more symbolic meaning: an acknowledgement of them being part of Greek society, which they are constantly reminded they are not. Experiences of harassment because of their Albanian citizenship inevitably create resentment.

\begin{abstract}
ZV: Why do want to apply for the Greek citizenship?
Genti (male, 18, Thessaloniki): So that I am free! So that I don't pay all this money and that I can go everywhere I like! I want to go to Albania, just go, not to wait until the order is released by the police. So that I can go to England, to... wherever. We are like slaves! It's not only the freedom, but also all these years that I have been here. You are the same as the others, why should you be singled out by the others? Why? Because it has happened when I have been with a group of friends, two Albanians and three Greeks walking down the road and the police stopped us 'What are you doing here? Show us your ID.' The Greeks show their ID and then us the Albanians, and they say 'You three go home; the Albanians come with us!' Why should I feel this? It's such a bad thing! ${ }^{10}$
\end{abstract}

\footnotetext{
${ }^{9}$ Rete G2-The Network of the Second Generations in Italy (www.secondegenerazioni.it) - has few posts from the Albanian second generation, although they are the largest second generation group in Italy. The cover photo on the webpage on 11 January 2013 portrayed a second generation lady with the caption 'Dateci 'sta cittadinanza e datecela subito!' [Give us this citizenship and give it to us immediately!]'

${ }^{10}$ An important development in attitudes towards citizenship was the change of the Citizenship Law in Greece in 2010. According to Law 3284/2004 Greek Nationality Code citizenship in Greece could be acquired by declaration. This gave the possibility to many Albanian-origin chil-
} 
Citizenship is thus important in relation to experiences of discrimination and also in terms of social mobility, hence its direct association with experiences in education and labour market integration. Citizenship, however, is predominantly mentioned as a 'ticket' to the experience of mobility. This is not only associated with the family-related experiences across the Greek-Albanian border, but also mobility experiences and aspirations of cosmopolitanism, extending their world to European countries and beyond.

\subsubsection{References to the City and Locality}

Cities are becoming increasingly prominent in the literature on the incorporation of foreign immigrants (Brettell 2000), although studies on cities and the second generation remain rare. Their earlier relative omission is related to an assumption that has long framed migration studies, namely that nation-states are homogeneous entities. As a result, data taken from research in cities have been considered as representing the situation in the whole nation-state (Glick Schiller and Çağlar 2009, p. 183).

Structural approaches dominate studies of immigrants' incorporation in cities, with research mainly directed at ethnicity, policy agendas and immigrant groups' characteristics. Cadge et al. (2009, p. 3) attempts to bring culture into the study of the city as a context, noting that the economic characteristics of localities have been given far more importance than their cultural resources. These authors find that the way incorporation is conceptualized and advocated among officials and stakeholders in a city is related to variations in the way cities create and deploy their "culture armature'. However, they did not study this role of the city from the perspective of the immigrants. The current study points to a difference between the two generations in the way they refer to the city and locality. Parents evaluate the city in terms of the perceived success of their migration project. The second generation is more engaged in discourses on 'city identity' and culture, and also makes reference to localities within the city. Therefore, the generations differ in their understandings of space and their appreciation of cosmopolitanism (Szerszynski and Urry 2006).

The cosmopolitan orientation and practices found in this study among the first generation are in line with the very limited existing research available on non-elite cosmopolitanism (Kothari 2008; Werbner 1999). Particularly evident in Florence, cosmopolitanism is referred to and symbolically used by the natives and the migrants for different purposes: by the natives to enforce the boundaries and by the migrants to include themselves. Due to its boundedness to locality and the significance of this space for the local identity and the nation-state, this reference to and symbolic use of cosmopolitanism by the Albanian migrants in Florence is 'safe' and does not conflict with the expected loyalty towards them as 'national outsiders' (Kofman 2005, p. 87).

dren whose parents had resided lawfully in Greece for a number of years to gain Greek citizenship. This law was suspended in early 2013 in order to make the requirements tighter for the applicants. 
The time factor and stage of incorporation may also pay a role in this respect. My findings show that aesthetics and cultural capital are important to the long-term immigrants. Kosic and Triandafyllidou (2003) — in one of the very few studies of Albanians in this kind of context-examine coping strategies and identities among Albanian immigrants in Florence. Interestingly, they found no reference to that city's particularities in their respondents' narratives. Sometimes parents' narratives of belongingness and culture noted the cultural distinctiveness of their towns of origin in Albania, showing a 'translocal' appreciation of urban culture (Brickell and Datta 2011). As Farije explains below, the distinct identity of these urban centres is seen as a core element of the Albanian culture.

Farije (female, 45, Florence): In our culture we had well-known towns, like Përmet and

Korça... Towns that would be in the same line and standard with the European or global culture. And then we from the south [of Albania] had a tradition of emigration, so we were more cultured, in the way of working, dressing... We had that, we were more advanced than the others.

The significance of the local urban setting is particularly evident among migrants in Florence. Their tendency towards assimilation is enhanced by the city's special status within Italy. This is reflected in the eagerness of Albanian immigrants - both first and second generation - to embrace the distinctive local and regional identities, to aspire to be un fiorentino propio, a 'real Florentine'. Parents and children mentioned identifying with Florence and Florentine identity and culture, seeing it as a reputable culture and a famous and distinct location and accent in Italy.

Florence is also appreciated for its cosmopolitan atmosphere, which creates opportunities for acquiring new skills, such as learning foreign languages, but also offers immigrants an 'experience of the world'. Its great reputation fosters an emotional belonging and ease of calling it home. The qualities of its space and its beauty intensify these feelings of belongingness. Furthermore, although the cosmopolitan second generation still finds Florence too small, it nevertheless stimulates an interest in history and art and an eagerness to become more cultured.

However, the lack of Italian citizenship diminishes perceptions of incorporation, leading immigrants to feel excluded from the 'right to the city' as a political space (Lefebvre 1996, pp. 147-159). The right to the city is also diminished by personal experiences of discrimination. Discrimination is perceived differently depending on the level of interaction and the type of relationship attempted with the locals. Certain spaces in the city centre are viewed as closed to immigrants. Indeed, some are characterized by brutality and harshness, like the questura (police office where sojourn permits are issued) and the regularization process (Triandafyllidou 2003), though these have little to do with universal cultural values.

In contrast to perceptions of Florence, parents and teenagers in London relate more to the borough and its composition and character. Albanians in London also referred more to the ethnic composition and the different social conditions in different areas in London. Parents experienced London's 'super-diversity' (Vertovec 2007) as 'estranging', and both the first and the second generation mentioned unsafe living conditions as a barrier to social integration. 
Donika (female, 45, London): In the beginning when we came here, this [Barking] was a very bad neighbourhood. If you saw a police car driving at high speed, surely it was headed towards our neighbourhood [smiles]. This last two to three years has changed a lot. However, it is still full of black people, Polish and Albanians. We see policemen around when they arrest people and stuff them in the police cars just like pigs. But now we are used to having policemen around; we even greet them [smiles].

$\mathrm{ZV}$ : And why did you say that Plumstead is not really a great place?

Era (female, 14, London): because I consider it boring, compared to the bigger areas like London, being in London you wouldn't compare it to Plumstead, it's small. It's really... like, here in the road there is only chicken and chips shops and Chinese shops. It is not a good place, it's not posh... I don't know, it's not rich.

References to the city and locality are much less common in the case of Thessaloniki, although acknowledgments of it as a big urban space with possibilities of entertainment for young people do occur.

Endri (male, 18, Thessaloniki): [I am] from Thessaloniki. I think... um, Thessaloniki has a life, you can go out, you can do many things; you can play... enjoy nightlife. [I belong] to Thessaloniki... it is here I am used to now, I don't know Albania... it is here I grew up, here is where my friends are... I feel better here than in Albania.

City and locality can also have more nuanced meanings for the second generation and parents who originate from rural areas in Albania, which is especially the case of the subsample of the participants in Thessaloniki.

Fran (male, 49, Thessaloniki): For example, when I was young I only rarely went to the city, but now I have become an inhabitant of Thessaloniki! Whereas my son has no problem here; he can return home at 10 PM after he finishes football training.

Fran notes the difference between him and his son in perception of space, because of his own origin from a remote village in Albania. Many teenagers mentioned their adaptation to urban life. This disjuncture between the two generations in terms of 'spatial cognition' is one of the most striking intergenerational discontinuities, which will be further discussed in Chap. 5 .

\subsubsection{Socialization and Integration}

\subsubsection{Social Integration in Schools}

School is obviously a key institution for the socialization of minors, and this is particularly so for children of immigrant origin, since for them socialization outside of school may be difficult.

Aldo (male, 15, Thessaloniki): At school you learn many things, you spend some good hours and you learn interesting things, especially me who is not Greek... It is better for me, who hasn't been born here, that I go to school and learn the language and learn Greek history. I believe that without school there would be no life for Albanian children in Greece!

Shared values in terms of education are one important criterion for socialization in school. Older siblings, and in general those who accept their immigrant origin, 
often take educational excellence as a criterion in choosing their friends. Because of ethical considerations it was impossible to interview teenagers who had quit school and had a bad relationship with their family. However, the narratives of those interviewed do reveal that there is a segment of Albanian-origin teenagers in all of the three cities who had performed poorly in education and were subject to disciplinary measures from schools. Some of them had also had problems with the police. Substance abuse, participation in gangs and non-amicable breaks with home are some of the phenomena in London. In Greece and Italy there was a problem of Albanian-origin boys creating their own groups and bullying other students as part of a reactive identification.

Social exclusion and discrimination by peers are common at school. Sometimes educational success is a cause of jealousy from the native children, which can result in physical harassment.

Maria (female, 12, Thessaloniki): One day we were playing volleyball. One of the children put his hands together like this and hit me on my head, so not with the ball but with his hands, like this. 'This is because you are good in English', he said.

There is a difference, however, in the degree to which children of various origins make friendships with each other. This is especially so because the composition of schools and the presence of minorities is significantly different between London and the other two cities. In London it is common for Albanian-origin teenagers to have few co-ethnics in the same schools, since the Albanian community is geographically dispersed.

$\mathrm{ZV}$ : What is the atmosphere like at school?

Darina (female, 13, London): We are four girls that stay together: it's me, the other is Somalian, one is English and the other is South American; so we are all different cultures [in English]... sometimes when I see those of African origin or the English that stay together as a group, sometimes I feel, like, empty inside because I say 'How bad I don't have one Albanian here', but anyway... But I do have Albanian friends outside of school.

ZV: Do children of different origins make friends with each other?

Maria (female, 12, Thessaloniki): In most of the cases they don't. They mostly make friends with those from their own country. When some new child comes who is from another country, like from Albania, other children who are from Greece don't behave well with him. They laugh at him... Towards those from the developed countries, let's say if someone is German, in that case there isn't racism. There are Germans at school; there aren't English, but if there were, there wouldn't be racism towards them. There are Germans and no one says anything, actually they are the best-liked. This happens only with children from countries that don't have good economic conditions, I think.

Angelo (male, 17, Florence): In my case, having come here at the age of two... they have always considered me an Italian, understand? Not a foreigner; I have never had such problems. But if someone comes... it depends how he behaves. If he is a normal person among the others then there won't be any problems. If instead he starts fussing a bit, the others start 'thinking' about it, understand?

Children who arrived at school age and had to start education without language skills were often a target of bullying. Despite being 'white' they were 'visible' because of a different way of dressing and looking, which are very important factors in socialization and 'acceptance' of teenagers in schools. 
ZV: I would like to know something about your school experience.

Eliana (female, 15, London): Now it's fine, I like it. And they won't know that I am Albanian at school and they don't mind that now. And I have lots of black friends and stuff in school.... In the beginning, because I was new and I didn't know English... And it came to the stage that I had to move school, because the students there were so horrible. because I was new and I had short hair as well and I didn't look like the others and they would sort of treat me differently; treat me like 'woooo'. I got to the stage when I was really upset with that school, so I moved to a different school. And in that [new] school there were Albanians as well, so I could communicate and I had a translator. So that school was better, so I stayed in that school... and they treated me the same.

Racist discrimination and exclusion are sensitive issues in the British educational system, and teenagers there are more aware of their right to react. Those in Thessaloniki are more submissive and see their silence at times as the cost of future acceptance by their peers. In London, teenagers recognize the importance of the mixed ethnic composition of schools for their 'smooth' integration. The majority of the children interviewed reported making friends easily with other minority-origin children due to the affinity they felt due to their immigrant origin, but also in terms of cultural particularities, such as parents' strict discipline and pressure for educational achievement. They said that the other minority-origin students were easier to socialize with and made them feel more welcome.

$\mathrm{ZV}$ : Has your origin been a source of problems at school?

Altin (male, 16, London): No, my friends... we all joke about, because all my friends we are different, one black, one mixed-race, one Asian, you know... we are mixed as a group.... Can I mention them? Khan is Asian, Bob is mixed race, King is black; we are all mixed, but we all stay together. There are other groups that stay with themselves, but they don't start trouble with anyone else.... So we all mess about, have jokes with each other: 'Oh, you are Albanian; you are Bangladeshi, you know, whatever... African...', but we only joke about it. I have never gotten into a fight over racism in school.

In contrast to the 'openness' of inter-racial friendships in London, the situation in Florence is more nuanced, while in Greece harassment and exclusion from peers at school is blatant and widespread. One interesting trend is the attitude of Albanianorigin teenagers towards students of the same origin, especially new immigrantorigin children in schools. Teenagers who had experienced assimilation and hidden their Albanian origin tended to exclude such children and stick to their native peers and their own assimilated peer group:

[E]ven the kids, I don't know, they very easily look down on the others. They're very proud if they're good, they're good students, you know, A-grade students. They're very proud if a Greek child asks them to come to their birthday party or something, because you know parents, 'Ah, she's Albanian, but she's a good girl; she's the best student in the class', she finds it flattering and she goes there and she looks down on the others [of same ethnicity] very, very easily.

There are, however, cases in all three cities whereby the settled second-generation teenagers become the main support to and best friends with the newly arrived children, whom they help in learning the language, in schoolwork and in integrate them into their peer group. This occurs both towards Albanian-origin children and towards children coming from other countries. 
Blerim (male, 13, Thessaloniki): When I was in the first and second year... that's what I remember on every occasion... when someone came from Ukraine, they all started laughing at him and insulting him. And I told them, 'Stop it! That's what you did to me and I don't want this to happen to anyone anymore!' And they let him alone, and allowed him to make friends with us... I don't let them offend others anymore... But they didn't know what they were doing those times!

\subsubsection{The Role of the Peer Group}

One of the core arguments of this book is that literature on integration of the second generation has been overly concerned with the role of ethnicity and overlooked processes of socialization and the role of friendships and peer group. Very few studies have included the role of the peer group. One of these (Wessendorf 2007a), found that friendships are considered very important by the second generation, impacting their lives on various levels, ranging from daily experiences to generalized feelings of belongingness in the host or home country.

In all three cities studied here, the social life of the teenagers is limited due to the financial constraints that immigrant families face. Therefore, socialization with native peers outside of school is obstructed by different standards of living and modes of social activity. In general, the presence of the extended family and cousins of the same age in the host country makes up for the lack of peer-group friends.

However, socialization and having a strong peer group are often powerful means of feeling integrated. The composition of the peer group also conditions feelings of identification. The importance of the peer group is usually paramount compared to the abstraction of ethnic identity. As a result, teenagers who identify with the culture and identity of the host country and consider themselves integrated look for and in general have native or well-integrated Albanian-origin friends.

On the other hand, teenagers recognize socialization as being dependent on personality. Being 'cool', that is, being socially skilled and successful in age-related activities, can overcome the barriers to socialization based on ethnicity. There is also a growing 'wisdom' among the teenagers, who see that attitudes among natives towards immigrant-origin people vary and that hiding their identity is not necessarily the best way to integrate.

Maria (female, 12, Thessaloniki): A child that comes from Albania to Greece makes friendships only if he is good at sport... He has to be good at sport, have many friends, know the language and be good-looking.... This is enough.

Erjol (male, 17, Florence): I know many Albanians that say Italy sucks, after having been here for many years. They say they want to go back to Albania. No, Italy doesn't suck, it depends if you know how to integrate or not. That's it. It depends on the type of the person, it depends on your networks, it depends on how one speaks to people. And on how one is ready to integrate.

Patterns of socialization and peer-group composition are also affected by the attitude of the parents. In general, parents encourage socialization with natives because it is seen as a source of social capital for the children or a way to make up for the lack of social capital transmitted from the parents. Albanian parents' attitudes in this 
respect are in sharp contrast with those found for other immigrant groups (see, e.g., Panagakos 2003 on Greeks in Canada). By the same token, parents sometimes resist socialization with peers from the same ethnic group. Some parents worry about male solidarity and gang behaviour among Albanian-origin teenagers. In London, many parents were worried about their children associating with black peers, because of the latter's perceived link to gangs and violence.

Donika (female, 45, London): When we came here, my husband... he used to say to our oldest son, 'You shouldn't stay with the blacks, neither with the Kosovans, nor with the Albanians.' I used to argue with my husband, and say that maybe our son should choose his friends himself.

The main difference between the three field-work sites in terms of socialization and the role of peers is the accessibility of the native-origin peers. In Greece, Albanianorigin teenagers repeatedly spoke of the difficulty of socializing with Greek peers, not only because of the prejudice of the native teenagers towards those of immigrant origin but also because of strong opposition to these kinds of friendship by the Greek parents. There is also a parallel tendency to distance from Albanian-origin peers because of the strong stigmatization associated with Albanian immigrants. With the passing of time, Albanian-origin teenagers in Greece are cognizant of a change of the attitude of the host society towards immigrants and towards them. They appear to be politically aware of this change and the impact it has on their positioning in the Greek society.

In London, Albanian-origin teenagers had friends of various nationalities. Indeed, other minority-origin teenagers were often their best friends. They explained these friendships as based on a shared understanding of the strictness and discipline expected by their parents. Many of the teenage girls I interviewed in London told me that they were cut off from after-school clubs and activities, school trips, birthday parties and other activities that were not strictly related to the educational curriculum. A few reported not having any friends, apart from a few relatives and cousins of a similar age.
ZV: Do you have a life outside of school, friends, do you go out?
Ilda (female, 14, London): Most of my time is spent in school; when I come home I do my homework, I watch TV, I eat, I go to sleep.... I can't really go out. I am not really allowed. My mum, she doesn't like me going out everywhere; you know how places are sometimes. But I don't want to go either, I don't know, there is nowhere for you to go. I have got my aunties here, my mum's brother is here, and I have got cousins here... like two of my cous- ins are here, yeah so... I don't really think I need anyone else but my family.

London's complex social geography and spatial-ethnic segregation (and mixing), plus the striking social stratifications experienced there, expose the Albanian-origin teenagers to people from deprived and underprivileged backgrounds, which are resented by the parents.

Flutura (female, 43, London): The oldest son used to go out to the park and it was hard to bring him back home. He goes out with English boys every Friday. I am actually a bit annoyed because of this; you know, English people here are bërrnut [rubbish]; poor, with divorced parents... Worse than us! 
The culture of teenage gangs and drugs in 'rough' areas of London has already caused serious issues with teenagers' social integration and education. Some teenagers mentioned how the lack of goal-oriented peers has impacted their own motivation. This experience, especially problematic in the case of boys, shows the impact of segregation in immigrant and working-class areas and the effects of peer pressure in diminishing the motivation of immigrant-origin students to aim for social mobility, as common in the US literature on the downward mobility of some groups in the second generation (Zhou 1997a). In the final two quotes in this section we hear from a father and a teenage girl about the challenges of friendship and peer pressure in the 'difficult' environment of inner-suburban London.

Fatmir (male, 41, London): My oldest son is now in college and works at the same time. In the second and third year of high school he was rewarded as the best student with a gold medal. But the next year he made very bad friends and completely lost interest in school. In one year! Most of those guys were black, because 90 per cent of the students in that school are black. I don't mind that, my own friends are black. Luckily I noticed in time because here it is very easy for the children to end up in trouble. One of his friends was killed two months ago.

Eliana (female, 15, London): It is just the way England is. The environment here is closed... Not everyone welcomes you, especially in this area. It's hard to live. because if you are different, then it is going to cost you a lot to be different or to even have the guts to try and do something different here, it is difficult... Because there are teenagers with their weed and their crack here which is... and they will try to put you into stuff that you don't want to do. Especially now that like people are at school, girls are at school, smoking, drinking. I don't want to get involved in that. It is easy to get involved in it. It is harder to not get into.... If you say no, they will get angry with you.... You never know what people here will do!

\subsubsection{Immigrant and Ethnic Organizations}

In general, Albanian-origin teenagers' degree of participation in immigrant and ethnic organizations is related to parents' attitude towards such organizations. Ethnic organizations are approached by the parents when they want their children to learn Albanian, which in turn improves parents' networks and children's social life. Independent initiatives by teenagers are lacking. Indeed, many interviewees did not know of the existence of Albanian organizations in the city. Nevertheless, where participation does occur, it affects teenagers' identification and integration in various ways. As illustrated by the narrative below, it helps to foster a distinct Albanian identity enriched with the learning of languages and traditional Albanian dance. ${ }^{11}$

ZV: Why do you come to the Albanian classes?

Darina (female, 13, London): I just like the idea that something... is done. Because Indians and Africans, they have their own thing, so I said to myself 'I should go, too and see...' I am also keen to learn; I would like to learn better.

\footnotetext{
${ }^{11}$ Representatives at the conference 'The promotion of the collaboration between Albanian diaspora in the UK and the central and local authorities for local development' organized in London, 10 June 2011, mentioned that only about $1 \%$ of the Albanian-origin children go to Albanian weekend classes.
} 
Eliana (female, 15, London): I go to Albanian classes because I learn something new. I meet new people, a different place to be. It's just a different thing to do and I like it. And dance obviously.

Ethnic organizations can also help in countering discrimination. In turn, the activities of such organizations make up for a lack of socialization of the teenagers, constrained by the conservative attitude of Albanian parents towards their children and their fear of problems of youth and crime in London. Albanian weekend classes meant a lot to some of the teenage girls, like Darina and Eliana above. The social aspect of such activities appears as important as the symbolic attachment to Albanian language and identity that they confirm in their narratives. Moreover, these organizations provide a way of practising elementary organizational and entrepreneurial skills and may be a starting point for some of the children in terms of artistic activities.

\subsubsection{Discrimination}

In all three field sites, the teenagers interviewed experienced the burden of a 'stigmatized ethnicity'. Although to a varying and declining extent, the Albanian identity is still articulated in negative terms in the media and in the public discourse. 'Albanian' has become the personification of an inferior status, and the Albanian culture is considered as bearing primitive, uninteresting and ugly features. This is why the teenagers dreaded recognition of their ethnic identity, since negative labelling has caused a contraction of their ethnic status and agency. Although the 'antiAlbanian' discourse is most entrenched in Greece and Italy, it has also appeared in the UK, and has been picked up by children in school.

Darina (female, 13, London): Yes, once someone had written something bad about Albania in a newspaper, and I didn't like it. I was like, 'What was their problem?'... Albanians here in England... They rob banks. Like 'What the hell?' and this sets a bad view of Albanian people.

Discrimination blocks integration strategies, since being unaccepted causes teenagers to retreat and stop trying to establish relationships with native peers. Discrimination, however, is neither a homogeneous nor standard experience, and apart from ingroup differences, it is experienced differently by parents and children. While parents have accepted the existence of discrimination and responded to it, consciously or unconsciously, with a range of attitudes and strategies, children find it puzzling and hard to accept. Rather than a state of denial, the reaction of the second generation arises out of the frustration. They experience acculturation and a strengthening of ties and belongingness to the host society. Yet, at the same time they encounter the resistance of the 'host' society towards them, which 'grants' acceptance only on the basis of an exclusive ethnic identity, thus preventing the formation of 'healthy' hybrid identities.

There are also age-related differences in perceptions of discrimination: older teenagers personalize and internalize it more, whereas the younger ones see it more 
as external and exaggerated. The older children commented on their parents' inability to help them cope with the strong discrimination towards Albanians throughout the 1990s. This points to what has already been emphasized in the literature: that the mode of incorporation of the first generation has a strong impact on the second generation, providing differing amounts of cultural and social capital and exerting differential pulls on their allegiances (Levitt and Waters 2002, p. 15). By analogy, the findings of the current study suggest that the stage of incorporation can be very important. Younger children seem more relaxed towards language use and visits to the homeland. They show more interest in the Albanian language and TV (some of these observations are dealt with in the next chapter). Although attitudes towards Albania and Albanian ethnic identity are not always positive among the younger siblings, they do demonstrate a better capacity to take a stance towards their ethnicity and their identity in general.

There is also a gender difference in the way Albanian teenagers experience discrimination and harassment on the basis of their origin. In general, boys face harsher discrimination, both physical and verbal. They are also more vocal and reactive against experiences of discrimination. Among girls, discrimination is mainly experienced in the form of exclusion and mocking. They are more prone towards hiding these issues from their parents and usually under-report instances of discrimination during the interview - at least as far as I could tell.

Discrimination is also experienced in love relationships, or what is expected in future partnerships.
Klejdi (male, 17, Florence): To tell you the truth I haven't had problems. The first things I say are my name, surname and then say that I am Albanian. But it has happened with girls, to be fair, or with the parents of the girls more precisely, and because I am Albanian I would have issues with the father of the girls [that I was dating]. But I haven't given it much importance... like it or not, I am Albanian.
Dana (female, 15, Florence): For example, I was with a group of friends and an Italian guy comes and approaches me, out of interest... When he got to know I was Albanian, he left saying, 'Aww, Albanian! God, no!'

The way discrimination is experienced and perceived by the Albanian-origin teenagers varies from city to city. In both Thessaloniki and Florence discrimination is expressed by the natives partly because of an undesired similarity perceived with the Albanian second generation - in claims of membership, appearance, behaviour and customs. This is evident partly because of the 'broad' space of contact that the second-generation teenagers have with the Italian and Greek natives. '[D]ifferential treatment occasioned by irrelevant unlikenesses' (Banton 1994, p. 91) is, in effect, rooted in the exclusionary definition of national membership in Greece and Italy. In London, contact between Albanian-origin teenagers and natives is 'mediated' by other minorities, so they have the possibility to make use of the 'spaces' created by the multicultural society of London. A paradox arises from the relatively greater cultural similarity between Albanian culture and the cultures of Greece and Italy: discrimination appears stronger in the two countries where the cultural (and geographical) distance to Albania is less, whereas in London the cultural-spatial distance to Albania is greater, but discrimination is less strong. 
Teenagers in Thessaloniki express their opposition towards discriminative practices, both as a general principle and in their selection of their friends, boyfriends or girlfriends and future partners. As the parents also realize, children feature both as 'victims' of the first generation's arrival and problematic settlement within a 'homogeneous' host society, and as the strongest agents of boundary-blurring processes. The presence of the children in schools is an everyday reminder of growing differentiation and heterogeneity within Greek society, while their educational success has sometimes caused significant 'ethnic identity incidents' by initiating discourses of national, ethnic and racial identities, with the 'rejected flag bearer' having become the symbol of their discrimination in Greece (see Kapllani and Mai 2005; Tzanelli 2006).

Unlike the explicit discrimination experienced in Greece, the second generation in Florence experiences a more subtle discrimination.

Lela (female, 36, Florence): When we came here in the beginning, we were people taken and thrown into a society we knew nothing about! Whereas these [the children] who are growing up here, I can't really say that they, the poor children, don't know about it, although there are certain things that they experience... many things that have to do with razzismo sottile [subtle racism]... [sighs] There are many children in schools, when they reach the age of 12-13 there is a kind of racism... because when you are little you don't understand it... 'Ah, how well you speak Italian! But now you are Italian, you are not Albanian anymore!' It's devastating for the children! This thing that you are Italian, you are not Albanian anymore.... So they wonder, 'Am I Italian because I speak Italian or... because you see me as Italian? And by the way, what's this difference between Italian and Albanian?' There are some painful things for the children [to cope with].

Teenagers in London were generally more relaxed and their perceptions of discrimination were less internalized than in the two other cities. They had a more understanding attitude towards difference and multiculturalism within schools and beyond. Achieving full settlement and citizenship in Britain and the wide range of opportunities expected 'freed' them from strong negative perceptions of Albanian identity.

ZV: What's your attitude towards the Albanian community in the UK or worldwide? Altin (male, 16, London): Um...I think it's good. Some Albanians are doing good work into their community, like setting up schools where my sister goes. She goes to learn Albanian, Albanian dance and all stuff like that, which is good. And then there are Albanians that break the law in England, America, everywhere. That's not good, but you know... I think Albanians make the world [smiles] a better world probably... No one can say Albanians are bad for the community or for the world. I mean, that's just stupid, everyone has a unique... has something unique that their country brings to the world, to the community.

Objections towards discrimination indicate awareness of politics of identity and an engagement with the public discourse at an individual level. Banton (1994, p. 5) maintains that "patterns of inequality established in one generation are easily transmitted to subsequent generations because people grow up regarding them as right and natural'. Albanian teenagers' objection to discrimination is therefore a promising sign in terms of prevention of their downward social mobility in these cities. 


\subsection{Conclusions}

This chapter analysed the patterns, dynamics and strategies of integration of Albanian immigrants and their children in Thessaloniki, Florence and London. Both groups' perception and experiences of integration have changed over time and in different stages, making the idea of integration as a process central to our understanding of the phenomenon as a long-term 'outcome' of the settlement of immigrant groups and their descendants. Legal status and regularization have been main factors conditioning the integration of Albanians and their descendants at all three sites. However, different from what most of the literature on illegal migration has found, migrants are not passive receivers of state regimes in this regard. Ruhs and Anderson (2010) contend that the main strand of future research on illegal migration should be the differentiated agency of migrants in their engagement with the state's legal and policy frameworks. While migrants' illegality is widely condemned by states, host country governments have repeatedly taken a pragmatic stance, allowing selective regularization and distinguishing different types of legality and illegality (Ruhs and Anderson 2010, p. 197).

Although the spatial and demographic context plays a significant role in shaping differences in terms of integration across the three sites, we saw that the socioeconomic background and capital of the first generation affect the integration of both immigrants and their children. More importantly, the way the two generations perceive their integration is significantly different: parents and children strive to integrate into different segments of the receiving society. In very broad terms, social and cultural integration is much more valued by the second generation, while the first generation puts most of its effort into structural integration. The second generation also expresses a broader perception of the opportunity structure in the host country, unlike their parents' mono-dimensional view of their migration project as aiming towards economic prosperity and education for their children.

The two generations, moreover, differ in the way they experience discrimination and are affected by discrimination differently. While the first generation feels discrimination based mainly on being different from the native population, discrimination towards the second generation is perceived on the basis of similarity. The second generation's physical, cultural and behavioural similarity or identicality to peer-age host-society natives causes the latter to partially 'reject' them, both in social spaces and in other spheres. This syndrome is particularly acute in Florence. Discrimination is thus an important barrier to integration. It obstructs structural integration, which in turn, supporting Gordon's (1964) view, becomes a barrier to social and cultural assimilation. This dynamic is most evident among the second generation. The tendency towards participation in non-ethnic institutions is also stronger among the second generation; however, this participation is obstructed by the low social and cultural capital transmitted by the parents and the general lack of resources.

These differences between the two generations also have a spatial element. Children and parents differ in their understanding of space and geography, and they plan 
and evaluate their integration through different spatial frames of reference. Children are more cognizant of their locality, neighbourhood or city. This was especially evident among the Albanian teenagers in Florence. The disjuncture found between the two generations in terms of 'spatial cognition' constitutes one of the most striking intergenerational discontinuities.

Structural and cultural differences across the three sites affect the way immigrants and their children perceive their possibilities for integration and the various processes of integration. The situation in terms of institutional arrangements with regard to education, labour market, housing, religion and legislation is different at each of the sites, supporting the comparative context integration theory (Crul and Schneider 2010).

Referring to the distinction between de facto and official multiculturalism by Joppke and Morawska (2003), we see a difference in the way the Albanian immigrants and their descendants are positioned in the three cities. Two revealing examples are the role of immigrant organizations and schooling arrangements. Official multiculturalism in London implies an a priori recognition on the part of organizations and schools of the rights of minorities. Yet, in schools, small minorities deriving from new migrations are largely overlooked, as the a priori recognition is usually focused on old and sizeable minority groups. De facto multiculturalism is taking shape in Florence, as seen in local policies that promote interculturality, which have resulted in smoother integration in schools of the second-generation children, especially those that arrive at school age. In turn, as mentioned in Chap. 1, integration measures are largely absent in Greece, and Thessaloniki has no local policies to enhance integration of immigrants and their descendants. The role of organizations there is far less significant too, as structurally speaking, they are weakly catered for by the state.

Differing appreciations of multiculturalism are apparent in the integration trajectories of Albanian immigrants at each of the sites. Referring to the definition of Gans (1992), we found rapid acculturation of migrants in Greece and Italy, shown most clearly in their religious identities. But also in these two countries the process of assimilation - the shift of membership from ethnic to non-ethnic social organizations and institutions - has been much slower. Acculturation was largely imposed by assimilation pressures in the host society in the early stages of settlement and integration. Increasing signs of intentionality (Todd 2005) appeared in later stages, with more autonomy in evidence among migrants, who consciously adopted acculturation as a general strategy to obtain a more advantageous positioning in the host society, or felt remorse about the early-stage assimilation and identity change that had occurred. This process, furthermore, has gendered patterns, most pronounced in the case of the first generation, with women experiencing a more rapid process of acculturation and integration in general.

In terms of trajectories or patterns of integration predicted by the classic assimilation and segmented assimilation theories, a general upward mobility was found among the first generation at all three sites. In turn, there was very little evidence of ethnic embeddedness. Ethnic embeddedness was mainly found within the Albanian community in London, in pressures placed on girls and parents' expectations of 
them. However, the issue here seems more a gendered view on moral values rather than those associated with a typical 'ethnic enclave' - spatially and socially segregated and organized around a common culture or ethnic niche, usually emphasizing differences with the host country's culture. As regards the theory of segmented assimilation, especially in the case of the second-generation teenagers, the three clear 'outcomes' of integration that the theory predicts are difficult to assess, not least because processes of adaptation and acculturation at this age are very complex. Another important element that makes the theory only partly applicable is the lack of a 'transnational' element in the integration of the second generation, which is the focus of the next chapter.

Open Access This chapter is distributed under the terms of the Creative Commons Attribution Noncommercial License, which permits any noncommercial use, distribution, and reproduction in any medium, provided the original author(s) and source are credited. 


\section{Chapter 4 \\ Transnational Ties and Attitudes Towards Return}

One of the main developments in the migration literature of the past few decades is recognition of and research on migrants' double belongingness and their ties with the receiving and the home countries. Transnationalism has irrevocably changed the way we see migration's effects on migrants' and their descendants' cultural worlds, their cognitive geographies and their pathways of integration and patterns of mobility. This chapter aims to further the understanding of transnational ties by offering a cross-generational view of the way Albanian migrants and their descendants experience these across different contexts, domains and levels. The section on the first generation looks at return visits, ties through the media and technology and remittances. It also includes a section on attitudes towards return. These attitudes are framed and evaluated transnationally, based on feelings of belongingness and a more-or-less rational appreciation of opportunities in both the home and the host country. The section on the second generation follows a similar though not identical structure. As it becomes apparent in the data, the themes treated have their own particularities for the second generation, as well as reflecting the role of the parents. The findings show that the first and the second generation establish and maintain different kinds of transnational ties. These ties change over time, though the effect of time on transnational ties is different, with some ties strengthening and others weakening over time and being replaced by different ones. Furthermore, transnational ties appear here to be contingent on institutional aspects and they have an impact on migrant integration and mobility, although these impacts are mutual and differ between the three main sites of this study. Overall, the data call for a look beyond the nation-state, both symbolically and spatially, as a presumed 'unit' of reference for transnational ties. 


\subsection{Theorizing Transnational Ties Beyond the Nation-State}

The terms 'transnationalism' and 'transnational community' became formal in academia in the 1990s, as migration scholars started to insist that, rather than being two separate domains, the homeland and the home country were interconnected transnationally in terms of the economic, social, political and cultural affairs that migrants were involved in. These 'affairs' were found to be sustained, regularly or on a more situational basis, involving both migrants and their descendants and operating at different levels (Morawska 2003).

Debates on transnationalism are placed within a broader discourse on the nationstate and its role as a regulator and determinant of social and political life dynamics. Levitt and Jaworsky (2007, p. 133) conclude that the literature on transnationalism acknowledges the role of the state in shaping transnational practices, by enabling or constraining migrants' political claims, but these authors conceive the relationship between the state and migrants as multiple and not disappearing or one-sided. Others maintain that, rather than being weakened by immigrants' transnationalism, the receiving state remains a major actor in influencing the intensity, forms and directions of transnationalism (Joppke and Morawska 2003). The emergence of the term 'transnationalism' came about in part as a response to 'methodological nationalism' and a certain bounded view of society and culture associated with it (Glick Schiller 2004; Wimmer and Glick Schiller 2002).

Glick Schiller et al. (1995, p. 50) maintain that the conduct of transnational lives is related to three main contextual factors: the history of immigration and modes in which immigrants are received in the host country; migrants' cultural resources; and discrimination and hostility faced by an immigrant group. Generally speaking, large-scale and politically motivated migrations give rise to transnationally oriented migrant communities. The cultural resources of a migrant group have been found to shape transnational practices, such as the type of ethnic niches that migrants occupy and political activities that connect with home countries. Finally, a high degree of discrimination in the receiving country is associated with 'reactive transnationalism' or a tendency towards engagement in activities that reaffirm migrants' collective identity and open up opportunities for niche-based economic prosperity (Faist 2000a).

More recently, Dahinden (2009, p. 11), while reaffirming that there is a relationship between mobility and transnationalism, adds a time element to these findings, although she cautions us to distinguish between different forms of transnationalism. ${ }^{1}$ She finds that the longer the migrants stay in the receiving country, the less transnational they are, and the strength and the proportion of transnational ties diminishes as the duration of stay increases - an argument that supports assimilation theory. At an individual level, the degree and kind of transnational engagement are

\footnotetext{
${ }^{1}$ As for the time element, Guarnizo et al. (2003) found that political transnationalism increases with time in migration.
} 
conditioned by factors such as gender, social class, migration channel, legal status, economic means and migration and settlement history. These factors interact with others related to community structure, gendered patterns of contact and political circumstances in the homeland (Pessar and Mahler 2003; Vertovec 2009).

Academically, the field of transnational studies is fragmented and coherent theoretical frames to define transnationality are missing (Yeoh et al. 2003). In an attempt to ascertain the authority of the term, Vertovec $(2001,2009$, pp. 4-13) maintains that both theory and research on transnationalism have been grounded upon rather distinct conceptual premises. He emphasizes six of them, which overlap and are interdependent: social morphology, types of consciousness, modes of cultural reproduction, avenues of capital, sites of political engagement, and (re)construction of place and locality. A clearer and more relevant classification is that of Faist (2000b, pp. 202-210), who refers to the density of ties and linkages and offers a classification based on three groups. Firstly, transnational kinship groups are characterized by reciprocity and are especially common among first-generation labour migrants and refugees. Second are the transnational circuits based on principle of instrumental reciprocity, consisting of a constant circulation of goods, people and information across the sending and receiving countries. Finally, transnational communities go beyond kinship systems and consist of strong and dense social and symbolic ties over time and across space.

However, much less is spoken about transnational identities, and culture seems to be 'lost in the move from the old to the new country' (Levitt 2005, p. 51). This is slightly surprising, since Vertovec (2001) points out that transnationalism encompasses modes of cultural reproduction, associated with a fluidity of constructed styles, social institutions and everyday practices. Levitt $(2005$, p. 51$)$ maintains that research on race, ethnicity and immigration has mainly focused on the transition from the old culture to the new and argues for 'bringing culture back in'. She describes social life and institutions under the influence of transnationalism as undergoing fundamental changes while giving rise to new cultural practices and institutions, which furthermore feed back to existing cultural conventions.

On transnationalism and culture, Glick Schiller (2004, p. 450) argues that the development of the transnational paradigm has helped academics to reconceptualize the terms, moving away from existing definitions that are based on the idea of culture as discrete, stable and historically specific. Transnationalism scholarship deploys a broader and boundless concept of culture, which is based on elements such as social relations, social structure and a set of inter-generationally transmitted patterns of action, belief and language. These arguments, however, seem not to fully address the need to move away from a bounded notion of culture. Reviewing the literature on diaspora and transnationalism, Nagel (2002, p. 250) proposes a reconceptualization of culture as a 'constant production and reproduction of social meanings through relationships of power, located not only in the nation-state but also in households, neighborhoods, workplaces'. Olwig (2003) likewise maintains that the notion of cross-border arenas of transnational processes defined against the notion of nation-state bring the danger of narrowing down the field of investigation. Rather, a broader approach is needed that focuses on socio-cultural systems 
in relation to migrants' life trajectories and fields of interpersonal ties, while also considering the national and transnational structures that condition the migratory movements.

The concept of transnational social spaces has been an important development in the study of transnationalism (Vertovec 2001). Different authors opt for the suffixes field or space. Pries (2001, p. 21) emphasizes the stability and pluri-locality of social spaces and defines them as "configurations of social practices, artifacts and systems of symbols that are characterized and defined by their density and importance in time and geographical space'. Faist (2000a) furthermore observes that transnational social spaces develop in two phases: in the beginning they are the outcome of international migration of mainly the first generation, while in a second phase they are passed on to migrants' descendants and seem to develop a life of their own. During their migration history, which often involves recurrent migration and transnational movements, international migrants are involved in transnational exchanges and build multiple ties of familial, economic, social, religious, cultural and political nature on the basis of which there are various forms of resources and capital.

On the other hand, the concept of transnational social fields uncovers another essential element in the way transnational processes are conceptualized: that of the level of interaction and subjectivity. Levitt (2005), recognizing the simultaneity of migrants' activities, calls for a move away from the neat division of migrants' connections into local, national, transnational and global. Simultaneity also applies to these different levels of interaction, as social fields are not only multi-layered crossings of nation-states, but while making and unmaking relationships and ties within these fields, migrants are influenced by laws, social institutions and conventions that operate locally, nationally, internationally and globally. On examining the simultaneity of migrants' incorporations in both sending and receiving countries, however, we should consider that homeland and host country socio-economic and status ladders do not always operate on the same principles and criteria. Consequently, migrants often face different opportunity structures in homeland and host societies, and may move up or down the ladder in respect to one of the two, or experience downward or upward mobility in both of them (Levitt and Jaworsky 2007, p. 139). Many well-educated Albanian migrants experience de-skilling and devaluation of their human capital because they are only able to access low-status jobs in destination countries.

In developing the concept of transnational social fields, Glick Schiller (2004) adds a more subjective element, distinguishing transnational ways of being from transnational ways of belonging. Transnational ways of being consist of instances of behaviour through which people conduct or are related to transnational activities. On the other hand, transnational ways of belonging tell us about cultural representation, ideology and identity related to these activities. These are processes of an emotional nature, through which people connect to different locations bound together by a common destiny and history, through memory, nostalgia and imagination. Pessar and Mahler (2003, p. 815) implicitly suggest that both ways of being and ways of belonging are affected by people's social locations within 'gendered geographies of 
power'. The differentiation is firstly expressed through different access to migration; and gender, race, ethnicity, nationality, class, sexuality and so on condition ways of thinking about migration. Although under-researched, issues of power are thought to have considerable relevance for the current dynamics of transnational processes and are expected to persist in creating uneven trends in these processes (Glick Schiller 2004; Vertovec 2009).

This current study employs the distinction between transnational ways of being and ways of belonging as the basis of its data interpretation since these concepts are considered less vague than the notions of transnational social spaces and fields, and therefore, more suitable for empirical research (see also Snel et al. 2006, p. 288). The concept of diaspora is also de-emphasized since there is little by way of a strong Albanian community in any of the three cities; nor is there a symbolic identification, belongingness to a common homeland and shared past or a common current or future destiny among Albanian migrants and their descendants (Clifford 1994).

Cognition, on the one hand, and the 'classics' such as gender, class and race/ ethnicity, have re-established themselves by finding recognition as a bunch of factors shaping transnational processes. However, a more spatial approach can also be noted here. Pries (2001, p. 28) calls for a rethinking of the relationship between the social and the spatial, claiming that the spatial should be recognized as an independent force affecting the social. Peraldi's (2005) approach is enlightening in presenting a particular account of migration and mobility. The case of suitcase traders and their trading routes, which connect the northern and southern shores of the Mediterranean, demonstrates that the nation-state cannot contain cultural dynamics, social interactions and professional careers and positionality in various networks. These traders' sociability is not organized in relation to territories but to several localities, while their universe is made up of scattered urban and metropolitan spaces. Such mobilities appear to be 'marked with the triple seal of emancipation, deterritorialisation and transnationalism' and give rise to sequential and irregular geographies of migrant diasporas under the effect of globalization (Peraldi 2005, p. 60, 2007).

Therefore, the current study will analyse both integration and identity and transnationalism considering their relations to space and to place. Transnational ties are usually seen as established across two nation-states: the sending and the receiving country, although the developers of the concept were inspired by a critique of methodological nationalism, so the common practice of taking the nation-state as the unit of analysis when immigrants' integration was under scrutiny (Wimmer and Glick Schiller 2002). Increasingly, however, scholars point to a less dichotomous picture than one that portrays transnational linkages as between a single homeland and a diaspora. In fact, research shows that such linkages span numerous localities and places (Duvall 2003, p. 301). Importantly, migrants' ties are not only established across nation-states but also influenced by laws, social institutions and conventions, which operate at several scales: the local, national and global. These are not neatly divided, but rather integrated in the making and experiencing of transnational ties (Levitt 2005; Levitt and Glick Schiller 2004). This integration of multiple scales defies a hierarchical understanding of the local, national and global, contributing to a better grasp of the multiple loyalties, attachments and identifications of citizens 
(Isin 2007). As a result, the integration of these levels and the acknowledgement of the interactions and multiplicity of processes that take place simultaneously at these various levels has given rise to concepts such as 'glocalization' (Roudometof 2005).

But spatial dimensions have not been widely incorporated in the studies of transnationalism, especially those on the second generation, although Vertovec (2009, pp. 4-13) mentions the construction of place and locality as one of the distinct conceptual premises of theory and research on transnationalism. The lack of research on spatial dimensions is surprising, as space is a well-established concept in migration literature. King (1995, p. 27) maintains that 'migration stretches particular forms of social relations across space: both the social relations of capitalist production and the personal social networks that reproduce migration chains through time. The meaning of place for a migrant torn from his or her roots is indelible.' Kivisto (2001) picks up on this 'gap' in his review of the literature on transnationalism. He strongly supports the view that place counts in transnational ties and spaces, since the vast majority of immigrants are located in one particular place, rather than simultaneously in two worlds. Thus, there is a need to rethink the relationship between the social and the spatial.

The findings of research for this book offer a cross-generational analysis of space, place and locality in the context of European migration. Locality, space and place, especially related to the urban context, consist of relatively new strands in the study of migration and integration (Glick Schiller and Çağlar 2009). Within this body of work translocal ties have been defined as ties connecting places or localized life-worlds whose distinctiveness is retained despite global migration flows (Brickell and Datta 2011; Conradson and McKay 2007; Ma 2002). Translocalism consists of 'situations where immigrants do not maintain multiple, intense, routinized bonds and networks with the homeland, family, friends, and communities. Instead, those efforts most often are likely to be moderate and periodic, somewhat casual and uneven and not routine' (Barkan 2004, p. 340). Therefore, in order to understand translocality we need to focus on subjectivity-place relations, which are shaped by global flows and inherent dynamics of power and agency, creating new forms of locality (McKay 2006). Translocality usefully allows for the study of the local, which is often overlooked in research on migration, transnationalism and globalization (Brickell and Datta 2011).

In turn, return migration has mainly been studied by focusing on those migrants who eventually returned; attitudes towards return have been little studied (see Elizur 1973). Even when attitudes have been included in analyses, they are approached mainly in terms of the economic impact of intentions to return on contributions to the homeland:

From this perspective, the relevant policy goal should be to encourage the family, social and economic ties that keep alive the prospect or possibility of one day returning home, even if this does not eventuate. Indeed, it could even be argued that the most desirable economic scenario is one in which all migrants keep alive the intent of returning without ever doing so (Ahlburg and Brown 1998, p. 148)

Inclusion of attitudes in analyses of return migration has gone hand in hand with their clear definition and a greater understanding of their role in the process of 
return migration, which takes on new and more complex dimensions when analysed through the transnationalism paradigm. Dustmann et al. (1996, p. 233) maintain that return intentions are valid information for understanding migrants' behaviour irrespective of the outcome, that is, whether return actually takes place. More recent is the situating of these attitudinal variables as part of the return process, involving the transnational experience of the children of migrants. This is surprising because some recent research shows the importance of children in building and maintaining transnational ties. As will be shown later in this chapter, children have strong attitudes towards return and are one of the main factors affecting the family's return project.

\subsection{The First Generation}

\subsubsection{Return Visits}

Although the transnational ties of the first generation take various forms, return visits have a special importance. This is because they concern visits to family and kin, which are a strong obligation in Albania. Return visits hold this importance even though they occur less frequently than contacts through media and technology, which take place, in many cases, on a daily basis. According to Duvall (2004, p. 53), transnational studies assume the existence of connections between homeland and the receiving country, but the physical movement of migrants has been overlooked compared to other 'transnational exercises'. Kibria (2002, p. 297) adds the voluntary element of such visits, defining them as short-term returns to the homeland for purposes of tourism, leisure, seeing family and learning about the culture. Duvall (2003), however, sees these visits as taking place within the wider diaspora; hence, they have a broader role in linking numerous social fields and maintaining transnational identity structures.

For most of the first-generation Albanian migrants and some of the second generation, these visits were impossible in the early years of settlement and childhood, respectively. This was due to the history of immigration of this group and certain objective factors including the delayed regularization process, the phenomenon of chain migration and therefore the presence of relatives in the receiving country (less so in the case of the UK), the existence of 'family hubs' in other countries, the stage of incorporation of this immigrant group and the way it was perceived in the receiving country. As Duvall (2003) observes, borders and state policies have crucial importance. Due to the 'illegal' nature of much Albanian migration, return visits were not possible for a number of years. However, transnational ties are also shaped through memory and nostalgia. This type of tie is far more common among the parents' generation.

Lela (female, 37, Florence): When I go out for a walk, sometimes I feel so lost in my thoughts and I don't know anymore where I am; I feel like I am taking a walk in Durrës. 
There are these moments when I have nostalgia and I feel like I am walking around in my country. I listen to people speaking in Italian and I feel like they speak Albanian. When I go to Albania, in a week I see so many things, so many changes and I miss so much the past, the childhood I spent there, my friends, everything. So I don't find myself neither there, nor here.

Return visits have changed in terms of their meaning and frequency over the years. Once the issue of 'papers' was resolved, most of the first generation immediately undertook return visits, and continue to do so. A smaller number have ceased visiting, or visit only very occasionally. The narratives illustrate the high emotion felt on the first return visit to Albania, on getting to know the place and reuniting with relatives after a long gap. The preparation for such return trips is generally described as a time of joyful anticipation for all concerned. The visits' emotional character, imbued with longing and belonging, is a general feature, though usually associated with other reasons revealing an instrumental rationale of these visits (see Box 4.1).

Attitudes and expectations of the extended family in Albania have a strong impact on the continuation and frequency of return visits. This role of the extended family has only recently been acknowledged in the transnational communities literature. The role of kinship networks has mainly been studied in relation to chain migration and the initial settlement of migrants (Choldin 1973); the focus on kinship in terms of return visits is recent (Mason 2004). Writing of the Caribbean context, Conway and Potter (2009, p. 234) note that intra-generational family connections expressed in family love, obligations and responsibilities are among the strongest reasons for transnational mobility, mainly in terms of return. This view, however, contrasts with Albanian migrants' attitudes towards the collective culture. Their narratives indicate a shift towards individuality on the one hand, but they also reflect changes observed in Albania during return visits, such as the loosening of ties between relatives and a changing appreciation of kin, along with diminishing appreciation of community values and a move towards 'appearances' and materialism. This is also noted in other authors' writings on Albania. Misha (2008, p. 125) maintains that the transition in Albania was accompanied by a crisis of the value framework that underpinned the country's social organization before the collapse of communism; this in turn caused social fragmentation in Albanian society.

\footnotetext{
Abaz (male, 44, Thessaloniki): Visits to Albania have become less frequent. This last time I went I was returning after six years. I went for New Year, because New Year's is our traditional celebration, as you may know. I went there two years ago, but it wasn't the same atmosphere as before... Everyone was just staying home, minding their own problems. The visits to the relatives, I am not saying they were not taking place anymore, but from 100 per cent, I could say they were reduced by 75 per cent! There weren't visits anymore, back and forth to relatives' houses. I felt like love and respect for kin and relatives were diminished in comparison with the old times when we were there.
}

Some of these changes in perception are part of an evolution in adulthood of the importance of the extended family; or difficulties with in-laws' interference in the relational sphere. Relationships between men and women often change markedly during migration, involving more empowerment of the women and more importance given to the nuclear family and independence from in-laws and relatives. There is 
also opposition from parents and the second generation towards interference by the extended family in the choices that parents make for children, especially girls.

Anila (female, 35, Florence): Last time we went, me and my husband, his parents interfered. He is very stressed because he works long hours and I understand him, but they don't get it that this human being is really tired and is working very hard. I don't see him myself all day; I see him only in the evening. And I also need to stay with him... We are spending all our lives like this! All year I see my husband once a week on Sunday, I also need to spend time with him, but they were with us morning till evening in our house. They made my life hell! I had to sacrifice myself for his mum and dad.

A trend that cuts across the data is that of return visits providing an occasion to meet for relatives who have migrated to different countries. By the same token, they offer a rare opportunity for members of the second generation to meet, for instance, cousins. They thus constitute an important setting for the creation and restoration of multiple transnational kinship ties.

\section{Box 4.1 Thessaloniki-Tirana Return: A Bus Ethnography}

I am on the bus travelling from Thessaloniki to Tirana, 'replicating' the trips I used to take as a student 5 years ago. Since my time in Greece, migrants' movements are much more frequent. There are more travel agencies, which also keeps the price low. A return trip by bus costs $€ 56$. A travel agent in Tirana told me that the trip by plane would cost $€ 140$, and 230 for a one-way flight during Easter. The high cost of air travel is a major reason why most transnational movements between Greece and Albania happen by bus. The new 'Egnatia' road has made a big difference in the speed of travelling.

The bus is full of people. The Easter holiday is just starting, so families, students and young men are headed to Albania. Young people studying in Greece are returning home for the Easter holidays. A granny is visiting relatives to mourn a deceased family member. There are middle-aged menmigrant heads of families with family back in Albania too. There are single men and mothers with children going for holidays. Usually the front seats are reserved for young ladies (students) and other women travelling alone, the elderly and people in bad health. The driver does not need to be told; whenever he sees a young lady unaccompanied, he reserves the front seat for her.

In the bus, the students' talk about their life in Greece and exchange stories with labour migrants. 'I was doing very well when I was in high school, but married quite early and couldn't continue', a mother says to the student next to her. Starting in Korçë, the bus stops in every village, or rather, anywhere close to the migrants' houses, or where relatives wait for them. Approaching Tirana, only the students remain. Earlier in the trip, their conversation was about feelings of subordination in relation to Greek peers, experiences with locals and opinions on international affairs. After we cross the border the main themes are the bad infrastructure in Albania and the incompetence 
of border officer, while so many highly skilled and educated people abroad are unemployed. When entering Tirana, 'the highly skilled despair' for the country 'not being made yet' is displayed: the still unfinished road close to Tirana bearing the symbolism. The chatter fades away as we approach the centre of the capital.

\begin{abstract}
$\mathrm{ZV}$ : How has the frequency of the return visits changed over the years?
Tony (male, 41, Florence): Until my parents passed away, I was going twice a year, and when they were ill, even four to five times a year. I went four times in 1999 when my dad passed away and the same when my mum passed away. I was there both for the funeral and the other rites. I went again in 2007 for the first anniversary and in 2008 I went again because my niece from Manchester was visiting. I hadn't seen her for eight years, so went on purpose to meet those cousins. Now they [the visits] will be yearly, because I have my brothers there, and then we can't really go often, because of work here, expenses... Whereas when my parents were there, we were more prone to go and we were sacrificing something, because it was a beautiful thing. I was arriving and at the door of the house were mum and dad waiting for me... Now we will go a little bit to one brother, a little bit to the other, and just once a year.
\end{abstract}

Close relations with the extended family and a high propensity to make return visits may reflect weak social integration in the country where these immigrants and their children live. But the opposite may also be true: visits may serve only to reveal the emotional distance, even alienation, they feel towards Albania. They notice the changes that have occurred in their own identities and in their homeland during their absence (see Duvall 2003, p. 299). This 'disembedding' from Albania was evident in the narratives.

Anton (male, 38, Florence): The fact is that I feel a little bit alien when I walk on the street. Not in my house, the house remains the same, my parents are the same. But you go out in the street and see the changes in the town and you don't see anyone from those you left 16 years ago. You see a new generation with a new soul, you realize this and you feel a stranger in the place where you were born and grew up and spent your adolescence, more there than in the place where you live now... abroad.

There is also a feeling of opposition and subtle exclusion by general society in Albania towards immigrants, or a lack of consideration, growing over the years, that makes return visits a negative experience and discourages their continuation. Paralleling other research on return visits, this research found many articulations of 'othering' and even anger towards migrants during these visits (see Potter and Phillips 2006, p. 586). In the Albanian case, this may reflect the assimilation of the first generation, especially in the case of those in Florence.

Michelino (male, 46, Florence): It's not that we don't love Albania. I love Albania. That's why I go there every year. Although they treat us very badly, starting with the politicians of Albania. They take advantage because they know we can't exist without going to Albania. They know we will go anyways... But we are learning!... If you would go there and say these things, people start laughing at you. They would say, 'What's wrong with him? There he goes, the stupid one from Italy!' They take us for idiots when we go there. 'They have lost it completely, these people that come from Italy!' 
The difficulties of travelling, including long hours of waiting at the border, are another negative aspect of return visits. Albanians living in Greece got stuck at the border for hours, even days, during holiday seasons. Those in Italy have negative recollections of Albanian ports. Some migrants articulate the issue of bad infrastructure as just another symptom of the disrespectful attitude of the Albanian state towards its emigrants and diaspora. Cost is a considerable barrier for those living in Britain and Italy, since they must rely on air transportation. These difficulties are mentioned as reasons for the discontinuation of return visits to the homeland and an orientation instead towards holidays in touristic areas of the countries where they live or in other countries or big cities (see also Duvall 2003, p. 302).

Transnational movements differ across the three countries and between genders. There are cases when only the father continues visiting, reflecting the poor social integration of Albanian men compared to women.

$\mathrm{ZV}$ : Who takes the initiative for the visits?

Sidorela (female, 22, Florence): My dad... because... my mum is practically completely adapted to the Italian world. She feels more Italian than Albanian. My dad, on the contrary, no. He feels more Albanian than Italian, so it's him... who always wants to go.

One factor that contributes to differences between sites is the situation with regard to regularization and residence papers. Difficulties with papers in Greece have obstructed transnational movements to Albania and other countries. From time to time, the Greek authorities have allowed Albanians to travel home only during holidays. Such constrictions impacts transnational care and transnational family ties.

Entela (female, 42, Thessaloniki): We can travel only when they [the authorities] decide. They give us a document like that and we go. I have told to my parents 'You have to die at Christmas or Easter, because before or after we cannot come. We don't have papers!'

In contrast, acquisition of British citizenship marks the beginning of a dynamic period of transnational movements, which are also facilitated by the good airline connections from London. Though initially only back and forth to Albania, these movements soon began to include other European destinations as well.

Miranda (female, 34, London): I will go to Bologna with my husband and my elder son because I found some very cheap tickets from London. How can you not travel with these prices! Fantastic! We have relatives there, so we see them and leave our son there then we go to Rome, me and my husband for a short holiday.

\subsubsection{Transnational Ties Through Technology}

Reference to the use of information and communication technologies (ICTs) within the transnationalism and migration literature is recent, as one would expect due to the relatively new emergence of these technologies (e.g., Binaisa 2009). There is an obvious need to investigate the nature and implications of transnational ties established and maintained through ICTs, as well as their impact on migrants' strategies of integration (Christiansen 2004; Panagakos and Horst 2006). Transnational ties are expected to challenge existing concepts and theories of migration and to create a 
need for theorizing on the links between technological advances and migration and immobility (Smith and King 2012).

The migrants in this study used ICT in various ways to keep in touch with Albania and relatives abroad, although the ICTs used has changed over time. Invariably, the ICTs used are dependent on the financial situation of the family, as technologies are not usually prioritized over other needs and the goal of saving. The telephone was the first means by which migrants kept in touch, independent of their legal status, though the frequency of calls to Albania depended on the financial means available and migrants' relationship with the extended family. Links via digital broadcasting and the Internet are a far more recent phenomenon, though their use depends on education and access to appropriate devices.

The use of mobile phones, too, differs between the skilled and unskilled migrants, or the more and less educated. The more educated migrants interviewed were typically involved in various forums and international mailing lists, via which they took part in discussions on important events and developments in Albania. ${ }^{2}$ These online discussions gave rise to a form of political transnational involvement, sometimes resulting in declarations and petitions sent to the Albanian government or other international bodies. In some cases, the online forums linked users in Albania with those in the 'historical diaspora' in the USA and the Albanian immigrant communities in other countries. ${ }^{3}$ One forum, for example, had surveys on whether the events in Albania on 21 January 2011 were tantamount to a coup d'état ${ }^{4}$ and how the post-communist transition had impacted people's lives. Political transnationalism is otherwise lacking within the Albanian immigrant communities. Transnational ties of the highly skilled via the Internet are furthermore enabled by the websites of various Albanian newspapers published online.

Albanian families in all three countries have subscribed en masse to the private digital broadcasting platform DigitAlb. ${ }^{5}$ This platform enables families to keep in touch with events in Albania, although first-generation migrants are its main consumers. There is also a difference in the types of information that the two generations consume from this platform. The first generation is interested in day-to-day news, while the second generation relates to it more casually, with teenagers watching mainly music shows and foreign movies and younger children watching cartoons. Watching media from the homeland is also a way for the first generation to express their 'positioning' in the host society and their need to be connected to the homeland.

\footnotetext{
${ }^{2}$ See, e.g., the webpage of the network of Albanian academics abroad: www.alb-shkenca.org/ accessed 16 January. Also, there are various pages on Facebook, such as Albanian Women Network UK; UK Albanians Network; The Albanians in the UK; British Albanian Kosovar Council; Centre for Albanian Studies.

${ }^{3}$ See, e.g., The Albanian Forum (www.forumishqiptar.com or www.webalbania.com) accessed 16 January 2013.

${ }^{4}$ On 21 January 2011 there were massive public demonstrations in Tirana against corruption of the government that caused three deaths.

${ }^{5}$ DigitAlb was launched in July 2004 (www.digitalb.al accessed 16 January 2013).
} 
Fatmir (male, 41, London): I don't watch the English channels anymore since DigitAlb was issued. I don't watch them... It's five to six years now. Probably a bit in the morning when my wife checks out the news. But otherwise I watch DigitAlb... We are another 'dough', another generation; those who are twenty years old have no problem (to integrate), but us.

Although most parents subscribe to DigitAlb in order to be in touch with Albania, some use to so their children hear Albanian and retain the language. Therefore, the use of digital broadcasting is also related to the migrants' and their descendants' identification. In general, Albanian broadcasting is not present in households where families are moving towards assimilation, although transnational ties are maintained via the telephone and Internet.

The three countries differ in terms of the performance and maintenance of transnational ties through ICTs. Greece is less advanced in technological developments, so there transnational ties are maintained mainly through Albanian TV and telephone calls. In Florence, alongside the difference in the sample composition there (study participants were largely skilled migrants originating from urban areas in Albania), digital broadcasting was one of the main means of contact, but ties through the Internet were also common. In Britain, DigitAlb entered many Albanian households not only as a means of maintaining transnational ties but also out of necessity, since many among the first generation were not proficient in English. Resonating with other research on transnational ties (Snel et al. 2006), their exclusive watching of the Albanian media may well further decelerate the social integration of lowskilled Albanian migrants in Britain.

$\mathrm{ZV}$ : Who wants to watch Albanian TV more?

Drita (female, 45, London): The children like both, the Albanian and the English. But I get very nervous because I don't know what they are saying and I switch channels immediately. That's why I have bought the satellite and we watch our country's TV.

Furthermore, contact with Albania via TV has an important function in enabling comparison and evaluation of the living standards in both countries.

Donika (female, 45, London): But especially when we watch on TV young people in Albania who speak three foreign languages, I tell him [my son]: 'Do you see this? No light or running water and look how much they study.' His cousin who has the same age is studying to become a dentist, and tells us she has to study using a candle!

\subsubsection{Remittances}

Remittances have long been studied within the framework of transnational ties. Classic writings consider them a key component of the tie between migrants and their families (Stark and Lucas 1988, p. 478). Initially remittances were considered as an economic factor at a macro level. Many studies therefore employed a quantitative methodology in their study. Qualitative studies or those following a mixedmethod approach are rare and recent.

First-generation migrants maintain transnational ties to their 'home' communities in Albania in the form of social, financial and material remittances. However, 
the degree to which each type of remittance is welcomed by the communities in the home country is different and the understanding of their meaning has changed over time. Different types of remittances are also related to each other.

Following Levitt (1998) and Levitt and Lamba-Nieves (2011), social remittances are flows from immigrants to the home country that have to do with ideas, behaviours, identities and social capital, which are remoulded by the migrants during their stay in the host country. One example pertinent to Albanian migrants is migrants' change in manners and behaviour in public spaces during the return visits, and their emphasis on sharing and sometimes even pressing their newly acquired norms and habits on their home-based kin.

Lida (female, 46, Thessaloniki): People have changed a lot in Albania. There is a big difference in terms of manners; I noticed this last time I went to Albania. There are many changes, but still a lot of work is needed! Especially in terms of manners, behaviour, these things. Still a lot of work is needed, because all migrants have changed so much in terms of behaviour, that's why there are these clashes, as we saw this morning, with the bus's timetable. They should be accurate with the timetable!

A special case of social remittances relates to Albanian artists in the respective countries. Especially in Florence there is a concentration of artists who organize activities and exhibitions there, elsewhere in Italy and further afield in Europe. In some cases these consist of a particular form of two-way transnational engagement. While these artists keep their ties with Albania and with other cultural centres in Europe, they also organize promotional activities on Albania in the host country. For some artists, the social and material remittances originate from Albania. In other cases, previous transnational connections have led to more permanent settlement, reversing the flow of remittances.

Pali (male, 48, Florence): The visits to Albania have become less frequent. Nowadays I have ties with Albania because of my creative activity... Basically I am like a migrating bird... since my creative activity started and was moulded there, although I try to make it universal. I have my philosophy, for example, in terms of happiness. Everyone has his own thing, so creativity should be without frontiers. From this point of view, my creative activity is modest. But I say to myself, if there exists a society, a country that needs free information, a small 'window', that is my country. Because I have my relatives there, my nephews, my 'cell' there and I see it how it functions. So, in a few words, it is my artistic activity that takes me to Albania. I go every year and organize a performance, a theatre or dance performance, an exhibition.

Social remittances also appear in the form of transnational initiatives inspired by a more entrepreneurial and proactive attitude cultivated during the stay in the host country. Different from the experience of immigrants in other European cities (see, e.g., Fauser 2007), however, these initiatives arke not related to activities of immigrant organizations or local-level politics. Moreover, social remittances of this kind are often obstructed by the disjuncture between migrants and those at home. The latter are generally not receptive towards migrants' ideas and projects.

Michelino (male, 46, Florence): I went to the municipality of Peqin and told them, 'Could I bring two buses for free and you employ two of my relatives here?' The buses would then become the property of the municipality. So that also Peqin has two buses; one departs from the far end of the town, the other from the centre and this way Peqin's pensioners 
will have public transport, they won't need to carry everything all around! While two of my relatives will get a job and I won't need to help them financially anymore. I told them, but they started laughing; they wouldn't believe that I would send the buses for real. So we Albanians are the cause of our own problems!

Financial and material remittances continue to be an important way in which migrants keep in touch with Albania. The frequency and size of such remittances differed depending on both the changing needs of the immigrant family (whether there were children and what their needs were) and changing perceptions of the obligation to send remittances. In the early years of immigration, the uncertain legal status affected flows of earnings and savings to Albania. Apart from contributing to the immediate survival needs of the family in the homeland, financial remittances were spent on land and construction. Usually the remittances were used for a house or space for a potential business so as to secure self-employment in case of return (see also Dalakoglou 2010).

However, unlike the findings of other research (e.g., Glick Schiller and Fouron 2001; Hemming 2009), this study found that achieving social status in Albania upon an eventual return was not a strong motivator among the participants of this study. Financial remittances were usually sent by male migrants, but there is also evidence that some mothers send remittances to their families, mainly in the form of financial support to elderly parents (see Smith 2009). Nevertheless, the desire of family in Albania for financial remittances has caused tensions and unfulfilled expectations.

\begin{abstract}
Michelino (male, 46, Florence): People in Albania can never have enough (remitted money)! Our parents can never have enough, neither can the brothers, sisters, cousins... They behave like strangers now because you haven't helped them, but whom to help first? When you have fifty poor people to help, you will help first those closer to you. But the others don't speak to you anymore!... Whom to help first? We are being paid 1,000 euros a month now... But I think that to some people we shouldn't send even a cent! Not even a 100 euros, not to the family, not to anyone! They should go and ask the state for help, those they have voted for and have promised them all those things... Not to come and ask me, ringing my phone all the time.
\end{abstract}

The narrative above touches on a broader point of debate: would the study of remittances be more informative if the perspective of the senders were considered or that of those receiving remittances in the home country? The impact on the country of origin has been especially popular field of study thus far (Åkesson 2011; King et al. 2011). Even recent projects on remittances (e.g., UN-INSTRAW 2007) do not pay equal attention to the implications of remittance sending among migrants in the destination country. Increasingly, however, scholars are moving away from a focus on the economic dimensions to look at relationships between migrants and those left behind and to explore the nature of the transaction itself (Åkesson 2011).

Recent quantitative research reports diminishing remittances in the medium and long term and establishes a link between remitting behaviour and intentions to return (Jones and De la Torre 2011). However, there is little evidence of an overall shift in migrants' socio-economic commitment from origin to destination. Classic studies on remittances speak of a 'mutual interdependence' established between the migrant and family back home through remittances (Stark and Lucas 1988, p. 479). Yet family expectations can also adversely affect transnational ties. As a result of 
negative experiences such as those described by Michelino above, and a lack of appreciation and understanding of the difficulties and sacrifices of migrants in the host countries, return visits may not continue to be regular over time. Mason (2004) reports tensions between returning migrants and their extended family back in Pakistan, but in that case the tensions do not seem to have affected the continuation of visits.

ZV: Do you visit Albania? Will you go this Easter?

Merita (female, 52, Thessaloniki): Well, I don't think so...

Husband: we have to deal with the papers of Kleo. Besides Merita is jobless. In Albania we have to spend. The children don't like to go either. When we return and we have to wait 24 hours at the border... gosh, they can't stand that! We also don't have a place to stay in Tirana any more because when we left we emptied the flat in order to rent it out.

There is thus a mutual change of attitude both among first and second immigrant generations and among those left behind in Albania. Adults see their extended family with different eyes. They feel more independent and focused on their own nuclear family. On the other hand, a noticeable change is perceptible within the collective culture of Albania. Warm welcome from the extended family is no longer guaranteed once everyone has started their own family and the older generation has passed away. Explicitly or implicitly, Albania-based relatives indicate an unwillingness to host visitors 'for free'. As the children grow up, and because of cultural changes on both sides, the first generation no longer considers the sending of remittances to the extended family to be an obligation. This attitude is especially emphasized by migrants in Greece and Italy, who point to the long time spent supporting their families while 'nothing changes in Albania'. Meanwhile, the economies of the countries where they live (especially Greece) have declined. This has discouraged return visits, especially if migrants have no place to stay and must ask extended family to host them.

Buying or constructing a house in Albania helps to resolve the accommodation situation and relieve tensions. Thus, material remittances often consist of houses being built, either as potential family homes or summer houses, in order to facilitate return visits. Otherwise, material remittances take the form of presents to family members - clothes, toys, electrical appliances, televisions or even a bath tub, especially among Albanian migrants in Thessaloniki who travel by bus.

\subsubsection{Attitudes Towards Return}

Literature on return migration - 'the movement of emigrants back to their homelands to resettle' (Gmelch 1980, p. 136) - is growing, although little research has been conducted on factors that affect return. This is despite the fact that attitudes towards and intentions to return have been already identified as an important variable in migration research, since they affect migrants' links to the home country (Alhburg and Brown 1998).

Many Albanian migrants in London, Thessaloniki and Florence contemplate return continually over the years. At the same time, there is a growing uncertainty 
towards return. It is common for parents to feel like temporary residents in the host country, while also being aware of the progressive establishment of ties over the time spent there. In many cases, return is seen as definite, but only after a certain number of years. This time 'gap' usually reflects the benefits of staying and working in the host country, and is also dependant on the ages and stage of education of the children. Many parents see return as possible only after children have finished school and university studies and have settled into a job in the host country.

Qerim (male, 46, London): If it was for me, I would leave tomorrow! When I came my goal was to stay here and earn enough money to buy a house [in Albania]. But as they say in Albania, 'You know [what happens during] the outbound journey, but not the inbound one!' Yet, I am pessimistic about our return, because the children now are at different ages... and you don't want to ruin their future possibilities that might be here... My son says about return, 'Whenever you like now, but later in life I don't guarantee you that I would like to return to Albania.' But then after him we had the girl and she is growing up now, and then the little boy... Maybe return will remain a dream. Because one has to consider the reality.

Some first-generation migrants rule out the possibility of return, despite in many cases planning or desiring a transnational life after they stop working. Life under communism and poverty is referred to as a memory that makes return improbable.

Farije (female, 45, Florence): For the moment I have told people, 'even when I die, just throw me in some corner. Just don't take me to Albania!' I don't have nostalgia because we suffered a lot in our youth... we suffered to an extreme degree!

The education of children and plans for their future are mentioned as key obstacles to return (see also Teo 2011). However, although children's opposition to return is one of the main reasons stated by the parents as a barrier, parents have their own implicit and unstated dilemmas in regard to return. Sometimes, indeed, it is the children who point these out, remembering discussions they've overheard at home. Parents' uncertainties regarding return relate most of all to employment, as they consider whether they would be able to resume their professional identity or whether they should consider investing. Among the highly skilled, return depends on opportunities and development of a professional career in the host country.

Some consider pension and insurance. Migrants contribute to social security schemes in the host country, and they are aware of the poor services in Albania to support returning migrants in their later-age lives.

Michelino (male, 46, Florence): It's not that I have made up my mind to stay all my life here, but we have contributed here. I have been working here for 20 years, and in 10 years I will be retiring. I can't go back to Albania, leaving my contributions here. But even if I returned, what will I do there?

Houses and resources accumulated in Albania during the years of migration abroad facilitate plans of return, although such investments can be controversial in the family since they bring up the topic of return, which is usually resisted by the children. Nevertheless, parents see investments made during the migration years as a means to provide employment, for them and their children in case of return. For some, ideas of return are inspired by the economic progress Albania has made and which migrants witness during return visits. 
ZV: Where do you think your children will have a better future?

Flutura (female, 43, London): If they don't study here, they will go to Albania and work in our shops. You know, I really lost my mind when I went there last time. People have got luxury houses which we don't even dream of here in England. I don't know how they have managed to earn all that money, but still... And it's time Albania gets ready to welcome its people [back]. In 5-10 years Albania has changed.

Sometimes it is the intention to return that inspires investment in the homeland. Intentions and plans to return may be made in the recognition that parents will return on their own and children will remain in the host country.

$\mathrm{ZV}$ : Do you speak in the family about the future?

Lutfie (female, 36, London): I work too hard and don't have time to start this kind of conversation. They [the children] see their future in the UK. When we discuss going back to Albania, the children don't like the topic at all. My husband and I though, we want to spend our retirement in Albania. We are buying a house there.

Attitudes towards return differed across the three field sites. Intentions to return were more explicitly among the first generation in London. Perhaps this is related to their shorter time of residence there compared to the two other sites, so they are less 'settled'. Unlike what King et al. (2003) found in the pre-regularization stage, now that migrants have achieved their goal of settlement, as they grow older and the children settle in Britain, some parents are contemplating return. Parents would like to go back to their own environment, where kin and other networks are denser and there is greater support, better weather for their retired style of life, and in the case of the skilled migrants, as a way to 'rehabilitate' themselves from the downgraded migrant status and re-establish themselves as professionals.

Donika (female, 45, London): I see my future in Albania. I would be the first to leave from here! I am more comfortable there. Here especially the climate is a big problem for me. I say to the children as well, 'I would go if it wasn't for you.'

Some parents in Florence are contemplating return or actually returning because the cost of living in Florence makes it impossible for them to save sufficiently to realize their plans for educating their children. Migrants in Thessaloniki mention long-term residence in Greece as a reason to stay, while harsh discrimination and the accumulation of a certain financial capital inspire return. Migrant women see return as improbable; they regret not having gained skills that would facilitate return, because of their work in the domestic sector.

Monda (female, 50, Thessaloniki): I don't think I am going back to Albania. It's impossible. I left my job there 16 years ago. There are so many new teachers now. The only thing I have there is the house that Enver Hoxha gave us. If I go back, how will I live? I would start a business, but what a shame I didn't gain any skills here. A real shame, we didn't learn a profession. For example, if I learnt to make clothes, or to cook, so I could open a small restaurant and sell pizzas, but we don't know how... Or at least if I had a lot of money I would open a café or start a business. So how can I consider returning to Albania? Unless my children migrate to another country, then I might go back, but even then I can't because there we don't have a pension.

The recent economic crisis in Greece has had serious implications for migrants' attitude towards return. Recent statistics from the Government of Albania show high 
numbers of returnees from Greece, 62,639 in 2009 and 50,735 in 2010. Return is expected to affect both migrants and their families, as well as Greek and the Albanian society. To date, very little is known about this phenomenon. Some international media maintain that a large segment of the Albanian community in Greece has returned or plan to return (The Economist, 14 January 2012). They also briefly mention that children of migrants are feeling alienated and experiencing difficulties in what is for them a new environment (Reuters, 6 April 2012). This phenomenon is expected to increase in light of recent developments in Greece, such as the near bankruptcy of the state and the prospects of a withdrawal from the euro zone and a long economic recovery.

\subsection{The Second Generation}

\subsubsection{Return Visits}

Empirical research is growing on return visits of the second generation (see King et al. 2011a, 2011b for a Greek case study and a comprehensive literature review). However, their position within transnationalism theory, with its focus on identities as dynamic entities, is unclear (Duvall 2004, p. 53). In the case of the Albanian second generation, there are two trends in the way return visits are experienced: either as a happy time of holiday celebration or as a 'compromise' with parents who must go to Albania to fulfil family obligations or who choose Albania as a cheap option for the summer break.

Since all of the study participants lived in urban areas in the host society, a main facet of visits to Albania was an experience of freedom, play, nature and village life (see also King et al. 2011b), especially among those who welcomed trips to Albania and viewed them as a happy time. Interestingly, this view is shared by children born in the receiving countries. Many of them had been pleasantly surprised and impressed by Albania's natural beauty. Holiday time is especially enjoyable because of parents' lack of free time to spend with their children in the receiving country. This creates a mental distinction between the two places - the cities where they live for work and school, and Albania for holidays, emotional nourishment and fun. Therefore, for these second-generation participants, return visits produced an idyllic image of Albania. This was especially so for children who had been plucked out of their Albanian environment at an early age and deprived of extended family support. For them, return visits were a chance to 'restore' their childhood, catching up with old friends and making new friends with whom they kept in touch.

Blerim (male, 13, Thessaloniki): I always stay there in the village, I don't go anywhere else [during the visits]. I don't go to Mamurras [the main town in his region of origin in Albania] or Tirana. I don't like to go anywhere. When I am there, I stay with my cousins. We all go and play all together, because I know everyone there. We are like brothers, because it's a small village, so we all play together... That's what I like, that we are all together. 
Return visits to the homeland also invoked memories, cultural rediscovery and longings (see also Le Espiritu and Tran 2002). Galvanized by experiences of traditional Albanian hospitality, family events and socializing, houses being built and so on, adolescents generally express the intention to continue visiting in adulthood. There was also an appreciation of Albania as a tourist destination. But apart from 'pleasure-seeking', this is also an 'emotional tourism' inspired by a feeling of familiarity and comfort (see Basu 2004, p. 153).

Locality is an important factor that shapes the content of return visits and attitudes towards their continuation. Duvall (2003, p. 301) introduced the concept of locality in the study of return visits and transnational movement referring to different countries as destinations for the visits. However, locality (or, perhaps better, translocality, see Brickwell and Datta 2011) is also related to the content and the quality of the return visits. For migrants whose families live in remote villages in northern Albania, where living conditions are harsh and there are few opportunities for leisure activities, return visits were limited to visits to relatives' homes and experiences of nature. Migrants with family in urban Albania had more positive experiences, since there were more entertainment opportunities for teenagers. Most research (e.g., Smith 2002, p. 161) has described visits as a return to parents' hometowns or villages. In the Albanian case, however, the transnational experience is less bound to a particular place, due to the internal migration of many relatives, migrants' building of houses in the capital or other major urban centre (Vullnetari 2012) and the touristic preference of the second generation for beach holidays.
ZV: Why were you in Albania? Do you go often?
Lutfie (female, 37, London): We go to Albania for holidays. We go often. Children like to go on holidays to Albania; they can't wait to have their tickets. But when they go there, they get bored easily. Their opportunities to play and get entertained are very limited, there is no electricity for the TV, no park or playground, so the entertainment is running after the cat, catching the chicken, killing the flies... So they ask to go back [to the UK].

As indicated by some of the narratives above, family in Albania is an important reason for return visits. Visiting relatives and friends (Backer 2012) is at the heart of these trips. Yet the role of the extended family in the quality of the return visits is often overlooked in research. In the current study, parents and grandparents figured especially prominently among the extended family. They provided emotional support and praised and cared for children and grandchildren. Parents and children describe this 'special treatment', alongside pampering and affection by other family members in Albania. Gardner (2012, p. 906) describes this strong emotional aspect of return visits:

\footnotetext{
Whilst we must beware of essentialisms... emotions such as love are themselves cultural constructs worthy of interrogation, research with children reminds us that, rather than economic transactions, political networks or cultural criss-crossings [important though these are], it is human relationships that ultimately lie at the centre of transnational social fields, linking people and places. In our attempts to see transnationalism through children's eyes, one of the main lessons we learn is that the love that children tend to readily express for their relatives is what keeps those people and places bound together.
} 
The importance of the family is transmitted to, and is still strong in, the lives of the second generation. Girls in particular tend to spend a lot of time with extended family, especially with the grandparents in the family hosting the migrants. They also accompany the family on visits and attend weddings and other family events. Weddings, a life ritual and collective cultural event in Albania, are important occasions for which migrants coordinate holidays in the homeland. Moreover, return visits are not only a source of fun and enjoyment, but also occasions to be present and to provide support to the extended family.

The frequency of visits changes over the life course. When grandparents become elderly, the first generation returns home more often to provide care and support. These opportunities are embraced by many of the second generation, with teenagers expressing their readiness to be present in such situations. The role of other family members, especially similarly aged cousins, can be paramount in inspiring continuation of such visits among second-generation teenagers, as well as the touristic aspect, especially for those in late adolescence.

Altin (male, 16, London): I usually go for six to seven weeks to Albania every summer holiday. I think... I love it, I mean, I go spend time with my cousins, who are a bit older than me, 20 years old, you know, but um... It's good, we take my cousin, go and see the other cousins in another city. I like to travel, because if I am in Albania, I don't like to just stay at home. I live in Tirana, so I like to go Shkodër, Durrës, Elbasan, wherever I can. Just for fun and to spend as much time with my family, because then after six weeks you have to come back England, more school.

Mondi (male, 48, Florence): Children are always the same, they always want to go. Because... my brother-in-law has children; it's nine in the family and twelve children. They get together as they are also of the same age. They also keep in touch by phone.

Yet attitudes often change when members of the extended family also migrate to the same city or country. As other research has found, time abroad weakens ties with the homeland. This is especially true among Albanians in Florence. Once the extended family has also migrated, the frequency of return visits becomes less regular, and when they do go, it is mainly to look after their investments in Albania.

Gjergii (male, 17, Florence): We go to Albania because of belongingness to our nation and our land, let's say, and then we have a few relatives, no? So we go to meet them and for being close to our nation, not to lose the customs... I don't know, there is always a feeling of belongingness to go there, let's say. Even though with every year that goes, this feeling of belongingness is weaker a little bit, because the interests that I used to have there have decreased because my relatives are here now. And then school, friends and all the rest, so I feel more 'tied' here, let's say. I go there for matters of... don't know, economic reasons, the house to repair, and all the rest. Because we have two houses,... We go on holidays let's say; more than anything, to break the monotony of life here in Italy.

Another reason that inspires return visits is the simplicity of life, the collective spirit of people, and the lack of harassment. For teenagers, this simplicity and freedom seem to clash with the pressure of having to make important life choices at the end of adolescence. Those who do not struggle with identity issues may be caught between the economic opportunities in the receiving country and a longing for a life rich in emotional and social support in Albania. 
Admir (male, 14, London): I think I have more fun there. I think people are more caring. I feel more welcome there, more at home. I think if I could have the education I have in England, if I could have that in Albania, I would rather stay in Albania.... I think here where we live, there is... we have a few friends near us, but there is not... You know, people are not kind; they are kinder in Albania. I think you enjoy yourself more. Here [in England] it is mainly for work, school, depending on what you do.

There is, however, a second trend in attitudes towards return visits: teenagers who resist visiting Albania. Discrimination and the negative stereotypes promulgated by the media and beyond in the host country seem to impact teenagers' willingness to maintain ties with Albania. Moreover, teenagers notice the difference in economic development, infrastructure and culture. Furthermore, as King et al. (2011b) found among the Greek and Cypriot second generations, girls feel constrained by the culture and gender restrictions. Aware of the patriarchal family organization, they perceive the places where they return as a 'small world' that allows no room for a young woman's identity to be expressed and further developed. The gender problems and cultural backwardness are also observed by the boys, although they are less frequently mentioned. Some teenage girls experience restrictions from their parents during their holidays in Albania in terms of going out, while others, conversely, observe with awkwardness the liberal attitude towards styles of dressing and relationships among their peers in Albania. This contrast with the values their migrant parents speak to them about.
ZV: Why do you go to visit Albania?
Eneida (female, 15, Florence): Because it's my fatherland. I was born there... then because I have my grandparents... When I go there, I feel ... really like in my house, so I feel very free... yeah, I feel well, but... well, at times not very free, because of this thing of all those rules to follow... I don't know... Exactly because it's also a male society... and I say this also to my parents. I don't know, if a guy wants to do something then it's alright, and if instead the girl wants to do something, it's not okay.
Manjola (female, 18, London): When I go to Albania, I mostly talk to my grandmother and aunts, not much with the cousins of my age. They are very 'civilized' and wonder how come I am such a good girl.

Return visits during adolescence tend to become a burden if they are not accompanied by a variety of activities and entertainment. This is especially true for children and teenagers who do not speak Albanian (though in some cases, returning for the summer season is precisely for the purpose of learning the language). They begin to miss friendships and relationships in the host country and want to spend summer holidays there. Though return visits may also result in relationships with Albanian youngsters, such trips in general become less frequent in later adolescence and early adulthood.

Once the second generation comes of age, they often widen their horizon, also making independent visits to other countries and places of interest, for example, where other family members have migrated. As Gowricharn (2009, p. 1634) points out, the second generation's transnational orientation is by no means a 'zero-sum game', and the dichotomy of home-host country reduces the complexity of the ties and the sites of reference to which the second generation refers in their everyday lives. Return visits in adolescence and early adulthood may be part of the socializa- 
tion and general cosmopolitanism of that particular age, driven in this case by the feeling of exotic rediscoveries in the homeland.

Return visits and ties with the homeland in general give rise to a comparative transnational appreciation of the opportunities in the home and host country. These ties and comparisons inform and shape teenagers' attitudes towards return to the homeland. This resonates with the work of Louie (2006, p. 566) who observed that multiple frames of reference inform the identity formation of second-generation Chinese and Dominican adolescents in the USA and their views on education. Ilda (female, 14, London) clearly sees herself as 'better off' in London:

I don't know, if I hadn't come to England, some things wouldn't have changed. I don't know, I have experienced a lot from coming here. When I go to Albania I see children and other girls who would like to be in my place, to come here, have money, have food, go to school and have everything sorted out for you, not having to worry for everything. Whereas over there, people have to pay for everything and they don't have much money... You get to know what they feel. I don't really know, because I came to England when I was five, so I don't know in a way. But when you see them, with their old clothes, I feel sorry for them and you feel like giving them everything.

On the other hand, children may feel mocked if the extended family or locals in Albania find them 'assimilated' and changed. Zinn (2005), likewise, notes that the second generation's experiences on visits to the 'homeland' include instances of encountering barriers to acceptance by Albanian society.
Alfonso (male, 15, Florence): I am not afraid to say here that I am Albanian, but when I go to Albania they call me Italian! We have remained stranieri [foreigners] everywhere! [smiles]
Olta (female, 16, Thessaloniki): We go to our aunties... when I decide to go there I feel so happy, but once I am there, the next day I get very bored, because I see people, what they do all day and get really bored all day... To tell you the truth I get very bored when I go there, because you want to watch TV, the electricity is cut and you say, 'Oh, why I had to come here?!' When there is electricity, we watch TV, we go out sometimes... I try to go out, but I don't even like to go out, because they look at me like wondering which planet I have come from. So I prefer to stay home but I can't kill the time like that, so I get bored and I want to leave as soon as possible.

The way that the second generation experiences return visits varies somewhat by host country. Although two overall trends mentioned above are found across the three sites, the distancing of the second generation from return visits is most evident in Florence. These in London indicate more appreciation of the family and nature in Albania, perhaps because they are mainly from rural northern Albania, which has a 'wild' landscape and strong family values. Those from Thessaloniki either opposed return visits as a result of the discrimination they experienced in Greece and their resulting prejudice towards Albania or they cherished the trips to the homeland as providing a completely different atmosphere filled with care, play and acceptance.

In Britain a 'blocked transnationalism' is prominent among Albanian migrants due to slow regularization. Blocked transnationalism creates estrangement and disrupts children's emotional ties with Albania.

Lajmir (male, 18, London): If I would go there, I would be a refugee for the second time! I don't know anything. I left when I was 12 years old, a child... Now... I would go once, 
to see how things work and then simply... maybe once a year; for the family mostly. And that's it.

Initial adaptation during return visits appears to be more difficult for the children visiting from Britain than for those from Greece and Italy because of significant differences in weather and food. Visits of those living in Greece are more frequent because of the close proximity with Albania.

Daniela (female, 17, Thessaloniki): Let's hope we won't stop going, like we did before when we didn't have papers. If we have papers we go often. Because we can go even for a Saturday or Sunday because it's close; it takes just a couple of hours. Dad goes very often during the weekends.

In summary, transnational ties take a more mobile form and meaning for the second generation than for their parents. Other salient features of transnational ties are material and emotional remittances and exchanges and the character of return trip experiences, based on advantage, convenience, curiosity and escapism.

\subsubsection{Transnational Ties Through Technologies}

Like the first generation, second-generation teenagers maintain transnational ties through various technologies, including digitally broadcast Albanian TV, the Internet and telephone. The use of CDs, DVDs and other media is common, but not as systematic. Consumption of homeland media is part of daily life for many teenagers. Some teenagers are passive consumers, watching Albanian TV alongside their parents since households often have only one television. If left to choose, most teenagers show a selective approach (see Panagakos 2003), combining programmes from the 'host' country media with homeland digital broadcasting.

Eliana (female, 15, London): It's always on, 24/7. It is only Albanian TV we watch, except when I have my Hollyoaks or Eastenders or something. Other than that, I don't really watch much English TV. I don't really watch Albanian TV, I prefer films and stuff. But I watch, like, Albanian Big Brother is coming up soon. Or I watch music shows, because I like Albanian music a lot. Like half of my music is Albanian, the rest is English. I also watch documentaries about Albania, or just random stuff that's on, I just watch it.

Digital broadcasting plays an important role in informing the second generation about Albania, inspiring curiosity about its history, culture and current issues, and keeping the idea of a homeland alive. Following Albanian programmes is also a way of cultivating double identification and belongingness.

Lira (female, 15, Florence): I am really keen to learn about Albanian history. When it comes to Italian history sometimes I skip it, I don't study it, whereas on Albanian history I always watch documentaries on DigitAlb. This week there was a documentary on Enver Hoxha, which I watched because I was curious to know about him.

Era (female, 14, London): When it comes to TV, I prefer Albanian to English, I don't know... because it has more channels and it is just more interesting to know about your country, like what's going on there, like you need to be informed, even if though you don't live there you like to be updated or whatever. So I prefer like, watching, like Albanian music, Albanian news, Albanian programmes, shows... whatever... Say a new Albanian 
song comes up I would know it, the same with English... I am kind of both... because it is my country really, no matter how bad it is, I still like it much better than this country because like my family is there and... I like Albanian music and the more years go by I like it better, the more I am into it.

The Internet is another means for teenagers to carry out independent research on Albania and its history and culture.

Altin (male, 16, London): I always go on Google, on the Internet and type in 'Albania and this' whatever... I have read about Enver Hoxha, I have read about Skanderbeg, you know, Sali Berisha ${ }^{6}$ and all that. You know, to pass the time, and learn something about Albania.

Participation of second-generation teenagers in Albanian Internet forums is limited. For example, the Rete G2 Network of Second Generations in Italy, has few posts from the Albanian second generation, even though they constitute one of the most numerous second-generation groups in Italy. The only network organized by the second generation and youth I came across is Fundjava Shqiptare (The Albanian Weekend), ${ }^{7}$ which, according to its organizers aims to counteract the social disintegration of Albanians. Nevertheless, the site was also a space to for teenagers to express hybrid identities in the making, allowing them to combine youth culture as experienced in the 'host' country with the familiarity of Albanian language and peers. The quote below is taken from the forum of this network and is an example of the combination of the two languages in everyday life:

Username: London GirL

bukuranja what do u mean e nesermja moj se me hallakate, [tomorrow because you are messing me up] the party is next month I think ma ngrine gjakun [my heart stopped for a moment], but anyways let me know nese eshte neser [if it's tomorrow] I'd love to come.

Websites and Internet forums can serve as a site to exercise symbolic ethnicity. This is expressed virtually by choosing usernames in chat forums such as 'forever_an_Albanian' or 'Albanian red and black' and using the Albanian flag and other national symbols as profile pictures. Nevertheless, the use of Internet platforms to express ethnic identity and build online communities, as do many second-generation groups (Brower 2006), is relatively limited among Albanians. While research shows websites to be a space for self-expression and cultivating a collective identity (on the Chinese second generation in Britain, see Parker and Song 2007), secondgeneration Albanians are far more passive and individual in this regard.

Transnational ties through ICTs are dependant on, and also have an impact on, knowledge of the Albanian language. Poor proficiency in Albanian is a main obstacle to teenagers' establishment and maintenance of ties with Albania. Some teenagers improve their written Albanian via online conversations with cousins in Albania. Yet much Internet communication between Albanian second-generation teenagers

\footnotetext{
${ }^{6}$ Enver Hoxha was the dictator of Albania between 1944 and 1985. Skanderbeg is an historical folk hero, as noted earlier. Sali Berisha was the Prime Minister of Albania when research for this book took place.

${ }^{7}$ www.fundjava.com. Last accessed 18 January 2008. The website and the forum were down in April 2011. The organizers in 2008 noted lack of funding. By the end of 2013 the same group appears as transformed into an events enterprise called ZigZag Events.
} 
takes place in English, especially when it involves the diaspora in North America. Of course, Internet access is an important factor (Panagakos and Horst 2006). The Albanian second generation tends to be in more frequent touch with relatives in other countries through the Internet rather than in Albania due to the greater prevalence of Internet access in countries like Germany, Britain and the USA.

Ties through the Internet can also play a role in keeping in touch with relatives, giving rise to virtual mobilities that interweave kinship and friendship ties (Adey 2010). Increasingly, the Internet provides a means for transnational care and emotional bonding. Telephone calls with grandparents and Internet calls to cousins were common at all of the three sites.

Drita (female, 45, London): My children are very close to my mother. So when I give them a pound as pocket-money they save it and buy a phone card to talk to her. They really love her. They don't speak often... maybe every two or three weeks. Sometimes they spend the money with their friends and then, when they feel they miss her, you see them showing up with a telephone card. I feel sorry sometimes that they don't spend the money with their friends on chocolates or other things.

Jonida (female, 15, Florence): With my relatives; we call my grandparents. My mum calls them practically every two days, it's a habit. I also speak to them through the phone, but also through the Internet with a webcam so that we can see each other.

\subsubsection{Attitudes Towards Return}

There is a growing literature on the return migration of the second generation (Byron and Condon 1996; Chamberlain 2005; King and Christou 2010; Phillips and Potter 2009). We know little, however, about attitudes towards return among second-generation minors, or the conditions and negotiations within the immigrant family that might stimulate or obstruct return. Much research sees the phenomenon of transmigration as a process which in the long term can diverge along different trajectories (Grillo 2007, p. 1999). Three main narrative strands emerge from the interviews of my study. Firstly, a number of second-generation teenagers contemplate return to Albania for better social integration, reunion with the wider family and possible business opportunities. A second trend is represented by the tendency towards 'onward' migration (Newbold 1997), particularly to North-West European countries from Florence and Thessaloniki and in a few cases from London onwards to North America. Finally, some teenagers show a cosmopolitan orientation towards global cities and an eagerness to get to know other cultures. Indeed, for many second-generation teenagers 'return' implies mobilities rather than permanent return (Urry 2007).

The majority of the Albanian second generation is either against or unsure about future permanent return to Albania. Feelings of belongingness to the host country are a main reason for rejecting return. This is seen in a feeling of familiarity with the location where they live and the everyday experiencing of life events there. Lack of fluency in the Albanian language is a further brake on return. Parents are aware of their children's lack of desire to return, mostly due to the structural issues 
of reintegration in Albania, in terms of becoming part of various systems which are significantly different from what they are used to. In particular, girls point to the social problems in Albania and difficulties of integration in Albanian society. They notice some of these issues during return visits; for instance, differences in terms of manners and civility and in customer service. A more crucial issue is gender inequality and a feeling of helplessness and that things will not change. Therefore, some teenagers are determined not to return to Albania.

Yet there are factors that 'pull' in the other direction, towards return. After their struggles to integrate in the host society, both parents and the second generation recognize the positive aspects of a potential return to Albania. Recently, this trend towards thinking return has been enhanced by the weak economic situation in the countries where migrants live, especially in Greece. Opportunities for business in Albania were mentioned by the teenagers at all three sites. Teenagers think they may take advantage of the opportunity once they have come of age and secured some financial capital. Experiences and activities in the host country can also serve as inspiration for business plans upon return to Albania.
ZV: Where do you see your future?
Alfonso (male, 15, Florence): In Albania.... We will start a business, because here it's very difficult. You need a lot of money. Even an Albanian boy who is last in our class wants to go and start a business in Albania. [smiles] There are quite a few Albanians in my school, and everyone wants to go and work there. For example, I would like to go and open there a school for classic ballet dance.
Angela (sister, 12): Yes, and it would be good to also help the children there because there are many children that need help. I have been to the hospital there and didn't like how it was... So I would like to go to Shkodër and become a cardiologist or a paediatrician.

There are, however, differences between the three cities in terms of teenagers' attitudes towards return. Synthesizing these, intentions to return are affected by the degree of social integration in the 'host' societies and especially experiences of discrimination in the two Southern European cities, in contrast with the multiculturalism of London. Teenagers in London appreciate the broad range of opportunities that they have in Britain, which generally prevents any serious consideration of a definitive return to Albania. A good higher education system and the consequent possibilities to integrate into the labour market are the two main reasons why teenagers and their families indicate plans to continue their stay in Britain. Furthermore, the acquisition of citizenship has 'relieved' some of the worries of integration and given them the possibility to take advantage of options and opportunities in the homeland. However, this is not the whole story: in a few cases, the lack of social integration and the climate are reasons for teenagers to contemplate a return to Albania after education in Britain.

Eliana (female, 15, London): I would like to go and live in Albania when I am older, because I find myself happier there than here. Here you have friends and stuff, but in Albania it is also the climate, because here it can get a bit sad and depressing because you don't get a lot of sun or anything. Whereas in Albania the climate and atmosphere is much warmer than here. There it's warm, lots of people, everyone would say 'Hi' to you or whatever. Here you just walk down the street, it's raining, no one says 'Hi' to you, everyone is looking down, minding their own business. Um, like Albanians are really friendly when I go, the ones I 
have met so far. So hopefully I can go to Albania once I pass, find a good job there, with enough money for me to live with.... because my parents aren't going to stay for all their life here either. They know they want to go and live and die in Albania, as do I.

Altin (male, 16, London): My dream is to do good in school, get a job that pays well, work for 10 to 15 years, but [then] I want to go to Albania and live there, build a house, build a business or something, in Albania before I am 40. It's not that England, London is not a good place; I mean it's good, it's alright, but my home is Albania. I am Albanian, I would rather live there, have family there. Here I have no family, except for my mum, dad, sister, brother. No cousins, no uncles... I would rather live in Albania.

Thoughts about return and plans for mobility are rather more variegated among the second generation at the two southern sites. Some second-generation youngsters are returning to Albania to attend higher education. This is mostly as a result of the difficulties of accessing higher education in Greece. In Albania international colleges offer studies in English, some affiliated with American or Italian universities. In some cases, this results in 'counter-diasporic migration' of secondgeneration youth (King and Christou 2010), while the first generation is still in the host country.

The opposite trend also exists. A family's experience with migration seems to inspire a more mobile attitude towards their future life and ideas of settlement. Therefore, some teenagers in Greece and Italy are contemplating migration towards more economically successful countries.

Genti (male, 18, Thessaloniki): It doesn't matter. We have grown up here and there. We can go to another country, we can return here; wherever it is, wherever we like to be. Probably in Greece, Germany, England, wherever. I don't have a specific target. If things don't go well, I will go to England.... I would like to go and live there and see how it is.

Viola (female, 14, Thessaloniki): I would like to travel to so many countries. I want to go and see places... I have heard that there are so many different beautiful countries. I have heard England is very beautiful and I like English... So I would like to go abroad.

Teenagers in Florence naturally expressed this flexible attitude towards future migration, based on appreciation of opportunities in Italy, Albania and elsewhere in the world, especially other European countries. Apart from the issue of papers, which conditions their movements at this stage, their understanding of spatial movement, settlement and their geography of thinking in general is broader than that of the first generation. The migration project of the first generation was mainly inspired and oriented towards economic security for the family, better education and better life prospects for the children. In contrast, migration to Italy is sometimes itself seen by the second generation as a way of offering the possibility to encounter and 'practice' cosmopolitanism.

Klejdi (male, 17, Florence): It was good because by changing country you learn, you get to interact with other kind of people, with other cultures, and this is not a bad thing. This changes a lot in a person.

Plans for future migration are interwoven with a cosmopolitan orientation, even if this may ultimately be constrained by resources. This reflects Beck's (2002) view that the focus of cosmopolitan sociology should be on inequality in terms of possibilities to be mobile. Nevertheless, cosmopolitanism is appreciated over 'monocultural' societies by the teenagers because it would ensure their 'invisibility'. 
Xhilda (female, 18, Florence): If I could, I would go to another country to live, but not here in Italy. For example, in London or in Germany. I really like Germany... but it is very difficult to make documents there. And then it's difficult to go and start a life there. Because I am making my life here; what would I do in Germany, wash dishes? I have my life here, my parents... and they are getting old.

Dana (female, 15, Florence): If you want better prospects you can go and do the university in London. I would like to do that.

ZV: What would you achieve by going somewhere else?

Dana: We open our eyes a little bit.

Xhilda: More money. Culture, you see something else.

Klejdi (male, 17, Florence): Italy is finished in my opinion.

Xhilda: Besides, my parents have always moved... since I was very little we were moving to other places. Here and there. We have always tried to improve our lives.

Dana: Besides, we always look for better in life.

Xhilda, above, also spoke of the cosmopolitan orientation cultivated in communist Albania by her professional parents and their internal migration in an otherwise isolated country. Delanty (2006) states that cosmopolitanism is not only a result of globalization; it can be found in any society where social mechanisms and dynamics give rise to new cultural forms and processes of self-transformation, which in turn transform the social world. Nevertheless, cosmopolitan tendencies are framed between the need to move to a more accepting society where one is more 'invisible' and the genuine desire to explore and know the world. These aspirations are especially evident among the teenagers in Florence, perhaps reflecting their assimilation in Italian society, since a tendency to migrate 'northwards' out of Italy is common among Italian youth (Conti 2008). It is also common among those in Thessaloniki, but less so among the teenagers in London. The tendency to migrate in search of better opportunities is also seen as a legacy of the first generation, as well as a reflection that conditions in the host country are deteriorating.

Erjol (male, 17, Florence): When I grow up I want to explore the world. Maybe Europe... In my opinion opportunities here will start diminishing because Italy is declining economically... It's declining a lot. So let's see... The future is uncertain in Italy. If I finish school and don't start working, I will go somewhere else. Basically I have seen how my father has lived. He has always gone where there is work. He went to Greece, then came here. He did well here and stayed... Same for me, if I don't do well here, I will go... like my Romanian friend did. He went to London. So basically one goes where there are more opportunities.

Teenagers' attitudes towards mobility go beyond the issues of papers and border crossings. As hinted at in the narratives above, teenagers feel at odds with the idea of crossing the border, the demands for paperwork and the fragmentation of their journey to Albania. Despite institutional constraints, imaginative travel is an important part of these teenagers' future projections.

\subsection{Conclusions}

This chapter showed that both the first and the second generation develop and maintain various kinds of transnational ties. These ties change over time alongside the process of integration in the host country. As the various patterns of integration and 
identification unfold, different kinds of transnational ties are established and the patterns of their maintenance change over the years.

Transnational ties show different patterns between and within the two generations. These differences are demonstrated both in the symbolic elements of these ties and in the more logistical ones. In particular, return visits constitute significant events in the immigrant family. They tend to evoke emotions and feelings of longing and belonging, although also highlighting underlying tensions and differences between parents and children and between immigrants' nuclear family and the extended family and kin networks in the homeland. Return visits stimulate parents and children to question and re-evaluate their identity and related issues such as gender relations, discrimination and the institution of family.

Nevertheless, the first generation usually prioritizes integration over transnational ties, especially in terms of the distribution of family resources and attitudes towards future life goals. The concepts of 'transnational ways of being' and 'transnational ways of belonging' (Glick Schiller 2004) both find support in my data, although each has changed over time. Transnational ways of being are much more common among both the first and the second generation. Transnational ways of belonging are more emphasized among the first generation, although this belonging is mainly to the past spent in Albania and to their families, rather than a symbolic belongingness expressed in the name of a group towards a homeland. In turn, the geographical approach, emphasizing space and place, and associated mobility tendencies and orientation are more a second-generation phenomenon, and members of the second generation also show tendencies towards cosmopolitanism. Whilst both the first and the second generation demonstrate forms of 'strategic cosmopolitanism' - the capability of vulnerable individuals and groups to understand and negotiate cultural diversity in order to live in environments characterized by insecurity (Kothari 2008) - the teenagers are significantly more prone towards mobility and cosmopolitan imaginaries and practices.

The spatial references in these teenagers' narratives indicate both global-to-local and local-to-local dynamics, in addition to transnational ties. Firstly, the locus of integration for the second generation goes beyond the host and home country discourse. In this particular case, feelings of integration and cosmopolitan orientation counter the perception of the national realm as the locus for integration. A glocalized cosmopolitanism (Roudometof 2005) seems to explain their relations with culture and space. Talking about different degrees of attachment to particular cultures, locales and regions, Roudometof (2005) employs the concept of glocalization - the transforming effect of globalization at a local level - to operationalize the cosmopolitan-local continuum. He concludes that a combination of both global and local forms of identity is very possible.

This study joins previous research in challenging the taken-for-granted continuation of remittances and in acknowledging that in some cases and among some groups remittance flows decrease or stop. Therefore, the picture is far more complicated than 'migrants are the original givers while those left behind are more or less passive receivers' (Åkesson 2011, p. 337). Moreover, migrants in this study engaged in discourses on cultural change and individuality and, more importantly, 
on civic responsibility and government accountability in relation to those left behind and obligations to support them financially. This perhaps relates to the contrast between the ambiguous understanding and adoption of neo-liberalism in Albania and strands of thinking and a return towards welfare in the Western world, experienced by migrants in the receiving societies (see also Reeves 2012). While collective remittances and engagement in developmental programmes is unusual among Albanian migrants, despite this also being the case among migrants from other postcommunist countries (Isabaeva 2011), the discourse of some migrants indicates a shift from the obligation to regularly support family and kin to certain social and economic enterprises that would affect the community welfare and alleviate social problems. Future research could explore these discourses in greater depth within immigrant families and during return visits to Albania, as well as attitudes among the second generation.

In terms of differences between the three sites, the findings of this chapter are very much in line with one of the classic writings of transnational studies. Glick Schiller et al. (1995, p. 50) maintain that the conduct of transnational lives is related to three main contextual factors: the history of immigration and modes in which immigrants are received in the host country; migrants' cultural resources; and discrimination and hostility faced by an immigrant group. Furthermore, the state is a major factor in conditioning and shaping transnational ties (Joppke and Morawska 2003; Levitt and Jaworsky 2007). This is especially true regarding return visits and other spatial mobilities, for which the mechanism of regularization plays a crucial role. Because discrimination was much stronger and more persistent at the two southern research sites, transnational ways of being and belonging were much weaker in Thessaloniki and Florence, along with the phenomena of identity contraction and mimicry (Romania 2004). In turn, transnational mobilities were severely obstructed by the irregular nature of Albanian migration and the long process of regularization:

\footnotetext{
A study of mobilities must be able to simultaneously normalize an array of forms of mobility but not minimalise the ways in which legal status, as well as global racialising categories, can make a world of difference in terms of the ease of travel, the repercussions of trying to move, and whether or not the traveller gains or loses status from being from elsewhere (Glick Schiller and Salazar 2013, p. 188)
}

The current study's findings support Vertovec (2009, p. 80), who maintains that the relationship between transnationalism and integration is not a zero-sum game. They are also in line with Dahinden (2009, p. 11), who found that the longer migrants stay in the receiving country, the less transnational they are, and the strength and proportion of transnational ties diminishes as the duration of stay increases - an argument that supports assimilation theory. In this study, integration and transnational ties interact in different ways: for some, the more integration, the weaker their transnational ties. But certain transnational ties, such as those maintained using ICTs continue to exist through the integration process. It appears that integration and transnational ties do develop at different paces; moreover, certain transnational ties develop progressively, but others do not. Transnational ties through ICTs have been rising and evolving, from telephone to TV to Internet and Skype. Return visits, however, were initially obstructed by lack of papers; they developed in intensity 


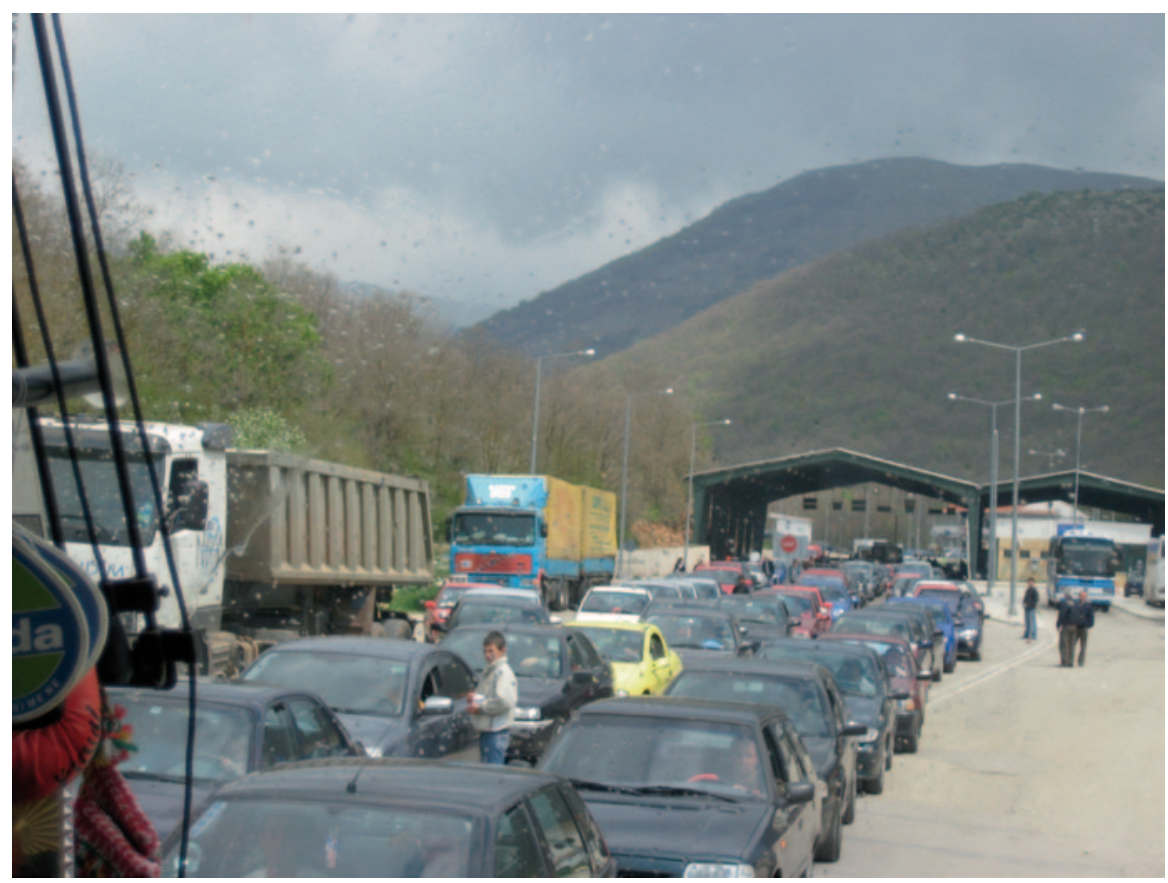

Fig. 4.1 'Keen transnationals': Albanian migrants in Greece returning to Albania for Easter 2008 through the Kapshticë -Xristalopigi border point

after regularization, and then ceased or were reduced because of clashes with kin or disappointments with the way migrants were treated in the home country. Or in some cases they increased because of (perceived) business opportunities in Albania.

The data on the role of kin and locality support the view of Nagel (2002) and Olwig (2003) that a broader approach is needed focusing on socio-cultural systems in relation to migrants' life trajectories and fields of interpersonal ties and on culture as produced and reproduced the nation-state in migrant households, neighbourhoods and workplaces. The typology offered by Faist (2000b), comprising transnational kinship groups, transnational circuits and transnational communities, is not fully supported by the data. These constructs are based on the principle of reciprocity either within kinship groups or within circuits crossing countries, or the more symbolic reciprocity over time and space, which are rather missing among Albanian migrants and their descendants (Fig. 4.1).

Open Access This chapter is distributed under the terms of the Creative Commons Attribution Noncommercial License, which permits any noncommercial use, distribution, and reproduction in any medium, provided the original author(s) and source are credited. 


\section{Chapter 5 \\ Intergenerational Transmission of Ethnic Identity, Integration and Transnational Ties}

Intergenerational transmission in the context of migration is a largely understudied phenomenon. This is despite significant research on the role of the family in socialization of children and young people, and the significant literature on migration from a generational perspective. After analysing identities, integration and transnational ties, this chapter turns to intergenerational transmission between the two generations. It starts with theoretical and conceptual aspects, followed by sections on transmission of identities, integration and transnational ties, ending with a conclusion.

In this study, intergenerational transmission is shown to be a complex and fragmented process, defined and redefined over time by first-generation migrants and their children and showing differences in terms of content, means and intensity of transmission. Regarding content, generational interaction involves transmission but also disruption, with some values being transmitted and others withheld by the parents. Teenagers are independent actors, not just passive receivers, in the process of intergenerational transmission, making it a two-way process. The means and intensity of transmission emerge as relative to the content being transmitted: the types of ties or identification and integration aspects. This chapter also contributes to the understanding of intergenerational transmission as contingent on the legal status of migrants and regularization processes, showing that these have an important effect on transmission, particularly with regard to integration.

\subsection{Intergenerational Transmission in the Context of Migration: The State of the Art}

Study of the relationship between generations is limited in the migration literature, although the significance of intergenerational relations in migration is manifold. Condon (2009) relates intergenerational relationships to major events in the migration process: the migration decision, maintenance of family relationships in the place of origin during migration, and the integration of the second generation. As 
these events are interrelated, intergenerational transmission among migrants in the receiving country is found to have features that distinguish it from that in native families (Phalet and Schönpflug 2001).

Much of the existing, limited literature on intergenerational transmission among immigrants is made up of quantitative studies conducted at a macro-level and based on large datasets on the performance of the first generation and how that affects the second generation's economic integration and socio-economic mobility (see, e.g., Bauer and Riphahn 2007; Borjas 1992, 1993). From a theoretical perspective, Esser (2004) adopts a similar focus. He maintains that structure-institutional and cultural factors at the national level — are the most important determinants of intergenerational transmission. Taking the example of the educational system, he attributes a major role in the process to generalized forms of capital, not limited by ethnicity, or to human capital in the form of technical and administrative knowledge.

Condon (2009) maintains that the relationship between the generations has particular relevance within the family sphere. However, more culturally oriented studies have also appeared in the form of surveys based on large samples (Nauck 2001; Phinney and Vedder 2006; Schönpflug 2001). These emphasize inter-group differences and the role of the context and structure in intergenerational transmission. Phalet and Schönpflug (2001) base their study on transmission of values of collectivism and achievement between generations of immigrants on two main assumptions. Firstly, they acknowledge the potential conflict in the process because of the differences in the cultural frameworks of the host society and the sending country. They also, secondly, note that transmission of values can be regarded as more important amongst immigrant families than amongst natives. Taking the case of Turkish families in Germany and the Netherlands, compared to Moroccan families in the Netherlands, they note differences in the context, content, mediation process and intensity of intergenerational transmission. Recent research has attempted the study of intergenerational transmission in the context of African migration (Attias-Donfut et al. 2012), adopting a mixed-method, comparative and transnational approach and offering accounts of development and maintenance of intergenerational relations. However, research that takes a retrospective approach cannot capture children's experience, whilst case study methodologies based on research at the national level do not allow theorization on intergenerational transmission as a process at a micro-level.

The role of context has been disputed in research emphasizing the role of capital transmitted from the first generation - human and cultural capital in particular. For example, Schönpflug (2001) hypothesized that, because of the differences in culture between the sending and receiving country, intergenerational transmission in immigrant families will be either dysfunctional or successful but segregated from the majority culture. This has been a major assumption of intergenerational transmission studies, which are based on the belief that migration disrupts the transmission process, especially when the culture of the host country is very different from the original one. Schönpflug (ibid.) studied the content of transmission and 'transmission belts' - the factors that can enhance transmission-focusing on fathers and sons, working with families in Turkey and with Turkish-origin families in Germany. She suggested that in a discontinuous cultural context parents would be less motivated to transmit their standards and attitudes to the next generation. However, she found that continuity in the cultural context does not enhance intergenerational 
transmission. Rather, it was the father's educational level that moderated the intergenerational transmission, with parents' values found to be transmitted more significantly in families with high and middle-level education, but not in those with low education. Adolescence appeared to be a strong determinant of the intergenerational transmission dynamics, with early and middle adolescence being the most favourable for an effective transmission of values, making the inclusion of intergenerational transmission in the study even more important.

Discontinuities have also been found in studies of the intergenerational transmission of language, although the literature on this topic is particularly limited (Casey and Dustmann 2008). For example, Bleakley and Chin (2008) based on micro-data from the 2000 US Census found that parents' English language proficiency significantly and positively impacted the second generation's language proficiency, preschool attendance and educational attainment. Casey and Dustmann (2008), on the other hand, studied the intergenerational transmission of language and its impact in the labour market integration. They found that parental language proficiency does impact the labour market integration of the second generation, but this impact was significant only in the case of girls. This was explained by men's greater flexibility and access to jobs for which language proficiency is not so important.

More importantly, there is a tendency in the second-generation literature to see parents as a 'constant' - both culturally and in terms of settlement and spatial mobility. Migrant parents are seen as static and as the standard by which to measure differences with the children's new identities, whereas the dynamic life experience of parenthood is totally ignored. Getting married, becoming parents, growing old these life-course milestones of the first generation are not taken into consideration when intergenerational transmission is studied.

In order to analyse the intergenerational transmission, the current study adopts the operationalization of Phalet and Schönpflug (2001) as a guiding tool. They studied intergenerational transmission in terms of content and the characteristics of the mediation process. However, questions on intergenerational transmission in this research were conceptualized as open-ended and the goal was to investigate the process as whole. Complementary to the quantitative research available on the topic, this book examines whether parents are prone to transmit to their children and what, how transmission varies through time and on different topics, and how patterns of integration of the first generation affect the intergenerational transmission to their children and vice versa.

\subsection{Intergenerational Transmission of Identity}

\subsubsection{Transmitting 'Albanianness'}

Intergenerational transmission of Albanian identity and culture has taken place according to three main trends. First - but only in a few cases - children report parents actively encouraging them to learn about the history of Albania and about customs and wedding traditions. 
Second, there are cases of parents consciously deciding not to transmit their ethnic identity to the children. These were mostly instances in which the parents themselves were experiencing identity contraction, either because of harsh discrimination or as a way to fully assimilate into the host society. Parents may then choose not to teach their children Albanian, not to take them to Albania for visits and not to teach them Albanian customs. Parents usually eventually regret the decision not to transmit Albanian identity, especially where language is concerned. Nevertheless, the consequences of this earlier attitude for teenagers are irreparable in many cases. Teenagers find it hard to learn Albanian at an older age, and many of those who were taught to identify wholeheartedly with the host country's culture refuse to make any effort to connect with the parents' past.

Representing the third trend are Albanian migrants who expect their children to maintain a symbolic identification as Albanian, preserving some customs and respect for traditions and institutions, especially the family. Across the three sites I found a genuine interest among the second generation to learn about the folk culture of Albania - the old traditions, costumes and tales. Skanderbeg is by far the most popular historical figure in the narratives of the parents. Some teenagers in London are, indeed, quite ethnically 'aware' and 'involved', despite their ethnic identification being only symbolic. Some teenagers had taken the initiative to research the history of Albania and became active in cultural causes, such as the preservation of the Albanian language.

Donika (female, 45, London): Yes, I often speak to them about Albanian culture. My husband tells them how we were raised and how we lived, but I tell him, 'Please, they don't understand.' I tell them about Skanderbeg, my husband sometimes about Enver Hoxha, but I don't like politics. They do like to hear about Albania in general. The youngest one, my daughter, asks me to tell her about the old songs and folkloric music.

Intergenerational transmission (and also disruption) also takes place through foods. These are not always welcomed by the children, but they were invariably mentioned by parents as expressions of their double identity. Some teenagers, too, expressed their double identity and belongingness through the food that was prepared and consumed at home, while those rejecting Albanian identity also took a stand, dismissing 'ethnic' cooking as a principal activity in the Albanian family.

Mirjeta (female, 36, Thessaloniki): As for the cooking and food, they will like it one time and another time they prefer to eat something else. You know those things we used to like when we were in Albania, for example, trahana or papare, ${ }^{1}$ the children are like 'ewww'! Era (female, 14, London): When we are at home, we speak English, and then we speak Albanian as well. I don't know, we do a bit of both in language, food, everything. Like one night we could have chips and one night we could have... I don't know, something Albanian, like pilaf ... when it's Eid or whatever... When it's Christmas we have a turkey, but we also have baklava ${ }^{2}$ like Albanians and it's kind of mixed, if you know what I mean. Rudina (female, 18, Florence): No, we cook very Italian, like pasta, things like that. Not Albanian food, or sitting there and cooking for hours, like in Albania. We don't have that... [except] baklava [smiles]. We make my cousin who lives downstairs cook us baklava.

\footnotetext{
${ }^{1}$ Trahana-food used for breakfast, similar to a handmade cereal. Papare - a sweet in central Albania.

${ }^{2}$ Pilaf - steamed dry rice, usually served with meat. Baklava - a sweet pie, typical dessert for special occasions.
} 
As parents experience strong discrimination and negative stereotypes, they avoid putting much emphasis on ethnic identity. Discussions on Albanianness and Albania are also avoided due to the loaded meaning of 'Albanian' and the very negative connotations attached to it. For some, ethnic identity is transmitted indirectly by counteracting the bad stereotypes that exist about Albanians.

Clara (female, 41, Florence): When he [my son] was going to school when he was little, he was coming back home crying. He was saying, 'They call me Albanese. I don't know why they insult me!' Because at home we tell him that we are Shqiptare. ${ }^{3}$ I had to explain to my son that Albanese is the translation of Shqiptar in Italian. Just like the Italiani are called in the USA, so the Albanians are called Albanesi in Italy. It was then he realized what was happening. Because listening to the TV and others speaking, he had thought that Albanese meant criminal!

Maintaining a positive attitude towards Albania and Albanianness in general and not cutting ties in the face of stereotypes is sometimes the best that parents can do in order for the second generation to not completely lose contact with their roots. Sometimes parents, especially the highly skilled ones, used indirect means, like books and positive documentaries on Albania, to trigger interest or increase knowledge of their children about Albania and its history and culture. DigitAlb service is present in many families and serves the same purpose. Therefore, when parents get engaged in the transmission of ethnic identity, they focus on 'core' elements or myths (Malcolm 2002), such as the language being a very old one in the Balkans. Parents also point to positive changes in Albania, such as the rapid development of tourism. Some among the highly skilled parents take a more proactive approach and try to challenge their children's feelings of inferiority because of their origins. Drawing on a bigger cultural repertoire they refer to important historical events and offer examples of a symbolic value by putting the modern discrimination of Albanian identity in a broader context.

Pali (male, 48, Florence): I have continuously tried to liberate her [my daughter] from this kind of complex, basically for her not to be afraid [to admit her Albanian identity], although her country of origin is not liked, and there is nothing to be extraordinarily proud about in being Albanian. There are many good Albanian qualities, which should make one feel good. Among others, she also had an American friend. Her answer was, 'Dad, being American is something valuable, being Albanian is not that valuable.' ... So yeah, she had this regret for being Albanian.

Parents are also cognizant of the enormous difference between them and their children's generation due to their own very simple childhood, starved of resources and entertainment. This impacts the 'content' of intergenerational transmission, and expectations on the part of the parents (Fig. 5.1).

Agroni (male, 42, Thessaloniki): We Albanians don't have culture... And besides what to teach to the children? The oldest one comes back from school at 4.40 PM, what to teach her? She will have to do her piano lesson, to have a shower, to do her homework, so when can I teach her the Albanian culture? We had more free time when we were young in Albania, and besides there were different conditions. I used to care for my sister who was younger than me. My mother used to go to work, those were the laws of Enver [Hoxha].

${ }^{3}$ Shqiptarë is the Albanian translation for 'Albanians'. 
Substantial differences were observed in terms of the intergenerational transmission of identity across the three sites. In Britain, a conservative attitude towards Albanian culture reflects partly the more traditional North Albanian origins of most Albanians there, but it can also be understood as a reactive stance towards a very different culture and environment and a perceived impossibility to embrace it. These differences create a cultural closure, in contrast to the southern cultures of Greece and especially Italy, with which Albanian first-generation migrants are more familiar. On the other hand, the problems of youths in the London suburbs are a real issue for Albanian parents for whom parenting is a top priority. Holding on to the Albanian culture is seen there as a way to protect the family and the children from social problems that many teenagers in the host country face.

As a result, the intergenerational 'gap' is more evident in Britain. Feelings of alienation were expressed by the parents, who suddenly find themselves unable to understand the youth culture around them. Parents in Britain were far more insistent in preserving Albanian culture, which was often equated with strict discipline and having a 'normal' family-centred life. By contrast, at the two Southern European sites, Albanian parents were generally very open towards the host society's culture, as long as respect for the family, education and hard work were appreciated by the second generation. Intergenerational transmission is most direct and linear among Albanians in Florence. According to Phinney and Vedder (2006, p. 182):

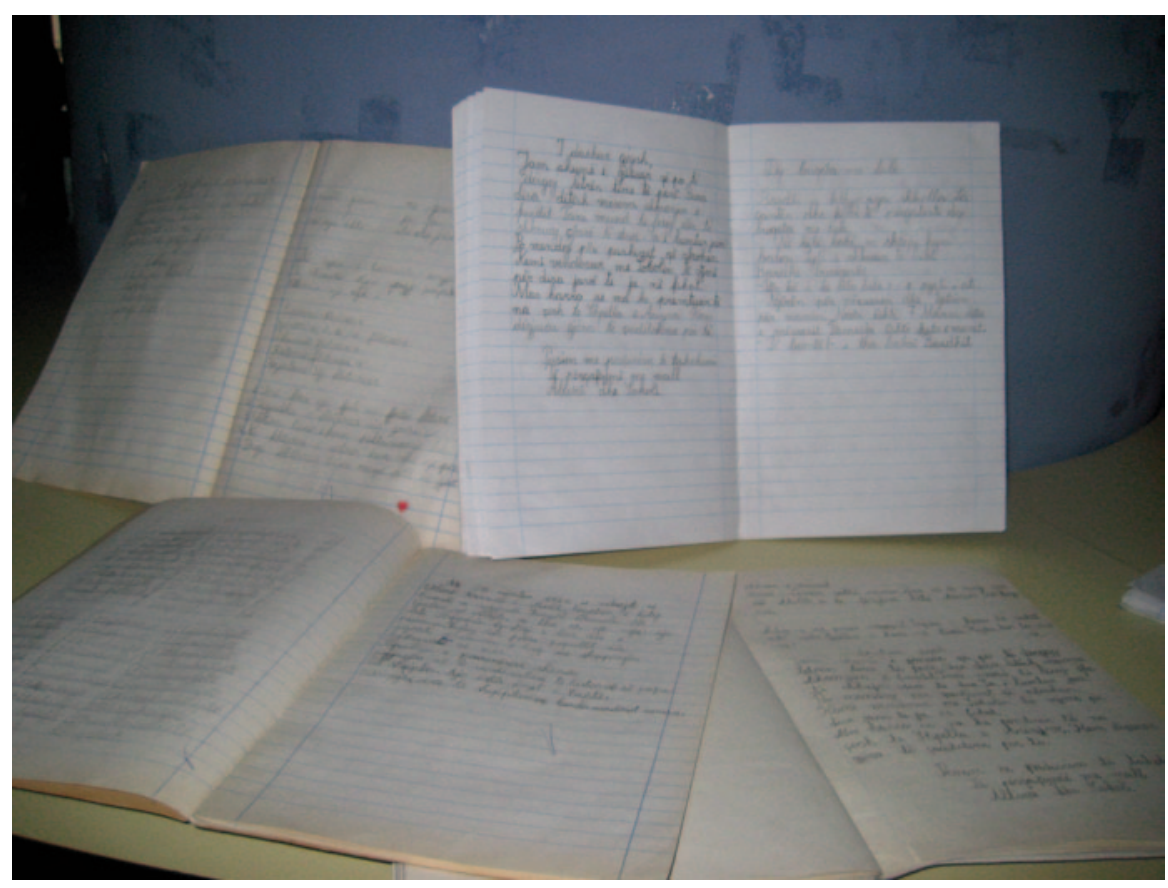

Fig. 5.1 Children's notebooks of Albanian language class organised by the association 'Mother Tereza' in Thessaloniki 
Acculturative pressures, beyond the effect of normal developmental processes, contribute to differences between immigrant adolescents and their parents.... Thus the intergenerational discrepancy is larger in the presence of what might be called an acculturation gap, that is, when adolescents lean towards assimilation and parents wish to maintain their own cultural traditions without assimilating.

The acculturation gap is small in Florence due to the affinity with the Italian culture and language which parents felt even before migrating to Italy. Even children born in Albania were sometimes given Italian names, such as Mario and Aldo. Parents' assimilation helps to soften the intergenerational divide.

Michelino (male, 46, Florence): Of course, he [adolescent son] has his own mentality but I give him leeway because I know the mentality of Italian children. I cannot stop my child, to separate him from his peers and give him our Albanian mentality when he is making his life with the Italians. He has total freedom from us parents... We understand him, despite our tough life that we had before, we still know everything, although he thinks we don't. We pretend we close an eye, but we still keep an eye on him.

Differences across the three sites are also observed in terms of parents' and teenagers' attitudes towards intermarriages. In general, parents in Greece and Italy were open towards relationships and intermarriage between their children and the locals, despite their preference for the children to marry an Albanian. Albanian partners were preferred less to preserve ethnic identity than to suit the family's status and economic situation. On the other hand, some of the highly skilled urban-origin parents actually preferred their children to marry natives. By contrast, parents in Britain were very much against intermarriage with locals. The element of race, which is not prevalent in Greece and Italy, comes up as one of the most challenging topics for the parents in London. Among them, transnational marriages between their children and Albanians back in Albania were even being contemplated. There were also instances of marriages arranged at an early age for the girls, usually at the insistence of parents so as to prevent intermarriages, especially with people of other races. Parents ultimately dread intermarriages of any kind, expecting such relationships to involve unhappiness for their families and divorce for their children.

Qerim (male, 46, London): This may be a mistake, but I have reached the point and have told my son, 'Even if she was the worst of Albanians, that's who I want you to marry, so that you stay together.'

As a result of the parents' attitude, many teenagers in London felt pressure to seek an Albanian partner.

$\mathrm{ZV}$ : Do you have a girlfriend? I just wanted to know her ethnic origin.

Lajmir (male, 18, London): Okay, at the moment, no. But only with Albanians, period!

Simply I don't want to mix the race, for the family's sake.

\subsubsection{Language}

Language is often quoted as a main feature of Albanianness, as part of family tradition and a means to connect with Albanian relatives. Language is transmitted as a resource or as part of identity, but often not accompanied by other elements of 


\section{Box 5.1 Sites of Socialization: Albanian Organizations and the Youth in London}

Today I was invited to a party organized by an Albanian organization in London for teenagers. For some time I had been planning to visit an Albanian business in London, and this was also an opportunity to do that, too. The restaurant in East London hosting the party looked much like the restaurants in Albania: the way the tables were arranged, the banknotes attached at the bar (thought to bring financial reward), the television tuned to the Albanian channel BBF which promotes commercial Albanian music, and the Albanian food.

A group of boys arrived first. They were of Kosovan origin. The oldest opened his laptop and began to set up the WiFi. When the girls came in they sat in another corner, completely indifferent to the boys. A father came in to see for himself who he was leaving the daughter with. As more teenagers arrived, the pattern became increasingly evident: girls and boys sat or stood apart and did not talk to each other. 'Where are you from?' a 12-year-old boy of Kosovan origin asked me. 'From Albania', I answered. 'Hey girls, this girl is from Albania'; he tried to start a conversation with the Albanian girls nearby. They shouted at him rather meanly and then completely disregarded him. 'They are not girls, man. They are dogs! Whoof!! They are vicious, man!' he said, referring to the rough response from the girls. An Albanian mother in her late thirties approached me:

\footnotetext{
Do you see girls and boys apart? I don't know... I don't understand! In my time, we used to make friends, kiss and hug the boys of our class or neighbourhood. But here [in London] only the mountain people [she means the highlanders from northern Albania] have come. They don't let the girls go out, not to mention socialize with boys. I asked one of the families I know whether his daughter was coming to this event. He was totally against it.
}

At some point Besmir, the boy of Kosovan descent, set up his WiFi and had prepared a rap song and dance with his friend. He started to sing, everyone sat down to listen. The music stopped and it was time to eat. The 'rapper' boy asked, 'Is this halal?' He wanted to know about the meat served at the party. I didn't know, but asked the bartender, who swore vigorously that it was halal for sure, since he was himself a Muslim.

I left the party both enlightened and confused. Certainly capturing these interwoven identities was not easy, but observing the interaction in these different sites of socialization was fascinating.

Albanian ethnicity or belongingness. Many Albanian parents consider the language as the main common feature and show an appreciation of it as a resource of cultural distinction. This attitude often grows among parents after many years of life in the host country. During the first years of immigration, many parents recall having very little time to spend with family and placing very little emphasis on their children's mastery of Albanian. The difficulties they themselves encountered with the host 
country's language also play a role in preventing them from pressuring their children to learn or retain Albanian.

The transmission of language is affected by the migration experience and the stage that parents are at when children are growing up. This is particularly evident in London, where the Albanian first generation is very 'behind' in terms of English language proficiency. In Florence and Thessaloniki, parents learnt the host country's language earlier and quicker, although most were still not proficient in reading and writing. In London the involvement of teenagers in the process of regularization and paperwork provides a passive way for them to maintain some Albanian.

With few opportunities for learning Albanian through formal language classes, language is mostly transmitted in a passive way, through everyday communication at home. Children's language is therefore informal and dialectal, depending on the parents' region of origin in Albania and their level of education. Other less common means of teaching language are limited readings in Albanian, the Albanian media (DigitAlb) and interaction during visits in Albania. However, due to differences in the host-country language proficiency of the parents, this process is fragmented. Moreover, younger siblings tend to be less proficient in Albanian, though they usually have better mastery of the host language. Siblings often speak English, Italian or Greek amongst themselves.

Language proficiency can play an important role in parent-child relations and contribute to the shaping of power dynamics within the family. There is a transnational shift in the positionality of parents and children because of language which impacts on the migration experience in the host country and the transnational experience in the 'home' country for the parents and children, respectively. It should be mentioned once again, however, that the highly skilled first-generation migrants invest more in learning the language of the host country. This enables them to help their children with their lessons, and in general increases the social capital that parents transmit to the children. Lida (female, 46, Thessaloniki) was asked what language she uses at home:

Both. I had to learn Greek because I couldn't speak when I went shopping. Now I know how to speak and also to read a bit, but I can't write. I actually learnt more from the children. They learnt quickly at school and I picked up a lot from listening to them. They used to laugh at me because I used to make many mistakes. But guess what? Now I am their translator, because they don't speak Albanian, so for some words and expressions they have to ask me.

The intergenerational transmission of language is also affected by discrimination and is part of the overall strategy of integration in the host society. Parents who migrated in the early 1990s preferred to have the language of the host country taught to their children (Zinn 2005). However, more than a premeditated choice, the disruption in intergenerational transmission of language seems to have been a decision made by inexperienced migrants under pressure of strong discrimination in the first years of settlement in Greece or Italy, where more vital issues were given priority. As discrimination is diminished nowadays, and as the second generation comes of age, the lack of proficiency in Albanian is acknowledged as a barrier both for transnational experiences and for other plans, like return and other potential 
projects related to Albania. As the second generation comes of age, children start regretting their full assimilation and lack of proficiency in Albanian, which prevents them from interacting with their home country and experiencing the 'simultaneity' (Levitt and Glick Schiller 2004) otherwise natural to their transnational condition. This is especially the case of teenagers in Florence where assimilation of the second generation is most evident. Sometimes this regret manifests in feelings of reproach towards parents for their failure to transmit the language.

Lela (female, 37, Florence): When they were little they didn't mind [not knowing Albanian], but now that they are older... and are confronted more often with Albanians, because there are many Albanians of their generation and more or less they speak Albanian... I see now they would like to speak Albanian. But they speak really badly and they blame it on me. And I say that for me it was fundamental that I teach you Italian. Because that meant for me that the children could be integrated in the institutions and for example be able to stay after school and socialize with the Italian children. And besides the priority of immigrants is to work and pay the rent.

The transmission of ethnic identity and especially that of language is also enhanced by the presence of relatives and grandparents in Italy (see also Levitt 2009). Increasingly, the grandparents visit and, at times, co-habit with their children and grandchildren in Tuscany. In the Italian context this is increasingly common, and with the naturalization of Albanians in Britain the extended family is more present there also.

However, while King and Vullnetari (2006) demonstrated the importance of the 'migrating grandparents' in providing care to the grandchildren in their study of Thessaloniki, my study shows that the role of grandparents is broader. The first impact is shown in the retention of language. Grandparents do not speak Italian (or Greek, etc.) and cannot learn it, so this encourages the family members, including children, to speak Albanian. Furthermore, as grandparents feel far more attached to Albania, they want to watch Albanian TV. Sometimes the arrival of grandparents is the reason for Albanian migrant families to buy the satellite package offered by DigitAlb. The presence of Albanian media in turn has improved the language proficiency of the children.

\subsubsection{Ethnicity at a Micro-Level: The Family}

Respect for the family is one of the main normative values that the first generation strives to transmit to the second. Against an individualized and materialistic culture of the receiving society, parents hold on to family and kinship solidarity as important values that will ensure happiness and stability for their children. The intergenerational transmission of these values to adolescent children has sometimes taken place, however, against a backdrop of fragmentation of the family due to migration. As a result, the intergenerational transmission is very much affected by the way the bonds and boundaries within the family are played out.

The importance of the family is very strong too among teenagers, although in some cases they also adopt more independent and 'casual' ideas about marriage and family. 
ZV: So what would be your main future life goals?

Darina (female, 13, London): To finish university, to become a dentist, to have my own clinic, to buy my own house, be happy... Um, maybe have a family, I don't know... I like the single life... just stay with my family, my mum and dad, to have them for a long time. ZV: Are there conflicts between you and your parents?

Sidorela (female, second generation, 22, Florence): [At present] the way I live it's okay for my parents. But maybe there will be problems in the future because I would like to go abroad for some time, but parents want children to stay at home! So they would like that I live in some place close to them so that they can see me almost always! Yes, conflicts of this kind.

On the other hand, compromises on issues of independence, casual dating and nightlife have been used by parents' as a strategy against an open conflict of values with adolescent children, or a loss of interest of the second generation towards parents' values systems and the family in particular. In Thessaloniki and Florence, parents are open to children adopting new cultural practices and the host country's ways of behaving. In general a combination of the two traditions is expected from the children, but parents do insist on the preservation of respect for the family. Parents sometimes struggle to transmit a sense of respectable status and authority. Although issues of emotionality and bonding do not take precedence in immigrant families, they are more observed in families of the highly skilled immigrants.

Dora (female, 43, Florence): We have tried to 'shrink' a little bit and to come to their level so that they understand our existence, because we cannot cancel our past! We need to preserve our past because it is a beautiful past. They [the children] know very well from which family they come from. Because they remember the feasts at home with all the relatives, grandparents and everything... And the values we had... so when we are at home I put the DVDs of their birthdays so that they can see themselves, but also the grandpa and grandma that passed away, the relatives that are far away, some cousins... because it the feelings and the emotions that make you live, because life is not the pub. Life is not the disco!

Within the context of a healthy family, other matters, such as ideological and cultural issues, and especially gender roles, are discussed and redefined. Mothers take care that they transmit autonomy to the daughters while they try to prevent $m a$ chismo and inculcate respect for gender equality in their sons. This is especially the case among Albanian parents in Florence. Some parents would like to pass certain symbolic traditions to the children, but see these traditions within the framework of family life and the collectivity more in general, rather than as fostering a distinct ethnic identity in their children. Self-identification as Albanian is thus related to family traditions and a healthy family life rather than to the group's ethnic identity.

\subsubsection{Lifestyle Values and Cross-Generation Tensions ${ }^{4}$}

Apart from the intergenerational transmission of the 'core' elements of ethnic identity and important institutions such as the family, communication between the two

\footnotetext{
${ }^{4}$ Note that despite this aspect being important in terms of intergenerational transmission, this is not a project that falls in the field of social psychology and so cross-generational tensions are not a
} 
generations takes place through an everyday negotiation of values and the shaping and reshaping of daily life practices. At all three sites parents generally praise the host-country culture for its good manners-being cultured was associated with the idea of having kulturë under communism, which referred to having good manners and being presentable. This is not to say that intergenerational conflict does not take place. There is a typical 'intergenerational disruption' because of the inability of parents to keep up with the changes taking place in the family because of the impact of social and economic conventions in the host country, usually referred to as a different lifestyle. At a micro-level, however, parents notice the differences between their idea of good behaviour and responsibility, and children's adoption of the host country's individualistic attitude, rejection of authority in the family and lack of appreciation of the sacrifices parents have made in order to achieve an improvement in material comfort.

\begin{abstract}
ZV: Do you speak at home about Albanian and English culture and the behaviour of the children?

Fatmir (male, 41, London): Every day, every day... something happens with the children and we say, 'We are not English!' or 'We are not African'... For example, when someone comes home, you should stand up to show respect, whereas when I enter my son's room I see the girls and boys with their feet up on the couch saying 'Hiiii'; they just look at me once. They don't have respect, they throw things here and there. We used to have culture, maybe because we didn't have much, I don't know! We used to keep things with care, to clean them. Whereas nowadays, they don't care, 'no problems, I will take another one', they say. This has made people lazy and has affected culture and everything else.
\end{abstract}

This kind of conflict is especially lamented by daughters, who just want to have a social life like their host-country peers. If parents oppose this, the children put it down to the 'Albanian culture'.

Anna (female, 16, Thessaloniki): Sometimes... when I go out, because I see my friends who are Greeks, their parents are more free, more laid-back... They return home later... But mine instead are... typical Albanian parents. For example, 'Come back on time', 'Where did you go?' 'Be careful!' 'Don't have boyfriends!' 'Don't do this; don't do that...' the classics! So it is only on these topics that we sometimes have conflicts.

Boys are reproached about sexuality, appearance and nightlife. In some cases parents find it hard to accept boys' nightlife, even when they are in late adolescence. This puts considerable pressure on both parents and teenagers.

ZV: Would you say your parents would like you to behave in a certain way?

Alfonso (male, 15, Florence): You could say that. For example, when I wear big trousers, 'Go back and change!'... When I wear hip-hop loose trousers. Sometimes I get ready for school she goes, 'Why have you worn these?' Sometimes when she is not paying attention I just run out of the house quickly [smiles].

Dora (female, 43, Florence): We also had arguments because my husband had that idea, 'Be careful with the girls, the one that you get to know, that's the one you should marry. I don't want you to change girls like the Italians do. We are not Italians!' That's what he asks from them. 'Choose a good girl, and don't play her around, because they are all the same.' And that's where the arguments started, because it's not easy, it's actually very difficult. And then, 'not Italian, but Albanian'.

main focus of this study. However, the data are testimony to feelings and experiences that participants have expressed in terms of generational issues. 
Those second-generation teenagers who rejected the Albanian 'identity' showed a judgemental attitude towards Albanian culture. Parental discipline and rules were often mixed with Albanianness. As a result, intergenerational conflict at times caused teenagers to identify reactively with the host country's culture. While discipline and the strict attitude of parents are considered important features of the Albanian culture, ethnic identification, or at least the choice of the ethnic label (in the case of Genti, below, Greek), is related to the main issues teenagers face in their everyday lives and the way these are handled within the family.

\footnotetext{
Genti (male, 18, Thessaloniki): Definitely Greek... Greek. Because I have been here since I was eight years old and it's difficult for me to have the Albanian culture. I don't think the Albanian culture is inferior, but I feel more like a Greek boy. And that's why we have debates with our parents all the time. For example, they reproach me and tell me, 'You are always going out for coffee', basically things like this that I do, understand? The cultural differences between countries. Here teenagers go out every night to clubs and tavernas.... 'What are these people doing?' my mum says. 'How can they go out every night?' I used to tell her, 'I am coming back at 2 or 3 AM.' 'At 10.15 you should be home!' But I used to tell her my friends return at that time. I still have many problems because of this, not only me but all the children that have come here. Because they have grown up here in another way.... Being Greek it's more.... It's like you are free. Greek parents and children don't have that distinction between them.
}

The issues of discipline and sexuality are especially sensitive in London. Parents' lack of social integration makes them overprotective and cuts the children off from the social life of their peers. This is even more emphasized because of the lack of social and emotional support that parents in Britain face due to their lack of extended social networks and their recency of arrival.

\subsubsection{Migrant Identity and the Communist Past}

Another problematic theme is the transmission of what was described in Chap. 2 as the 'migrant identity' - the ambition to achieve and excel through hard work. In general the migrant status is not particularly empowering for the parents as key actors in the transmission of this value, especially if they have become de-skilled through migration. Whilst some teenagers appreciate their parents' sacrifice and empathize with the 'migrant identity', which in turn favours a more linear intergenerational transmission of certain values, in many cases children do not welcome the migrant identity discourse. An opposition is created between simplicity and hard graft that the parents are used to (both in Albania and in Greece, or wherever) and the materialism of the teenagers.

Agron (male, 42, Thessaloniki): Look, there are two main factors. That system [the communist system] taught us many things in different conditions, but now the conditions are different, there aren't the same conditions. We were doing things because of fear, because of ideology, that's why we had that self-containment, but nowadays you can't restrict the children because they have their lives, the mentality is totally different. One day they might even say to you, 'You know what? Why don't you get out of my sight, because I have my own life, I do what I want!' But it's also this other thing, that we cannot provide the same living conditions that Greek, English or German parents can, who have a secure life. We 
still don't know where we are! Although we are in Greece, a bit better than in Albania, and we aren't suffering for water and electricity, but financially... we can't afford much, so we teach the children with that poverty we grew up with in Albania.... But my daughter cannot understand the topic of communism. I have to explain to her the communist theory, the development, the good and bad sides, that it had a principle that everyone had a job, but there was no profit, understand?

Not always is this past known by, or transmitted to the children. In some cases, there is curiosity on the part of the second generation, but there are also cases in which teenagers resist such narratives by the parents. The stories about communism are usually told in order to make clear the contrast between parents' past and children's current opportunities. Communism is usually described in highly negative terms because of its restrictions and lack of options. Yet some parents look back and appreciate the closeness between people and the collective culture, which contrasts with the individual culture in the places where they now live. Certain stories related to communism fascinate the children.

ZV: What do you know of your mum's past?

Rudina (female, 18, Florence): I know something, the regime under which people used to live. The communist regime, I know about her family, yes, more or less I know everything... The communist regime was constraining people to do the military service. All women had to attend military service. This has really hit me! How did she do that, I try to imagine. When I told my friend Francesca that my mum has done military service, she started laughing [smiles].

Parents often withhold information from their past, especially about the dire poverty and living conditions in Albania, as they feel it is difficult for the children to understand. In other cases, as Le Espiritu and Tran (2002) found among Vietnamese in the USA, Albanian parents point to differences in material resources and opportunities to develop that their children have, compared to the way they grew up. In general, parents who themselves experienced assimilation want their children to see only their new identities. They may withhold information about the communist past to avoid expressions of contempt and pity from the children, which would sadden the parents or make them feel ignorant and weak in front of their offspring.

ZV: What do you know about your parents' past in Albania?

Egla (female, 15, Florence): Sometimes when my brother or sister ask many things, they always tell us how in Mirditë they used to carry wood, and they used to travel during the night because they lived in the mountains, my mum used to work when she was young, and they didn't have whatever they wanted to eat, like us here. So when my brother asks for things, my dad says 'Okay, I will get that for you, but think about the way we used to live.'

The issue of materialism is especially salient among the Albanian second generation in Florence, as material goods are embraced as a way to assimilate. This causes an intergenerational 'gap' in both an emotional and a cultural sense. The highly skilled and successfully integrated parents actively challenge this attitude; they refer to global frameworks of understanding poverty and fighting materialism. A highly skilled parent in Florence, for example, took her teenage sons on a trip to Africa to challenge their demand for expensive clothes and their high emphasis on appearance. The difference with these experiences is that they are not only used in order 
to discipline or motivate the children; parents are themselves coming to terms with materialism and the severe lack of resources and their materially poor past, especially during communism.

Lela (female, 37, Florence): I have tried [to give my children a normal life] but not only by telling about the life we had because it's difficult. It's difficult for me to tell them that I saw a banana for the first time when I came to Italy! It's difficult for me to make a comparison of my childhood with theirs! It's impossible! It's unimaginable because they haven't lived that... I can't make comparisons between my life and theirs because in any case when they came here they had TV, videos, things that for us... I couldn't even think about them. There was only one TV in the neighbourhood; there we used to gather, all the children. Because there were only three 'authorizations' to buy a TV for the whole neighbourhood, so who would get it first? And besides, the TV was bought with a 'lottery'! Forty people from the same cooperative used to contribute monthly to a common sum ... [sighs] I can never forget these memories because I treasure what I have lived, but it is incomprehensible to the children! It took some time for me to believe this myself and was wondering whether they would understand. But they used to respond to me, 'Mum, that's your life, things that you have done. It doesn't concern me.'

While these findings have particular resonance in the case of the Albanian migrants and their children because of the communist past, they are compatible with other research in the field. Commercial consumption, hedonism and a re-articulation of identity through 'appearance' are found to be characteristics of the Italian society since the 1980s (Ferrero-Regis 2008). In turn, research on materialism and adolescence has shown that increased materialism is strongly related with peer influence and decreased religiosity (Flouri 1999). The findings of the current research show once more the strong tendency towards assimilation of the Albanian youth, seen through their embracing of their peers' socialization and consumption patterns.

\subsection{Intergenerational Transmission of Integration}

\subsubsection{Parents'Settlement and its Impact on Children's Integration}

Consistent with other research, this study found the intergenerational transmission process of Albanians in Thessaloniki, Florence and London to be strongly affected by the patterns of integration of the first generation (Levitt and Waters 2002). Across the three sites, parents' lack of proficiency in the host country's language, in particular, was voiced by both children and parents themselves as one of the main difficulties that the families faced. This forced the children to take up many of the parents' responsibilities in terms of managing family life, such as dealing with institutions, doing paperwork and connecting the parents with the outside world. The lack of language skills creates divisions between parents and children and sometimes also resentment among the children towards parents who cannot perform their parental role, especially in school with teachers and peers. More importantly, 
parents' inability to communicate and be self-sufficient has damaged parent-child boundaries within the family, as parents have been unable to function and children have missed parents as role models and figures of authority. Parents' lack of experience with the host environment and lack of language skills sometimes led children to feel let down.

$\mathrm{ZV}$ : Has their language been a problem to you?

Anna (female, 16, Thessaloniki): In the beginning, when I was at school and my mum and dad came to get the grades, they didn't know Greek so well and I felt a bit ashamed. I felt a bit bad. But now they know it well, I don't have a problem.

Especially in London, there are cases of strong 'gendered' perceptions related to children's educational performance and future integration in the labour market. In general, mothers emphasize the empowerment of daughters through education and a potential career, referring to their own experiences of gender oppression in Albania and within their marriages. Their perceptions of gender divisions in labour and family furthermore influence their suggestions of career choices for their children, for sons reflecting the need to earn a living and for daughters the possibility of longer term career-building.

ZV: How do they do at school?

Lutfie (female, 36, London): They are boys and as boys they do okay, average. If I had a girl, I would push her more for education so she gets 'a job with a chair' [Albanian way to refer to office-based jobs].

ZV: Do they want to go to university? What job do they want? What do they want to become?

Lutfie: Mechanic, plumber, cook—jobs with money.

Parents' evaluation and expectations of their own and their children's integration are often related to their past and their upbringing under communism. For many low-skilled parents, the best outcome of their migration project - economic security and security in the family - is mentioned as satisfactory, although as long-term migrants there is in all cases a critical self-evaluation of their trajectory and the evolution of their economic and social integration in the host country. The welfare and progress of the children was an important reason to migrate, and many parents have made heroic sacrifices and submitted themselves to harsh living and working conditions in order for their children to have better opportunities. Some parents explain these sacrifices in terms of self-denial-'forgetting who we were'-describing a rapid and painful de-skilling process in order to provide the necessary resources for their children's education.

It should be noted once again that the process of settlement followed a different course in the three sites of this study. In Thessaloniki and Florence, one parent generally came first, nearly always the father, and the rest of the family joined him after a few years. This allowed parents to get regularized, find stable employment and learn the language to some degree. This accumulated human and social capital prepared a smoother settlement path for the rest of the family and children.

In Britain, parents and children migrated together in most cases. While parents were keeping their eye on the labour market and financial gains, worrying about the outcome of their status and coping with psychological problems, children had 
to adapt to their parents' insecurity and to their inability to function in the country where they were trying so hard to settle. In some cases, this failure of parents to integrate, which then became a burden on the teenagers, led to remarkable development of the latter's agency.

Qerim (male, 46, London): There are problems between children and parents, but the role of parents should be great; all the vices of the children are parents' deficiencies. My older son, now sixteen, slams the doors around the house, but that's not him, that's me coming home from work at $10 \mathrm{PM}$ and going back the next day to work at $5 \mathrm{AM}$ for years and years when he was younger. Why? Because we were with a 'negative'; my friend was taken from his house with his wife and children at $5 \mathrm{AM}$ and was deported [sighs].

Era (female, 14, London): I would like them [my parents] to speak English because it would make my life so much easier. I wouldn't have to translate for them, you know... all the time. I don't know, when we go to solicitors, when we phone up important people, everything... I translate for them, I do forms, housing and stuff like that.

Altin (male, 16, London): We had to go and see different people, like judges. We had to go to Croydon, the Home Office. Usually I would go with my mum and dad, because I would help them with translating. I would have to always call, like when someone important would call, an English person would call, I would help to translate that 'I am a foreigner' or whatever, something like that. So yeah, it did get in the way of school.

\subsubsection{Transmission of the Migration Project}

In general, both parents and the teenagers considered the migration to have been a good step for the family, an opportunity 'for a better life'. Girls were appreciative of the migration so they could live a life without fanaticism and restrictions. There was also an appreciation of the opportunities offered by the host country in contrast to the living standards in Albania.

ZV: What do you think about the decision of your parents to come to Greece. Was it a good or a bad decision?

Anna (female, 16, Thessaloniki): A good decision. If we were still in Albania, we would be like my cousins there: a bit poorer.... Okay, it is nicer there. They are more human, closer to each other, but they are let's say... live in poverty. Here in Greece we... are a bit more comfortable, better-off. We are better here, so I think this decision was good.

The only difference of opinion was found among teenagers whose parents were highly skilled and had experienced de-skilling because of migration. They expressed empathy, but at times also contempt, for their parents' decision to migrate.

Especially because of the sacrifice they submitted themselves to in reaching and settling in the host country, parents are very set on the success of their migratory plans, which are largely concentrated on the children. Sometimes the success of the migration project is equated with the realization of children's education, the securing of financial stability and an overall better future.

Drita (female, 45, London): So far I am very pleased with the children's progress. I hope they will continue this way and I will be the happiest mother in the world if my children become someone. I tell them, 'Look at your mother, how she is living on benefits, like a piece of... Even if I started work, I would be working as a cleaner, so please take my 
example and study hard!' And my daughter comes back from school and says she got a high grade I am in tears because I think I suffered but my children won't.

Parents emphasize taking advantage of opportunities, but also a goal-oriented life, focused on achieving financial security for the family and providing a better future to the children. Children, however, do differ in their perceptions of their parents' migration and sacrifice. Some teenagers, especially those who experienced the first years of migration while they were growing up, bonded with their parents and express empathy for the hardships they suffered.

Albi (male, 13, London): I think it [my parents' life] is very hard, because they have spent all this like stuff. They have been working to spend money on like a house. Every time she says they worked hard, I believe her. It is really hard to get a house in England, because it costs you a lot. I kind of feel sorry for them.

Aldo (male, 16, Thessaloniki): My parents have come here to earn money and buy a house and make our future. We are not here to wander around and kill time as the Greeks do. We have come here from another country for a better future.... They want me to go to university because they don't want me to struggle and get exhausted as they did for so many years. They want to see me well-off, with a house, with an office-based job, so that I won't be 'under the sun' like they were when they came here.

Many parents try to 'dilute' the discrimination that their children face and, interestingly, they intentionally avoid inducing negative feelings towards the host country in their children. On the one hand, this attitude shows a consciousness of the politics of identity, an acknowledgement of the existence of ethnic boundaries and an acceptance of the very porous boundaries around the Albanian 'group'. On the other hand, good parenting and children's prosperity seem to take priority over the collective identity and its recognition. There are also cases when parents find it hard to acknowledge discrimination themselves, and especially of their children. This is also a way to react towards a possible diagnosis of their decision to migrate as negative and harmful to their family.

Monda (female, 50, Thessaloniki): We do not have this attitude... like pushing children to be against the Greeks, because if we would say to the children, 'The Greeks do this, the Greeks do that!' then the child develops hate, because these things are taken from the parents. We don't want the children to have hate. We let them grow with the culture of here. We will give them the Albanian culture, our family tradition, the love and not to forget Albania. Even when it comes to history, we tell them this is our history, this is how things stand. We don't know what historians and states do; that's their job. We are taught this way. They are taught in a different way, and everyone has his own right. We don't induce hate in children... No, no.

Since perceptions of the success of the migration project differ among the first generation across the study sites, there are differences in the way they transmit their family's migration project to the children. Since the realization of a better future for their children is held as one of the main goals of the migration project, the more the first generation gets its migration goals realized, and the more the second generation comes of age, the more the parents feel uncertainty and anxiety about their children's future in the host country. In Greece and Italy, the main issues relate to structural integration. In Greece they are especially associated with an uncertain legal status and a very impenetrable higher education system. 
Pali (male, 48, Florence): Every time we used to have conflicts with my wife around the decision to come to Italy we would be saying, 'Our life is how it is, but we are constructing our daughter's future'. Sometimes this is also an excuse to justify our decisions... putting the welfare of our children first and feeling like a devoted parent. But then when we see that the interest of her generation here for education is zero we wonder whether this was a mistake. We ruined our future, we abandoned mother and father, our job and all the rest... and when we think that things could have gone differently, we wonder whether migrating was not a good decision.

In Britain parents express concern about teenagers' social integration and intermarriages since there are positive expectations about structural integration due to the gaining of citizenship, a prestigious educational system and a flexible labour market. Possibilities of return to Albania are evaluated and contrasted with the chances of entering higher education and getting integrated in the labour market in the host country, while the difficulties of reintegration in the home country are an important theme in these 'British' narratives. Seeing the presence in the host country as an opportunity, mothers in London comment on their children's complacency, individuality and autonomy as distinct values of the second generation, which do not meet parents' expectations. The narratives also give interesting insights into the differences between the (limited) everyday mobilities of children in metropolitan areas, compared to the freedom experienced by the first generation in their premodern home country.

Mirlinda (female, 34): We enjoyed our childhood, we used to play outdoors, but our children stay closed in at home all the time.

Arjana (female, 32): Well, our children don't lack anything. This is making them lazy and they are falling behind with the lessons. Here [in England] they have all the possible opportunities. I got engaged by my father at the age of 16 and then I had to quit school. It was really finished at that point!

Mirlinda (female, 34): It is difficult to bring up children here. They have a lot of freedom. When we were children we didn't even think we could oppose our mothers! Here the child says everything in your face how he feels about something. I mean, we got married and we didn't know what that involved!

The intergenerational transmission of integration, however, can be disrupted by parents' return plans and their parallel investments in a possible return to Albania. This obviously conflicts with children's general aspiration and plans to stay in the host country. Uncertainty about the poorly developed educational system in Greece makes parents pessimistic about their children's future and their decision to migrate with their families.

Abaz (male, 44, Thessaloniki): I am just worried about the future. The children are in a foreign country. Will they finish school, will they work? What will they do? I am a bit worried about this. Sometimes I even think I made a bad decision for the children, probably I reduced their motivation. It would have probably been better if they were in their own country, in Albania. On the other hand, I think that they are abroad, they are in Europe. Greece is now a European country, there will probably be an extra opportunity... I don't feel very certain, to be honest, about the children's future. 


\subsection{Intergenerational Transmission of Transnational Ties}

\subsubsection{General Patterns}

Previous research observes that transnational ties develop in two phases: in the beginning they are the outcome of international migration of the first generation, while in a second phase they are passed on to migrants' descendants and seem to develop a life of their own (Faist 2000a). In this study, the process of 'passing on' is dynamic and involves inter- and intra-generational differences, as well as tensions within the nuclear and the extended families of immigrants. The attitude of the parents towards transnational ties has changed over time, with a move from an appreciation of transnational ties because of obligations felt towards those left behind, to a view of transnational ties as more instrumental and dependent on the needs and conditions of the nuclear family in the host country. This change is positively related to the length of stay in the host country (see also Dahinden 2009). As a result, the change is much more evident among the first generation in the two southern sites, where Albanians have a longer 'history' of migration and settlement.

Although, summarizing key findings from the three previous chapters, agency and culture are important factors in determining the identification and integration patterns of both the first and the second generation, structural variables were also found to be important. In the case of transnational ties, both generations experience a higher degree of autonomy in terms of their establishment and maintenance. Furthermore, transnational ties of both the first and the second generation are related to their identification and integration patterns and vice versa.

As a result, the transmission of transnational ties exhibits various patterns with, in many cases, parents and children differing in their attitudes towards return visits. First, the maintenance or disruption of transnational ties may be 'linear'. This is the main pattern found in the field data. Here, the first generation keeps transnational ties and wants to pass them on, involving the second generation in the maintenance of those ties. However, there are also cases where the first generation has internalized stigmatization and discrimination, and therefore is prone to 'loosening' transnational ties. This second pattern affects children's attitudes and their actual establishment and maintenance of ties, not least because they lack resources to do so. Third, intergenerational transmission can show a discontinuous pattern, with the second generation being resistant towards the transmission of ties from the first generation. Or, children might act as independent actors in the establishment of ties, for example through the Internet or by showing keenness to continue visiting, despite parents' estrangement from Albania.

Dana (female, 15, Florence): My parents don't want to go to Albania. Not at all! It's me who wants to go. For example, we went this year and had a lot of fun. Now they are saying 'after three years'. I really like to go. Next year I don't think we are going. They don't want to go, they don't like it [Albania].

Objective factors may obstruct the transmission of transnational ties. For example, the possibility to return on visits depends on parents' type of employment. Those 
who have jobs in services or tourism, and many of those who are self-employed, find it difficult to travel during the holidays, because they have to work during these periods, though this is the only time their children have vacation from school. There are also differences between the highly skilled and the unskilled parents. The former tend to be more aware of the importance of cultivating the native language and of the negative impact of discrimination, which makes them keener on the maintenance and transmission of ties to Albania. They also encourage the second generation to be involved in other activities for cultural exchange.

However, we should not underestimate the differences in the motives of the first and the second generation for keeping ties with the homeland. Parents need to relate to their past in the homeland, to deal with feelings of loss and longing, memories of childhood, of places and of different sensations. They also need to work to smooth the disruption of their life course because of migration.

Mondi (male, 48, Florence): When I go to Albania I am organized. Usually I go during the winter because of the work in the restaurant. My wife and children go in the summer, me during the winter. I go to Durrës to see my parents and the in-laws, from there to other relatives in Milot, and stay there. If I take 15 days off I divide them five in Durrës, five in Milot and five in Skrapar. I don't come back to Italy without going to Skrapar. Because it's the place where I was born... the nostalgia... it's the place where I was born. I just can't... can't go without seeing it. Understand? I have a picture this big at home.

Discrimination acts as a moderating factor in intergenerational transmission and, as a result, it affects attitudes towards transnational ties. A general dichotomy seemed to exist among the teenagers. Because of discrimination and exclusion in the receiving countries, some children preferred to cut all ties with Albania. Some even refused to say the name of Albania during interviews; they referred to it as 'there'. In these cases, transnational ties were conditioned by the image of Albania in the host countries, and also by the attitude of the receiving society, which considers these ties to be an expression of identification and loyalty towards Albania. In the second case, discrimination and the resultant exclusion in the host society inspired transnational ties as a way to make up for the lack of social life and friends. Nonetheless, teenagers' views on transnational ties, in particular, return visits can change over time.

Rabije (female, 63, London): My grandchildren have never been [to Albania] since they came here. They refuse to go. They left so early, when they were very little... you know... parents are here with them.

Anna (female, 16, Thessaloniki): We usually go at Christmas and Easter, and sometimes during the summer. We go because my parents want to go. I usually don't want to go. Because I don't have anything to do there, because we have a house in a village, and Albanian villages are... the roads are horrible! I am used to here in Greece where it's different. I don't know the language, nothing. And besides I don't like to go to Albania, that's why.... I will go less often in the future... because my parents will not tell me continuously what to do, and I will do what I want and I don't think that I will go to Albania let's say continuously. I will go sometimes, but not often.

Vilma (female, 15, Thessaloniki): When I go there I get accustomed very easily. Immediately when I get out of the car I get accustomed with the place, I like to go out, to speak with people, to see what they learn, where they live. Because I have come here and I have learnt about Greek history, whereas about my country I know nothing and I like to learn many 
more things.... Here I feel like a stranger, I have been here 10 years and I still feel foreign. I go very often to Albania and I see the differences between the two countries and I see that

I am not from here... It seems like I belong more to Albania than here.

In terms of adaptation in the host country and migrants' transnational orientation, my study contrasts with research that has found that a high degree of discrimination in the receiving country to be associated with 'reactive transnationalism' (Itzigsohn and Saucedo 2002, p. 72) or a tendency towards engagement in activities that reaffirm migrants' collective identity (Faist 2000a; Popkin 1999). In the Albanian case, experiences of discrimination in the receiving country were found to cause disruption of transnational visits and a distancing of the second generation from transnational ties, since migrants' ethnic identification was linked to their maintenance of ties with the homeland. Transnational orientation is maintained or rejected on the basis of their self-identification, their identification by others, and their perception of the homeland (see also Leichtman 2005, p. 281).

In effect, the attitude towards transnational ties is related to attempts to divert discrimination and integrate into the host society. The identification of the Albanian children in Thessaloniki shows the deep impact that the negative articulation of Albanianness has had on the teenagers' identification and attitude towards their homeland (Vathi 2010a). In Italy, this articulation is more subtle, but the exclusionary attitude of the receiving society towards Italian identity and the pressure to assimilate has caused a similar attitude. There is, therefore, a relationship between identification as Albanian and feelings of affinity towards Albanian culture, and the propensity or lack of opposition towards transnational ties.

The following sections focus specifically on the transmission of attitudes towards visits to Albania and towards return.

\subsubsection{Intergenerational Transmission of Attitudes Towards Visits}

Despite their change in attitudes over the years, parents acknowledge the lack of social support to them and their families on the part of the host society as well as their children's exposure to discrimination. They see return visits as a source of muchneeded support and 'fun time' to ensure a more positive childhood for the children.

Mimoza (female, 39, London): The first time I went it was very emotional. It was very emotional.... Because I have mum and dad, brothers and sisters and I go to see them. And besides, come on, it's my country.... And for the children, so that they learn their language, the history, to know the places and to know the relatives. It's good for them to know their relatives.

Bardhi (male, 45, Thessaloniki): When my daughter goes to Albania, with grandmothers, grandfathers, with the cousins there, she sees that her country is beautiful, she likes it. Because there during holiday visits she is more free, she makes friends... All the time they have fun during the summer in Albania, and the communication with caring and loving people like grandparents, uncles, aunts and other relatives... their love is great. Because of this, the visits in Albania remain in children's memories. So my daughter wants to go often and when I ask her 'Do you like Albania?' She is always positive and wants to go. I believe 
this is the reason, especially as they are under significant pressure here, with the Greek language... It's very difficult to bring up [Albanian] children in Greece!

Egla (female, 15, Florence): Mum takes these trips only for us. Before we used to go for the grandparents because they were old and we wanted to see them, but if it was for mum and dad they wouldn't go every year, because it's very expensive. But we have come to Italy and we are still very young so they send us every year; if it wasn't for us, they would go once in 2 or 3 years... But they sent us so that we don't stay here all the time, because there isn't much to do as you get stuck at home, everyone minds his own business so.

In the quote of Abaz below we also see how the return visits contribute to children's identification. This is a result of the emotional and social support that second-generation children experience during these visits, which serves as a resource, cushioning the effects of isolation and exclusion in the 'host' country.

Abaz (male, 44, Thessaloniki): My youngest son has a strong feeling of patriotism towards Albania. It surprises me because he came here one year old. We go always during the summer to Albania. He likes socializing there, because he has cousins of the same age. He plays with them, so he likes it better there than here. Here, he feels a bit excluded. Here there are many Greek, Russian and Turkish children but he is not very fast in making friends. He is shy. He has only one friend, so he always says, 'Dad I like it better in Albania.'

Return visits also help in introducing the children to their parents' past and in narrowing the emotional 'gap' between the two generations, which widens during the years of settlement in the receiving society. Many of the narratives refer to the children's lack of knowledge about their parents' past, education and lifestyle. These visits, therefore, help to counter feelings of disruption between the past of their parents and the family's current life as settled immigrants.

Entela (female, 42, Thessaloniki): We go first to see our relatives, I don't want to cut the ties. I want to go and see what's going on, what kind of changes, to see them from up close. I see the changes on TV, but I want to see them in reality. I also want the children to go and see the place. I don't want to distance them from Albania. For example, soon there will be a wedding of one of the relatives in the village of my husband in Lushnjë. And I asked my husband to take our holidays so that we could go with the children, because they don't know what the village looks like! They ask me time after time. So I want the children to go and see the village and the place where their father grew up.

Return visits can be especially significant for skilled migrants, who experience a temporal restoration of their professional identity. They thus provide a unique occasion for children to see this side of their parents' identity.

Fatmir (male, 41, London): When we went to Albania after eight years I took my son and went to the café where we used to go always with my colleagues from the theatre. And musicians were coming, both the professionals and the amateurs... They were coming and were hugging me, 'Hi, how are you?' Everyone. And we sat there for a coffee. My son was staring at us, 'They still respect you, even after so many years!'... That's why every time we go, I feel a different person when I go there.

The first generation's relations with the homeland, and especially with the extended family, condition the return visits of the second generation. But parents' relationships with the extended family are not always positive (see Levitt 2009, p. 1226). Children are sensitive to family conflicts, which in turn impacts on their perception of the homeland and Albanian culture. 
Era (female, 14, London): Yeah, the reaction of people and how they are over there. In Albania people are well... yeah... All they think about is, I don't know... money and things. Sidorela (female, 22 Florence): I have not been to Albania because my parents have come here to work. The fact is that when you go to Albania it's not that you have only two people waiting for you, you have the whole community! And when you go there, they all expect something, don't they? Even 10 euros. But if you make the calculations: two hundred people multiplied by 10 €euros.

Some second-generation teenagers find it hard to deal with kinship traditions and conventions of family support in Albania. This is most evident in the narratives of those in late adolescence, who have less appreciation of the affection and support of grandparents (or the grandparents may no longer be alive).

Rudina (female, 18, Florence): My visits are like this: first of all when we go, we go all together, me, my mum, my cousins. So it's a little bit like sending me to my home [smiles]. We go there... okay, I go and see my aunt who lives in Tirana. I go often to her. But I don't feel at home, I feel a little bit like out of place. I go out with my cousins, go for a walk. But then I stay at home and can't wait to come back to my house here.

Anna (female, 16, Thessaloniki): I go [to Albania], but I don't know anything. For example, when my mum goes she says, 'I feel so well in my village', whereas I don't like it in Albania. Because I don't have friends, I don't know the language, so I have difficulties. Whereas when I am in Greece I have my friends, I know the language, I feel more comfortable... that's it... To them, the visits mean a lot of things. Because they remind them of their childhood, their village, the people... they see their relatives who they love, people they grew up together with, so they have a good time, because they know the language so they don't have problems.

Older teenagers recognize the difference in meaning that these visits held for them and for their parents. Their reluctance to continue visiting is sometimes expressed in contrasting emotionalities of the two generations, as well as in attitudes towards a possible return.

\subsubsection{Intergenerational Transmission of Attitudes Towards Return}

Children's attachment to the 'host' country and parents' plans for children's education are the main reasons why parents put return plans on hold.

Lirime (female, 38, London): It's a big one, because we are, you know... we are fighting. We are fighting. It is between us and the children. So that [return] is the big question mark. And we don't know what to do!

There is also a relation between return and intergenerational transmission. Families who plan to return are very oriented towards savings and investment in Albania. These parents put little effort into integrating in the local environment where they live, so the human and social capital they accumulate is very limited. The gap with the second generation in these cases can be enormous. Intentions and plans to return do, however, stimulate parents to teach Albanian to their children and since the family lives cut off from the rest of the receiving society and frequently visits Albania, children are transmitted and independently pick up many Albanian customs and are more in contact with Albanian culture. 
Clara (female, 41, Florence): One of my neighbours left the house 10 years without curtains! And the installations and other wires of the house were on the floor. 'Why should I fix up the Italian house?' she used to say. 'But your children are growing up here. What kind of idea of a home will they have?' Saving everything, she managed to buy two houses, one for each of her children. The children grew up here and they don't want to go to Albania, so the two houses have remained empty. In the end she was forced to buy a home here in Italy.

As mentioned earlier, second-generation teenagers are indecisive about return, although in all three sites parents' decisions to return in many cases depends on where the children will settle. Many parents express their wish to be close to their children in later life. Attachment to the children and the ties that both parents and children establish in the host country make return an unnatural move.

$\mathrm{ZV}$ : Where do you see the future?

Selim (male, 66, Florence): Well, we have an only daughter, so our life is related to hers... according to the tradition of the Albanian family, we are close to our children. So our future is where the future of Aulona is.... Her future is here, because it's here she was educated and got employed. And most likely it's here she will marry, when the time comes [smiles].

At times parents use the prospect of return as a threat to the children, to motivate them to succeed in their studies or to show better discipline. This again points to the disjuncture between parents and children in terms of their perceptions of their settlement and belongingness in the host country.

Flutura (female, 43, London): If he continues like this, my son will do really well. Maybe my daughter will do even better, but she is very shy, only studies. We say to them every night, 'You have to study; if you don't study we will go back to Albania.'

It is very common for parents and children in the same family to have different plans and attitudes towards return. Differences between mothers' and fathers' attitudes are common, too. Where there are differences, Albanian men appear keener to return. They feel less socially integrated abroad and are more symbolically attached to Albania.

$\mathrm{ZV}$ : Where do your parents see their future and your future?

Altin (male, 16, London): Well, my mum wants to stay here, to be honest.... She wants to earn more money. Maybe build another house in Albania or something. My dad... definitely wants to go to Albania, I think, because his mum is getting old, you know, he wants to spend time with his mum. He goes every summer of course, with us, but he goes winter as well and he leaves us here, so he goes winter to see his mum, on his own. So yeah, he wants to go to Albania for his mum, but he has to stay here for our education, for our future.

\subsection{Conclusions}

This chapter examined the intergenerational transmission of ethnic identity, integration and transnational ties between first-generation Albanian migrants and their adolescent children. Far from a quantifiable process, intergenerational transmission was found to be complex and fragmented. Its features appear to be changing over time, involving redefinitions of concepts, values and practices and of their 
importance, by both parents and children. Intergenerational transmission is largely conditioned by parents' capital and discrimination in the host society. Means and strategies of transmission are focused on counteracting stigmatization and are characterized by a lack of focus on ethnic identity and culture of origin, in favour of equipping the second generation with universal values and lifelong lessons.

Intergenerational transmission, however, was found to have particular features, depending on the content of transmission. Ethnicity is sometimes 'activated' as a way for parents to react to the intergenerational 'gap', which is generally wider in immigrant families. In this dynamic process, parents are the main actors. Furthermore, parents purposefully transmit some values and institutions, while consciously withholding others.

Highlighting the difference between the primordial understanding of ethnicity and the experience of ethnicity in everyday life is also important in the case of the intergenerational transmission. As Kibria (2002) maintains, most research on the second generation has focused on primordial ethnic identity, which is indeed what is referred to by both parents and children when reactive identity or avoidance and rejection of Albanian identity are articulated and experienced. Nevertheless, ethnic identity and its transmission are understood and experienced as major factors in Albanian migrants' and children's everyday lives, especially in relation to 'host' institutions and the public realm. Its impact on migrants and their descendants depends on their socio-economic status as well as their gender (Anthias and YuvalDavis 1992).

A main finding of this chapter concerning intergenerational transmission is the role of legal status, since the role of legal status has not been identified in previous research on this topic. The irregularity of parents seems to have a strong impact on the transmission of identity, integration and transnational ties. As mentioned in Chaps. 2-4, the lack of 'papers' affects feeling of belongingness among the first generation. Irregular status hampers integration in particular, especially social integration is concerned. Irregular migrants did maintain contacts with the homeland, via telephone calls and remittance-sending. But irregular status was a barrier to the maintenance of ties in the form of return visits. This reveals a relationship between irregularity and intergenerational relations - a point which has not been made in the existing migration literature. Eckstein (2002) maintains that generations are defined not only by their genealogy, but also by the social conditions they experience premigration and post-migration. As the data presented in Chaps. 2-4 show, there is a blurring of distinction between generations due to the disempowering and alienating effects of lengthy regularization processes.

Nevertheless, the first generation usually prioritizes integration over transnational ties, especially in terms of distribution of family resources and the orientation towards future life goals. This inevitably affects the intergenerational transmission of these ties. Parents were generally keen to transmit symbolic ties and were meticulous in regard to more material ties. However, the second-generation teenagers also acted independently in establishing ties and showing willingness to maintain ties, despite their weakening over time in the first generation. 
Finally, the intergenerational transmission of transnational ties is not as automatic and uniform as outlined by the very limited literature in the field. For example, Faist (2000a) observes that transnational social spaces develop in two phases: in the beginning they are the outcome of international migration of mainly the first generation, while in a second phase they are passed on to migrants' descendants and seem to develop a life of their own. The findings show that certain ties are transmitted more easily, whilst others are overlooked or transmitted passively.

Open Access This chapter is distributed under the terms of the Creative Commons Attribution Noncommercial License, which permits any noncommercial use, distribution, and reproduction in any medium, provided the original author(s) and source are credited. 


\section{Chapter 6}

\section{A Cross-generational Assessment of Identification, Integration and Transnational Ties}

Processes of migration and settlement are complex and life-changing for those involved. They entail risks, emotions and transformation, loss and empowerment, disruptions and growth. In no way are they ordinarily linear, cause-effect events and trajectories. As a result, conceptual and empirical accounts can only try to do justice to the main milestones of these processes.

This final chapter revisits the five sets of research questions posed in this book, presenting some final analyses and answers to them.

- What are the patterns of identification of the Albanian first and second generation? What is the role of ethnicity in identity construction?

- Do Albanian migrants and their children establish transnational ties with the 'homeland' and the Albanian culture? If so, what is the nature of these ties?

- What factors condition identity formation, transnational ties and pathways of integration, for example, the role of the family, the institutional framework and regularization processes?

- What are the patterns of the intergenerational transmission of ethnic identity, integration and transnational ties?

- How do ethnic identity, integration and transnational ties interact? What factors affect these interactions, and how do they ultimately impact on integration?

The first section reviews migration research in terms of links between identities, integration and transnational ties. Reflecting the general structure of the book, subsequent sections summarize and elaborate on findings regarding ethnic identity, integration, transnational ties and intergenerational transmission. The final section reconsiders theoretical assumptions related to identification, transnational ties and integration, and the concepts of agency, power and capital, demonstrating interconnections between identification, integration and transnational ties. As the main goal of this research was the study of integration, the book concludes with a reinterpretation of integration within the framework of agency, power and capital, and mobility, as contingent on time and space. The chapter rounds off with some remarks on the wider implications of research in this field, including reflections on the integration of Albanian migrants and their descendants, and on minority studies in general. 
In short, it calls for a reappraisal of the purpose of social science research and the extent to which political agendas and the topics leading public discourse guide research and migration scholarship. Referring to the concept of the 'second generation', this book is critical of notions that may help to reproduce social divisions and ideologies that are not based on an egalitarian philosophy.

\subsection{Links Between Identity, Integration and Transnational Ties}

The way that the interactions between identification, integration and transnationalism are presented in the literature has been affected by academic ideologies and paradigms. Wimmer and Glick Schiller (2002) warn against a groupist way of thinking in viewing and studying migrant transnational social fields. They maintain that the term 'community' in the study of transnationalism has been ambiguously used as standing for sets of networks, without questioning the importance of ethnicity and a collective memory in their creation and maintenance. In turn, according to Glick Schiller (2004), development of assimilation as the master concept to explain immigrants' integration neglects the role of transnational ties, despite a recognition since the early days of migration research that many immigrants learn to identify with their ancestral land only after they settled in the receiving country. Similarly, multiculturalism makes no reference to transnational ties, although it acknowledges the persistence of cultural differences and identities among some segments of immigrant populations, even in the post-migration generations. Although both the new assimilation theory and the segmented assimilation approach acknowledge the role of the country and context of origin in their discussions of migrants' integration or lack of integration in the host country, it was only after the 1990s that transnational migration scholars added migrants' transnational engagement as a third perspective in these conversations (Levitt and Jaworsky 2007).

Three main assumptions have framed the relationship between ethnic identity, integration and transnational ties. The first relates to classic assimilation theory-that migrants ultimately assimilate into the host society's culture (Gans 1992). Very little theorizing has referred to mobility and cosmopolitanism. The second assumption is that assimilation and the maintenance of ethnic identity and transnational ties can coexist, thus they are not necessarily mutually exclusionary processes (Itzigsohn and Saucedo 2002; Levitt and Waters 2002). Gans (1997) maintains that ethnic identity is even compatible with assimilation, taking the case of ethnic activists who live public 'ethnic' lives, but assimilated private ones. This argument points to Vertovec's $(2009$, p. 80) presentation of the relationship between transnationalism and integration not as a zero-sum game. Various modes or components of each of these constructs can be selectively combined by migrants. Gans's ideas on acculturation and relationships with other constructs are also in line with recent developments on the role of culture and immigrants' assimilation. Levitt (2005) maintains that early on researchers were more interested in the process of immigrant incorporation and 
paid little attention to the cultural elements that were transformed along the way. Rather, culture and cultural influences were studied under the term 'ethnicity' and, with the latter's decline, the role of culture was rather ignored.

As the immigration literature shows, historically the process of identification with and involvement in the host societies has gone hand-in-hand with engagement in transnational spaces. Trajectories are found to include different patterns of integration into different layers of the receiving society's hierarchies, or variously labelled upward and downward mobility and ethnic enclave embeddedness, which apply to both immigrants and their descendants (Joppke and Morawska 2003).

Consequently, nowadays the discussion of transnationalism is closely related to the concept of ethnic identity or with patterns and processes of integration. Yeoh et al. (2003) point to developments in the field of transnationalism as being focused, firstly, on the shape of transnationality - its edges and the processes and relations that constitute them-and secondly, on what constitutes identity formation and identity politics in transnational social spaces. On this second point, Vertovec (2001) maintains that many migrants' transnational networks of exchange and participation are grounded upon a perceived common identity. Dahinden (2009) finds that ethnicization and type of identification are related to migration history and reasons for emigrating. The act of migrating and motives related to it appear to strengthen ethnic belonging, giving rise to a kind of uniculturalist transnational subjectivity. Other research relates mobility and transnationalism with the role of family and kin, although the role of the latter is still very understudied. Concentrating on gender, Pessar and Mahler (2003) show that kin and friendship circles that stretch beyond borders continue to impact people's gender and social positionality.

The third framework assumption is that the process of integration is associated with different patterns of immigrant transnationalism, implying that the two processes proceed in parallel but at unlike pace. These different patterns of transnationalism are also marked among migrants of different socio-economic status and operate similarly at the local level of integration (Dahinden 2009). In particular, exclusion and disadvantage are thought to be related to transnational orientation. From its inception, the new immigrant transnationalism was conceptualized as a strategy of resistance 'from below' that members of marginalized and underprivileged racial or ethnic groups posed against the hegemonic powers of nation-states that regulated both their economic and political activities and conditioned their symbolic activities and commitments. However, the way that different migrant groups have reacted towards disadvantage has varied. They have combined strategies of challenging their status, retreating to their transnational identities and even adopting the dominant society's negative stereotypes of themselves (Joppke and Morawska 2003). Elements of this last strategy are observed among Albanians in Italy and Greece (King and Mai 2008, p. 208, 209).

A final point is that most of the literature on the interactions between identity, integration and transnationalism draws on the experiences of the first generation. However, as pointed out by Portes (1999), the most dynamic part of the interaction between ethnic identity, integration and transnational ties takes place in the children of migrants, especially as regards socio-cultural integration. Following this line of 
argument, this chapter presents the main findings of the current research, addressing each main research question in turn.

\subsection{Ethnic Identity}

The role of ethnicity in identification processes among Albanian migrants and their children was listed as the first unknown of this project. The question of what role ethnicity plays in migrant identification was then related to the research summarized in Chap. 2 on ethnic identity as a main factor in the integration of migrants in various situations worldwide. Related to the particular group under study here (Albanians), researching the role of ethnicity is even more important since previous research on other ethnic groups has suggested that widespread discrimination and stigmatization of the first generation could be interpreted as bequeathing a negative 'legacy' to the second generation. Chapter 2 analysed the identification processes of the first and the second generation of Albanian migrants, taking a broad approach towards the understanding of these processes and examining the effect that ethnicity has on them.

The experience of the Albanian first generation and that of the Albanian-origin teenagers in this study indicates that the specific ethnicity characteristic of an ethnic group is not - in this case - the central frame of reference that affects identity processes. As Barth (1969, p. 14) observed, there seems to be a difference between the process of self-ascription to an ethnic group, and the experience, and especially the performance, of an ethnic identity. In the current research, the choice (or not) of the ethnic label and articulations of belongingness seem to be rational and to change over time, depending on an evaluation of opportunities in the home and the host country, and the host society's politicization of ethnicity and its attitude towards immigrants.

Therefore, the references to ethnicity, at least when primordial ethnicity is considered, seem to be instrumental and conditioned by its centrality in the host societies' context. The patterns of identification processes, for both the first and the second generation, are context-bound and shaped by factors operating at different levels, related to the structural features of the host society and the characteristics of the immigrant group: the institutionalization of sharp symbolic boundaries by the dominant group and the politicization of the 'other'; the positioning and the relative size of the migrant group; the mode and stage of incorporation of the first generation; and different sources of social capital interacting at different levels, especially within the family. As evidenced throughout this, these factors intersect with class (high skilled and low skilled, more or fewer years of education) and gender (see Anthias and Yuval-Davis 1992).

As a result, the blending of cultures - an expectation one would have when researching second-generation teenagers - is not the general main trend when the Albanian teenagers' identification is concerned. Although hybrid identities appear to be under construction, the recognition of such identities is discouraged because of 
stigmatization of the Albanian culture in the everyday environment and denial of full membership and belongingness to the host society and culture.

Albanians' cultural repositioning as a group in a host society and the abovementioned strategies of migrants and their children can be related to the structure of Albanian ethnic identity, as discussed in Chap. 2. Scholars point to historical primacy, cultural homogeneity and indifference towards religion as 'myths' of Albanian identity, employed symbolically by the Albanian diaspora in its historical struggles to build a national ideology (Malcolm 2002). Others see Albanian ethnic identity as based on the honour of the family and kinship and on respect for one's given word, while considering the lack of a single common religion to be a historical obstacle to a strong ethnic identity (Dingo 2007), referring thus to a more micro-level ethnicity. However, rather than attributing these identification patterns to essentialized traits of identity, in the case of these settling and integrating migrants and their descendants, identification is affected by the 'other', or the native mainstream, which has a privileged power position in the host country and an affirmed and advantageous positioning at a national and international level. This positioning provides a positive signifier to the identity ambivalence and fragility, encouraging thereby an assimilatory form of integration.

\subsection{Integration}

The study of integration, seen in relation to ethnic identity, was the main focus of the TIES project, from which this book's research was drawn in its broadest sense (but not in its methodological or empirical detail). A major hypothesis underlying the comparative approach of the TIES programme of research is that different contexts within Europe impact on the integration of the second generation in a different way to produce different outcomes. Chapter 3 focused on the integration dynamics both of the first-generation Albanian migrants and of their children. Integration was conceptualized as a process rather than a state. While certain factors such as, for example, regularization schemes, the institutional environment and the media were expected to impact on integration, as other research in the field has shown, the inductive approach of this research uncovered other patterns and outcomes. Furthermore, this research has added value because it studies integration across two generations at the same time, as well as in three cities, each located in a different country, adding a comparative dimension.

Important differences were found in integration between the different groups and sites and between the structural and socio-cultural dimension. The first and the second generations differ in terms of their tendency and expectation to integrate and in the sectors of the host society to which they strive to belong. The different policy frameworks and institutional arrangements indeed appear to be important factors affecting the integration of both the first and the second generation, justifying the 'comparative integration context theory' (Crul and Schneider 2010, p. 1249). In terms of different dimensions of integration, structural integration is the main goal 
of the first-generation migrants, whereas the second generation is geared more towards the dimension of social integration, seen through socialization, friendship circles and host-country youth culture. This latter trend (socio-cultural integration) could be the focus of future research on the integration of youth of immigrant origin, since as Glytsos (2005) points out, social integration affects structural integration and vice versa.

It also appears that the relative and absolute size of the Albanian immigrant community is an important factor in the emergence of stigmatization and discrimination at a macro level and the formation of stereotypes that block interactions at a micro level. In Greece, and for some time also in Italy, Albanians were the largest immigrant group, while in Britain they are a small group. Following Esser's (2004) theory of integration on the basis of relative and absolute size of the immigrant group, and also Barth's (1969) ecological model, this differentiating fact alone likely played an important role in the way they were perceived in these host countries and the characteristics of the respective inter-ethnic boundaries. At the two southern sites, in the face of bright boundaries, assimilation into the host society was attempted by means of an individual boundary-crossing strategy, but was obstructed by the exclusive nature of ethnic identity as developed in the public discourse in the host societies. This exclusivity is especially marked in the Greek case. As Dümmler et al. (2010, p. 34) conclude:

[I]f symbolic boundaries are widely agreed upon and institutionalised through reified ideas about culture, nations, tradition and gender relations, then minority groups have to deal with social boundaries that assume a kind of natural and objectified character. This in turn renders it impossible to blur, cross or shift the boundaries.

Similarly, Wimmer (2008), observing earlier developments in the literature, rightly notes that boundary-crossing can be made even more difficult by the dominant groups' sealing their boundary against trespassers. At the two southern sites, the problematic Albanian ethnic identity was instrumentalized and stigmatized in order to bolster the 'purity' of the respective national identities.

In this research the politicization of ethnicity appears to have reinforced the basis of social exclusion; religion counts as the main element on which the racialization of minorities is constructed. For Albanians it is not so much their 'Islamic' identity for which they are vilified, for - as we saw_-Albanians wear their religious heritage lightly. Rather, it is their non-belonging to the hegemonic, national religions of Greek Orthodoxy in Greece and Roman Catholicism in Italy. The cases of Greece and Italy thus show the institutionalization of bright boundaries or sharp symbolic categorizing distinctions based on religion, citizenship and language (Alba 2005; Lamont and Molnar 2002). Therefore, while national belonging at an international level is increasingly defined in terms of civic participation (Tzanelli 2006) and in transnational studies single loyalty to the nation-state and the consequent pressure on immigrants to assimilate is regarded as a thing of the past (Glick Schiller et al. 1995, p. 51), this is not yet the case in the new immigration countries in the Southern Europe. In turn, multicultural organization and specific policies in London seem to tone down salient expressions of discrimination and create social and institutional spaces for people of immigrant origin to integrate. Nevertheless, the class distinctions and the parallel societies created by the faults of multiculturalism 
(Johnson 2007) make Albanians part of the struggle of minorities in London to join the native mainstream, by counting on their racial invisibility.

Otherwise, the Albanian-origin teenagers show a weak 'ethnic agency' to implement strategies that target the location of existing boundaries or to modify their meaning by challenging the hierarchical order of ethnic categories. The boundaries are externally erected, and strategies that require a group's ethnic action are not distinguishable. More visible is the tendency towards boundary-crossing and repositioning, performed at an individual level and accompanied by an indifference towards co-ethnics, referring to the negatively articulated 'Albanianness' as a reason for distancing. When positioning themselves along ethnic and social boundaries, external categorization and identification by others are the main frames referred to by Albanian-origin teenagers, although there are differences between the middleand lower-class second generations, with the former being more autonomous in their inclination towards the retention of the culture of their country of origin (see also Morawska 2003, p. 157). This also reminds us that, in contrast to what US authors maintain, the operation of structural factors can have a reverse effect on ethnic identification. In the absence of ethnic agency, a structural factor such as discrimination can weaken rather than strengthen the vitality of the ethnic group (Waters 1990). Furthermore, although discrimination is an important factor hampering integration, this research shows that the role of the family, the educational system and micro-level socialization can significantly enhance patterns of integration.

It is important to distinguish between the integration strategies of the two generations. In the case of the second generation, we see a different perception of the space in which they integrate. The literature on the second generation's integration developed in the USA has emphasized ethnicity, while European scholars have developed models that concentrate on the institutional aspects of different national contexts in Europe, without giving any rationale for the indirect exclusion of ethnicity and culture. The element of space has appeared rather scarcely in literature on the first generation, and mainly in terms of their transnational ties and practices. In the case of the second generation, Christou (2011) relates space and locality to experiences of return to the homeland. However, to date, no research on the second generation has made any mention of the role of space in terms of integration in the 'host' country.

The second generation appears to be more engaged in discourses on city identity and culture and more observant towards the qualities of space and beauty, which affect feelings of belongingness. Cosmopolitan orientation, predisposition towards mobility and appreciation of diversity are much more evident among the second generation. This represents their different understanding of the nation-state as a 'unit' of integration. However, the cosmopolitan orientation could also be linked to age-related attitudes and aspirations. Research on young people has shown that the emergence of the youth as a social category is consonant with Western modernization. As a result, tendencies towards experimentation, hedonistic consumption and mobility are considered important markers of teenager identity (Kjeldgaard and Askegaard 2006). It should be mentioned nevertheless that while this research contributes to the literature on new immigrants in Europe by including both the first and the second generation, future studies should extend this focus to other regions and groups. 


\subsection{Transnational Ties}

Transnational ties were treated in-depth in Chap. 4. According to the literature, transnationalism and integration are not exclusive phenomena; they coexist and take place with different relationships and pace in different contexts and across different immigrant groups. This research investigated the establishment and performance of transnational ties of both the first and the second generation and the intergenerational transmission of these ties between the two.

Transnational ties were found to develop along with the process of settlement in the host country. Nevertheless, transnational ties do not develop in isolation from the bumpy developments in the receiving and home country and family and kin politics. In contrast to a large body of research on transnationalism, this study found transnational ties to fade or be disrupted by tensions in transnational social fields. These findings contrast especially with studies on families and transnationalism that support the persistence of family and kin networks and of ethnic solidarity. For example, Lima (2001, p. 91) maintains that 'the transnational family is buffered by its extensive social networks, allowing the transnational experiences to form a fluid continuum rather than a radical divide compartmentalising life into two separated worlds'. The contrast is even more striking with studies pointing to a centrality of migration in families' identities and ethos, resting on a basis of loyalty towards the family back home (Chamberlain 2005, pp. 64-66). Instead, rather more akin to what Levitt (2009) observes, the transnational ties of Albanian immigrants and their children expose the moral disjunctures between migrants and those remaining behind, since each group relies on different cultural references.

Other researchers have picked up on the role of kin and the pressure they exert on transnational networks, although not in relation to return visits. Glick Schiller (2004, pp. 461-462) observes that studies of transnationality should take into account the contradictions and disparities within transnational social fields and focus on the intersections of kin and local and national institutions. This finding on the role of kin and its impact on transnational ties is reiterated by Carling (2008, p. 1474):

$[\mathrm{T}]$ he differences and tensions between the two groups must be taken seriously. When transnationalism coexists with ever greater barriers to migration, there is a danger of obscuring these frictions through a focus on hybridity and flux and an abandonment of the traditional binary of origin and destination.

There is thus a need to focus on cultural changes under way in the sending countries and within immigrant families which may lead to redefinitions of cultural norms. In a broader sense, these findings support a research emphasis on the role of culture in transnational engagements and experiences, seen now in relation to micro-level interactions and migrants' interpersonal ties, without overlooking the national and transnational structures that condition migratory movements (Olwig 2003).

In terms of adaptation in the host country and migrants' transnational orientation, this study's findings contrast with research that has associated a high degree of discrimination in the receiving country with reactive transnationalism (Itzigsohn and Saucedo 2002) or a tendency towards engagement in activities that reaffirm 
migrants' collective identity and open up 'entrepreneurial enclave' opportunities for economic prosperity (Faist 2000a; Popkin 1999, p. 232). While 'reactive transnationalism' is not the case, 'linear transnationalism' and 'resource-based transnationalism' (Itzigsohn and Saucedo 2002, p. 789) are common among Albanian migrants and their children in the three cities. Experiences of discrimination in the receiving country were shown to disrupt transnational visits and lead some in the second generation to distance themselves from transnational ties, since migrants' ethnic identification is linked to their proneness to visit the homeland, while transnational orientation is maintained or rejected on the basis of migrants' self-identification and identification by others and their perception of homeland (Leichtman 2005, p. 281).

These insights also point to the existence of variation in transnational engagement according to factors such as gender, social class, migration channel, legal status, economic means and migration and settlement history, often combined with factors related to community structure, gendered patterns of contact and political circumstances in the homeland (Pessar and Mahler 2003; Vertovec 2009). The length of stay in the receiving country also matters (Dahinden 2009). But instead of talking of increase or decrease we should concentrate on the redefinition of transnational ties by both immigrants and their countries of origin.

Again related to capital, this study shows that transnational orientation and experience differ between the skilled and unskilled migrants and their children. This resonates with previous research, which has shown that transnational ties and cosmopolitan orientation can vary according to class (Kothari 2008).

\footnotetext{
Whether referring to transnationals, translocals, cosmopolitans, hybrids, creoles, hommes des confins, postnationals or anything else, we have to be aware that there are different personal and institutional subject positionings vis-à-vis nation, ethnicity, culture and class, that multicultural and intercultural practices ... may take many different forms, and that there is no magical state, accessible through transmigration, which allows people readily to escape national, ethnic and cultural rootedness. (Grillo 2007, p. 212, 213)
}

Attitudes towards return are another important element analysed under transnational ties. In previous research, intention to return has been examined mainly as a factor affecting migrants' contribution to the home country (see, e.g., Duvall 2004). The current study found attitudes towards return to be developed through a transnational understanding and evaluation of opportunities in both home and host country, thus also throwing light on integration patterns. This research findings presented here offer powerful evidence of the key importance of the transnational paradigm in analysing attitudes towards return (King 2000). The literature on migration and return is responding slowly, with literature on transnationalism, migration and mobility developing along separate paths. As Byron and Condon (2008, p. 231) put it, 'the return migration narrative, as we may call it, is often represented as fixed, yet the study of successive generations of migrants and returnees at different points in time reveals a dynamic system constantly nourished by information flows'. Future research could elaborate on this aspect of transnational ties by including attitudes towards return as part of research on transnationalism and integration. More research could also focus on the role of locality on integration and transnationalism and the cosmopolitan orientation of the second generation: these being insights that emerged particularly during the field work in Florence. 


\subsection{Intergenerational Transmission}

Inclusion of intergenerational transmission in this study's research design reflects the need to consider how the two generations interact and impact on each other's identification, integration and transnational ties while they settle in the host country. As such, this study responds to the current gap in research on intergenerational transmission, especially through a qualitative methods approach (Attias-Donfut et al. 2012).

In terms of content, the process of intergenerational transmission consists both of intergenerational discontinuities and linear transmission. For example, parents' lack of interest in transmitting the Albanian language and the second generation's autonomous development of religiosity constitute cases of intergenerational discontinuity. Moreover, the intergenerational transmission process is far more complex than the one-way transmission (parents to children) which is embodied in most standard thinking and research on the topic. The current research showed intergenerational transmission to be bidirectional, although the intensity, mediation and content differ for transmission from parents to children and from children to parents. This is in line with findings on intergenerational transmission outside of migration research, which finds parents' role and influence to be stronger than that of the teenagers (see, e.g., Pinquart and Silbereisen 2004); but the reverse process is by no means absent.

Far from being a quantifiable process, intergenerational transmission appears to be complex and fragmented, changing over time and involving redefinitions of concepts, values and practices and their importance by both parents and children. This process is conditioned by parents' capital (human, social, cultural, etc.) and moderated by discrimination. Means and strategies of transmission are focused on counteracting stigmatization and lack focus on ethnic identity and culture of origin, in favour of achieving financial security and equipping the second generation with universal values and lifelong lessons. The process of intergenerational transmission is characterized by negotiations and strategies that counteract the disadvantageous status as migrants and as a stigmatized group. The dynamics and content of this transmission appear to be positively affected by the empowerment and accumulation of various forms of capital by the parents, who aim to ensure that the second generation experiences upwards mobility. There are, however, significant differences across the three cities. Due to the familiarity and affinity of the first generation with Italian culture in general, and language in particular, intergenerational transmission there is less conflictual and fragmented than in the other two settings and groups.

Discrimination appears to be an important factor that disrupts intergenerational transmission, especially in the case of ethnic identity and transnational ties. From a theoretical perspective, Esser (2004) holds a similar view. He maintains that structure - that is, institutional and cultural factors at a national level - are the most important determinants of intergenerational transmission, taking as example the educational system. He attributes a major role in the process to generalized forms of capital, not restricted to ethnic limits, and especially to human capital in the form of technical and administrative knowledge. 
The findings of this research indicate that intergenerational transmission is significantly affected by the first generation's particular patterns of identification, integration and transnational ties. For a hybrid identity to be constructed and acknowledged by the second generation it is important that a healthy intergenerational transmission of ethnic identity and transnational ties takes place. Although earlylife experiences of discrimination or social acceptance certainly influence the ethnic identification of the teenagers, emotional and social support, alongside the capital transmitted by the family, cushion discrimination and enable teenagers to draw on different cultural resources during adolescence and later in life.

\subsection{Re-interpreting Integration: Agency, Capital and Power}

Finally, this book has dealt with the relationship between ethnic identity, integration and transnational ties, the factors that affect this interaction, and its impact on integration. The findings presented in Chaps. 1 through 5 confirm that identity, integration and transnationalism interact with each other. Most previous research, however, does not explain why some identities become salient and are activated in the transnational social context (Levine 1999, p. 168).

The Albanians in Thessaloniki, Florence and, increasingly, London have now completed the 'golden' first 5-10 years of immigration and settlement, and have put plans for return 'on hold', partly to secure a better education and potentially better life prospects for their children. ${ }^{1}$ Indeed, the successful settlement and integration of the children is an important goal and also an indicator to which the first generation constantly refers to when evaluating the outcomes of their migration project. The lack of resistance towards discrimination and the forced assimilation experienced in the early years of settlement (especially in the two Southern European sites), alongside the change of attitudes over the years, could well be explained within the framework of capital and power. Barth (1969, p. 28) does not elaborate extensively on this element, but senses an 'anomalous' general feature of ethnic identity as a status: while ascription rests mainly on origin and commitment, the performance of the roles required to realize identity is conditioned on certain assets.

Similarly, the current research found ethnic identification to be significantly related to the distribution of resources. According to Levine (1999), it is common for social and cultural factors that become progressively established and elaborated upon by being used for describing identities and social situations to be related to differential access to resources. This differentiation is thought to be inevitably related to conflict and ideological perspectives, which in turn contributes to ethnicity becoming institutionalized. Jenkins (1997) observes that the relationship between

\footnotetext{
${ }^{1}$ As mentioned earlier, a significant number of migrants and their families, primarily from Greece, have returned to Albania since the beginning of the economic crisis in 2008 (when field work for this book was carried out).
} 
the distribution of resources on the one hand, and penalties of identification on the other, is characterized by a combination of domination and resistance, taking place in both the internal and external dimensions of identification. Identity in these processes is an important criterion for distribution, while the distribution patterns are in turn significant in the constitution of identity. Furthermore, Barth (1994) maintains that ethnic competition for resources and all other ethnic processes can only be understood by referring to and including the state as an important actor in the provision of public goods and the regulation of the lives and movements of groups and categories of people.

Experiencing migration as the only way to improve their existence, and then facing discrimination, made Albanian migrants in the three countries unable to draw or rely on any resources, while experiencing harsh identification penalties. Therefore, the 'shift' among Albanian migrants towards ethnic identification also reflects the relevance to them and their understanding of generic principles of hierarchical social differentiation - and how access to economic resources conditions the ability of different actors to categorize others (Jenkins 1997). It also shows that access to economic resources obstructs or enables a group's collective ethnic agency and its ability to define its own ethnic identity. Todd (2005, p. 452) explains identity change in terms of three variables: existing identity structure, power relations and resource distribution. Due to the micro-level ethnicity that Albanian migrants display and all of the structural conditions they have faced in the host countries, it is migrant and parental identities that characterize the first generation. From their narratives, it seems that the ethnic identification of their incorporation strategies is indeed the realization of their migration project: a better life for them and a brighter future for their children. This strongly impacts the individual boundary-crossing strategies of their descendants.

The contraction and transformation of identity can be better understood in light of research which has shown that agency and culture, and all the interrelations of which they are a part, are marked by the notion of power. As Ratner (2000, p. 430) maintains, the individualist notion of agency as based only on personal meanings ignores the barriers agents encounter in their struggles for a sense of equality, democracy and fulfilment. A common view in the literature recognizing power as a factor shaping the social world is that people are situated in different social locations, which are influenced by power hierarchies, including those attached to gender (Pessar and Mahler 2003). Power hierarchies are also taken as the mechanisms that make individuals into subjects through the imposition of categories and their impact on actors' individuality (Foucault 1982, p. 781). In turn, power and capital are interrelated, with the possession of capital resting on the basis of power (Bourdieu 1989). It is for this reason that the emergence of mimicry - discussed by other researchers as a sign of losing oneself in favour of social integration (Romania 2004) - at this stage of integration contains a strong element of intentionality (Todd 2005). The accumulation of capital strengthens a sense of autonomy, which in turn makes mimicry itself a strategy of integration informed by new competence in understanding social hierarchies and identity politics. These findings are in line with the revival of interest in 'power' in identity studies. 
To create a theory of a social self as constituted and constitutor of social life, which situates individual beingness with multiple simultaneous various connected interrelationships, we need to also acknowledge that relationality does not mean equality and that social networks connect us all to institutions linked to various states of unequal power. (Glick Schiller 2012, p. 527)

The inclusion of capital in studies of immigrants' integration, and that of the secondgeneration in particular, is not new (see, e.g., Zhou and Bankston 1994), although theories of integration and the limited studies of intergenerational transmission have not yet really acknowledged capital and its relations to power and agency as factors affecting integration. While parents' insistence on children's education appeared to be an important factor in this research, as in many other studies of the integration of the second generation (Modood 2004; Zhou 1997b), the main finding here is that capital appears in various forms and at various levels (see also Bankston and Zhou 2002; Coleman 1988) in its impacts on integration. Furthermore, different forms of capital are differently important to the first and the second generation. Financial and human capital appears more important in the case of the first generation, who ascertain through experience that expertise and skills in the workplace will provide more security and increase their agency. As mentioned in Chap. 3, social capital based on individual characteristics that affect socialization, and that derive from peer group networks - an aspect almost completely ignored in the second-generation literature - is very important in immigrant-origin adolescents' feelings of being integrated. Therefore, the second generation is more appreciative of the social and cultural capital that can be harnessed to create opportunities - for instance, in accessing employment once their education has come to an end.

Mobility and cosmopolitan tendencies among the second generation are one of the most important findings of this research. Where integration is concerned, the dichotomy between homeland and host country was especially emphasized by the second-generation respondents. While, in the case of the first-generation, research often focuses on their migration process and economic dimensions of their lives in the country of settlement, research on the second-generation has often focused on their allegiances, ties and sense of belonging. One reason for this is a common view among scholars of immigration that the integration of the second-generation is a good indicator both of immigrants' degree of integration and of the more general legacy of contemporary immigration for the receiving societies (Portes 1994; Thomson and Crul 2007).

It is uncommon for the literature on the second-generation to make any reference to cosmopolitanism. One of the few studies to do so, Warikoo (2004), observes a change in the ethnic identification of the Indo-Caribbean second generation in New York and talks about a cosmopolitan ethnicity. One explanation for the emergence of a cosmopolitan ethnicity relates to the alleged influence of the media, causing more fluid identity 'choices', changing previous patterns of understandings of race in the USA. Colombo et al. (2009a) introduce cosmopolitan identification as one of the collective identification types among adolescent children of immigrants in Milan, referring to the particularities of the 'Italian setting' and lack of institutionalized forms of assimilation. In most of the literature on the second generation, however, 
the descendants of migrants are measured against their native peers; what is of interest in this context is whether they retain their parents' culture or assimilate into the host country's culture. Not surprisingly, a hyphenated identity - seen as a new identity of the descendants of migrants drawing from the cultures of both the host country and the country of origin (or 'homeland') — is one of the main findings in the second-generation research (Gans 1994, 1997).

As a result, the 'social sciences as static' —or the failure of research to recognize the role of mobility - applies especially to studies on the integration and transnational ties of the second generation. Sheller and Urry (2006, p. 208) introduce the mobility paradigm:

Even while it has increasingly introduced spatial analysis the social sciences have still failed to examine how the spatialities of social life presuppose (and frequently involve conflict over) both the actual and the imagined movement of people from place to place, person to person, event to event.

Only recently has research on second-generation transnational ties identified a difference in the way the second generation establishes and experiences these ties, as compared to the first-generation. According to Leitchman (2005), the criteria that inspire the transnational ties of the later generations are different from the primarily economic and political ones of the first generation of migrants. Other research notes that the transnational behaviour of the second generation is more complex than portrayed to date in the literature. Arguably, the second generation is not looking for a home; neither are they involved in a 'zero-sum game' between an attachment to the host country that leads to detachment from the homeland, or vice-versa (Gowricharn 2009, p. 1634). Yet, the relationship of the second-generation to space and locality is rarely studied. Meanwhile, as Graham (2000) points out, there is a need for interdisciplinary studies in the broad field of population studies to integrate understandings of space and place developed in social sciences and beyond.

As discussed in Chap. 4, Albanian-origin teenagers show strong cosmopolitan tendencies and consider the migration of their parents as capital, capital that they further harness through their imaginaries, intentions and plans to be mobile and explore other cultures and places. These findings challenge methodological nationalism to the core; viewing second generations' integration, transnational ties and identifications through the home-host country dichotomy has served to reify the nation-state and reaffirm said methodological nationalism.

The mythscape of the nation (and of what is seen as 'home') is one of the romance of nostalgia - a longing for a lost past and a projection of a restored future purity, which plays off the binaries of past and future and here or there, without acknowledging global connectivity. (Glick Schiller and Salazar 2013, p. 195)

The 'global connectivity' cultivated or aspired to by the second generation is testimony to the importance that mobility has in understanding 'second-generation' experiences. Since the second generation is seen as the legacy and measure of integration of migrants and minorities in a receiving society, it also brings a new dimension to the study of the nation-state as the potential container of socio-political processes in which those who experience mobility and stasis are involved. The 
translocal, transnational and global and cosmopolitan references of these teenagers offer new insights to the study of identity, integration and transnationalism. These references challenge binaries of difference - native and the ethnic 'other' — in terms of identification and spatial home-host country dichotomies, in terms of integration and transnational ties, which have long dominated social sciences and migration research (Glick Schiller 2012a, b).

Therefore, the integration of the second-generation does not relate directly to their primordial ethnicity. Although the way that primordial ethnicity is articulated in the host country's discourse affects the way the second generation perceives their culture of origin, it is capital that affects their integration. The two generations give importance to and harness different forms of capital. Nevertheless, both the social and the financial and human capital disposed and transmitted by the parents impact on the second generation's integration because they enable the second generation to harness more social and cultural capital. The opposite - the lack of such capitalobstructs teenagers' integration strategies.

Mobility and cosmopolitanism are forms of such capital, existing and harnessed, which, in the case of the descendants of migrants, display significant interrelations with power and agency. This research found that the second-generation teenagers aimed for social mobility through the acquisition of native citizenship, so that they could move away from the 'migrant' category. The relation that these processes have with space and place adds another important dimension to this study and to migration research more broadly. However, spatial mobility is the main goal behind the desired citizenship, not least because of the recognition that being mobile is an indicator of 'belongingness' vis-à-vis the mainstream, and therefore, of upward social mobility. Here, then, is another important opportunity for future research on the Albanian second-generation: investigating their education-to-work transition, which is usually seen as crucial to the social mobility of people of immigrant or minority origin. The next few years will be a good opportunity to carry out this research, given the cohort-age of the second-generation currently.

Meanwhile, in both generations, the existence of capital appears to increase their autonomy and to affect their perceptions of integration, by making integration in the host society, and the embracing of its culture, more of an option. Capital thus affects the building of boundaries and their permeability. Therefore, the increase in the experience of Albanian migrants, associated with a steady accumulation of resources and capital enabling the gaining of power and vice versa, has caused a significant change in agency; alongside this is a growing knowledge of identity politics and class, and a capacity to recognize symbolic boundaries and the mechanisms that determine them. This process of external identity contestation, followed by selfquestioning and hybridization at a later stage, may well constitute the genesis of a delayed 'reproduction' of ethnicity in the Albanian diaspora.

Furthermore, although the notions of the second generation and hybridity have been widely related to the broader concept of diaspora, the findings of this book show a more dynamic picture. As mentioned above, although hybrid identities are emerging, they are not explicitly claimed by the first and second generation. As with patterns of mimicry, the attitude towards hybridity is affected by external 
categorization, as is the claim of a common homeland. With the accumulation of capital and the gaining of power, which affect the understanding of identity politics and the opportunity structure in the 'host' country as well as attitudes towards Albanian identity, there is now a clearer recognition of the connection with others of the same origin in the country where they live - and beyond.

Among Albanian migrants in these three cities, the idea of diaspora as a source of positive identification is thus a recent development, with different features at each of the sites. In London, this idea is rooted in Albanian organizations' actions towards achieving recognition of the Albanian 'community' as one of many ethnic communities in Britain. More symbolically felt is the 'self-recognition' among Albanian immigrants in Florence - based on a feeling of permanence and settlement in the receiving country. In turn, a very strong contestation of the Albanian identity in Greece, and the unsettling situation with papers, makes the Albanian community in Thessaloniki oriented towards Albania in less symbolic terms - so the issue of hybridity here is a more ambivalent one. These findings make the concept of diaspora largely irrelevant for the analysis of the identification and settlement patterns of Albanian migrants, in line with other work that discusses the limitations of the concept of diaspora as based on common historical roots and destinies and on internal coherence and unity (Ang 2003; Clifford 1994).

An in-depth study of a cross-generational migration and settlement in different contexts and sites creates an acute awareness that the study of the second generation has been essentialized. The 'second generation' is seen as a very particular group in the migration literature, expected to perform, outperform, fail, or assimilate, integrate or cause a 'Balkanisation' (Aparicio 2007, p. 1170) of the places where they live. By constructing the 'second generation', we reify ethnicity and emphasize the nation-state and its impact, in the definition of identities and also as a frame of reference for immigrants and their descendants. This study shows that the second generation is externally defined, at least culturally speaking, and that second-generation teenagers do not see the ethnicity of their origin as an intrinsic quality of them. More importantly, they make use of all the limited resources at their disposal and beyond, and view their integration processes through broader geographies - showing sometimes a cosmopolitan orientation, but also using localized reference points, such as the school, city or urban neighbourhood.

It is thus important to reflect on the semantics of academic concepts and more so on the way power differentials may be reproduced in the academic discourse. Positionality issues aside, doing work with particularly stigmatized and vulnerable groups presents professional dilemmas, and questions concerning the purpose of such a study are inevitable: 'We do research in order to help people. I don't know about you; who are you thinking to help?' Although this project does not fall into an action research design, its main goal is to give voice to the participants, not least because Albanians have been criminalized and marginalized in the countries in which they live. By leaving the reading, evaluation and interpretation of this research to the academic community, the book ends with a note on the fascinating strength and resilience that Albanian migrants and their children have shown throughout these 20 years of settlement in different European countries, despite facing persistent 
adversities. The humility, hope and courage, the significant improvement of their families' welfare, and the strength of the teenagers contributing to this research (which academics frame into concepts and theories) are a significant and positive story. Paralleling the historical research on other, older, immigrant groups within Europe, such as the Irish or the Italians, this may well be a defining moment in the history of 'successful' settlement and assimilation of Albanians in other European countries. Albanian migrants and their children show nothing less than remarkable cultural mechanisms and versatile attitudes towards integration in the 'host' country. Is this not what we refer to when we speak about the modern notions of culture, and what European societies expect of immigrants after all?

Open Access This chapter is distributed under the terms of the Creative Commons Attribution Noncommercial License, which permits any noncommercial use, distribution, and reproduction in any medium, provided the original author(s) and source are credited. 


\section{References}

Adamson, W. L. (1993). Avant-Garde Florence: From modernism to fascism. Cambridge: Harvard University Press.

Adey, P. (2010). Mobility. London: Routledge.

Ahlburg, D. A., \& Brown, R. P. C. (1998). Migrants' intentions to return and capital transfers: A study of Tongans and Samoans in Australia. Journal of Development Studies, 35, 125-151.

Åkesson, L. (2011). Remittances and relationships: Exchange in Cape Verdean transnational families. Ethnos, 76, 326-347.

Akroyd, P. (2000). London: A biography. London: Chatto and Windus.

Alba, R. (2005). Bright vs. blurred boundaries: Second-generation assimilation and exclusion in France, Germany and the United States. Ethnic and Racial Studies, 28, 20-49.

Alba, R., \& Nee, V. (1997). Rethinking assimilation theory for a new era of immigration. International Migration Review, 31, 826-874.

Ang, I. (2003). Together-in-difference: Beyond diaspora, into hybridity. Asian Studies Review, 27, $141-154$.

Anthias, F. (1992). Connecting "race" and ethnicity. Sociology, 26, 421-438.

Anthias, F., \& Yuval-Davis, N. (1992). Racialised boundaries: Race, nation, gender, colour and class and the anti-racist struggle. London: Routledge.

Aparicio, R. (2007). The integration of the second and 1.5 generations of Moroccan, Dominican and Peruvian origin in Madrid and Barcelona. Journal of Ethnic and Migration Studies, 33, $1169-1193$.

ASA. (1997). American Sociological Association Code of Ethics. www.asanet.org. Accessed 16 Sept 2013.

Attias-Donfut, C., Cook, J., Hoffman, J., \& Waite, L. (Eds.). (2012). Citizenship, belonging and intergenerational relations in African migration. Basingstoke: Palgrave.

Backer, E. (2012). VFR travel: It is underestimated. Tourism Management, 33, 74-79.

Bakewell, O. (2010). Some reflections on structure and agency in migration theory. Journal of Ethnic and Migration Studies, 36, 1689-1708.

Baldwin-Edwards, M. (2009). Regularisation in Europe (REGINE). Country studies: Greece: ICMPD

Baldwin-Edwards, M., \& Apostolatou, K. (2008). Greece. In H. Fassmann, U. Reeger, \& W. Sievers (Eds.), Statistics and reality: Concepts and measurements of migration in Europe. Amsterdam: Amsterdam University Press.

Baldwin-Edwards, M., \& Kolio, N. (2008). Immigrants in Greece: Characteristics and issues of regional distribution. Athens: ISTAME Report.

Bankston, C. L., III, \& Zhou, M. (2002). Social capital as process: The meanings and problems of a theoretical metaphor. Sociological Inquiry, 72, 285-317.

Banton, M. (1994). Discrimination. Buckingham: Open University Press.

Z. Vathi, Migrating and Settling in a Mobile World, IMISCOE Research Series,

DOI 10.1007/978-3-319-13024-8 
Banton, M. (2001). National integration in France and Britain. Journal of Ethnic and Migration Studies, 27, 151-168.

Banton, M. (2008). The sociology of ethnic relations. Ethnic and Racial Studies, 31, 1267-1285.

Barkan, E. R. (2004). America in the hand, homeland in the heart: Transnational and translocal immigrant experiences in the American West. The Western Historical Quarterly, 35, 331-354.

Barnardo's statement of ethical research practice.(2013). http://www.bris.ac.uk/education/research/centres/creole/resources/ethics/barnados.pdf. Accessed 6 Aug 2013.

Barth, F. (1969). Ethnic groups and boundaries: The social organisation of cultural difference. Boston: Little Brown.

Barth, F. (1994). Enduring and emerging issues in the analysis of ethnicity. In F. Vermeulen \& C. Govers (Eds.), The anthropology of ethnicity: Beyond ethnic groups and boundaries (pp. 11-32). Amsterdam: Het Spinhuis.

Basu, P. (2004). Route metaphors of "roots-tourism" in the Scottish Highlands diaspora. In S. Coleman \& J. Eade (Eds.), Reframing pilgrimage: Cultures in motion (pp. 150-178). Routledge: London.

Bauer, P., \& Riphahn, R. T. (2007). Heterogeneity in the intergenerational transmission of educational attainment: Evidence from Switzerland on natives and second-generation immigrants. Journal of Population Economics, 20, 121-148.

Baumann, G. (1996). Contesting culture: Discourses of identity in multi-ethnic London. Cambridge: Cambridge University Press.

Beck, U. (2002). The cosmopolitan society and its enemies. Theory, Culture and Society, 19, 17-44.

Beck, U., \& Sznaider, N. (2006). Unpacking cosmopolitanism for the social sciences: A research agenda. The British Journal of Sociology, 57, 1-23.

Benincasa, L. (2002). Teaching pre-schoolers about diversity: A view from Greece. Journal of Education for Teaching, 28, 103-122.

Berkeley, R., Khan, O., \& Ambikaipaker, M. (2006). What's new about new immigrants in the twenty-first century Britain? London: Joseph Rowntree Foundation.

Berry, J. W. (2003). Conceptual approaches to acculturation. In K. M. Chun, O. P. Balls, \& G. Marin (Eds.), Acculturation: Advances in theory measurement and applied research (pp. 17-37). Washington DC: American Psychological Association.

Bhabha, H. K. (1994). The location of culture. London: Routledge.

Binaisa, N. (2009). Ugandan migrants in Britain: Negotiating spaces of 'home' and 'belonging'. Brighton: University of Sussex, unpublished DPhil in Migration Studies.

Bleakley, H., \& Chin, A. (2008). What holds back the second generation? The intergenerational transmission of language human capital among immigrants. Journal of Human Resources, 43, 267-298.

Blumi, I. (2003). Defining social spaces by way of deletion: The untold story of Albanian migration in the postwar period. Journal of Ethnic and Migration Studies, 29, 949-965.

Bonifazi, C. (2000). European migration policy: Questions from Italy. In R. King, G. Lazaridis, \& C. Tsardanidis (Eds.), Eldorado or fortress? Migration in Southern Europe (pp. 233-253). London: Macmillan.

Bonifazi, C. \& Sabatino, D. (2003). Albanian migration to Italy: What official data and survey results can reveal. Journal of Ethnic and Migration Studies, 29, 967-995.

Borjas, G. J. (1992). Ethnic capital and intergenerational mobility. The Quarterly Journal of Economics, 107, 123-150.

Borjas, G. J. (1993). The intergenerational mobility of immigrants. Journal of Labor Economics, $11,113-135$.

Boswell, C. (2003). European migration policies in flux: Changing patterns of inclusion and exclusion. London: Blackwell.

Bourdieu, P. (1989). Social space and symbolic power. Sociological Theory, 7, 14-25.

Bourdieu, P. (2004). The forms of capital. In S. J. Bell (Ed.), The RoutledgeFalmer reader in sociology of education (pp. 15-29). London: Taylor and Francis.

Brettell, C. B. (2000). Urban history, urban anthropology, and the study of migrants in cities. City and Society, 12, 129-138. 
Brickell, K. \& Datta, A. (Eds.). (2011). Translocal geographies: Spaces, places, connections. Aldershot: Ashgate.

Brower, L. (2006). Dutch Moroccan websites: A transnational imaginary?. Journal of Ethnic and Migration Studies, 32, 1153-1168.

Brubaker, R. (2001). The return of assimilation? Changing perspectives on immigration and its sequels in France, Germany, and the United States. Ethnic and Racial Studies, 24, 531-548.

Brubaker, R. (2005). The "Diaspora" diaspora. Ethnic and Racial Studies, 28, 1-19.

Brubaker, R., \& Cooper, F. (2000). Beyond "identity". Theory and Society, 29, 1-47.

Brubaker, R., Loveman, M., \& Stamatov, P. (2004). Ethnicity as cognition. Theory and Society, 33, 31-64.

Burr, V. (2003). Social constructionism. London: Routledge.

Bushin, N. (2009). Researching family migration decision-making: A children-in-families approach. Population Space and Place, 15, 429-443.

Byron, M., \& Condon, S. (1996). A comparative study of Caribbean return migration from Britain and France: Towards a context-dependent explanation. Transactions of the Institute of British Geographers, 21, 91-104.

Byron, M., \& Condon, S. (2008). Migration in comparative perspective: Caribbean communities in Britain and France. London: Routledge.

Cadge, W., Curran, S., Hejtmanek, J., Jaworsky N. B., \& Levitt, P. (2009). The city as context: Culture and scale in new immigrant destinations. Malmö: Institute for studies of migration, diversity and welfare, Willy Brandt working papers in International Migration and Ethnic Relations.

Çağlar, A. S. (1997). Hyphenated identities and the limits of "culture". In T. Modood \& P. Werbner (Eds.), The politics of multiculturalism in the New Europe (pp. 169-185). London: Zed Books.

Calavita, K. (2005). Immigrants at the margins: Law, race, and exclusion in Southern Europe. Cambridge: Cambridge University Press.

Caritas/Migrantes. (2009). Immigrazione Dossier Statistico. Rome: Edizioni Idos.

Carling, J. (2008). The human dynamics of transnationalism. Ethnic and Racial Studies, 31, $1452-1477$.

Casey, T., \& Dustmann, C. (2008). Intergenerational transmission of language capital and economic outcomes. Journal of Human Resources, 43, 660-687.

Chadderton, C. (2010). Educational policy and minority ethnic young people in the UK. Network migration in Europe. www.migrationeducation.org. Accessed 6 Aug 2013.

Chamberlain, M. (2005). Narratives of exile and return. London: Transaction.

Choldin, H. M. (1973). Kinship networks in the migration process. International Migration Review, 7, 163-175.

Chong, K. H. (1998). What it means to be Christian: The role of religion in the construction of ethnic identity and boundary among second-generation Korean Americans. Sociology of Religion, 59, 259-286.

Christensen, P. H. (2004). Children's participation in ethnographic research: Issues of power and representation. Children and Society, 18, 165-176.

Christiansen, C. C. (2004). New media consumption among immigrants in Europe: The relevance of diaspora. Ethnicities, 4, 185-207.

Christou, A. (2006). American dreams and European nightmares: Experiences and polemics of second-generation Greek-American returning migrants. Journal of Ethnic and Migration Studies, $32,831-845$.

Christou, A. (2011). Translocal spatial geographies: Multi-sited encounters of Greek migrants in Athens, Berlin, and New York. In K. Brickell \& A. Datta (Eds.), Translocal geographies: Spaces, places, connections (pp. 145-161). Aldershot: Ashgate.

Clifford, J. (1994). Diasporas. Cultural Anthropology, 9, 302-338.

Cole, M., \& Maisura, A (2007). "Shut the f*** up", "you have no rights here": Critical race theory and racialisation in post-7/7 racist Britain. Journal for Critical Education Policy Studies (Vol. 5) [www.jceps.com/print.php?articleID=85]. Accessed 22 December 2013.

Coleman, J. S. (1988). Social capital in the creation of human capital. American Journal of Sociology, 94, 95-120. 
Colombo, E., Leonini, L., \& Rebughini, P. (2009a). Different but not stranger: Everyday collective identifications among adolescent children of immigrants in Italy. Journal of Ethnic and Migration Studies, 35, 37-59.

Colombo, E., Domaneschi, L., \& Marchetti, C. (2009b). Una Nuova Generazione di Italiani. L'Idea di Cittadinanza Tra i Giovanni Figli di Immigratti (A new generation of Italians: The idea of citizenship among young children of immigrants). Rome: Franco Angeli.

Condon, S. (2009). Looking at migration as a gendered process, a generational experience and one that both is shaped by and shapes time and the life course: How far have we come in IMISCOE C8 in understanding intersections between gender, age and generation? Paper presented at the IMISCOE Annual Conference Sustainable diversity, migration and social cohesion. Stockholm, 9-11 September.

Conradson, D., \& McKay, D (2007). Translocal subjectivities: Mobility, connection, emotion. Mobilities, 2, 167-174.

Conti, F. (2008). Perceptions of success: An investigation of Italian graduate migration to the United Kingdom. Paper presented to the ERSA Congress, Liverpool, 27-31 Aug.

Conway, D., \& Potter, R. B. (2009). Return of the next generations: Transnational mobilities, family demographics and experiences and multi-local spaces. In D. Conway \& R. B. Potter (Eds.), Return migration of the next generations: 21st century transnational mobilities (pp. 223-242). Aldershot: Ashgate.

Cresswell, T. (2006). On the move. London: Routledge.

Cross, M. (2000). Ethnic minorities and British social science: Three views. Journal of Ethnic and Migration Studies, 26, 364-366.

Crow, I. (2000). The power of research. In D. Burton (Ed.), Research training for social scientists. $A$ handbook for postgraduate researchers (pp. 68-80). London: Sage.

Crul, M. (1999). Explanations for school success among second-generation Moroccan and Turkish youth in the Netherlands. In M. Crul, F. Lindo, \& C. L. Pang (Eds.), Culture, structure, and beyond. Changing identities and social positions of immigrants and their children (pp. 91-111). Amsterdam: Het Spinhuis.

Crul, M., \& Schneider, J. (2010). Comparative integration context theory: Participation and belonging in new diverse European cities. Ethnic and Racial Studies, 33, 1249-1268.

Crul, M., \& Vermeulen, H. (2003). The second generation in Europe. International Migration Review, 37, 965-986.

Crul, M., \& Vermeulen, H. (2006). Immigration, education and the Turkish second generation in five European nations: A comparative study. In C. A. Parsons \& T. M. Smeeding (Eds.), Immigration and the transformation of Europe (pp. 236-250). Cambridge: Cambridge University Press.

Dahinden, J. (2009). Are we all transnational now? Network transnationalism and transnational subjectivity: The differing impacts of globalisation on the inhabitants of a small Swiss city. Ethnic and Racial Studies, 32, 1365-1386.

Dalakoglou, D. (2010). Migrating-remitting-"building"-dwelling: House-making as "proxy" presence in postsocialist Albania. Journal of the Royal Anthropological Institute, 16, 761-777.

Da Lomba, S. (2010). Legal status and refugee integration: A UK perspective. Journal of Refugee Studies, 23, 415-436.

D'Andrea, A., Ciolfi, L., \& Gray, B. (2011). Methodological challenges and innovations in mobilities research. Mobilities, 6, 149-160.

De Genova, N. P. (2002). Migrant "illegality" and deportability in everyday life. Annual Review of Anthropology, 31, 419-447.

De Vries, M. (1999). Why ethnicity? The ethnicity of Dutch Eurasians raised in the Netherlands. In M. Crul, F. Lindo, \& C.L. Pang (Eds.), Culture, structure and beyond (pp. 28-48). Amsterdam: Het Spinhuis.

De Waal, C. (2005). Albania today: A portrait of post-communist turbulence. London: Tauris, I. B.

Delanty, G. (2006). The cosmopolitan imagination: Critical cosmopolitanism and social theory. The British Journal of Sociology, 57, 25-47. 
Dingo, F. (2007). IdentitÃ Albanesi. Un'approccio Psico-Antropologico (Albanian Identity: A Psycho-anthropological approach). Rome: Bonanno Editore.

Dobson, M. (2009). Unpacking children in migration research. Children's Geographies, 7, 355-360.

Dronkers, J., \& Levels, M. (2006). Socio-economic and ethnic school segregation in Europe and Australia and educational achievement of migrant pupils coming from various regions of origin. Paper presented to the ISA meeting, Florence, 11-14 May.

Dustmann, C., Bentolila, S., \& Faini, R. (1996). Return migration: The European experience. Economic Policy, 11, 213-250.

Dümmler, K., Dahinden, J., \& Moret, J. (2010). Gender equality as “cultural stuff”: Ethnic boundary work in a classroom in Switzerland. Diversities, 12, 19-37.

Dürrschmidt, J. (1997). The de-linking of locale and milieu: On the situatedness of extended milieux in a global environment. In J. Eade (Ed.), Living the global city: Globalisation as a local process (pp. 56-72). London: Routledge.

Duvall, D. T. (2003). When hosts become guests: Return visits and transnational identities in a Commonwealth Eastern Caribbean community. Current Issues in Tourism, 6, 267-308.

Duvall, D. T. (2004). Linking return visits and return migration among Commonwealth Eastern Caribbean migrants in Toronto. Global Networks, 4, 51-67.

Dwyer, C., Modood, T., Sanghera, G, Shah, B., \& Thapar-Bjorkert S. (2006). Ethnicity as social capital? Explaining the differential educational achievements of young British Pakistani men and women. Paper presented at the conference ethnicity, mobility and society. Bristol, 16-17 March 2006.

Eade, J. (1997). Introduction. In J. Eade (Ed.), Living the global city: Globalisation as a local process (pp. 1-19). London: Routledge.

Eade, J. (2000). Placing London: From imperial capital to global city. New York: Berghahn.

Eckstein, S. (2002). On deconstructing and reconstructing the meaning of immigrant generations. In P. Levitt \& M. C. Waters (Eds.), The changing face of home: The transnational lives of the second generation (pp. 211-215). New York: Sage.

Elizur, D. (1973). Attitudes and intentions of Israelis residing in the US towards returning to Israel. International Migration, 11, 3-14.

Engbersen, G. (2003). Spheres of integration: Towards a differentiated and reflexive ethnic minority policy. In R. Sackmann, B. Peters, \& T. Faist (Eds.), Identity and integration: Migrants in Western Europe, (pp. 59-76). London: Ashgate.

Erikson, E. H. (1968). Identity: Youth and crisis. New York: Norton.

Esser, H. (2004). Does the "new" immigration require a "new" theory of intergenerational integration?. International Migration Review, 38, 1126-1159.

Eurydice (2004). Integrating immigrant children into schools in Europe. Brussels: European Commission, DG Education and Culture. http://www.eurydice.org/portal/page/portal/Eurydice/Pub Contents?pubid=044EN\&country=null. Accessed 6 Aug 2013.

Faist, T. (2000a). The volume and dynamics of international migration and transnational social spaces. Oxford: Clarendon Press.

Faist, T. (2000b), Transnationalisation in international migration: Implications for the study of citizenship and culture. Ethnic and Racial Studies, 23, 189-222.

Faist, T., Kivisto, P, \& Fauser, M. (Eds.). (2011). The migration-development nexus: A transnational perspective. London: Routledge.

Fakiolas, R., \& King, R. (1996). Emigration, return, immigration: A review and evaluation of Greece's postwar experience of international migration. International Journal of Population Geography, 2, 171-190.

Falzon, M. (2009). Multi-sited ethnography: Theory, praxis and locality in contemporary research. London: Ashgate.

Fauser, M. (2007). The local politics of transnational cooperation on development(s) and migration in Spanish cities. Bielefeld: Center on Migration, Citizenship and Development, Working Paper No. 24.

Fava, T. (2007). L'inserimento scolastico degli immigrati di seconda generazione nelle Marche (The school incorporation of immigrants of second generation in Marche). Paper presented at 
the conference 'Seconde Generazioni in Italia: Presente e Futuro dei Processi d'Integrazione dei Figli d'Immigrati. Bologna, 3 May.

Favell, A. (1998). Philosophies of integration. London: Macmillan.

Favell, A. (2000). Ethnic minorities in British social science: Three views. Journal of Ethnic and Migration Studies, 26, 358-363.

Favell, A. (2001). Integration policy and integration research in Europe: A review and critique. In A. T. Aleinikoff \& D. Klusmeyer (Eds.), Citizenship today: Global perspectives and practices (pp. 349-399). Washington, DC: Brookings Institute/Carnegie Endowment for International Peace.

Favell, A. (2002). Italy as a comparative case. In R. Grillo \& J. Pratt (Eds.), The politics of recognising difference: Multiculturalism Italian style. Aldershot: Ashgate.

Ferrero-Regis, T. (2008). Fatto in Italia: Refashioning Italy. Journal of Multidisciplinary International Studies, 5, 1-17.

Fibbi, R., Lerch, M., \& Wanner, P. (2007). Naturalisation and socio-economic characteristics of youth of immigrant descent in Switzerland. Journal of Ethnic and Migration Studies, 33, $1121-1144$.

Flouri, E. (1999). An integrated model of consumer materialism: Can economic socialisation and maternal values predict materialistic attitudes in adolescents? Journal of Socio-economics, 28, $707-724$.

Flynn, D. (2005). New borders, new management: The dilemmas of modern immigration policy. Ethnic and Racial Studies, 28, 463-490.

Foner, N. (1998). Towards a comparative perspective on Caribbean migration. In M. Chamberlain (Ed.), Caribbean migration: Globalised identities (pp. 46-61). London: Routledge.

Foner, N. (2002). Second-generation transnationalism, then and now. In P. Levitt \& M. C. Waters (Eds.), The changingface of home: The transnationallives of the secondgeneration (pp.242-254). New York: Sage.

Foner, N., \& Alba, R. (2008). Immigrant religion in the US and Western Europe: Bridge or barriers to inclusion? International Migration Review, 42, 360-392.

Foot, J. (1995). The logic of contradiction: Migration control in Italy and France, 1980-93. In R. Miles \& D. Thranhardt (Eds.), Migration and European integration: The dynamics of inclusion and exclusion (pp. 132-158). London: Pinter.

Foot, J. (2001). San Salvario, Turin: The creation of a dangerous place, 1990-99. In R. King (Ed.), The Mediterranean passage: Migration and new cultural encounters in Southern Europe (pp. 206-230). Liverpool: Liverpool University Press.

Foucault, M. (1982). The subject and power. Critical Inquiry, 8, 777-795.

Fowler, B. (1997). Pierre Bourdieu and cultural theory: Critical investigations. London: Sage.

Frashëri, K. (2007). Identiteti kombëtar, feja and qytetërimi' (The national identity, religion and civilisation). Social Studies: Journal of the Institute of Sociology, 1, 23-32.

Gabrielli, D., Strozza, S., \& Todisco, E (2009). Country Report Italy. Rome: Report of the Research Group 'Promoting comparative quantitative research in the field of migration and integration in Europe' (PROMINSTAT).

Gans, H. J. (1992). Second-generation decline: Scenarios for the economic and ethnic futures of the post-1965 American immigrants. Ethnic and Racial Studies, 15, 173-193.

Gans, H. J. (1994). Symbolic ethnicity and symbolic religiosity: Towards a comparison of ethnic and religious acculturation. Ethnic and Racial Studies, 17, 577-592.

Gans, H. J. (1997). Toward a reconciliation of "assimilation" and "pluralism": The interplay of acculturation and ethnic retention. International Migration Review, 31, 875-892.

Gardner, K. (2012). Transnational migration and the study of children: An introduction. Journal of Ethnic and Migration Studies, 38, 889-912.

Giddens, A. (1991). Structuration theory: Past, present and future. In C. G. A. Bryant \& D. Jary (Eds.), Giddens' theory of structuration: A critical appreciation (pp. 201-221). London: Routledge.

Gilroy, P. (1996). British cultural studies and the pitfalls of identity. In A. B. Houston, M. Diawara, \& R. H. Lindeborg (Eds.), Black British cultural studies (pp. 223-240). Chicago: University of Chicago Press. 
Glick Schiller, N. (2004). Transnationality. In D. Nugent \& J. Vincent (Eds.), A companion to anthropology of politics, 448-467. London: Blackwell.

Glick Schiller, N. (2012a), A comparative relative perspective on the relationships between migrants and cities. Urban Geography, 33, 879-903.

Glick Schiller, N. (2012b), Situating identities: Towards an identities studies without binaries of difference. Identities: Global Studies in Culture and Power, 19, 520-532.

Glick Schiller, N., \& Çağlar, A. (2009). Towards a comparative theory of locality in migration studies: Migrant incorporation and city scale. Journal of Ethnic and Migration Studies, 35, 177-202.

Glick Schiller, N., \& Fouron, G. E. (2001). Georges woke up laughing: Long-distance nationalism and the search for home. Durham: Duke University Press.

Glick Schiller, N., \& Salazar, N. B. (2013). Regimes of mobility across the globe. Journal of Ethnic and Migration Studies, 39, 183-200.

Glick Schiller, N., Basch, L., \& Szanton Blanc C. (1995). From immigrant to transmigrant: Theorising transnational migration. Anthropological Quarterly, 68, 48-63.

Glytsos, N. P. (2005). Stepping from illegality to legality and advancing towards integration: The case of immigrants in Greece. International Migration Review, 39, 819-840.

Gmelch, G. (1980). Return migration. Annual Review of Anthropology, 9, 135-159.

Gogonas, N. (2010). Bilingualism and multiculturalism in Greek education: Investigating ethnic language maintenance among pupils of Albanian and Egyptian origin in Athens. Newcastle Upon Tyne: Cambridge Scholars Publishing.

Golash-Boza, T. (2005). Assessing the advantages of bilingualism for the children of immigrants. International Migration Review, 39, 721-753.

Gordon, M. M. (1964). Assimilation in American life: The role of race, religion, and national origins. New York: Oxford University Press.

Government of Albania (2005). Migratory Bulletin. Tirana: Government of Albania and IOM.

Gowricharn, R. (2009). Changing forms of transnationalism. Ethnic and Racial Studies, 32, 1619-1638.

Goździak, E. M., \& Ensor, M. O. (2010). The way forward: Conclusions and recommendations. In M. O. Ensor \& E. M. Goździak (Eds.), Children and migration: At the crossroads of resiliency and vulnerability (pp. 274-280). Basingstoke: Palgrave.

Graham, E. (2000). What kind of theory for what kind of population geography? Population, Space and Place, 6, 257-272.

Green, A. (1997). Education, globalisation and the nation-state. Basingstoke: Macmillan.

Grillo, R. (2002). Immigration and the politics of recognizing difference in Italy. In R. Grillo \& J. Pratt (Eds.), The politics of recognising difference: Multiculturalism Italian style (pp. 1-39). Aldershot: Ashgate.

Grillo, R. (2007). Betwixt and between: Trajectories and projects of transmigration. Journal of Ethnic and Migration Studies, 33, 199-217.

Gropas, R., \& Triandafyllidou, A. (2007). Cultural diversity in Greek public and political discourses. Athens: ELIAMEP Working Paper.

Guarnizo, L. E., Portes, A., \& Haller, W. (2003). Assimilation and transnationalism: Determinants of transnational political action among contemporary migrants. American Journal of Sociology, $108,1211-1248$.

Hall, S. (1996). New ethnicities. In D. Morley \& K-H. Chen (Eds.), Stuart Hall: Critical dialogues in cultural studies (pp. 441-464). London: Routledge.

Hall, D. (1999). Representations of place: Albania. The Geographical Journal, 165, 161-172.

Hammond, P. E. (1988). Religion and the persistence of identity. Journal for the Scientific Study of Religion, 27, 1-11.

Hampshire, J. (2005). Citizenship and belonging: Immigration and the politics of demographic governance in post-war Britain. New York: Palgrave.

Hantrais, L. (1999). Contextualization in cross-national comparative research. International Journal of Social Research Methodology, 2, 93-108. 
Harré, R. (2002). Public sources of the personal mind: Social constructionism in context. Theory and Psychology, 12, 611-625.

Hastaoglou-Martinidis, V. (1997). A Mediterranean city in transition: Thessaloniki between the two world wars. Facta Universitatis, 1, 493-507.

Hatziprokopiou, P. (2004). Balkan immigrants in the Greek city of Thessaloniki: Local processes of incorporation in an international perspective. European Urban and Regional Studies, 11, 321-338.

Hatziprokopiou, P. (2006a). Globalisation, migration and socio-economic change in contemporary Greece. Processes of social incorporation of Balkan immigrants in Thessaloniki. Amsterdam: Amsterdam University Press.

Hatziprokopiou, P. (2006b). Migration and changing urban geographies in the European south: Evidence from the case of immigrants in Thessaloniki. Migration and Ethnic Themes, 22, $113-136$.

Heath, A., \& Cheung, S. Y. (2007). Unequal chances: Ethnic minorities in western labour markets. Oxford: Oxford University Press.

Hemming, A. (2009). Migrant identity on display: The xhiro in Rrëshen. Southeast European and Black Sea Studies, 9, 575-598.

Hertzog-Punzenberger, B. (2003). Ethnic segmentation in school and labour market: 40 year legacy of Austrian guestworker policy. International Migration Review, 37, 1120-1144.

Holmes, C. (1997). Cosmopolitan London. In A. Kershen (Ed.), London: The promised land? The migration experience in a capital city (pp 10-37). Aldershot: Avebury.

Iosifides, T. (2011). Qualitative methods in migration studies: A critical realist perspective. Farnham: Ashgate.

Isabaeva, E. (2011). Leaving to enable the others to remain: Remittances and new moral economies of migration in Southern Kyrgyzstan. Central Asian Survey, 30, 541-554.

Isin, E. F. (2007). City state: Critique of scalar thought. Citizenship Studies, 11, 211-228.

Itzigsohn, J., \& Saucedo, S. G. (2002). Immigrant incorporation and sociocultural transnationalism. International Migration Review, 36, 766-798.

Jenkins, R. (1997). Rethinking ethnicity: Arguments and explorations. London: Sage.

Jenkins, R. (2004). Social identity. London: Routledge.

Johnson, N. (2007). Building an integrated society. In M. Wetherell, M. Lafleche, \& R. Berkeley (Eds.), Identity, ethnic diversity and community cohesion (pp. 24-33). London: Sage.

Jones-Correa, M. (2002). The study of transnationalism among the children of immigrants: Where we are and where we should be headed. In P. Levitt \& M. C. Waters (Eds), The changing face of home: The transnational lives of the second generation (pp. 221-241). New York: Sage.

Jones, R. C., \& De La Torre, L. (2011). Diminished tradition of return? Transnational migration in Bolivia's Valle Alto. Global Networks, 11, 180-202.

Joppke, C. (1999). How immigration is changing citizenship: A comparative view. Ethnic and Racial Studies, 22, 629-652.

Joppke, C., \& Morawska, E. (2003). Integrating immigrants in liberal nation-states: Policies and practices. In C. Joppke \& E. Morawska (Eds.), Toward assimilation and citizenship: Immigrants in liberal nation-states (pp. 1-36). London: Macmillan.

Kadaré, I. (2005). Kombi Shqiptar në Prag të Mijëvjeçarit të Tretë: Sprovë (The Albanian nation in the beginning of the third millennium: A challenge). Tirana: Onufri.

Kadaré, I. (2006). Identiteti Evropian i Shqiptarëve: Sprovë (The European identity of Albanians: A challenge). Tirana: Onufri.

Kapllani, G., \& Mai, N. (2005). Greece belongs to Greeks: The case of the Greek flag in the hands of an Albanian student. In R. King, N. Mai, \& S. Schwandner-Sievers (Eds.), The new Albanian migration (pp. 153-172). Brighton: Sussex Academic Press.

Kasinitz, P., Mollenkopf, J. H., \& Waters, M. C. (2004). Worlds of the second generation. In P. Kasinitz, J. H. Mollenkopf \& M. C. Waters (Eds.), Becoming New Yorkers. Ethnographies of the new second generation (pp. 1-19). New York: Sage.

Kertzer, D. I. (1983). Generation as a sociological problem. Annual Review of Sociology, 9, 125-149. 
Kibria, N. (2002). Of blood, belonging, and homeland trips: Transnationalism and identity among second-generation Chinese and Korean Americans. In P. Levitt \& M. C. Waters (Eds.), The changing face of home: The transnational lives of the second generation (pp. 295-311). New York: Sage.

King, R. (1987). Italy. London: Harper and Row.

King, R. (1995). Migrations, globalisation and place. In D. Massey \& P. Jess (Eds.), A place in the world? Places, cultures and globalisation (pp. 5-45). Oxford: Oxford University Press.

King, R. (2000). Generalisations from the history of return migration. In B. Ghosh (Ed.), Return migration: Journey of hope or despair? (pp. 7-55). Geneva: IOM.

King, R. (2003). Across the sea and over the mountains: Documenting Albanian migration. Scottish Geographical Journal, 119, 283-309.

King, R., \& Andall, J. (1999). The geography and economic sociology of recent immigration to Italy. Modern Italy, 4, 135-158.

King, R., \& Christou, A. (2010). Cultural geographies of counter-diasporic migration: Perspectives from the study of second-generation "returnees" to Greece. Population, Space and Place, 16, $103-119$.

King, R., \& Mai, N. (2002). Of myths and mirrors: Interpretations of the Albanian migration to Italy. Studi Emigrazione, 145, 161-200.

King, R., \& Mai, N. (2004). Albanian immigrants in Lecce and Modena: Narratives of rejection, survival and integration. Population, Space and Place, 10, 455-477.

King, R., \& Mai, N. (2008). Out of Albania: From crisis migration to social inclusion in Italy. New York: Berghahn.

King, R., \& Mai, N. (2009). Italophilia meets albanophobia: Paradoxes of asymmetric assimilation and identity processes among Albanian immigrants in Italy. Ethnic and Racial Studies, 39, 117-138.

King, R., \& Vullnetari, J. (2006). Orphan pensioners and migrating grandparents: The impact of mass migration on older people in rural Albania. Ageing and Society, 26, 783-816.

King, R., Fielding, A., \& Black, R. (1997). The international migration turnaround in Southern Europe. In R. King \& R. Black (Eds.), Southern Europe and the new immigrations (pp. 1-25). Brighton: Sussex Academic Press.

King, R., Christou A., \& Teerling J. (2011b). "We took a bath with the chickens": Memories of childhood visits to the homeland by second-generation Greek and Greek Cypriot returnees. Global Networks, 11, 1-23.

King, R., Mai, N., \& Dalipaj, M. (2003). Exploding the migration myths. London: The Fabian Society and Oxfam.

King, R., Thomson, M., Fielding, T, \& Warnes, T. (2006a). Time, generations and gender in migration and settlement. In R. Penninx, M. Berger, \& M. Kraal (Eds.), The dynamics of international migration and settlement in Europe (pp. 233-268). Amsterdam: Amsterdam University Press.

King, R., Dalipaj, M., \& Mai, N. (2006b). Gendering migration and remittances: Evidence from London and northern Albania. Population, Space and Place, 12, 409-434.

King, R., Castaldo, A., \& Vullnetari, J. (2011). Gendered relations and filial duties along the Greek-Albanian remittance corridor. Economic Geography, 87, 393-419.

King, R., Christou, A., \& Ahrens, J. (2011a), "Diverse mobilities”: Second-generation Greek-Germans engage with the homeland as children and as adults. Mobilities, 6, 483-501.

Kivisto, P. (2001). Theorizing transnational immigration: A critical review of current efforts. Ethnic and Racial Studies, 24, 549-577.

Kjeldgaard, D., \& Askegaard, S. (2006). The glocalisation of youth culture: The global youth segment as structures of common difference. Journal of Consumer Research, 33, 231-247.

Kofman, E. (2005). Figures of the cosmopolitan: Privileged nationals and national Outsiders. Innovation: The European Journal of Social Science Research, 18, 85-99.

Kosic, A., \& Triandafyllidou, A. (2003). Albanian immigrants in Italy: Migration plans, coping strategies and identity issues. Journal of Ethnic and Migration Studies, 29, 997-1014. 
Kostovicova, D. (2003). The Albanians in Britain: Diasporic identity and experience in the education perspective since 1990. Journal of Southern Europe and the Balkans, 5, 53-69.

Kothari, U. (2008). Global peddlers and local networks: Migrant cosmopolitanisms. Society and Space, 26, 500-516.

Kraidy, M. M. (1999). The global, the local and the hybrid: A native ethnography of glocalisation. Critical Studies in Media and Communication, 16, 456-476.

Kroger, J. (2007). Identity development: Adolescence through adulthood. London: Sage.

Kyambi, S. (2005). Beyond black and white: Mapping new immigrant communities. London: Institute for Public Policy Research report.

Kymlicka, W. (2000). A North American view. Journal of Ethnic and Migration Studies, 26, 719-738.

Labrianidis, L., \& Hatziprokopiou, P. (2010). Migrant entrepreneurship in Greece: Diversity of pathways for emerging ethnic business communities in Thessaloniki. Journal of International Migration and Integration, 11, 193-217.

Lako, N. (2009). Mes Skuadrave Shqiptare të Identitetit (Among the Albanian Teams of Identity). http://balkanweb.com/gazetav5/artikull.php?id=54779. Accessed 6 Aug 2013.

Lamont, M., \& Molnar, V. (2002). The study of boundaries in the social sciences. Annual Review of Sociology, 28, 167-195.

Lazaridis, G., \& Koumandraki, M. (2001). Deconstructing naturalism: The racialisation of ethnic minorities in Greece. In R. King (Ed.), The Mediterranean passage: Migration and new cultural encounters in Southern Europe (pp. 279-301). Liverpool: Liverpool University Press.

Le Espiritu, Y. (1992). Asian American Pan-Ethnicity: Bridging Institutions and Identities. Philadelphia: Temple.

Le Espiritu, Y., \& Tran, T. (2002). Viêt Nam, Nuóc Tôi (Vietnam, my country): Vietnamese Americans and transnationalism. In P. Levitt \& M. C. Waters (Eds.), The changing face of home: The transnational lives of the second generation (pp. 367-398). New York: Sage.

Lefebvre, H. (1996). Writings on cities. Oxford: Blackwell.

Leichtman, M. A. (2005). The legacy of transnational lives: Beyond the first generation of Lebanese in Senegal. Ethnic and Racial Studies, 28, 663-686.

Leontidou, L. (1990). The Mediterranean city in Ttransition. Social change and urban development. Cambridge: Cambridge University Press.

Levine, H. B. (1999). Reconstructing ethnicity. Journal of the Royal Anthropological Institute, 5, $165-180$.

Levitt, P. (1998). Social remittances: Migration driven local-level forms of cultural diffusion. International Migration Review, 34, 926-948.

Levitt, P. (2005). Building bridges: What migration scholarship and cultural sociology have to say to each other. Poetics, 33, 9-62.

Levitt, P. (2009). Roots and routes: Understanding the lives of the second generation transnationally. Journal of Ethnic and Migration Studies, 35, 1225-1242.

Levitt, P., \& Schiller, G. N. (2004). Conceptualising simultaneity: A transnational social field perspective on society. International Migration Review, 38, 1002-1039.

Levitt, P., \& Jaworsky, N. B. (2007). Transnational migration studies: Past developments and future trends. Annual Review of Sociology, 33, 129-56.

Levitt, P., \& Lamba-Nieves, D. (2011). Social remittances revisited. Journal of Ethnic and Migration Studies, 37, 1-22.

Levitt, P., \& Waters, M. C. (2002). Introduction. In P. Levitt \& M. C. Waters (Eds.), The changing face of home: The transnational lives of the second generation (pp. 1-30). New York: Sage.

Lima, F. H. (2001). Transnational families: Institutions of transnational social space. In L. Pries (Ed.), New transnational social spaces. International migration and transnational companies in the early twenty-first century (pp. 77-93). London: Routledge.

Lindsay, G. (2000). Researching children's perspective: Ethical issues. In A. Lewis \& G. Lindsay (Eds.), Researching children's perspective (pp. 3-20). Philadelphia: Open University Press.

Lopasic, A. (1992). Cultural values of the Albanians in the diaspora. In T. Winnifrith (Ed.), Perspectives on Albania (pp. 89-105). London: Macmillan. 
Louie, V. (2006). Second-generation pessimism and optimism: How Chinese and Dominicans understand education and mobility through ethnic and transnational orientations. International Migration Review, 40, 537-572.

Lubonja, F. (2002). Between the glory of a virtual world and the misery of a real world. In S. Schwandner-Sievers \& B. J. Fischer (Eds.), Albanian identities: Myth and history (pp. 91-103). Bloomington: Indiana University Press.

Lubonja, F. (2003). 'Kaoskriza kulturore shqiptare'(The Albanian cultural chaos crisis). Përpjekja, $18,2-9$.

Lubonja, F. (2004). Albania after isolation: The transformation of public perceptions of the west. In A. Hammond (Ed.), The Balkans and the West: Constructing the European other, 1945-2003 (pp. 127-135). Aldershot: Ashgate.

Ma, E. K. (2002). Translocal spatiality. International Journal of Cultural Studies, 5, 131-152.

Mai, N. (2002). Between losing and finding oneself: The role of the Italian television in the Albanian migration to Italy. Brighton: University of Sussex, unpublished DPhil thesis in Media and Cultural Studies.

Mai, N. (2005). The Albanian diaspora-in-the-making: Media, migration and social exclusion. Journal of Ethnic and Migration Studies, 31, 543-561.

Malcolm, N. (2002). Myths of Albanian national identity: Some key elements, as expressed in the works of Albanian writers in America in the early twentieth century. In S. Schwandner-Sievers \& B. J. Fischer (Eds.), Albanian identities: Myth and history (pp. 70-90). Bloomington: Indiana University Press.

Marcus, G. E. (1995). Ethnography in/of the world system: The emergence of multi-sited ethnography. Annual Review of Anthropology, 24, 95-117.

Markova, E., \& Black, R. (2007). East European immigration and community cohesion. Brighton: Sussex Centre for Migration Research, Joseph Rowntree Foundation Report.

Marques, M. M., Rosa, M. J. V., \& Martins, J. L. (2007). School and diversity in a weak state: The Portuguese case. Journal of Ethnic and Migration Studies, 33, 1145-1167.

Martiniello, M., \& Rath, J. (2010). Introduction: Migration and ethnic studies in Europe. In M. Martiniello \& J. Rath (Eds.), Selected studies in international migration and immigrant incorporation (pp. 7-18). Amsterdam: Amsterdam University Press.

Mason, J. (2004). Managing kinship over long distances: The significance of "the visit". Social Policy and Society, 3, 421-429.

May, J., Wills, J, Datta, K, Evans, Y, Herbert, J., \& McIlwaine, C. (2007). Keeping London working: global cities, the British state, and London's new migrant division of labour'. Transactions of the Institute of British Geographers, 32, 151-167.

Mazower, M. (2004). Salonica city of ghosts: Christians, muslims and jews 1430-1950. London: Harper Collins.

McKay, D. (2006). Translocal circulation: Place and subjectivity in an extended Filipino community. The Asia Pacific Journal of Anthropology, 7, 265-278.

Misha, P. (2008). Arratisje nga Burgjet e Historisë. Ç’do të Thotë Sot të Jesh Shqiptar? (Fleeing from the prisons of history: What does it mean today to be Albanian?) Tirana: Toena.

Modood, T. (2004). Capitals, ethnic identity and educational qualifications. Cultural Trends, 13, $87-105$.

Morawska, E. (2003). Immigrant transnationalism and assimilation: A variety of combinations and the analytic strategy it suggests. In C. Joppke \& E. Morawska (Eds.), Toward assimilation and citizenship: Immigrants in liberal nation-states (pp. 133-176). London: Palgrave Macmillan.

Morgan, P. (2002). Between Albanian identity and imperial politics: Ismail Kadaré's The Palace of Dreams. Modern Language Review, 97, 365-379.

Moss, H. (2000). Language and Italian national identity. In G. Bedani \& B. Haddock (Eds.), The politics of Italian national identity: A multidisciplinary perspective (pp. 98-124). Cardiff: University of Wales Press.

Nagel, C. (2002). Nations unbound? Migration, culture, and the limits of the transnationalismdiaspora narrative. Political Geography, 20, 247-256. 
Nagel, J. (1994). Constructing ethnicity: Creating and recreating ethnic identity and culture. Social Problems, 41, 152-176.

Nauck, B. (2001). Intercultural contact and intergenerational transmission in immigrant families. Journal of Cross-Cultural Psychology, 32, 159-173.

Newbold, K. B. (1997) Race, primary, return and onward interstate migration. Professional Geographer, 49, 1-14.

Ní Laoire, C., Carpena-Méndez, F., Tyrrell, N, \& White, A (2010). Introduction: Childhood and migration-Mobilities, homes and belongings. Childhood, 17, 155-162.

Olwig, K. F. (2003). "Transnational" socio-cultural systems and ethnographic research: Views from an extended field site. International Migration Review, 37, 787-811.

Orellana, M. F., Thorne, B., Chee, A., Shun, W., \& Lam, E. (2001) Transnational childhoods: The participation of children in processes of family migration. Social Problems, 48, 572-591.

Pachucki, M. A., Pendergrass, S., \& Lamont, M. (2007). Boundary processes: Recent theoretical developments and new contributions. Poetics, 35, 331-351.

Panagakos, A. N. (2003). Downloading new identities: Ethnicity, technology and media in the global Greek village. Identities: Global Studies in Culture and Power, 10, 201-219.

Panagakos, A. N., \& Horst, H. (2006). Return to Cyberia: Technology and the social worlds of transnational migrants. Global Networks, 6, 109-124.

Parekh, B. (2000). Rethinking multiculturalism: Cultural diversity and political theory. London: Palgrave.

Parker, D., \& Song, M. (2007). Inclusion, participation and the emergence of British Chinese websites. Journal of Ethnic and Migration Studies, 33, 1043-1061.

Peek, L. (2005). Becoming muslim: The development of a religious identity. Sociology of Religion, 66, 215-242.

Peraldi, M. (2005). Algerian routes: Emancipation, deterritorialisation and transnationalism through suitcase trade. History and Anthropology, 16, 47-61.

Peraldi, M. (2007). The station of Alicante in the centre of the world: Wars at the borders and peace in the market along the North African routes to Europe. History and Anthropology, 18, 389-404.

Pessar, P., \& Mahler, S. (2003). Transnational migration: Bringing gender in. International Migration Review, 37, 812-846.

Phalet, K., \& Schönpflug, U. (2001). Intergenerational transmission of collectivism and achievement values in two acculturation contexts: The case of Turkish and Moroccan families in the Netherlands. Journal of Cross-Cultural Psychology, 32, 186-201.

Phillips, J., \& Potter, R. B. (2009). Quality of life issues and the second generation migration: The case of "Bajan-Brit returnees". Population, Space and Place, 15, 239-251.

Phinney, J. S. (1992). The multigroup ethnic identity measure. Journal of Adolescent Research, 7, 156-176.

Phinney, J. S., \& Vedder, P. (2006). Family relationship values of adolescents and parents: Intergenerational discrepancies and adaptation. In J. W. Berry, J. S. Phinney, D. L. Sam, \& P. Vedder (Eds), Immigrant youth in cultural transition: Acculturation, identity and adaptation across national contexts (pp. 167-184). London: Lawrence Erlbaum.

Pillai, R., Kyambi, S, Nowacka, K., \& Sriskandarajah, D. (2007). The reception and integration of new migrant communities. London: IPPR Working paper.

Pinquart, M., \& Silbereisen, R. K. (2004). Transmission of values from adolescents to their parents: The role of value content and authoritative parenting. Adolescence, 39, 83-100.

Platt, L. (2005). Migration and social mobility: The life chances of Britain's ethnic minority communities. Bristol: The Policy Paper, Joseph Rowntree Foundation Working Paper.

Popkin, E. (1999). Guatemalan Mayan migration to Los Angeles: Contructing transnational linkages in the context of the settlement process. Ethnic and Racial Studies, 22, 267-289.

Portes, A. (1994). Introduction: Immigration and its aftermath. International Migration Review, 28, 632-639.

Portes, A. (1998). Social capital: Its origins and applications in modern sociology. Annual Review of Sociology, 24, 1-24. 
Portes, A. (1999). Conclusions: Towards a new world-the origins and effects of transnational activities. Ethnic and Racial Studies, 22, 463-477.

Portes, A. (2010). Migration and social change: Some conceptual reflections. Journal of Ethnic and Migration Studies, 36, 1537-1563.

Portes, A., \& Rumbaut, R. (2001). Legacies: The story of the immigrant second generation. Berkeley: University of California Press.

Portes, A., \& Zhou, M. (1993). The new second generation: Segmented assimilation and its variants. Annals of the American Academy of Political and Social Science, 530, 74-97.

Potter, R. B., \& Phillips, J. (2006). "Mad dogs and transnational migrants?” Bajan-Brit secondgeneration migrants and accusations of madness. Annals of the Association of American Geographers, 96, 586-600.

Potts, L. (1990). The world labour market: A history of migration. London: Zed Books.

Pratt, A. C. (1995). Putting critical realism to work: Practical implications for geographical research. Progress in Human Geography, 19, 61-74.

Pries, L. (2001). The approach of transnational social spaces: Responding to new configurations of the social and the spatial. In L. Pries (Ed.), New transnational social spaces: International migration and transnational companies in the early twenty-first century (pp. 3-33). New York: Routledge.

Psimmennos, I., \& Kassimati, K. (2003). Immigration control pathways: Organisational culture and work values of Greek welfare officers. Journal of Ethnic and Migration Studies, 29, 337-371.

Ratner, C. (2000). Agency and culture. Journal for the Theory of Social Behaviour, 30, 413-434.

Reeves, M. (2012). Black work, green money: Remittances, ritual and domestic economies in southern Kyrgyzstan. Slavic Review, 71, 108-134.

Reuters (2012). For Albanians, the taste of capitalism turns sour in Greece. www.reuters.com. Accessed 6 April

Reynolds, T. (2004). Caribbean families, social capital and young people's diasporic identities. London: South Bank University, Families and Social Capital Working Paper No. 11.

Riccio, B., \& Russo, M. (2011). Everyday practiced citizenship and the challenges of representation: Second-generation associations in Bologna. Journal of Modern Italian Studies, 16, $360-372$.

Romania, V. (2004). Farsi Passare Per Italiani: Strategie di Mimetismo Sociale (Passing Themselves off as Italians: Strategies of Social Mimetism). Rome: Carocci.

Roth, G., \& Wittich, C. (Eds.). (1976). Max Weber: Economy and society. An outline of interpretative sociology. New York: Bedminster Press.

Rovolis, A., \& Tragaki, A. (2006). Ethnic characteristics and geographical distribution of immigrants in Greece. European Urban and Regional Studies, 13, 99-111.

Roudometof, V. (2005). Transnationalism, cosmopolitanism and glocalisation. Current Sociology, $53,113-135$.

Rumbaut, R. (1994). The crucible within: Ethnic identity, self-esteem, and segmented assimilation among children of immigrants. International Migration Review, 28, 748-794.

Rumbaut, R. (1997). Ties that bind: Immigration and immigrant families in the United States. In A. Booth, A. Crouter, \& N. Landale (Eds.), Immigration and the family (pp. 3-45). New Jersey: Lawrence Erlbaum.

Rumbaut, R. (2002). Severed or sustained attachments? Language, identity and imagined communities in the post-immigrant generation. In P. Levitt \& M. C. Waters (Eds.), The changing face of home: The transnational lives of the second generation (pp. 43-95). New York: Sage.

Ruhs, M., \& Anderson, B. (2010). Semi-compliance and illegality in migrant labour markets: An analysis of migrants, employers and the state in the UK. Population, Space and Place, 16, 195-211.

Sassen, S. (1991). The global city: New York, London, Tokyo. Princeton: Princeton University Press.

Salazar, N. B. (2011). The power of imagination in transnational mobilities. Identities: Global Studies in Culture and Power, 18, 576-598.

Scheper-Hughes, N. (2000). Ire in Ireland. Ethnography, 1, 117-140. 
Schönpflug, U. (2001). Intergenerational transmission of values: The role of transmission belts. Journal of Cross-Cultural Psychology, 32, 174-185.

Schrover, M., \& Vermeulen, F. (2005). Immigrant organisations: Introduction. Journal of Ethnic and Migration Studies, 31, 823-832.

Schwandner-Sievers, S. (1999). Humiliation and reconciliation in Northern Albania: The logics of feuding in symbolic and diachronic perspectives. In G. Elwert, S. Feuchtwang, \& D. Neubert (Eds.), Dynamics of violence: Processes of escalation and de-escalation in violent group conflicts (pp. 133-152). Berlin: Duncker and Humbolt.

Schwandner-Sievers, S. (2004). Albanians, Albanianism and the strategic subversion of stereotypes. In A. Hammond (Ed.), The Balkans and the West: Constructing the European other, 1945-2003 (pp. 110-126). London: Ashgate.

Sheller, M., \& Urry, J. (2006). The new mobilities paradigm. Environment and Planning A, 38, 207-226.

Silberman, R., Alba, R, \& Fournier, I. (2007). Segmented assimilation in France? Discrimination in the labour market against the second generation. Ethnic and Racial Studies, 30, 1-27.

Simon, P. (2003). France and the unknown second generation: Preliminary results on social mobility. International Migration Review, 37, 1091-1119.

Smith, R. C. (2002). Life course, generation and social location as factors shaping second-generation transnational life. In P. Levitt \& M. C. Waters (Eds.), The changing face of home: The transnational lives of the second generation (pp. 145-167). New York: Sage.

Smith, E. (2009). Gap-fillers or clan-destroyers? Transnational female solidarity and kin in the region of Fier. Southeast European and Black Sea Studies, 9, 555-573.

Smith, D. P., \& King, R. (2012). Editorial introduction: Re-making migration theory. Population, Space and Place, 18, 127-133.

Snel, E., Engbersen, G., \& Leerkes, A. (2006). Transnational involvement and social integration. Global Networks, 6, 285-308.

Sökefeld, M. (2001). Reconsidering identity. Anthropos, 96, 527-544.

Song, M. (1997). "You are becoming more and more English": Investigating Chinese siblings' cultural identities. New Community, 23, 343-362.

Stark, O., \& Lucas, R. E. B. (1988). Migration, remittances and the family. Economic Development and Cultural Change, 36, 465-481.

Stephan, C. W., \& Stephan, W. G. (2000). The measurement of racial and ethnic identity. International Journal of Intercultural Relations, 24, 541-552.

Szerszynski, B., \& Urry, J. (2006). Visuality, mobility and the cosmopolitan: Inhabiting the world from afar. British Journal of Sociology, 57, 113-131.

Tarifa, F. (2008). Of time, honour, and memory: Oral law in Albania. Oral Tradition, 23, 3-14.

Teo, S. Y. (2011). The moon back home is brighter'? Return migration and the cultural politics of belonging. Journal of Ethnic and Migration Studies, 37, 805-820.

The Economist. (14 January 2012). 'Heading home again: Worried Albanians in Northern Greeceprepare to go home. www.economist.com. Accessed 15 Jan 2012

Thomson, M., \& Crul, M. (2007). The second generation in Europe and the United States: How is the transatlantic debate relevant for further research on the European second generation? Journal of Ethnic and Migration Studies, 33, 1025-1041.

Timmerman, C., Vanderwaeren, E., \& Crul, M. (2003). The second generation in Belgium. International Migration Review, 37, 1065-1090.

Todd, J. (2005). Social transformation, collective categories, and identity change. Theory and Society, 34, 429-463.

Triandafyllidou, A. (2000). Racists? Us? Are you joking?" The discourse of social exclusion of immigrants in Greece and Italy. In R. King, G. Lazaridis, \& C. Tsardanidis (Eds.), Eldorado or fortress? Migration in southern Europe (pp. 186-206). London: Macmillan.

Triandafyllidou, A. (2003). Immigration policy implementation in Italy: organisational culture, identity processes and labour market control. Journal of Ethnic and Migration Studies, 29, 257-297.

Triandafyllidou, A., \& Veikou, M. (2002). The hierarchy of Greekness: Ethnic and national identity considerations in Greek immigration policy. Ethnicities, 2, 189-208. 
Tzanelli, R. (2006). "Not my flag!" Citizenship and nationhood in the margins of Europe. Ethnic and Racial Studies, 29, 27-49.

Urry, J. (2007). Mobilities. London: Polity Press.

Van Niekerk, M. (2007). Second generation Caribbeans in the Netherlands: Different migration histories, diverging trajectories. Journal of Ethnic and Migration Studies, 7, 1063-1081.

Van Oudenhoven, J. P., \& Ward, C. (2013). Fading majority cultures: The implications pf transnationalism and demographic change for immigrant acculturation. Journal of Community and Applied Social Psychology, 23, 81-97.

Vathi, Z. (2010a). A matter of power? (Ethnic) Identification of Albanian-Origin immigrants in Thessaloniki. Brighton: University of Sussex, Sussex Centre for Migration Research Working Paper No. 62.

Vathi, Z. (2010b). New Brits? Migration and settlement of Albanian-origin immigrants in London. Brighton: University of Sussex, Sussex Centre for Migration Research Working Paper No. 57.

Vathi, Z. (2012). Local identities, incorporation and identification of Albanian-origin immigrants in Florence. Modern Italy, 17, 51-68.

Vathi, Z., \& King, R. (2011). Return visits of the young Albanian second generation in Europe: Contrasting themes and comparative host-country perspectives. Mobilities, 6, 503-518.

Vehbiu, A., \& Devole, R. (2010). Kontakt nga afër (Contact from close by). Përpjekja, 26-27, 38-70.

Vermeulen, H., \& Govers, C. (1994). Introduction. In F. Vermeulen \& C. Govers (Eds.), The anthropology of ethnicity: Beyond ethnic groups and boundaries (pp. 1-10). Amsterdam: Het Spinhuis.

Vertovec, S. (2001). Transnationalism and identity. Journal of Ethnic and Migration Studies, 27, $573-582$.

Vertovec, S. (2007). Super-diversity and its implications. Ethnic and Racial Studies, 30, 1024-1054.

Vertovec, S. (2009). Transnationalism. London: Routledge.

Vertovec, S., \& Cohen, R. (2002). Introduction: Conceiving cosmopolitanism. In S. Vertovec \& R. Cohen (Eds.), Conceiving cosmopolitanism: Theory, context, and practice (pp. 1-25). Oxford: Oxford University Press.

Vollmer, B. (2008). Undocumented migration: Counting the uncountable: Data and trends across Europe. Brussels: Clandestine Project Report.

Vullnetari, J. (2007). Albanian Migration and development: State of the art review. Amsterdam: University of Amsterdam, IMISCOE Working Paper No. 18.

Vullnetari, J. (2012). Albania on the move: Links between internal and international migration. Amsterdam: IMISCOE Research, Amsterdam University Press

Waldinger, R., \& Perlmann, J. (1998). Second generations: Past, present, future. Journal of Ethnic and Migration Studies, 24, 5-24.

Warikoo, N. (2004). Cosmopolitan ethnicity: Second-generation Indo-Caribbean identities. In P. Kasinitz, J. H. Mollenkopf, \& M. C. Waters (Eds.), Becoming New Yorkers: Ethnographies of the new second generation (pp. 361-392). New York: Sage.

Waters, M. C. (1990). Ethnic options: Choosing identities in America. Los Angeles: University of California Press.

Waters, M. C. (1994). Ethnic and racial identities of second generation black immigrants in New York City. International Migration Review, 28, 795-820.

Werbner, P. (1999). Global pathways: Working class cosmopolitans and the creation of transnational ethnic worlds. Social Anthropology, 7, 17-35.

Werbner, P. (2010). Mothers and daughters in historical perspective: Home, identity and double consciousness in British Pakistanis' migration and return. Paper presented to the workshop 'Links to the Diasporic Homeland: Comparative experiences of second-generation and ancestral 'return' migration and mobility. Brighton, 14-15 May.

Wessendorf, S. (2007a). Who do you hang out with? Peer group association and cultural assertion among second-generation Italians in Switzerland. In T. Geisen \& C. Riegel (Eds.), Jugend, Zugehörigkeit und Migration. Subjektpositionierung im Kontext von Jugendkultur, Ethnizitäts und Geschlechterkonstruktionen (Youth, belonging and migration. Subject positioning in the context of youth culture and constructions of ethnicity and gender) (pp. 111-127). Wiesbaden: VS Verlag. 
Wessendorf, S. (2007b), "Roots migrants": Transnationalism and "return" among second-generation Italians in Switzerland. Journal of Ethnic and Migration Studies, 33, 1083-1102.

Westin, C. (2003). Young people of migrant origin in Sweden. International Migration Review, 37, 987-1010.

White, J. (2000). Italy: The enduring culture. London: Leicester University Press.

White, P. (1999). Minority residential histories in the city: Context, process and outcome. Paper presented at the Metropolis International Workshop, Lisbon, 28-29 September 1998.

Wieviorka, M. (1998). Is multiculturalism the solution?. Ethnic and Racial Studies, 21, 881-910.

Wimmer, A. (2008). The making and unmaking of ethnic boundaries: A multilevel process theory. American Journal of Sociology, 113, 970-1022.

Wimmer, A., \& Schiller, G. N. (2002). Methodological nationalism and the study of migration. Archives of European Sociology, 2, 217-240.

Winnifrith, T. (1992). Introduction. In T. Winnifrith (Ed.), Perspectives on Albania (pp. 1-13). London: Macmillan.

Worbs, S. (2003). The second generation in Germany: Between school and labour market. International Migration Review, 37, 1011-1038.

World Bank. (2011). Migration and remittances factbook. Washington DC: World Bank.

Yeoh, B. S. A., Willis, K. D., \& Fakhri, A. K. (2003). Introduction: Transnationalism and its edges. Ethnic and Racial Studies, 26, 207-217.

Young, A. (2000). Women who become men. Albanian sworn virgins. New York: Berg.

Yuval-Davis, N. (2006). Belonging and the politics of belonging. Patterns of Prejudice, 40, 197-214.

Zeitlyn, B., \& Mand, K. (2012). Researching transnational childhoods. Journal of Ethnic and Migration Studies, 38, 987-1006.

Zhou, M. (1997a). Segmented assimilation: Issues, controversies, and recent research on the new second generation. International Migration Review, 31, 975-1008.

Zhou, M. (1997b). Growing up American: The challenge confronting immigrant children and children of immigrants. Annual Review of Sociology, 23, 63-95.

Zhou, M., \& Bankston, C. L., III (1994). Social capital and the adaptation of the second generation: The case of Vietnamese youth in New Orleans. International Migration Review, 24, 821-845.

Zincone, G. (2006). The making of policies: Immigration and immigrant in Italy. Journal of Ethnic and Migration Studies, 32, 347-375.

Zinn, D. L. (2005). The second generation of Albanians in Matera: The Italian experience and prospects for future ties to the homeland. Journal of Southern Europe and the Balkans, 7 , 259-277.

Zontini, E. (2007). Continuity and change in transnational Italian families: The caring practices of second-generation women. Journal of Ethnic and Migration Studies, 33, 1103-1119. 


\section{Index}

A

Acculturation, 4, 8, 10, 48, 55, 74, 76, 111, 115,178

selective, 14

Adaptation, 3, 10, 48, 74, 76, 170

assertive, 87

Adolescents, 6, 31, 56

immigrant, 155

second-generation, 10,11

Adulthood, 10, 11, 124, 136, 138

Affinity, 55, 87, 107, 186

Age, 2, 152, 166

came of, 2

middle, 10

of Dante, 27

Agency, 4, 5, 18, 35, 177, 188, 189, 191

concepts of, 17

ethnic, 183

personal, 8

Alba, R., 38, 42, 74, 182

Albania, 1, 13, 20, 22, 29, 30, 34, 42-48, 50-62, 64-70, 78, 80-87, 89, 91, 93, 95, 99, 102, 104-106, 108, 111, $112,123,124,126-148,151-153$, $155,157,158,161,162,164-173$, 192

Albanian,

culture, $6,43-45,54,65,67,81,104,112$, $166,171,181$

identity, 37, 43, 44, 46, 54, 55, 62, 66-68, $71,110,111,113,151-153,174$, 181,192

tradition, 62

Anthias, F., 5, 68, 71, 174, 180

Aparicio, R., 3, 13, 192

Artists, 84, 88, 90, 130

Aspirations, 3, 35, 73, 93, 103, 145, 183

Assimilation, 2, 5, 74 linear, 67

multi-path model, 75

straight-line model, 7, 75

Asylum seeker, 19

Attitudes towards return,

intergenerational transmission of, 172,173

the first generation, 117,134

the second generation, 138, 142

Autonomy, 51, 57, 64, 115, 159, 167, 168, 191

B

Bajram, 61

Balkans, 23, 24, 43, 153

Baptism, 52, 53

Barth, F., 38-40, 63, 71, 180, 182, 187

Baumann, G., 90

Beach holidays, 85, 136

Beck, U., 17, 144

Belongingness, 9, 10, 23, 44, 173, 180, 191 symbolic, 34

Borders, 123, 179

Boundary, 40, 42 ethnic, 38,68

Boundary-blurring strategies, 67, 113

Bourdieu, P., 17, 18, 98, 188

Boyfriend, 65, 113

Bright boundaries, 182

Britain, 18-20, 25, 47, 48, 62, 80, 192

British, 19, 48, 66, 167

multiculturalism, 30

Brubaker, R., 38, 41, 75, 90

Bullying, 66, 106

Business, 58, 100, 131, 134, 144 ethinic, 66

C

Capital, 4, 8, 17, 186, 192

social, $3,10,12,15$

Z. Vathi, Migrating and Settling in a Mobile World, IMISCOE Research Series,

DOI 10.1007/978-3-319-13024-8 
Career, 50, 83, 100

professional, 133

Categorization, 38, 41

external, 192

social, 40

Catholic, 26, 43, 52, 53, 61

Childhood, 6, 11, 29, 123, 135, 153, 169, 170

Children, 2, 3, 6, 163

Christian, 43, 52, 61

Christou, A., 11, 16, 142, 183

Church, 52, 60, 93

Citizenship, 6, 8, 15, 22, 48, 77, 143, 182, 191

City, 2, 25, 84, 86, 192 global, 20

Civic responsibility, 65, 80, 147

Civilisation, 24, 66

Class, 191

social, 5,12

socio-economic, 10

Classic assimilation theory, 178

Co-ethnics, 9, 32, 71, 89, 92, 106, 183

Cognitive geography, 25, 109, 114

Collectivism, 150

Communism, 43-45, 124, 160, 164

Communist regime, 1, 44, 162

Community, 185, 192

Albanian, 30, 31

ethnic, $8,11,12$

Comparative, 3, 4, 12, 28, 181

Comparative integration theory, 12,181

Context, 4, 6, 12, 184, 192

European, 8

Italian, 60

local, 2

Cosmopolitan, 9 identity, 189

orientation, 103, 142, 144-146, 183, 185, 192

Cosmopolitanism, 1, 4, 17, 77, 103, 144, 191

Cosmopolitian, ethnicity, 67, 189

Cousins, 96, 108, 109, 170, 172

Cresswell, T., 17

Crime, 111

Critical realism, 29

Cross-cultural, 5, 16, 77

Crul, M., 2, 3, 5, 115, 189

Cultural capital, 84, 98, 104, 114, 150, 189, 191

Cultural reproduction, 119

Culture, 3, 5, 8, 17, 39, 40, 63, 191

ethnic, 15

urban, 30, 33
Curriculum, 24

educational, 97, 98, 109

Customs, 38, 62, 112, 152

ethnic, 44

D

Dahinden, J., 118, 147, 168, 179, 185

Dance, 62

Albanian, 88, 110, 113

De Genova, N.P., 78

Depression, 81

Descendants, 2, 3, 17, 190, 192

De-skilling, 47, 83, 165

Deterritorialisation, 121

Development, 3, 4, 26, 179, 192

Diaspora, 48, 119, 121, 192

Diasporic identity, 10, 32

Dictatorship, 46, 88

Digital broadcasting, 128, 129, 140

DigitAlb, 128, 129, 157, 158

Discrimination, 2, 8, 11, 92-95

Dispersal, 81, 86

Diversity, 5, 9, 21, 22, 183

Domestic, sector, 48, 90, 134

worker, 91, 93, 94

Downward assimilation, 2, 14, 75

Drugs, 87, 110

Duvall, D.T., 121, 123, 126, 135, 185

E

Education, 4, 5, 11, 12, 85, 87, 96, 189

Educational, performance, 7, 9, 13, 15, 30, 96-99

Electricity, 136, 162

Embeddedness, 41, 179 ethnic, 115

Emotionality, 159

England, 64, 81, 144, 167

English, 55, 63-65, 165

Enver Hoxha, 44, 53, 99, 140, 152

Equality, 18, 87, 188 gender, 159 racial, 16

Ethnic agency, 68, 71, 92, 183, 188

Ethnic community, 8, 11, 12, 14, 82

Ethnic identity, 4

Ethnic organizations, 110, 111

Ethnicity, 5, 7, 38-40, 43, 44, 64, 192 role of, 54,55

Ethnocentric, 16, 69, 74

Europe, 2, 4, 5, 8, 130, 167, 193

European, 2, 4, 5, 19, 192 second generation, 12,13 
European Union (EU), 19, 21, 23, 26, 30, 89, 90, 95

Exclusion, 2, 10, 21, 179, 182 economic, 13

Extended family, 108, 124, 128, 132, 158, 171

Extra-communitarian, 67

\section{F}

Faist, T., 78, 118, 120, 148, 168, 170, 175, 185

Faith, 45, 52, 60

Family, extended, 108, 124-126, 132, 135, 137, 146,171

nuclear, 91, 132, 146, 168

Family hubs, 123

Fashion, 92, 96

Favell, A., 19, 20, 26, 29, 74, 77

Field work, 1, 98, 185

First generation, 2, 3, 113, 115, 123

Flag bearer, 113

Florence, 1, 27, 28, 30, 31, 46

Focus groups, 30

Folk culture, 42, 152

Food, 55, 139, 140

Foreigner, 28, 48, 52, 87, 165

Foucault, M., 18, 188

Freedom, of movement, 82, 101

Friendship, 58, 63, 85, 106, 182

Frontistiria, 97

G

Gangs, 106, 109 teenage, 87,110

Gans, H., 5, 7, 8, 62, 76, 115, 178, 190

Gender, inequality, 143

relations, 146,182

roles, 50, 51, 58, 59, 91, 159

Gendered, 59, 71, 91, 115, 185

Generation, 2, 7

Germany, 3, 12, 80, 142, 144, 150

Glick Schiller, N., 5, 16, 29, 34, 40, 75, 103, $118,146,147,178,189$

Globalization, 20, 77, 121, 122, 145, 146

God, 52

Godparents, 52, 60

Gordon, M.M., 41, 74-76, 114

Government, 19, 74, 114, 147

Grades, 96, 164

Grandparents, 61, 136, 138, 142, 158, 170

Greece, 1, 3, 13-16, 22, 23, 30, 46, 61, 62, $67,92,101,102,111,192$
Greek, 15, 16, 22, 23, 25, 48, 50, 52, 55, 61, $63,65,68-70,80,84,87,91,93$, $98,102,105,109,113,135,138$, $157,161,182$

Grillo, R., 26, 27, 142

Grounded theory, 6

Groupism, 41

H

Hatziprokopiou, P., 2, 14, 22-25, 30

Health, 4, 20, 47, 80, 81

Higher education, 97, 98, 101, 143, 144, 167

Highly skilled, 19, 46, 50, 55, 56, 83, 92, 93, $133,153,157,162,165,169$

History of immigration, 25, 30, 33, 78, 118, 123,147

Holidays, 127, 135-138, 169, 171

Home Office, 81, 84, 165

Homeland, 6, 9-11, 34, 112, 118, 120-123, $127,128,132,136,137,139,140$, 146,192

Homework, 70, 109, 153

Household, 53, 59, 119, 129, 148

Housewife, 59

Housing, 2, 12, 21, 84, 165

Human capital, 3, 17, 35, 120, 150, 186, 189 , 191

Hybrid, 62-64, 111, 141, 180, 187, 191

Hyphenated identity, 190

I

Identity, 4, 37, 42, 46, 50, 51, 60, 151, 161, 178,180

Ideological, 29, 42, 44, 74, 99, 159, 187

Illegal, 4, 21, 22, 26, 78, 92, 114, 123

Immigration politics, 73

Immobility, 78, 128

Inclusion, 3, 4, 16, 25, 61, 75, 76, 151, 189

Incorporation, 2, 3, 11, 12, 15, 16, 25, 41, 74, $75,79,103,104,112,123,178$, 180,188

Individuality, 50, 57, 64, 87, 124, 146, 167, 188

Inequality, 76, 98, 113, 144

Information and communication technologies (ICTs), 127

In-laws, 91, 124, 169

Insertion, 74

Integration of, the first generation, 14,18

the second generation, $2,3,5,8,10,18$, $35,189,191$

Interculturalism, 30 
Intergenerational, discontinuities, 105, 115, 186 gap, 9, 122, 154, 162, 174

Intergenerational transmission of, identity, 33, 151, 154 integration, 163, 164, 167 transnational ties, 34, 168-170, 175 Intermarriages, 155,167 Interviews, 2, 4, 30, 62, 81, 169 Intra-generational, 124, 168

Investments, 133, 137 parallel, 167

Irregular, 22, 78, 82, 174

Islam, 43, 62

Italian, 10, 11, 25-27, 186

Italy, 1, 3, 11, 13, 15, 25, 26

J

Jenkins, R., 38-41, 54, 71, 188

Joppke, C., 6, 9

Jus soli, 77

K

Kadaré, I., 42-45

Kasinitz, P., 7

Key informants, 2, 20, 31, 37

Kin, 43, 65, 85-87, 91, 123, 124, 184

King, R., 3, 4, 14, 25, 144, 185

Kinship, 7, 181 transnational, 119, 125, 148

Kofman, E., 17, 103

Kosovar, 90

Kurbet, 54

L

Labour market, 4, 5, 9, 12, 13, 25, 143, 167

Landscape, 139

Language, $10,15,27,42,55,63,68,151$, $157,158,163,169,186$

Law, 21, 83 of truth, 18

Le Espiritu, Y., 7, 69, 162

Leave to remain, 86

Legal status, 73, 77, 80, 82, 119, 128, 166, 185

Legislation, 12, 26, 115

Leisure, 123, 136

Level, macro, 40, 129, 182 meso, 40,52 micro, 40, 45, 182

Levitt, P., 3, 5, 9, 11, 119, 120, 184

Life-course, 151
Lifestyle, 58, 67, 68, 76, 160, 171

Liminality, 88

Linear transnationalism, 185

Locality, 185, 190

London, 1, 20, 21

Longing, 124, 137, 169, 190

Love, 112, 124, 170, 172

Low-skilled, 1, 30, 48, 84, 93, 164

Lubonja, F., 42-45

M

Mai, N., 3, 14, 15, 113

Mainstream, 7, 10, 73, 181, 191

Marginalization, 2, 18, 75

Marriage, 10, 59, 92, 164

Materialism, 124, 161-163

Media, 15, 21, 68, 117, 189

Memories, 24, 136, 170

Mentality, 47, 51, 161

Methodological nationalism, 77, 118, 121, 190

Middle class, 8, 24, 75

Migrant identity, 46-48, 70, 161

Migrants, 1, 3

first-generation, 3

integration of, 4

Migration project, 34, 103, 144, 188 transmission of, 165-167

Mimicry, 46, 87, 188, 191

Minorities, 190 ethinic, 2, 5, 14, 16

Minors, 31, 105

Mobility, social, $8,12,18,19,93,103,110,113$, 191

spatial, 151, 191

virtual, 142

Morawska, E., 10, 74, 75, 183

Mother, 50, 51, 54, 58, 165, 167

Multiculturalism, 16, 19, 23-25, 76, 90, 99, 115,182

Muslim, 52, 54, 61

$\mathbf{N}$

National, 2, 5, 121, 186 identities, 182 ideology, 181

Nationality, 19, 22, 26, 31, 32, 121

Nation-state, 16, 22, 24, 29, 77, 182, 190, 192

Native, 8, 13, 21, 32, 183, 191

Naturalisation, 15, 77, 81, 82

Neighbourhood, 14, 56, 86, 87, 105, 163 urban, 192 
Networks, 3, 35, 74, 78, 85, 121, 134, 189 transnational, 184

Newspaper, 111, 128

NÍ Laoire, C., 6

North America, 2, 142

Nostalgia, 45, 120, 123, 124, 190

\section{O}

Occupational, mobility, 50, 94

Onward migration, 25, 142

Orellana, M., 6, 11

Organizations, $15,41,115$ political, 43

Orthodox, 43, 53, 54, 60, 61

Outsider, 21, 32, 52, 103

\section{$\mathbf{P}$}

Pan-ethnic, 7, 11

Papers, 78, 80, 81, 86, 102, 192

Parental identity, 37, 50

Parent-child relations, 31

Parents, 2, 3, 33-35, 171-174, 186

Patriarchal, 43, 45, 51, 85, 138

Peer group, 35, 56, 107 role of, 108,109

Power, 4, 18, 22, 188, 189 hegemonic, 179

Pray, 60

Primordial, 33, 38, 65 ethnicity, 191

Professional identity, 47, 48, 50, 133, 171

Proficiency, 68, 96, 141, 158, 163

Psychological well-being, 78

Public discourse, 47, 61, 62, 65, 95, 178, 182

$\mathbf{R}$

Race, 8, 19, 23, 155, 189

Racial, 14, 179

Racism, 8, 23, 61, 67, 68, 113

Reactive transnationalism, 118, 170, 184

Refugee, 24, 47, 66, 81, 82, 139

Regularization, 4, 6, 14, 22, 25, 26, 149, 174 schemes, 181

Relationships, 85, 86, 178

imaginative, 32

parent, 3,171

social, 40

Relatives, 55, 56, 68, 86, 89, 109, 124, $170-172$

Religion, 12, 62, 92, 182

Religious identity, 37, 51-54, 59-62

Remittances, financial, 131

material, 132

social, 129, 130

Representation, 29, 46

cultural, 41, 120

Resource-based transnationalism, 185

Rete G2, 141

Retirement, 134

Return, 81, 122

attitudes towards, 132-135

intentions, 123

migration, $11,25,122$

visits, 123-127, 132

Rights, 19, 48, 84

to the city, 112

Roots, 26, 43, 63, 65, 122

historical, 192

Rumbaut, R., 2, 3, 7, 9, 31

Rural, 4, 24, 30, 59, 139

\section{$\mathbf{S}$}

Salazar, N., 17, 47, 147, 190

Sassen, S., 20

Scale, 21, 30, 86, 121

Schools, 15, 96, 115

Greece, 16

Italian, 27

Second generation, 2, 3, 16, 51, 57, 178, 181

Albanian, 13-15

European, 11-13

Secularity, 61

Segmented assimilation, 8, 12, 115, 178

Segregation, 75, 86, 94, 110

counter, 25

Settlement, 7, 14, 17, 25, 29, 54, 193

Sexuality, 121, 160, 161

Siblings, 57, 58, 69, 96, 157

Similarity, 39, 76, 87, 114

Simon, P., 3, 12, 13

Simultaneity, 120, 158

Skanderbeg, 43, 141, 152

Skype, 147

Social constructionism, 28, 29

Social integration of, first generation, $60,74,182$ second generation, 52

Social mobility, $8,12,18,19,113$

Social networks, 86, 122, 161, 184, 189

Social security, schemes, 133

Socialization, $35,40,58,82,85,88,105,163$, 182,189

Society, 2, 5, 10, 170, 171, 181, 190, 191 hierarchies, 179 
Socio-economic, 3, 15, 34, 73, 75, 77, 174 traits, 9

Song, M., 7, 10, 69

Southern Europe, 3, 22, 87, 182

Space, 1, 4, 16, 34, 55, 103, 112, 119, 183, 190,191

social, 114

urban, 105

Sports, 57, 59, 96

State, $12,92,188$ regimes, 114

Stereotypes, 68, 77 negative, 14, 93, 138, 153, 179

Stigmatization, 2, 19, 20, 34, 63, 69, 109, $168,174,181,186$

Strategic cosmopolitanism, 146

Stratification, social, $87,88,109$

Stress, 81

Structure, 5, 8, 12, 18, 50, 76, 192 host-society, 82

Subjectivity, 120, 179

Suffering, 80, 162

Summer houses, 132

Sunday schools, 60

Super-diversity, 77, 104

Symbolic, 7, 16, 23, 42, 182, 191

T

Teacher, 2, 13, 16, 31, 163

Technology, 117, 123

Teenagers, 1, 2, 9, 32, 56, 59, 169, 187, 193 second-generation, 172, 174

Telephone, 128, 129, 174

Television (TV), 66, 69, 90, 95, 129, 139, 140

Temporal, 17, 171

Thessaloniki, 1, 24, 25, 30, 37, 165, 192

Time, 3, 4, 23, 81, 98, 125, 135

Tirana, 93, 132, 135, 137, 172

Tourism, 84, 86, 123, 169

Traditional, 24, 28, 45, 54, 59, 184

Translocality, 1, 122, 136

Transmission, content of, 150, 174, 186

intensity of, 149,150

means of, 129
Transnational,

care, 127,142

community, 118

social fields, 120, 136, 178, 184

social spaces, $120,121,175,179$

ties, 121-123, 127, 129, 191

ways of being, 34, 120, 146, 147

ways of belonging, 34, 120, 146

Transnationalism, $1,5,6,10,11,17,118$, $184,185,191$

Triandafyllidou, A., 14, 15, 22, 104

Tuscany, 28, 30, 58, 59, 158

$\mathbf{U}$

United Kingdom (UK), 1, 3, 10, 13, 15, 21, 30,136

United States of America (USA), 2, 5, 7, 10 , 183,189

University, 12, 15, 51, 97, 166

Upward mobility, 12, 13, 83, 115, 120

Urban, 4, 12, 16, 104, 136

Urry, J., 17, 103, 142, 190

V

Values, 3, 9, 13, 24, 158, 159, 173, 186

Vertovec, S., 10, 77, 104, 119, 120, 147, 185

Village, 60, 105, 172

Visa,

liberalisation, 22

Visiting relatives and friends, 136

Vocational, 12, 83, 100

\section{W}

Wage, 82

Waldinger, R., 8, 12

Waters, M., 3, 7, 9, 70, 183

Wife, 47, 51, 169

Wimmer, A., 5, 38, 40, 71, 178, 182

Within-group, 7

Workplace, 35, 119, 148, 189

Y

Youth, 6, 111

Albanian, 163

culture, 63

second-generation, 4, 13

Yuval-Davis, N., 5, 41, 42, 180 